UNIVERSIDADE DE SÃO PAULO

\title{
COMPARAÇÃO DE FERRAMENTAS PARA MODELAMENTO DE INDUTORES NA TECNOLOGIA CMOS
}

Angélica dos Anjos

Dissertação de Mestrado apresentada à Escola Politécnica da Universidade de São Paulo, para concorrer ao Título de Mestre, pelo curso de Pós Graduação em Engenharia Elétrica - Área de concentração: Microeletrônica. 
UNIVERSIDADE DE SÃO PAULO

\section{COMPARAÇÃO DE FERRAMENTAS PARA MODELAMENTO DE INDUTORES NA TECNOLOGIA CMOS}

Angélica dos Anjos

Dissertação de Mestrado apresentada à Escola Politécnica da Universidade de São Paulo, para concorrer ao Título de Mestre, pelo curso de Pós Graduação em Engenharia Elétrica - Área de concentração: Microeletrônica.

Orientador: João Navarro Soares Júnior 
Este exemplar foi revisado e alterado em relação à versão original, sob responsabilidade única do autor e com anuência de seu orientador.

São Paulo, 15 de maio de 2007.

Assinatura do autor

Assinatura do orientador

\section{FICHA CATALOGRÁFICA}

\section{Anjos, Angélica dos} Comparação de ferramentas para modelamento de indutores na tecnologia CMOS / A. dos Anjos. -- São Paulo, 2007.

$$
\text { p. } 127
$$

Dissertação (Mestrado) - Escola Politécnica da Universidade de São Paulo. Departamento de Engenharia de Sistemas Eletrônicos.

1.Circuitos integrados MOS 2.Indutores (Modelagem) I.Unisidade de São Paulo. Escola Politécnica. Departamento de Engenharia de Sistemas Eletrônicos II.t. 
"Se você tratar um indivíduo como ele é, ele permanecerá como é. Mas, se você tratá-lo como se fosse o que deveria ser, ele se transformará no que deveria e poderia ser."

(GOETHE) 


\section{AGRADECIMENTOS}

Primeiramente agradeço à Deus por me dar a capacidade e perseverança necessárias para o desenvolvimento e conclusão deste trabalho, pois sem Ele, nada seria possível.

Um agradecimento especial aos meus pais Alaíde e Manoel e à minha irmã Patrícia pela ajuda, apoio, amor, compreensão, carinho, inspiração, força e amizade.

Ao meu orientador Prof. Dr. João Navarro Soares Jr. pela grande colaboração na realização desse trabalho.

Um agradecimento especial aos professores Dr. Wilhelmus A. M. Van Noije e Dr. Luiz Carlos Moreira pela atenção e ajuda prestada.

Ao Conselho Nacional de Desenvolvimento Cientifico e Tecnológico $(\mathrm{CNPq})$, pelo apoio financeiro dado através da bolsa de mestrado.

À Fundação de Amparo à Pesquisa do Estado de São Paulo (FAPESP), pelo financiamento da fabricação dos circuitos integrados.

Aos colegas do grupo DMPSV-LSI, Cristian, Catalina, Sérgio, Cláudia, Marcelo, Fernando, Hugo e Paulo, pela ajuda ou palavra amiga nos momentos difíceis e nos felizes; e à Priscila e Helena, que não são do grupo mas fizeram grande diferença nos últimos meses.

Agradeço ao LSI (Laboratório de Sistemas Integráveis), LME (Laboratório de Microeletrônica) pelo uso dos equipamentos.

À todas as pessoas que me ajudaram direta e indiretamente na realização deste trabalho e que não foram citadas acima. 


\section{SUMÁRIO}

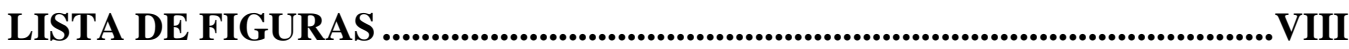

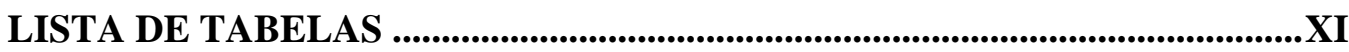

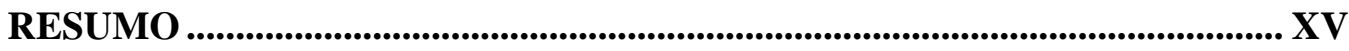

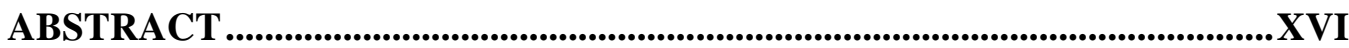

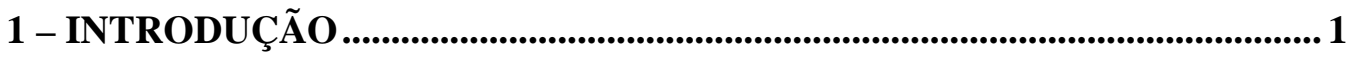

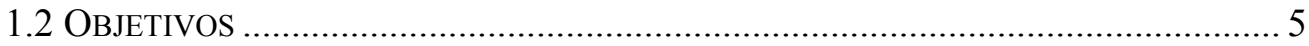

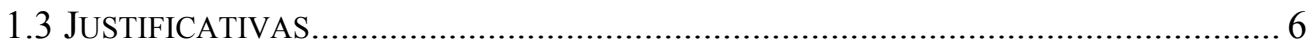

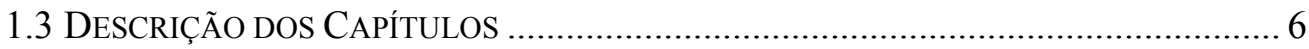

2 - TEORIA DE INDUTORES INTEGRADOS.................................................8

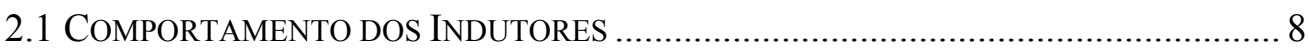

2.2 ESTRUTURAS DOS INDUTORES INTEGRADOS …................................................ 10

2.3 FENÔMENOS QUE DEGRADAM O FUnCIONAMENTO DOS INDUTORES .................. 12

2.3.1 Efeito Pelicular ...................................................................................... 12

2.3.2 Efeito de Proximidade ........................................................................... 12

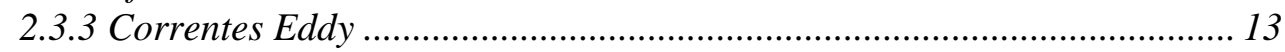

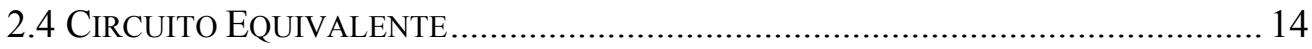

2.4.1 Capacitância entre os Segmentos ............................................................ 16

2.4.2 Capacitância do Óxido ....................................................................... 16

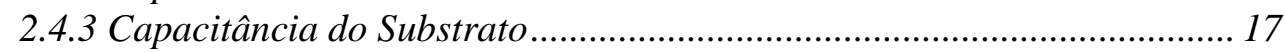

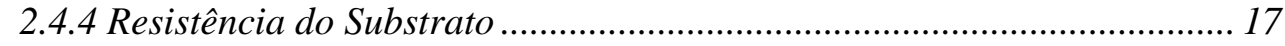

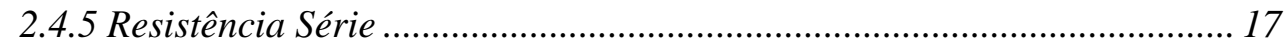

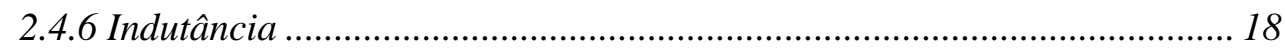

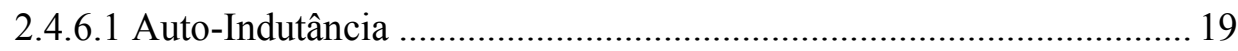

2.4.6.2 Indutância Mútua ............................................................................. 19

2.4.7 Limitações do Circuito Equivalente ......................................................... 20

2.5 FATOR DE QUALIDADE................................................................................. 20

2.6 TÉCNICAS PARA MELHORAR O DESEMPENHO DOS INDUTORES ....................... 21

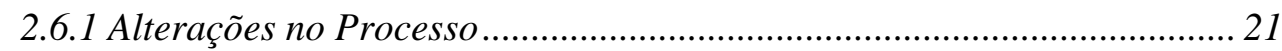

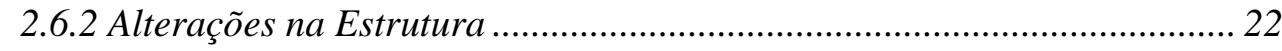

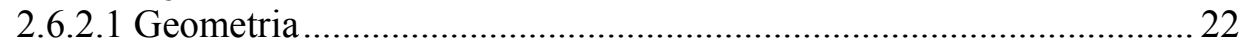

2.6.2.2 Número de Camadas .................................................................... 23

2.6.2.1 Grade de Silício Policristalino ..................................................... 24

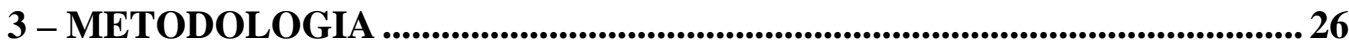

3.1 FERRAMENTAS UTILIZADAS E SOFTWARE PARA IMPLEMENTAÇÃO DAS

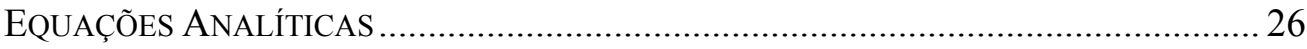

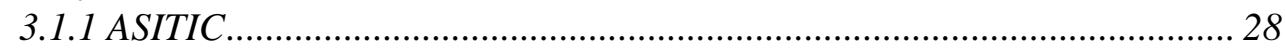

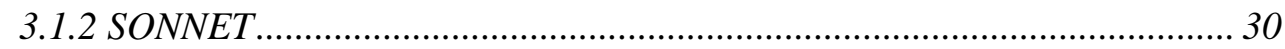

3.1.3 Software para Implementação das Equações Analíticas .......................... 34

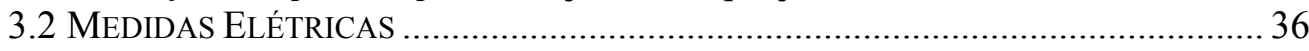




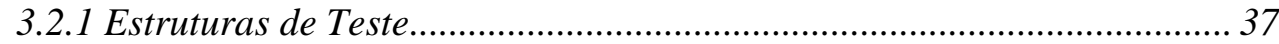

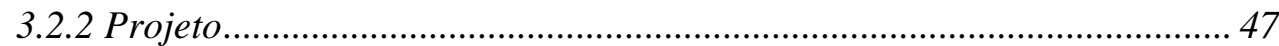

4 - APRESENTAÇÃO E ANÁLISE DOS RESULTADOS ................................. 50

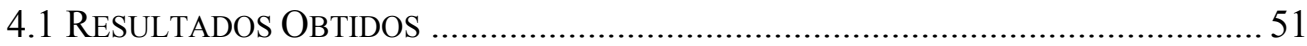

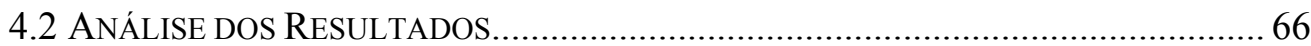

5 - CONCLUSÕES E TRABALHOS FUTUROS ........................................... 74

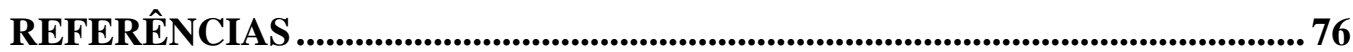

ANEXO A - CONFIGURAÇÃO DO ASITIC .................................................. 80

ANEXO B - CONFIGURAÇÃO DO MATLAB ..........................................91

ANEXO C - ESTRUTURA DE TESTE SIMPLES - ASSOCIAÇÃO SÉRIE E

PARALELO DE QUADRIPOLOS .............................................................. 102

ANEXO D - ESTRUTURAS DE TESTE (MATLAB).......................................... 105

ANEXO E - CARTA DE SMITH DAS MEDIDAS DO INDUTOR 3.............. 111

ANEXO F - VALORES MEDIDOS DOS ELEMENTOS PARASITAS ......... 113 


\section{LISTA DE FIGURAS}

Figura 1 - Representação de um circuito transceptor RF completo. 3

Figura 2 - Representação de um amplificador de baixo ruído, LNA: (a) diagrama

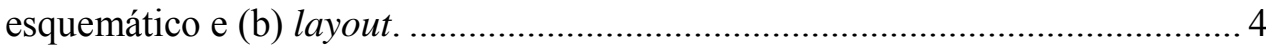

Figura 3 - Parâmetros geométricos do indutor retangular....................................... 10

Figura 4 - Formatos de indutores integrados: (a) retangular; (b) octogonal; (c) hexagonal; (d) circular.

Figura 5 - Formatos alternativos de indutores integrados: (a) solenoidal; (b) toroidal.

Figura 6 - Distribuição de correntes nos segmentos de um indutor para baixas e altas

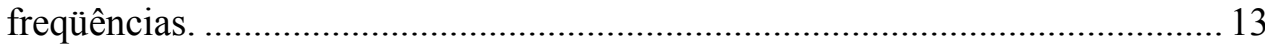

Figura 7 - Correntes induzidas no substrato................................................... 14

Figura 8 - Circuito equivalente do indutor - Modelo PI. ...................................... 15

Figura 9 - Circuito equivalente do indutor retangular - ilustração em corte.............. 15

Figura 10 - Espessuras que caracterizam um indutor de uma espira......................... 16

Figura 11 - Fator de qualidade versus o $l_{\text {ext }}$ para indutores quadrados e octogonais. 23

Figura 12 - Indutor com grade de silício policristalino: (a) vista 3D; (b) vista

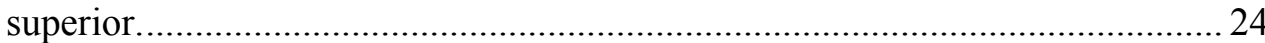

Figura 13 - Desenho das camadas do processo CMOS 0,35 $\mu \mathrm{m}$ da foundry AMS ... 27

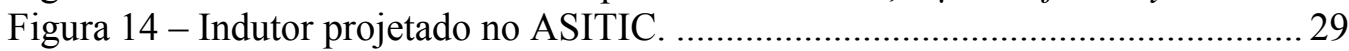

Figura 15 - Janela de configuração do SONNET para camadas dielétricas.............. 31

Figura 16 - Janela de configuração do SONNET para camadas metálicas. ............... 32

Figura 17 - Indutor projetado no SONNET ........................................................ 32

Figura 18 - Determinação do circuito equivalente: (a) modelo PI; (b) circuito

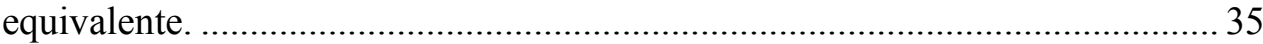

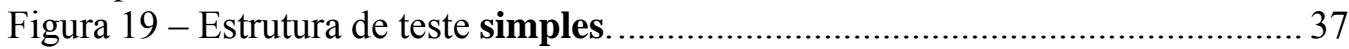

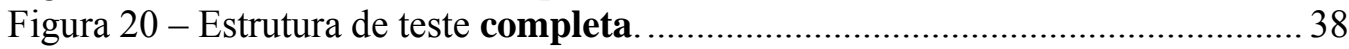

Figura 21 - Modelo equivalente das impedâncias das estruturas de teste................. 38

Figura 22 - Estrutura de caracterização short-open para a estrutura completa. ....... 39

Figura 23 - Estrutura de caracterização short para a estrutura completa.................. 39

Figura 24 - Quadripolo equivalente da estrutura de teste simples mais o indutor.... 40

Figura 25 - Quadripolo equivalente da estrutura de caracterização short/open da

estrutura de teste simples............................................................................... 40

Figura 26 - Quadripolo equivalente da estrutura de caracterização open da estrutura

de teste simples

Figura 27 - Quadripolo equivalente da estrutura de teste completa mais o indutor. 43

Figura 28 - Quadripolo equivalente da estrutura de caracterização short/open da estrutura de teste completa.

Figura 29 - Quadripolo equivalente da estrutura de caracterização short da estrutura

de teste completa.

Figura 30 - Quadripolo equivalente da estrutura de caracterização open da estrutura

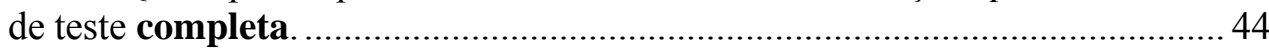

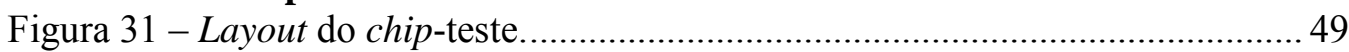

Figura 32 - Foto do chip-teste fabricado. .............................................................. 51

Figura 33 - Medidas dos quatro chips para a estrutura Ind1-completa e a curva

típica das ferramentas: indutância em função da freqüência. ............................. 53 
Figura 34 - Medidas dos quatro chips para a estrutura Ind1-completa e a curva típica das ferramentas: fator de qualidade em função da freqüência.

Figura 35 - Medidas dos quatro chips para a estrutura Ind2-completa e as curvas típicas das ferramentas: indutância em função da freqüência.

Figura 36 - Medidas dos quatro chips para a estrutura Ind2-completa e as curvas típicas das ferramentas: fator de qualidade em função da freqüência.................55

Figura 37 - Medidas dos quatro chips para a estrutura Ind3-simples e as curvas típicas das ferramentas: indutância em função da freqüência........................... 55

Figura 38 - Medidas dos quatro chips para a estrutura Ind3-simples e as curvas típicas das ferramentas: fator de qualidade em função da freqüência................ 55

Figura 39 - Medidas dos quatro chips para a estrutura Ind3-completa e as curvas típicas das ferramentas: indutância em função da freqüência...........................5 56

Figura 40 - Medidas dos quatro chips para a estrutura Ind3-completa e as curvas típicas das ferramentas: fator de qualidade em função da freqüência.................56

Figura 41 - Medidas dos quatro chips para a estrutura Ind4-simples e as curvas típicas das ferramentas: indutância em função da freqüência............................57

Figura 42 - Medidas dos quatro chips para a estrutura Ind4-simples e as curvas típicas das ferramentas: fator de qualidade em função da freqüência................. 57

Figura 43 - Medidas dos quatro chips para a estrutura Ind4-completa e as curvas típicas das ferramentas: indutância em função da freqüência........................... 58

Figura 44 - Medidas dos quatro chips para a estrutura Ind4-completa e as curvas típicas das ferramentas: fator de qualidade em função da freqüência.

Figura 45 - Medidas dos quatro chips para a estrutura Ind5-completa e as curvas típicas das ferramentas: indutância em função da freqüência.

Figura 46 - Medidas dos quatro chips para a estrutura Ind5-completa e as curvas típicas das ferramentas: fator de qualidade em função da freqüência.

Figura 47 - Resultados de simulações e da média das medidas elétricas para o indutor 1: indutância em função da freqüência

Figura 48 - Resultados de simulações e da média das medidas elétricas para o indutor 1: fator de qualidade em função da freqüência.

Figura 49 - Resultados de simulações e da média das medidas elétricas para o indutor 2: indutância em função da freqüência.

Figura 50 - Resultados de simulações e da média das medidas elétricas para o indutor 2: fator de qualidade em função da freqüência.

Figura 51 - Resultados de simulações e da média das medidas elétricas para o indutor 3: indutância em função da freqüência.

Figura 52 - Resultados de simulações e da média das medidas elétricas para o indutor 3: fator de qualidade em função da freqüência.

Figura 53 - Resultados de simulações e da média das medidas elétricas para o indutor 4: indutância em função da freqüência. A curva completa não inclui os resultados do chip3.

Figura 54 - Resultados de simulações e da média das medidas elétricas para o indutor 4: fator de qualidade em função da freqüência.

Figura 55 - Resultados de simulações e da média das medidas elétricas para o indutor 5: indutância em função da freqüência.

Figura 56 - Resultados de simulações e da média das medidas elétricas para o indutor 5: fator de qualidade em função da freqüência. A curva completa não inclui os resultados do chip4. 
Figura 57 - Curva média para medidas de indutância, curva típica determinada pelo SONNET e curvas "típica $+15 \%$ " e "típica-15\%" (indutor 2).

Figura 58 - $\mathrm{O}$ valor de (curva best - curva worst)/(curva típica) em porcentagem versus a freqüência. Na legenda son é para o SONNET, asi para o ASITIC e mat para o MATLAB; ind1 é para o indutor 1, ind2 para o indutor 2 e assim por diante.

Figura 59 - Vista em corte com algumas camadas: layer 0, layer 1, layer2, layer 3, metal 0, metal1 e via 0 . Os parâmetros são relativos ao arquivo de configuração típico.

Figura 60 - Quadripolo Z: modelo equivalente das impedâncias da estrutura simples.

Figura 61 - Quadripolo Z: associação série entre $Z_{c}$ ' e $Z$ '.

Figura 62 - Quadripolo $Y^{\prime}$ : associação paralela entre $Z_{p}$ ' e $Y^{\prime}$ '. 102

Figura 63 - Quadripolo $Y^{\prime}$ ': associação paralela entre $Z_{f}$ ' e $Y$ ',',. 103

Figura 64 - Carta de Smith do ind3-simples - S11 e S12. 104

Figura 65 - Carta de Smith do ind3-simples - S21 e S22.

Figura 66 - Carta de Smith do ind3-completa - S11 e S12.

Figura 67 - Carta de Smith do ind3-completa - S21 e S22.

Figura 68 - Impedância $z_{c}$ em função da freqüência para as estruturas completa e simples.

Figura 69 - Impedância $\mathrm{z}_{\mathrm{p}}$ em função da freqüência para as estruturas completa e simples.

Figura 70 - Impedância $z_{1}$ em função da freqüência para a estrutura completa...... 114

Figura 71 - Impedância $z_{2}$ em função da freqüência para a estrutura completa...... 114

Figura 72 - Impedância $z_{3}$ em função da freqüência para a estrutura completa...... 115

Figura 73 - Impedância $\mathrm{z}_{4}$ em função da freqüência para a estrutura completa...... 115

Figura 74 - Impedância $z_{f}$ em função da freqüência para as estruturas completa e simples. 


\section{LISTA DE TABELAS}

Tabela 1 - Influência das alterações nas estruturas dos indutores............................ 24 Tabela 2 - Dados extraídos do manual AMS para a tecnologia CMOS $0,35 \mu \mathrm{m}$. .... 28

Tabela 3 - Comparação dos métodos de utilização das ferramentas.......................... 36

Tabela 4 - Características dos indutores implementados. ......................................... 47

Tabela 5 - Faixa de freqüências onde o modelamento para o valor de $L$ é aceitável. A determinação da faixa de freqüências é realizada a partir das curvas típica $\pm 15 \%$.

Tabela 6 - Faixa de freqüências onde o modelamento para o valor de $Q$ é aceitável. A determinação da faixa de freqüências é realizada a partir das curvas típica $\pm 20 \%$ 


\section{LISTA DE ABREVIATURAS E SIGLAS}

$\begin{array}{ll}\text { ABS } & \text { Adaptative Sweep } \\ \text { AMS } & \text { Austriamicrosystems } \\ \text { CI } & \text { Circuito Integrado } \\ \text { CMOS } & \text { Complementary Metal-Oxide-Semiconductor } \\ \text { Completa } & \text { Estrutura de teste completa } \\ \text { D/A } & \text { Digital/Analógico } \\ \text { GMD } & \text { Geometric Mean Distance } \\ \text { GSG } & \text { Ground-signal-ground } \\ \text { ISM } & \text { Industrial, Scientific, and Medical } \\ \text { LNA } & \text { Low Noise Amplifier } \\ \text { LSI } & \text { Laboratório de Sistemas Integráveis } \\ \text { PA } & \text { Power Amplifier } \\ \text { PGS } & \text { Pattern Ground Shield } \\ \text { RF } & \text { Radio Frequency } \\ \text { Simples } & \text { Estrutura de teste simples }\end{array}$




\section{LISTA DE SÍMBOLOS}

\begin{tabular}{|c|c|}
\hline$\phi$ & Fluxo magnético \\
\hline$\mu$ & Permeabilidade magnética no espaço livre \\
\hline$\mu_{0}$ & Permeabilidade magnética do vácuo \\
\hline$\sigma$ & Condutividade do metal \\
\hline$\omega$ & Freqüência angular \\
\hline$\delta$ & Profundidade pelicular \\
\hline$\varepsilon_{0}$ & Permissividade do vácuo \\
\hline$\varepsilon_{\mathrm{ox}}$ & Permissividade dielétrica do óxido \\
\hline$\varepsilon_{\mathrm{si}}$ & Permissividade dielétrica do silício \\
\hline$\rho_{\mathrm{m}}$ & Resistividade do metal \\
\hline$\rho_{\mathrm{si}}$ & Resistividade do silício \\
\hline$A_{t}$ & Área total \\
\hline $\mathrm{C}_{\mathrm{ox}}$ & Capacitância do óxido \\
\hline $\mathrm{C}_{\mathrm{p}}$ & Capacitância paralela \\
\hline $\mathrm{C}_{\mathrm{s}}$ & Capacitância série \\
\hline $\mathrm{C}_{\mathrm{si}}$ & Capacitância do silício \\
\hline $\mathrm{d}$ & Distância entre os centros dos segmentos \\
\hline $\mathrm{f}$ & Freqüência do sinal \\
\hline $\mathrm{i}$ & Corrente \\
\hline $\mathrm{L}$ & Indutância \\
\hline $\mathrm{L}_{\text {auto }}$ & Auto indutância \\
\hline $1_{\text {ext }}$ & Comprimento externo \\
\hline$l_{t}$ & Comprimento total \\
\hline M & Indutância mútua \\
\hline $\mathrm{n}$ & Número de voltas \\
\hline$Q$ & Fator de qualidade \\
\hline $\mathrm{R}_{\mathrm{dc}}$ & Resistência de Folha \\
\hline $\mathrm{R}_{\mathrm{p}}$ & Resistência paralela \\
\hline $\mathrm{R}_{\mathrm{rf}}$ & Coeficiente do Efeito Pelicular \\
\hline
\end{tabular}




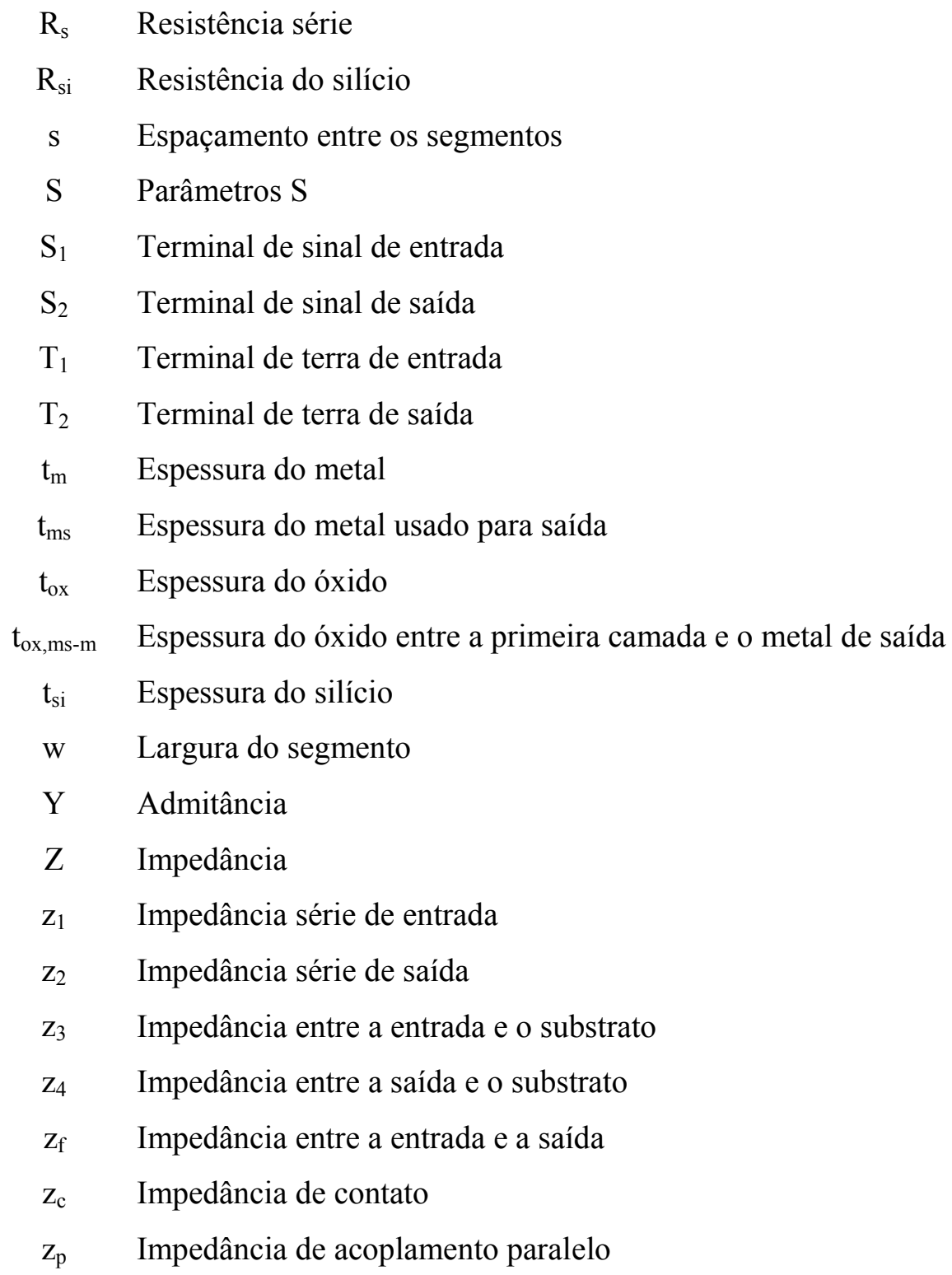




\section{RESUMO}

Duas ferramentas para modelamento de indutores planares, retangulares e integrados e as equações analíticas implementadas em um software, foram estudadas e analisadas, para determinar qual é a mais apropriada, ou seja, aquela que fornece os resultados mais próximos de medidas experimentais, com menor custo, maior velocidade, etc. Indutores planares integrados apresentam limitações severas em seu uso. As duas principais são: o baixo valor do fator de qualidade, que limita o ganho e a banda nos amplificadores e filtros que os utilizam; e a dificuldade no seu modelamento e na determinação dos parâmetros que os caracterizam.

Apesar das dificuldades no uso destes dispositivos, eles são aplicados em diversos sistemas, tais como transceptores que operam em rádio freqüências. Nestes sistemas, indutores são necessários e sua integração é essencial para se obter soluções completamente integradas.

As ferramentas estudadas para o modelamento de indutores neste trabalho foram: ASITIC e SONNET. As equações analíticas foram implementadas no MATLAB. A comparação entre as ferramentas e as equações foi feita por meio de cinco indutores construídos e medidos. Os indutores foram fabricados em tecnologia CMOS de 0,35 $\mu \mathrm{m}$ com quatro camadas de metal.

Para realizar a correta comparação entre os resultados simulados e as medidas elétricas, reduzindo ao máximo a interferência de elementos parasitas (inclusos pelos pads), os indutores foram inseridos em estruturas de teste. Estruturas de caracterização apropriadas foram também projetadas para permitir a eliminação do efeito das estruturas de teste sobre as medidas. 


\begin{abstract}
Two modeling tools for integrated planar square inductors and one software implementing analytical relations, were studied and analyzed, to determine which is the most appropriate, that is, the tools that will supply the closest results to experimental measurements with, lower costs, higher speed, etc. Integrated planar inductors present severe limitations in their use. The two main limitations are: the low value of the quality factor, that affects the gain and the band of amplifiers and filters where they are used; and the difficulty in modeling and determining of their parameters.

Inspire of the difficulties in the use of these devices, they are applied in many systems, such as transceivers that operate in radio frequency. In these systems, inductors are necessary and their integration is essential to obtain completely integrated solutions.

In this work the studied tools for inductor modeling were: ASITIC and SONNET. The analytical relations were implementing in MATLAB. The comparisons between the tools were made through five implemented and measured inductors. The inductors were fabricated in a CMOS $0.35 \mu \mathrm{m}$ technology with four metal layers.

In order to carry out the correct comparison between the modeled results and the electric measurements, minimizing the interference of pad parasitic elements, the inductors were inserted within appropriate test structures. Characterization structures were also implemented to allow the elimination of the test structure effects on the measurements.
\end{abstract}




\section{1 - Introdução}

Tem-se visto, nas últimas décadas, uma verdadeira revolução tecnológica devido à presença cada vez mais acentuada da eletrônica no dia a dia, com sua inserção em produtos já existentes (telefones, carros, etc.) ou com a introdução de novos equipamentos (celulares, computadores, etc.). Este fenômeno foi apenas realizável devido à microeletrônica e a possibilidade, por ela trazida, do desenvolvimento de circuitos integrados complexos com dimensões e custos reduzidos. Circuitos integrados, CI's ou chips, são circuitos completos colocados sobre o mesmo material semicondutor. A produção de circuitos semicondutores feita em silício vem crescendo muito; em 1998 era cerca de 98\% da produção, sendo que mais de $75 \%$ destes circuitos eram produzidos com tecnologias CMOS ([Br98], [It05]) (Complementary MOS onde aparecem transistores N e P).

A idéia de colocar circuitos completos em um mesmo chip, que hoje parece trivial, foi, na realidade, uma grande mudança nos conceitos vigentes sobre o uso de semicondutores. Após a descoberta do efeito bipolar em 1947 por Bardeen, Brattain e Schockley, os transistores bipolares passaram a ser vistos e usados como meros substitutos das válvulas, com as vantagens de serem menores e consumirem menor potência. Apenas anos mais tarde vislumbrou-se que vários dispositivos podiam ser fabricados juntos, integrados, e que níveis de complexidade jamais pensados poderiam ser atingidos. Os trabalhos pioneiros em circuitos integrados são o de $\mathrm{J}$. Kilby, Texas Instrument, em 1958 (este trabalho trouxe para Kilby o prêmio Nobel em 2000 [Me98]) e o de Noyce, Fairchild, em 1959. Inicialmente os circuitos integrados possuíam apenas alguns componentes (como por exemplo um oscilador implementado por Kilby, com apenas cinco componentes: um transistor, três resistores e um capacitor). Depois os circuitos evoluíram para sistemas com milhões

de transistores ([Sa88], [Ro98]) - o processador Pentium Extreme Edition (dual core) tem em torno de 376 milhões de transistores num único circuito construído numa tecnologia CMOS de $65 \mathrm{~nm}$.

Os componentes normalmente construídos dentro de circuitos integrados são: 
- transistores: são os componentes que constituem quase integralmente os circuitos digitais e boa parte dos circuitos analógicos. Como conseqüência disso, e de certa forma como causa, as tecnologias de fabricação de circuitos integrados são desenvolvidas para otimizar o seu desempenho;

- diodos: aparecem em poucas funções dentro de um circuito. Normalmente são construídos aproveitando parte da estrutura utilizada nos transistores;

- capacitores: são componentes muito importantes em algumas técnicas analógicas (filtros a capacitores chaveados, por exemplo). Podem ser construídos com camadas cuja função principal é a de interligação (camadas de metal). Algumas tecnologias especiais para circuitos analógicos oferecem uma ou mais camadas adicionais para permitir a implementação deste componente em menores dimensões e com características mais lineares;

- resistores: são componentes não muito usados mas quase sempre necessários em circuitos analógicos. Podem ser construídos com as camadas utilizadas na construção do transistor. Algumas tecnologias oferecem camadas adicionais para implementar este componente em menores dimensões, com maior qualidade e com características mais lineares;

- indutores: são componentes utilizados em poucos circuitos analógicos devido às dificuldades para sua implementação e utilização. Há basicamente três tipos de dificuldades: os valores atingíveis de indutância são muito baixos; a qualidade dos indutores, medida pelo fator de qualidade $Q$, é ruim; determinar com precisão os valores dos parâmetros deste componente, no momento do projeto, é complicado.

$\mathrm{O}$ trabalho desenvolvido aqui trata de indutores integrados em tecnologias CMOS. Ele se liga às pesquisas desenvolvidas pelo grupo de projeto de CI's do Laboratório de Sistemas Integráveis (LSI) do Departamento de Engenharia de Sistemas Eletrônicos da Escola Politécnica da USP. Este grupo vem projetando circuitos para recepção e transmissão, transceptor, de sinais em Rádio Freqüência (RF), como ilustrado na Figura 1. Um circuito transceptor completo é composto por LNA (amplificador de baixo ruído), PA (amplificador de potência), oscilador local, misturadores, filtros, D/A (conversor digital/analógico), buffers e antena. Estes circuitos têm sido desenvolvidos no LSI com a tecnologia CMOS de 0,35 $\mu \mathrm{m}$ da 
AMS (AustriaMicroSystems), que possui quatro camadas de metal e duas de silício policristalino, para operar na faixa de freqüência próxima a 2,4 GHz (faixa ISM, Industrial, Scientific, and Medical).

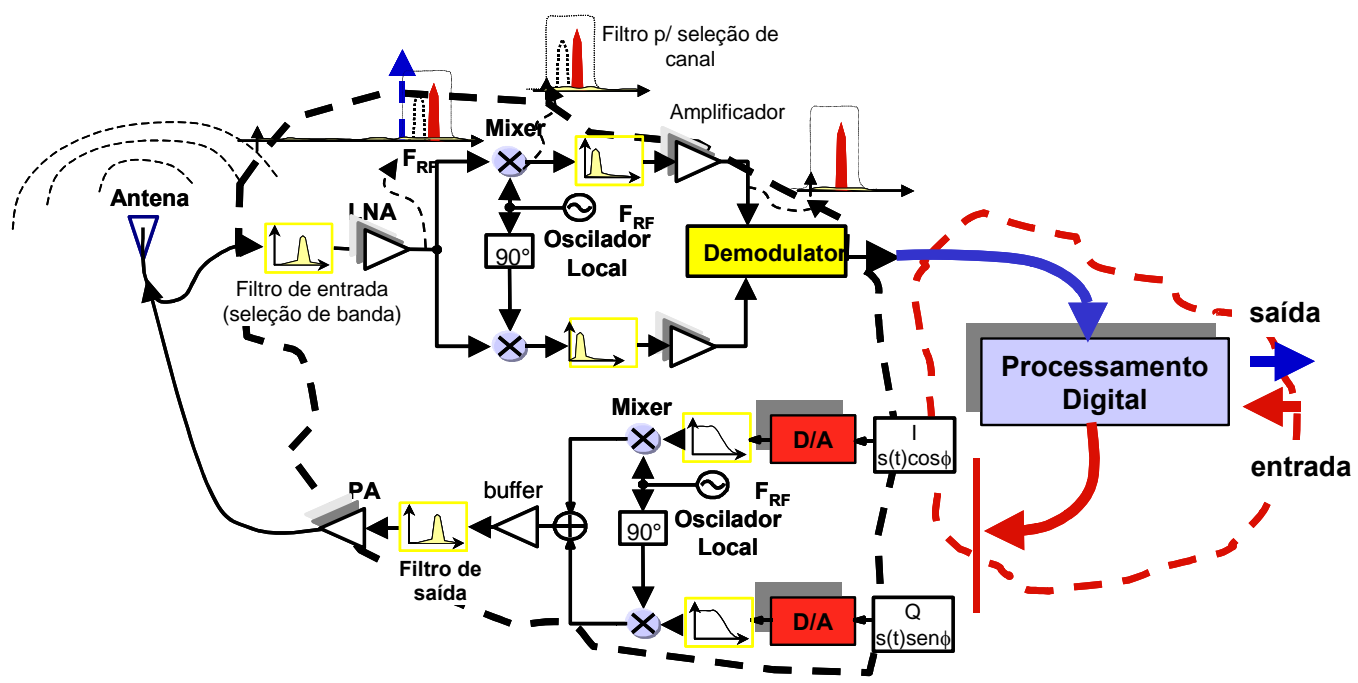

Figura 1 - Representação de um circuito transceptor RF completo.

Para aplicações como transceptores que operam em freqüências de 2,4 GHz, o uso de indutores é imprescindível. Eles são utilizados basicamente em três funções: para o casamento de impedâncias, para servir como carga em amplificadores e para construir filtros. Para compreender melhor estas três funções podemos considerar um circuito amplificador de baixa ruído, LNA (Low Noise Amplifier), um bloco básico de receptores RF. Este bloco recebe um sinal de baixíssima potência vindo da antena e deve amplificá-lo, introduzindo o mínimo de ruído para não distorcer as informações recebidas, e, à medida do possível, filtrá-lo. Na Figura 2 está representado um exemplo de LNA, tanto o esquemático, Figura 2 (a), quanto o layout, Figura 2 (b) [Fu03].

Neste circuito aparecem três indutores planares, $\boldsymbol{L}_{\boldsymbol{g}}, \boldsymbol{L}_{\boldsymbol{s}}$ e $\boldsymbol{L}_{\boldsymbol{d}}$, cujas funções são:

- $\quad \boldsymbol{L}_{\boldsymbol{g}}$ e $\boldsymbol{L}_{\boldsymbol{s}}$ : servem para casar a impedância da entrada $V_{\text {in }}$ do LNA com a impedância da antena. Normalmente antenas têm impedância de saída de $50 \Omega$ (ou $75 \Omega$, por serem padronizadas pelo projetista) e, portanto, para a máxima transferência de potência entre esta e o LNA, a impedância de entrada do LNA deve ter também $50 \Omega$ (resistiva). A entrada de um LNA costuma ser a porta de 
um transistor, $\mathrm{M}_{1}$, que converte tensões em corrente, e por esta razão, caso nada seja feito, a impedância neste ponto será capacitiva. Para torná-la resistiva é necessária a presença de um ou mais indutores;

- $\quad \boldsymbol{L}_{\boldsymbol{d}}$ : serve como carga do amplificador. O sinal de entrada convertido em corrente é novamente convertido em tensão no indutor, gerando o sinal de saída em $V_{R F}$. Tanto resistores como transistores poderiam ser utilizados nesta função, mas, nestes casos, com maior ruído de saída. Observemos que um indutor não produz ruído (no caso ideal);

- $\quad \boldsymbol{L}_{\boldsymbol{g}}, \boldsymbol{L}_{\boldsymbol{s}}$ e $\boldsymbol{L}_{\boldsymbol{d}}$ : servem para filtrar o sinal da entrada. Além das funções anteriores estes três indutores, junto com capacitâncias parasitas do circuito, acabam formando um filtro que deseja filtrar o ruído "out-band".

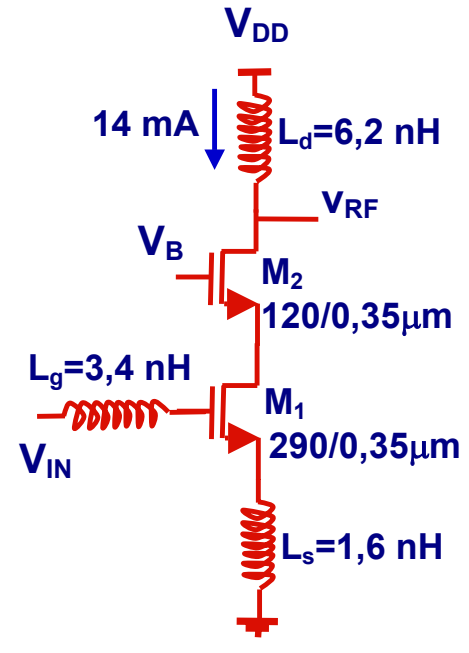

(a)

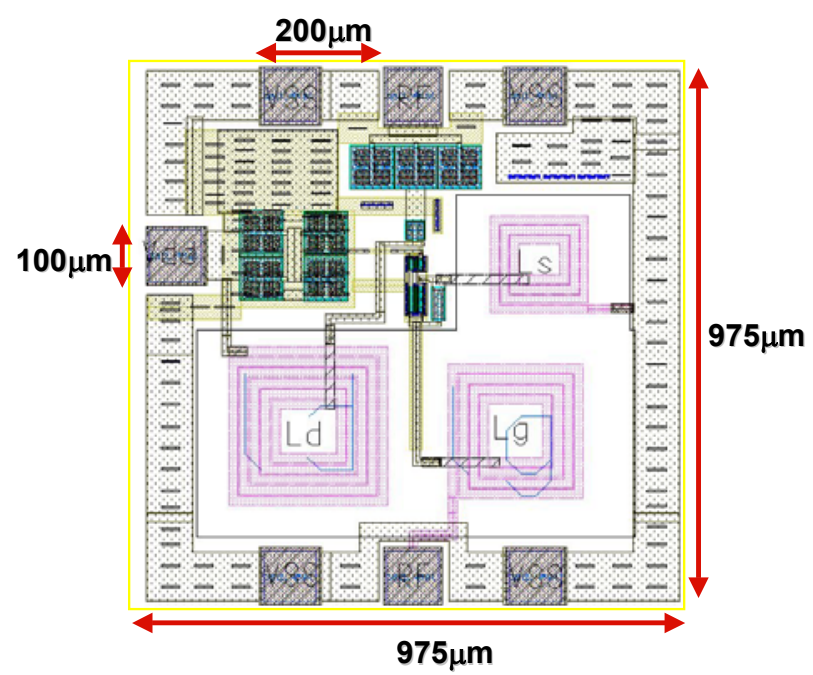

(b)

Figura 2 - Representação de um amplificador de baixo ruído, LNA: (a) diagrama esquemático e (b) layout.

Duas observações são interessantes neste ponto: a primeira diz respeito às dimensões dos indutores integrados - pela Figura 2 (b) fica claro que este componente ocupa uma dimensão considerável dentro de um circuito, isto porque para obter altos valores de indutância deve-se ter muitas espiras no indutor; a segunda, ao modelamento do indutor - um modelamento impreciso dos indutores resulta em um circuito com mau casamento, ganhos diferentes do esperado, filtros não corretamente centrados, maior ruído na saída, etc. 


\subsection{Objetivos}

O objetivo principal deste trabalho é analisar e comparar algumas ferramentas para o modelamento de indutores integrados e equações analíticas, com a finalidade de identificar qual é a que fornece resultados mais próximos do valor real (medido), tem menor custo, maior velocidade, etc. Foram utilizadas duas ferramentas de modelamento e as equações analíticas implementadas em um software para esta comparação:

- software ASITIC (Analysis and Simulation of Inductors and Transformers in Integrated Circuits) (versão Grackle (Linux_Intel)) [As03]: é um software desenvolvido com a finalidade específica de modelamento de indutores e transformadores integrados. Ele fornece um circuito RLC como modelo do indutor além de suas principais características elétricas. Sua distribuição é gratuita;

- software SONNET (versão 10) [So04]: é um software de simulação de campos do tipo 3D planar e que permite analisar várias estruturas. Para indutores ele pode fornecer diversos modelos (circuito RLC, parâmetros S, Z e Y, etc.);

- equações analíticas: foram implementadas no MATLAB (versão 7.0) que é um software geral de manipulação matemática e que foi utilizado para calcular parâmetros de indutores através da aplicação de equações teóricas e semiempíricas encontradas na literatura.

Para realizar a comparação, foram projetados, simulados e modelados alguns indutores retangulares. Posteriormente eles foram fabricados e caracterizados. Para a correta caracterização destes indutores foram estudadas e implementadas estruturas

de testes e de caracterização destas. As estruturas de caracterização permitem o cancelamento dos efeitos dos elementos parasitas, capacitâncias e resistências, inclusos na própria estrutura de testes.

Outros objetivos adicionais do projeto foram:

- conhecer as características básicas de indutores integrados e seu comportamento;

- estudar métodos para o modelamento destes;

- estudar estruturas para testes de indutores; 
- analisar o desempenho dos indutores alterando a estrutura (geometria, número de camada e grade) dos mesmos;

- determinar uma boa ferramenta de modelamento para os indutores integrados.

\subsection{Justificativas}

Nos indutores integrados há muitos efeitos parasitas indesejáveis que interferem em seu comportamento. Dentre estes temos as perdas de energia causadas, principalmente, pelas resistências de segmento, que aumentam com o efeito pelicular e o de proximidade, e as correntes eddy que atingem o substrato, degradando o funcionamento dos indutores, principalmente em altas freqüências.

Diversas formas de melhorar os indutores têm sido propostas, tais como o aumento da condutividade das camadas de metal para reduzir as perdas nos segmentos do indutor; o aumento da resistividade dos substratos para reduzir as correntes eddy; o uso de múltiplas camadas de metal para aumentar a espessura efetiva dos segmentos, reduzindo perdas; a conexão das camadas de metal em série para diminuir a área dos indutores; e o uso de uma camada mais espessa de óxido entre o indutor e o substrato para reduzir perdas no próprio substrato [Ni96]. De forma geral, o funcionamento de um indutor depende de muitos fatores, o que dificulta a determinação de seus parâmetros e, em conseqüência, seu projeto e modelamento.

Este trabalho foi desenvolvido para auxiliar na solução desta dificuldade, determinando uma ferramenta de modelamento para obter as características dos indutores utilizados. No grupo de pesquisa onde este trabalho está sendo realizado, vários circuitos implementados: osciladores, amplificadores de baixo ruído, amplificadores de potência, utilizam indutores e demandam uma ferramenta que modele adequadamente seu comportamento.

\subsection{Descrição dos Capítulos}

No capítulo 2 serão apresentados os fundamentos teóricos dos indutores integrados retangulares, ressaltando seu comportamento, as estrutura dos indutores, 
os fenômenos que degradam seu funcionamento, o circuito equivalente, o fator de qualidade e as técnicas para melhorar seu desempenho. No capítulo 3 serão abordadas as ferramentas utilizadas para modelamento e o software que implementou as equações analíticas, as características dos cinco indutores projetados e as estruturas de teste e de caracterização para a realização das medidas elétricas. A apresentação e análise dos resultados descritas no capítulo 4. No capítulo 5 as conclusões e os trabalhos futuros serão abordados. 


\section{2 - Teoria de Indutores Integrados}

Este capítulo destina-se a uma revisão sobre a implementação de indutores integrados, retangulares e passivos, em tecnologia CMOS. Serão apresentados o comportamento dos indutores, sua estrutura, os fenômenos que degradam seu funcionamento, o circuito equivalente, o fator de qualidade e algumas técnicas utilizadas para melhorar seu desempenho.

\subsection{Comportamento dos Indutores}

$\mathrm{O}$ indutor é basicamente um dispositivo que produz um campo magnético e armazena energia neste campo [Ha96].

Campos magnéticos são produzidos por cargas em movimento e podem exercer forças sobre cargas elétricas [Ha94]. O efeito dos campos magnéticos em indutores pode ser entendido pela aplicação das leis de Faraday, de Ampère-Maxwell [Ha96] e de Lenz [Go96]. As explicações destas leis e as relações que as governam estão dadas abaixo:

- Lei de indução de Faraday: variando o campo magnético $(d B / d t)$, produz-se um campo elétrico $(E)$, e a relação entre os campos é dada por:

$\oint E . d l=-\int_{S} \frac{d B}{d t} d s$

onde a integral de $E$ é feita sobre a linha que define a superfície em que é feita a integral de área de $B$.

- Lei de Ampère-Maxwell: aplicando uma corrente $(j)$ ou variando o campo elétrico $(d E / d t)$, produz-se um campo magnético $(B)$. A relação entre estas grandezas é dada por (a constante $\mu_{0} \varepsilon_{0}$ é acrescentada para manter as dimensões corretas):

$\oint B . d l=+\mu_{0} \varepsilon_{0} \int_{S} \frac{d E}{d t} d s+\mu_{0} \int_{S} j d s$ 
onde $\varepsilon_{0}$ é permissividade do vácuo $\left(8,85 \times 10^{-12} \mathrm{~F} / \mathrm{m}\right), \mu_{0}$ é a permeabilidade magnética no vácuo $\left(4 \pi 10^{-7} \mathrm{H} / \mathrm{m}\right)$ e a integral de $E$ é feita sobre a linha que define a superfície em que são feitas as integrais de área de $E$ e $j$.

- Lei de Lenz: o fluxo magnético de um campo induzido é oposto ao fluxo do campo que o induz.

A indutância $L$ de um indutor é a relação entre o fluxo magnético concatenado ao indutor e a corrente que gera este fluxo. Caso a corrente circule pelo próprio indutor, diremos que a relação é uma auto-indutância; caso circule por outro circuito, diremos que é a indutância mútua entre o indutor e este circuito. Considerando um indutor formado de $N$ segmentos, podemos escrever a relação ([Ha94], [Ha96]) (para meios lineares) abaixo para a indutância própria:

$L=\frac{N \phi}{i}$

onde $i$ é a corrente que passa pelos segmentos e $\phi$ é o fluxo magnético gerado pela corrente $i$ (considerando um fluxo igual em cada segmento).

Em um indutor, além do campo magnético e corrente, aparecem campos elétricos, campos induzidos e perdas. Seus efeitos são modelados por resistências e capacitâncias parasitas. Uma forma de determinar a qualidade de um indutor e o quanto ele se comporta com tal é através do fator de qualidade $Q$, que pode ser definido de acordo com [Ar98]:

$Q=2 \pi\left(\frac{\text { Pico de Energia armazenada }}{\text { Energia dissipada por ciclo }}\right)=\frac{\operatorname{Im}\left(\frac{1}{Y}\right)}{\operatorname{Re}\left(\frac{1}{Y}\right)}=\frac{\operatorname{Im}(Z)}{\operatorname{Re}(Z)}$

onde $Z$ é a impedância do dispositivo, $Y$ é a admitância, $I m$ e Re representam a parte imaginária e real de um número.

Indutores em circuitos integrados são difíceis de modelar devido a vários fenômenos eletromagnéticos subjacentes que ocorrem, principalmente em altas freqüências, e as perdas associadas à eles. Estes fenômenos interferem consideravelmente no comportamento do $L$ e, principalmente, do $Q$. Tais perdas podem ser reduzidas através de técnicas aplicadas à implementação dos indutores. 


\subsection{Estruturas dos Indutores Integrados}

Os indutores integrados passivos são construídos com uma ou mais espiras de metal colocadas acima do substrato. Elas podem ter vários formatos geométricos, sendo o valor da indutância e do fator de qualidade dependente destes. A Figura 3 ilustra um indutor retangular de uma espira, e os parâmetros geométricos que o caracterizam: o comprimento externo $\left(l_{\text {ext }}\right)$, a espessura do segmento do indutor $(t)$, a largura do segmento metálico $(w)$ e o espaçamento entre os segmentos $(s)$.

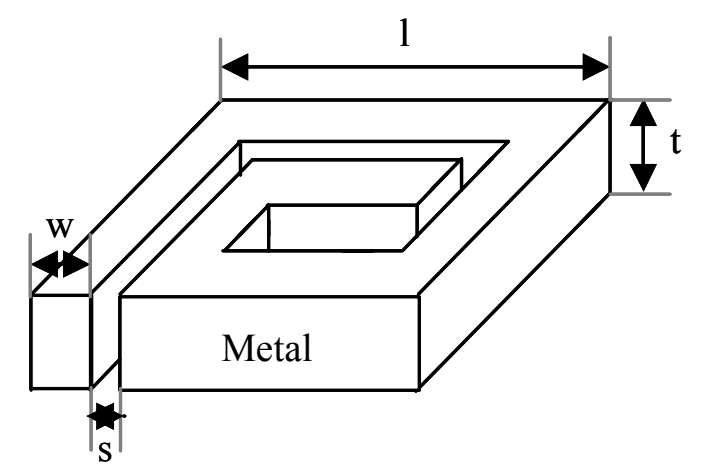

Figura 3 - Parâmetros geométricos do indutor retangular.

A Figura 4 ilustra alguns formatos geométricos de indutores comumente utilizados: retangular, octogonal, hexagonal, circular [(Th00), (Mo99)]. Nestes indutores os parâmetros importantes para o comportamento são: o comprimento interno $\left(l_{\text {int }}\right)$ e o externo $\left(l_{\text {ext }}\right)$, a largura dos segmentos metálicos $(\mathrm{w})$ e o espaçamento entre os segmentos $(\mathrm{s})$.

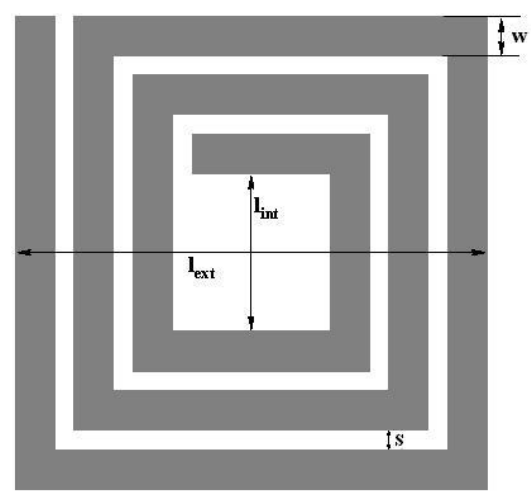

(a)

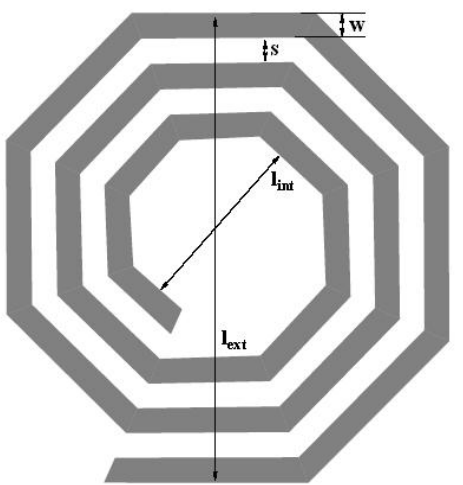

(b) 


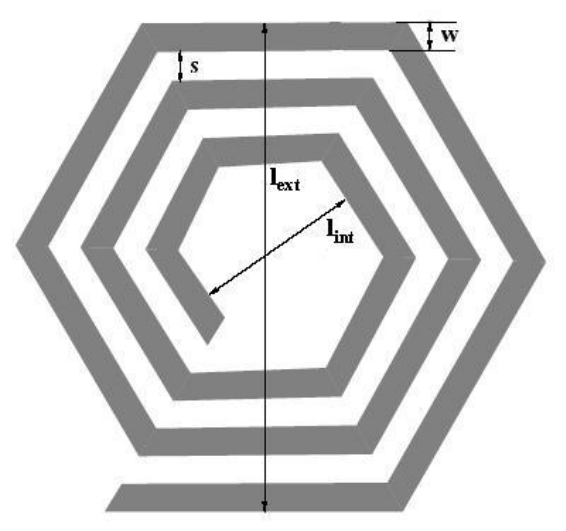

(c)

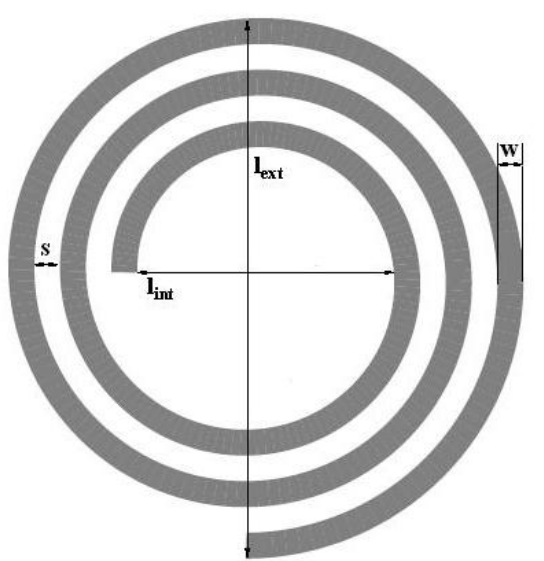

(d)

Figura 4 - Formatos de indutores integrados: (a) retangular; (b) octogonal; (c) hexagonal; (d) circular.

Além dos quatro formatos de indutores ilustrados acima, outros dois têm sido estudados pelo fato de alcançarem um maior valor de indutância, o solenoidal e o toroidal. A Figura 5 ilustra estes indutores, solenoidal [Ed98] e toroidal [Va05], juntamente com os parâmetros geométricos relevantes. Estas novas estruturas foram desenvolvidas para eliminar as correntes eddy (explicadas ainda neste capítulo) e confinar o fluxo magnético no próprio indutor.

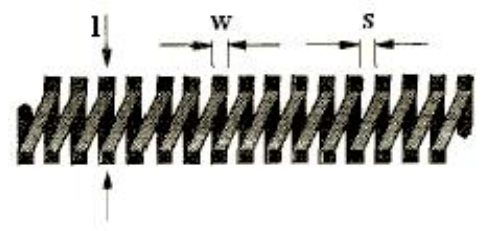

(a)

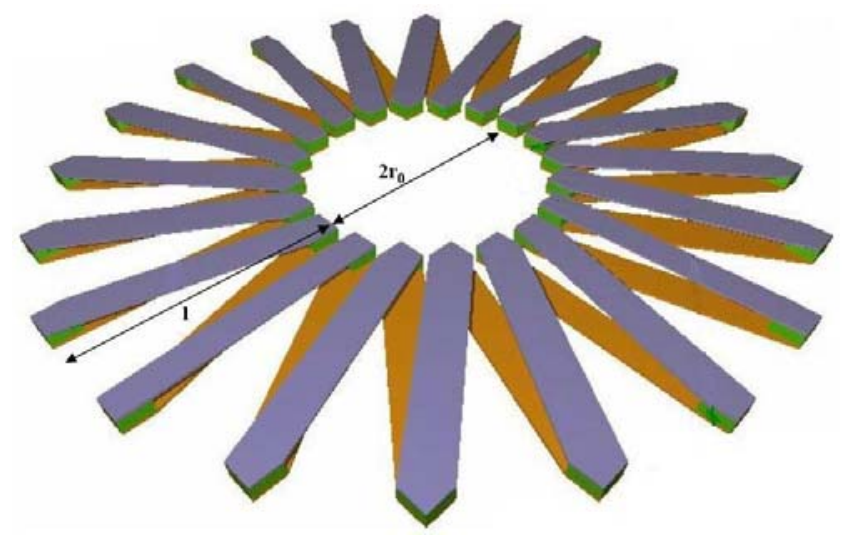

(b)

Figura 5 - Formatos alternativos de indutores integrados: (a) solenoidal; (b) toroidal. 


\subsection{Fenômenos que Degradam o Funcionamento dos Indutores}

Os principais fenômenos que influenciam negativamente o funcionamento dos indutores integrados são: o efeito pelicular, o efeito de proximidade e as correntes eddy. Estes efeitos ocorrem quando um material condutor (segmentos do indutor ou substrato da lâmina) é sujeito a campos magnéticos variantes. O efeito pelicular é o mais crítico deles [YU00].

\subsubsection{Efeito Pelicular}

Quando se tem um sinal elétrico de alta freqüência aplicado a um condutor qualquer, a energia eletromagnética não é transmitida no interior deste condutor, mas ela se propaga pela região periférica do condutor enquanto este simplesmente guia as ondas. Com isso, os elétrons do condutor tendem a ir para a superfície, havendo uma redução na área útil por onde passa a corrente e, consequentemente, o aumento da resistência do condutor. Este é o chamado efeito pelicular que ocorre também nos segmentos dos indutores integrados, acarretando um aumento nas perdas do indutor à medida que se aumenta a freqüência de operação. Falar da condutividade do material.

A partir das equações do campo elétrico e magnético, podemos encontrar o fator $\delta$, chamado de profundidade de penetração ou profundidade pelicular, que está relacionado com a profundidade da película por onde passam as correntes no condutor [Ha94]. Seu valor é dado pela equação [Mo99]:

$\delta=\sqrt{\frac{2}{\mu \sigma \omega}}$

onde $\mu$ é a permeabilidade magnética no espaço livre $\left(\sim 4 \pi 10^{-7} \mathrm{H} / \mathrm{m}\right), \sigma$ é a condutividade do material do condutor e $\omega$ é a freqüência em rad./seg. $(\omega=2 \pi \mathrm{f})$.

\subsubsection{Efeito de Proximidade}

O campo magnético gerado por condutores adjacentes altera a distribuição de correntes de um segmento, gerando altas densidades de corrente nas bordas que estão mais afastadas das linhas dos campos magnéticos. Este é o chamado efeito de 
proximidade que causa, como no efeito pelicular, o aumento da resistência do segmento e degrada o fator de qualidade (devido ao aumento da dissipação de energia no próprio condutor por efeito Joule) [Ts97].

A Figura 6 ilustra o comportamento das correntes nos segmentos de um indutor, à medida que a freqüência aumenta [Ca03]. São mostrados tanto o efeito pelicular como o efeito de proximidade.

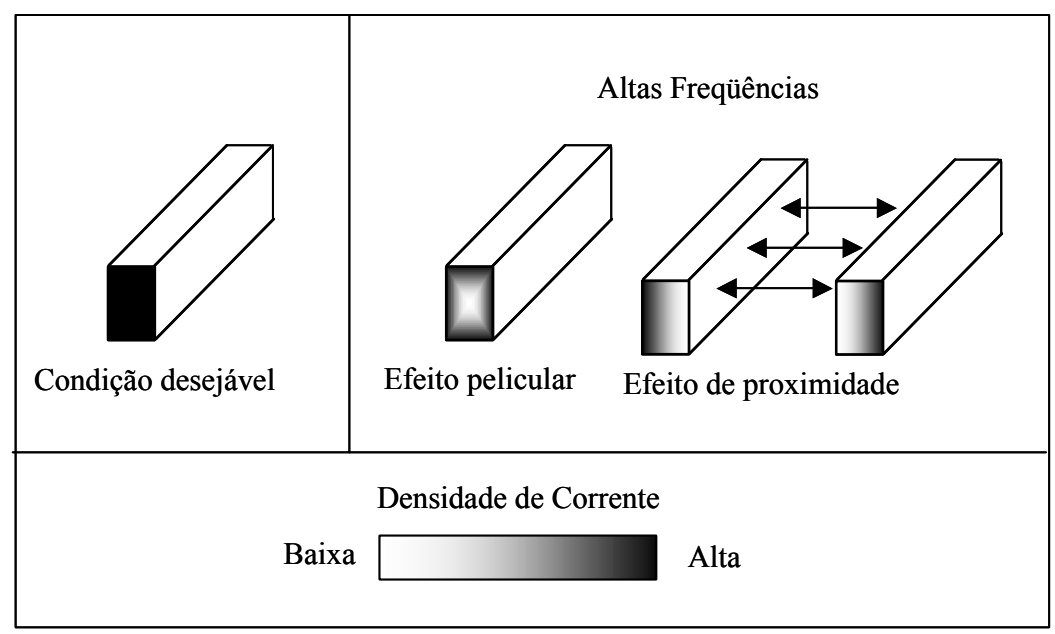

Figura 6 - Distribuição de correntes nos segmentos de um indutor para baixas e altas freqüências.

\subsubsection{Correntes Eddy}

As correntes elétricas que passam pelo indutor geram um campo magnético e parte deste acaba penetrando no substrato. Quando há variações nas correntes do indutor, o campo magnético gerado também varia, causando o aparecimento de um campo elétrico no substrato (eq. 1). Este campo fará com que surjam correntes no substrato, as chamadas correntes eddy [Ky01]. As correntes eddy causarão o aparecimento de um campo magnético (eq. 2) que, segundo a lei de Lenz, é oposto ao campo induzido pelo indutor, como pode ser observado na Figura 7. 


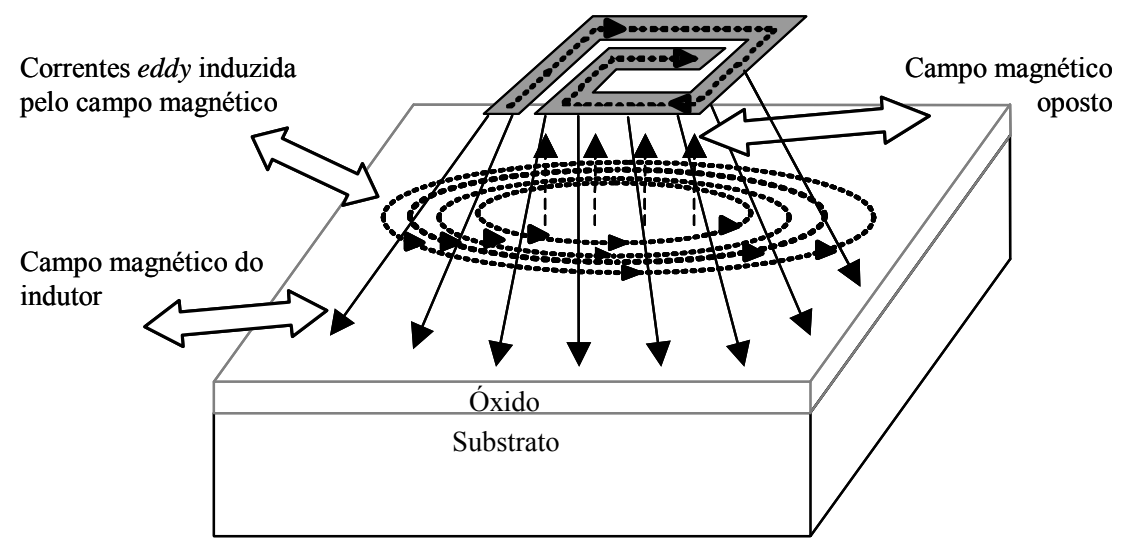

Figura 7 - Correntes induzidas no substrato.

As correntes de eddy têm três efeitos negativos sobre o indutor: reduz o valor do $Q$, pela dissipação de energia no substrato (efeito Joule); reduz o valor de $L$, devido ao fluxo magnético reverso gerado no substrato; aumenta o ruído no chip pois parte da corrente gerada se difunde pelo substrato e pode atingir circuitos próximos.

A intensidade da corrente do substrato é inversamente proporcional à sua resistividade, o que sugere que substratos de alta resistividade são melhores para se obter indutores de qualidade. O caso extremo da aplicação desta ideia é a retirada, via corrosão, de parte do substrato abaixo do indutor, o que resulta em um $Q$ elevado [Vi00]. Infelizmente, na maior parte das tecnologias CMOS, o substrato não tem resistividade tão alta para reduzir problemas de latch-up ${ }^{1}$ e a corrosão do substrato abaixo do indutor não é possível.

\subsection{Circuito Equivalente}

Um modelo elétrico, muito utilizado, para o indutor retangular está ilustrado na Figura 8 e denomina-se modelo PI [Yu99]. O modelo abrange a capacitância entre os segmentos $\left(C_{s}\right)$, a capacitância do óxido entre o indutor e o substrato $\left(C_{o x}\right)$, a capacitância do substrato $\left(C_{s i}\right)$, a resistência do substrato $\left(R_{\mathrm{si}}\right)$, a resistência série dos segmentos $\left(R_{S}\right)$ e a indutância das espiras $(L)$. Assim, por este modelo, o indutor é caracterizado por seis parâmetros (que podem ou não variar com a freqüência): as capacitâncias $C_{s}, C_{o x}$, e $C_{s i}$; as resistências $R_{s i}$ e $R_{S}$ e a indutância $L$.

\footnotetext{
${ }^{1}$ Latch-up é o disparo de um dos muitos tiristores parasitas que aparecem em estruturas CMOS. Quando isto ocorre em um circuito há um grande aumento de corrente que pode causar danos.
} 


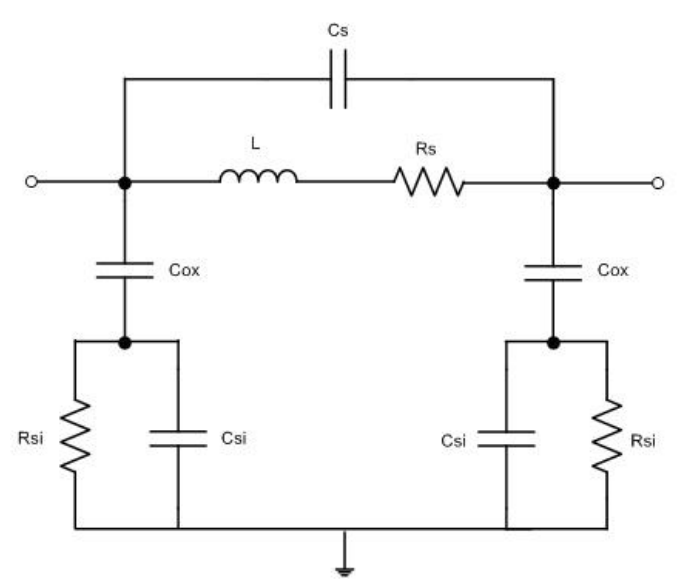

Figura 8 - Circuito equivalente do indutor - Modelo PI.

A Figura 9 ilustra o modelo PI em corte para uma melhor visualização (indutor de uma espira), destacando a posição dos elementos parasitas em relação à camada de metal (primeira camada), à camada de óxido (segunda camada), e ao substrato (terceira camada) [Yu99].

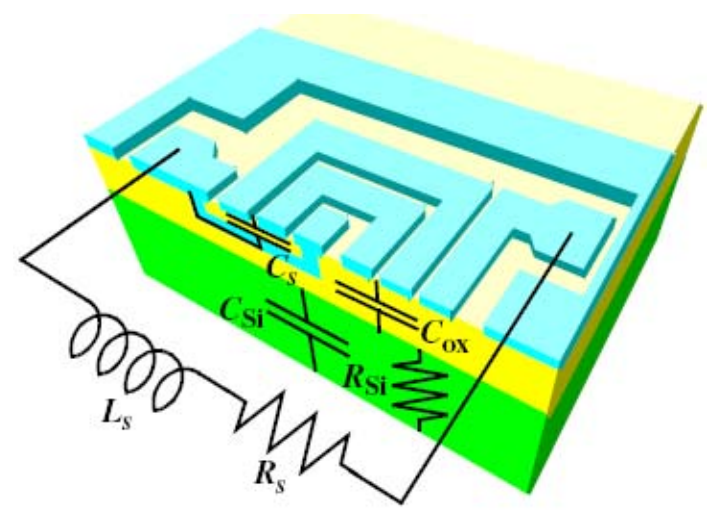

Figura 9 - Circuito equivalente do indutor retangular - ilustração em corte.

A Figura 10 ilustra as várias espessuras que caracterizam um indutor de uma espira: espessura do segmento de metal $\left(\mathrm{t}_{\mathrm{m}}\right)$; espessura do metal utilizado para a saída do indutor $\left(\mathrm{t}_{\mathrm{ms}}\right)$; espessura total das camadas de óxido $\left(\mathrm{t}_{\mathrm{ox}}\right)$, espessura de óxido entre a camada de metal dos segmentos e o metal de saída ( $\left.\mathrm{t}_{\mathrm{ox}, \mathrm{ms}-\mathrm{m}}\right)$ [Mo99]. 


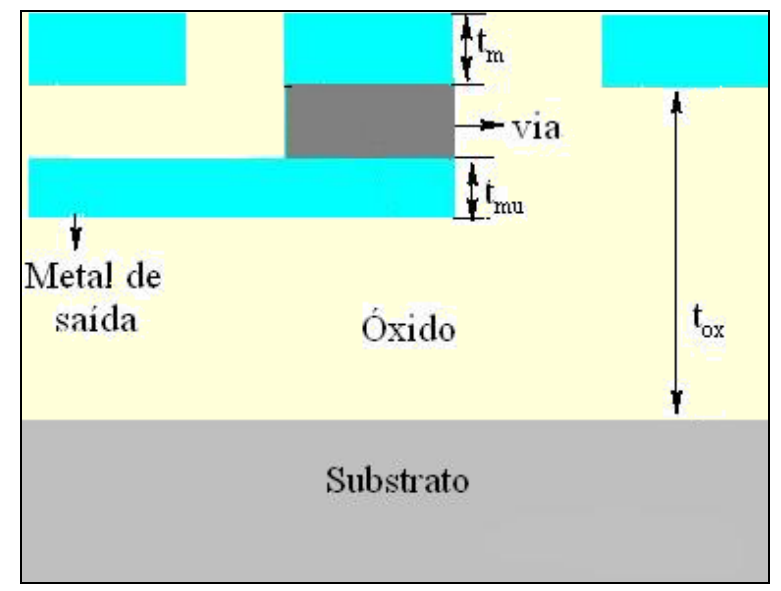

Figura 10 - Espessuras que caracterizam um indutor de uma espira.

Nas próximas seções serão apresentadas expressões simples e fisicamente intuitivas para cada um dos parâmetros descritos anteriormente. Estas serão utilizadas no software MATLAB para determinar os parâmetros do modelo PI de um indutor. Vale ressaltar que as equações analíticas descritas abaixo, para determinar os parâmetros do indutor, são uma das muitas encontradas na literatura.

\subsubsection{Capacitância entre os Segmentos}

A capacitância entre os segmentos do indutor $\left(\mathrm{C}_{\mathrm{s}}\right)$ tem um valor muito pequeno, e pode ser calculada pela expressão ([Yu00],[Mo99])

$$
C_{s}=n w^{2} \frac{\varepsilon_{o x}}{t_{o x, m s-m}}
$$

onde $n$ é o número de voltas do indutor, $w$ é a largura dos segmentos, $\varepsilon_{0 x}$ é a constante dielétrica do óxido $\left(3,45 \times 10^{-11} \mathrm{~F} / \mathrm{m}\right)$ e $t_{o x, m s-m}$ é a espessura do óxido entre a primeira camada de metal utilizada no indutor e o metal de saída.

\subsubsection{Capacitância do Óxido}

O valor desta capacitância depende, principalmente, da espessura do óxido ([Yu00], [Th00]) e pode ser dada por:

$C_{o x}=\frac{1}{2} \frac{\varepsilon_{\text {ox }}}{t_{\mathrm{ox}}} l_{t} w$ 
onde $t_{o x}$ é a espessura do óxido e $l_{t}$ é o comprimento total do indutor. $\mathrm{O}$ fator $1 / 2$ da equação é decorrente do modelo do indutor considerar dois elementos $\mathrm{C}_{\mathrm{ox}} \mathrm{em}$ paralelo (Figura 8).

\subsubsection{Capacitância do Substrato}

A capacitância do substrato poder ser calculada pela equação [Oh03]:

$C s i=\frac{1}{2} \frac{\varepsilon_{s i}}{t_{s i}} l_{t} w$

onde $\varepsilon_{s i}$ permissividade dielétrica do silício $\left(1,04 \times 10^{-10} \mathrm{~F} / \mathrm{m}\right)$ e $t_{s i}$ é a espessura do silício. $\mathrm{O}$ fator $1 / 2$ da equação é decorrente do modelo do indutor considerar dois $\mathrm{C}_{\mathrm{si}}$ em paralelo.

\subsubsection{Resistência do Substrato}

Uma das equações para esta resistência está apresentada a seguir [Cr96]. Ela modela as perdas no substrato causadas pelas correntes que aí aparecem (correntes eddy).

$R_{S i}=2 \rho_{S i}\left(\frac{t_{S i}{ }^{2}}{t_{S i}{ }^{2}+A_{T}{ }^{2}}\right)$

onde $\rho_{s i}$ é a resistividade do substrato e $A_{T}$ é a área total do indutor (para indutor retangular $\mathrm{A}_{\mathrm{T}}=l_{\text {ext }}{ }^{2}$, ver Figura 3). $\mathrm{O}$ fator 2 da equação é decorrente do modelo do indutor considerar dois $\mathrm{R}_{\mathrm{si}}$ em paralelo.

\subsubsection{Resistência Série}

A resistência série $R_{s}$ pode ser dada pela equação abaixo [Yu96]. Ela modela as perdas devido à condutividade finita dos segmentos de metal e o efeito pelicular [Ni96].

$$
R_{s}=\frac{\rho_{M} l_{t}}{w \delta\left(1-e^{\left(\frac{-t_{M}}{\delta}\right)}\right)}
$$

onde $\rho_{M}$ é a resistividade do metal, $t_{M}$ é a espessura da camada metálica, $\delta$ é a profundidade pelicular pode ser dada por [YU00]: 
$\delta=\sqrt{\frac{2 \rho_{M}}{\omega \mu}}$

onde $\mu$ é a permeabilidade magnética no espaço livre [Mo99] e $\omega$ é a freqüência em rad./seg. $(\omega=2 \pi f)$.

\subsubsection{Indutância}

Ao contrário dos outros elementos do modelo PI, que têm expressões simples, a indutância não é fácil de ser calculada. A indutância total no indutor é composta pelas auto-indutâncias dos segmentos e pelas indutâncias mútuas positivas e negativas existentes entre eles.

Para cada segmento metálico $j$ que compõe o indutor pode-se determinar uma indutância total conforme a equação abaixo [Mo01].

$L_{j}=L_{a u t o j}+\sum_{k \neq j}\left(2 M_{k j}\right)$

onde $L_{a u t o j}$ é a auto-indutância do segmento $j, M_{k j}$ é a indutância mútua entre o segmento $k$ e o segmento $j$ (pode ser positiva ou negativa) e o somatório é feito para todos os segmentos $k \neq j$.

As indutâncias mútuas entre segmentos têm uma quantidade de termos que cresce com o quadrado do número de segmentos, o que dificulta sua determinação [Mo99]. O número de segmentos de uma espira é determinado através do produto do número de segmentos por volta pelo número de voltas.

O valor da indutância total do dispositivo será dado pela soma de todos os termos $L_{j}$.

$\mathrm{Na}$ literatura é possível encontrar equações para as indutâncias que dependem apenas de parâmetros geométricos, como em [Mo01]. Por outro lado, com o aumento da freqüência há variações na distribuição das correntes e do fluxo magnético, que alteram o valor da indutância. Como pode ser observado em diversas publicações [Me04, Ni96, Ky01, Mo99] a determinação desta variação não é tarefa fácil. Esta é uma das razões para a utilização de softwares para modelar indutores.

O valor do parâmetro $L$ do modelo PI é considerado como independente da freqüência do sinal. Observemos que a variação com a freqüência do valor da impedância equivalente do circuito (soma do indutor, dos capacitores e resistores) 
pode ser calculada a partir da análise do circuito da Figura 8. Essa análise está feita no capítulo 3 .

\subsubsection{Auto-Indutância}

Uma corrente elétrica passando por um segmento causa o aparecimento de um fluxo magnético sobre o próprio segmento; a relação entre este fluxo e a corrente é a auto-indutância. A equação abaixo apresenta o valor da auto-indutância em um segmento retangular [Gr74].

$$
L_{\text {auto }}=2 l_{\text {ext }}\left[\ln \left(\frac{2 l_{\text {ext }}}{w+t_{m}}\right)+0,50049+\left(\frac{w+t_{m}}{3 l_{\text {ext }}}\right)\right]
$$

Para se obter nesta relação o valor da auto-indutância em nH, deve-se utilizar os valores de $l_{\text {ext }}, w$ e $t_{m}$ em centímetros.

\subsubsection{Indutância Mútua}

Uma corrente elétrica passando por um segmento $j$ causa o aparecimento de um fluxo magnético sobre qualquer outro segmento $k$; a relação entre este fluxo e a corrente é a indutância mútua entre $j$ e $k$. Esta poderá ser: positiva, quando as correntes que percorrem os dois segmentos têm componentes com mesmo sentido e direção; negativa, quando as correntes têm componentes com mesma direção e sentido oposto [Mo01]; ou zero caso as correntes sejam perpendiculares.

Para se determinar a indutância mútua entre segmentos paralelos utilizaremos a expressão abaixo [Gr74].

$$
M= \pm 2 l_{\text {ext }} \Phi
$$

onde $M$ é a indutância mútua positiva '+', ou negativa '-' , e $\Phi$ pode ser calculado pela equação abaixo.

$$
\Phi=\ln \left\{\left(\frac{l_{\text {ext }}}{G M D}\right)+\left[1+\left(\frac{l_{\text {ext }}^{2}}{G M D^{2}}\right)\right]^{1 / 2}\right\}-\left[1+\left(\frac{G M D^{2}}{l_{\text {ext }}^{2}}\right)\right]^{1 / 2}+\left(\frac{G M D}{l_{\text {ext }}}\right)
$$

GMD (geometric mean distance), utilizada acima, é obtido através da relação: 
$\ln (G M D)=\ln (d)-\left\{\left[\frac{1}{12\left(\frac{d}{w}\right)^{2}}\right]+\left[\frac{1}{60\left(\frac{d}{w}\right)^{4}}\right]+\left[\frac{1}{168\left(\frac{d}{w}\right)^{6}}\right]+\left[\frac{1}{360\left(\frac{d}{w}\right)^{8}}\right]+\left[\frac{1}{660\left(\frac{d}{w}\right)^{10}}\right] \ldots\right\}$

onde $d$ é a distância entre os centros geométricos de cada segmento.

Para se obter nestas relações o valor da indutância mútua em $\mathrm{nH}$, deve-se utilizar os valores de $l_{e x t}, w$ e $d$ em centímetros.

A indutância mútua calculada, assim como a auto-indutância, depende apenas das características geométricas dos segmentos envolvidos.

Por cálculos manuais o valor da indutância total é normalmente difícil de ser determinado devido ao grande número de indutâncias mútuas que aparecem entre os segmentos.

\subsubsection{Limitações do Circuito Equivalente}

Embora sejam considerados muitos elementos parasitas no modelo do circuito equivalente, algumas relações fornecidas apresentam limitações. A primeira é que na equação da resistência série não está incluído o efeito de proximidade, que causa o aumento do valor da resistência. Felizmente o efeito de proximidade é praticamente insignificante se comparado com o efeito pelicular [Mo99].

Outra limitação é que o efeito da indutância mútua entre o substrato e o indutor não está sendo considerado. Essa indutância mútua aparece devido tanto ao fluxo magnético gerado pelo indutor, que chega ao substrato, quanto ao fluxo magnético gerado pela corrente eddy no substrato, que chega ao indutor [Mo99].

Por fim, também não estão incluídas no modelo utilizado as capacitâncias laterais entre os segmentos do indutor.

\subsection{Fator de Qualidade}

$O$ fator de qualidade $Q$ é uma medida que determina a qualidade de um indutor ([Oh03], [Mo01]). Para o modelo da Figura 8, pode-se obter o valor de $Q$ através das equações abaixo [Yu98]: 
$Q=\left(\frac{\omega L}{R_{s}}\right) \cdot\left\{\frac{R_{p}}{R_{p}+\left[\left(\frac{\varpi L}{R_{s}}\right)^{2}+1\right] R_{s}}\right\} \cdot\left[1-\frac{R_{s}^{2}\left(C_{s}+C_{p}\right)}{L}-\varpi^{2} L\left(C_{s}+C_{p}\right)\right]$

onde $\quad R_{p}=\frac{1}{\omega^{2} C_{o x}^{2} R_{s i}}+\frac{R_{s i}\left(C_{o x}+C_{s i}\right)^{2}}{C_{o x}^{2}}$

e $\quad C_{p}=C_{o x} \frac{1+\omega^{2}\left(C_{o x}+C_{s i}\right) C_{s i} R_{s i}^{2}}{1+\omega^{2}\left(C_{o x}+C_{s i}\right)^{2} R_{s i}^{2}}$

A equação 17 pode ser pensada e reescrita como o produto de três termos:

$\mathrm{Q}=\left(\frac{\omega L}{R_{\mathrm{s}}}\right) .($ perdas no substrato).(fator de auto-ressonância)

onde o primeiro termo expressa o $Q$ de um indutor ideal $L$ com uma resistência série $R_{s}$; o segundo representa a energia dissipada no substrato (segundo termo à direita da equação 17); e o último se refere ao aumento da energia elétrica (energia no capacitor) em função da freqüência (terceiro termo à direita da equação 17).

\subsection{Técnicas para Melhorar o Desempenho dos Indutores}

Neste item serão apresentadas algumas técnicas para aumentar o valor da indutância e do fator de qualidade. Essas técnicas são constituídas por alterações no processo e na estrutura do indutor.

\subsubsection{Alterações no Processo}

Para obtenção de indutores de alta qualidade, podem ser aplicadas as seguintes técnicas que envolvem alterações no processo de fabricação:

- utilização de substrato com alta resistividade: isto resulta na redução das correntes que circulam no substrato e, em conseqüência, obtêm-se maiores valores de $L$ e $Q$. Infelizmente substratos de alta resistividade não são os mais adequados aos circuitos digitais CMOS, pois aumentam os problemas de latchup [We93]. 
- utilização de camadas metálicas mais espessas: com camadas mais espessas se obtém uma menor resistência nos segmentos e, assim, há um aumento no $Q$ do indutor. Observemos que se a espessura do metal já for algumas vezes maior do que a profundidade pelicular, aumentos desta não resultarão na redução da resistência série e na melhora do valor Q.

- utilização das camadas de níveis mais altos de metal: estas camadas são normalmente as mais espessas. Além disso, a camada de óxido situada entre o metal e o substrato também é mais espessa, o que reduz o acoplamento magnético e, principalmente, elétrico entre o indutor e o substrato.

\subsubsection{Alterações na Estrutura}

Essas alterações podem ser feitas através da variação da geometria e do número de camadas de metal utilizadas, incluindo associações em série ou paralelo de espiras, e da inclusão de grades de silício policristalino.

\subsubsection{Geometria}

Pode-se variar o formato e os parâmetros geométricos dos indutores para se obter um melhor comportamento. Como dito anteriormente, o formato pode ser circular, octogonal, retangular, quadrado, entre outros; os parâmetros que se alteram podem ser: o número de voltas do indutor $(n)$, o comprimento externo $\left(l_{\text {ext }}\right)$, a largura (w) e o espaçamento entre os segmentos (s). Variando-se a geometria obtêm-se valores distintos de $Q$ e $L$. A Figura 11 ilustra a dependência de $Q$ versus o $l_{\text {ext }}$ para dois formatos de indutor [In03]. Nesta Figura podemos observar que a forma geométrica que fornece o maior $Q$ é o indutor octogonal com o $l_{\text {ext }}$ de $60 \mu \mathrm{m}$. 

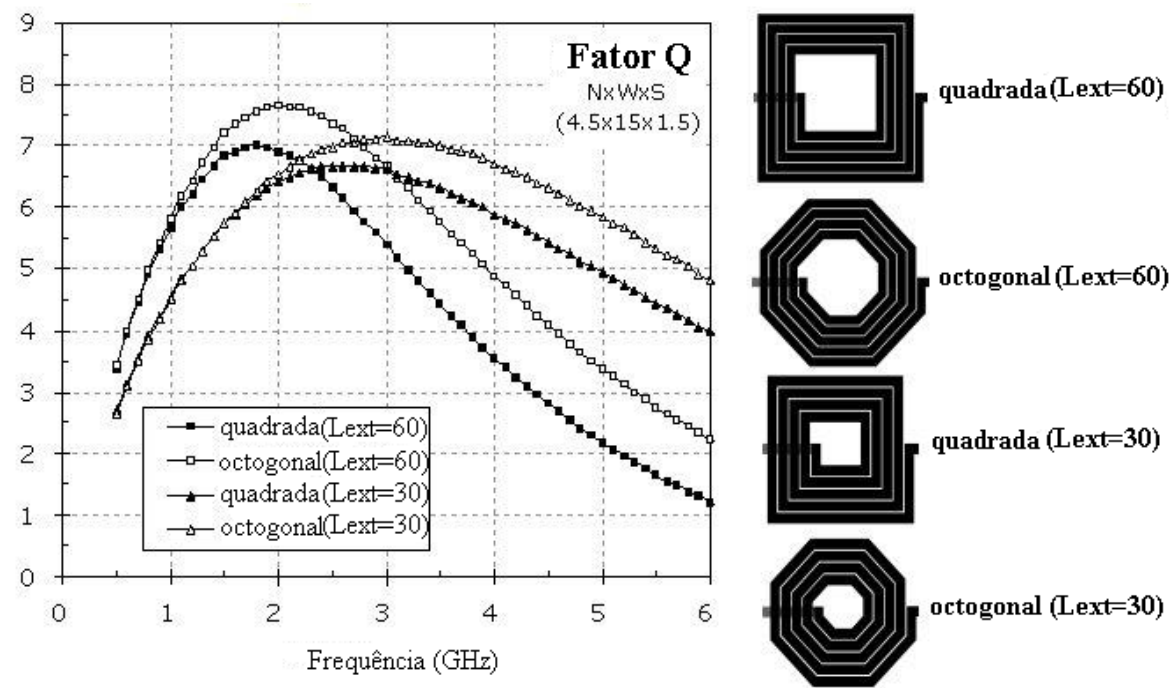

Figura 11 - Fator de qualidade versus o $l_{\text {ext }}$ para indutores quadrados e octogonais.

Quanto a influência da geometria no valor do $L$, determinou-se através de simulações que o valor da indutância aumenta com: o aumento do número de voltas do indutor, o aumento do comprimento externo, a diminuição da largura do segmento e a diminuição do espaçamento entre segmentos.

\subsubsection{Número de Camadas}

Os indutores podem ser implementados com múltiplas camadas de metais, utilizando-se de associações série ou paralelo de espiras construídas em diferentes níveis de metais, para se chegar a objetivos desejados.

$\mathrm{Na}$ associação em série a corrente percorre uma espira, passa para outra e assim por diante, aumentando o fluxo magnético gerado e, em conseqüência, aumentando o valor do $L$ (diretamente proporcional ao quadrado do número de espiras [Fe62]); em contrapartida tem-se a diminuição do $Q$, pois aumenta-se a resistência total dos segmentos.

$\mathrm{Na}$ associação paralela a corrente é dividida pelas várias espiras que compõem o indutor. $\mathrm{O}$ valor de $L$ sofre uma pequena redução, mas a resistência série é reduzida substancialmente o que garante um melhor $Q$. A Tabela 1 ilustra os valores da indutância e da resistência total dos segmentos para indutores construídos por associações série e paralelo de espiras em múltiplas camadas de metal [Me95]. 
Vale ressalta que M1, M2 e M3 correspondem a camada de metal 1, de metal 2 e de metal 3, respectivamente.

Tabela 1 - Influência das alterações nas estruturas dos indutores.

\begin{tabular}{|l|c|c|}
\cline { 2 - 3 } \multicolumn{1}{c|}{} & Indutância (nH) & Resistência série $(\boldsymbol{\Omega})$ \\
\hline M1 apenas & 2,06 & 9,8 \\
\hline M1, M2 em série & 7,71 & 19,6 \\
\hline M1, M2, M3 em série & 16,7 & 26,2 \\
\hline M1, M2, M3 em paralelo & 1,84 & 3,49 \\
\hline
\end{tabular}

\subsubsection{Grade de Silício Policristalino}

Uma das formas de aumentar o fator de qualidade é reduzir as perdas no substrato, perdas causadas pelas correntes induzidas pelo campo magnético e pelo acoplamento elétrico. Isto pode ser obtido através da utilização de uma grade de silício policristalino denominada Pattern Ground Shield (PGS) [Yu98], como ilustra a Figura 12.

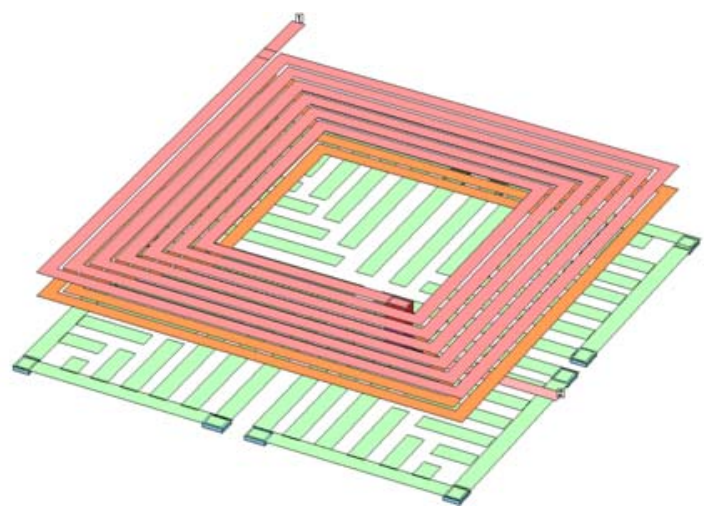

(a)

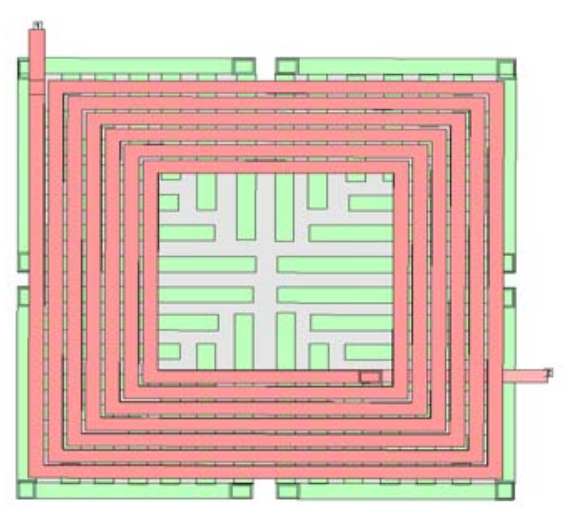

(b)

Figura 12 - Indutor com grade de silício policristalino: (a) vista 3D; (b) vista superior.

Quando o PSG é usado, as correntes induzidas pelo campo magnético, correntes de eddy, e pelo acoplamento elétrico passam do substrato para o silício policristalino que protege aquele. Aparentemente parece não haver qualquer ganho, pois as correntes simplesmente passaram de um material à outro. $\mathrm{O}$ ganho está no fato do silício policristalino ser mais condutivo e as correntes nele causarem menores perdas. 
A grade deve ter um formato especial, Figura 12, para evitar ao máximo a circulação de correntes nela, o que aumentaria o fluxo magnético reverso gerado e reduziria o valor de $L$.

Uma dificuldade com a utilização de grades é que elas causam o aumento das capacitâncias associadas ao indutor, aumentando o acoplamento elétrico (agora com a grade e não com o substrato). Assim, sua eficiência acaba sendo pequena e depende da tecnologia que está sendo aplicada. 


\section{3 - Metodologia}

Este capítulo é destinado à apresentação das ferramentas utilizadas na obtenção dos modelos dos indutores integrados. Serão apresentados o funcionamento e a configuração dos programas usados que serão avaliados através da comparação com as medidas elétricas realizadas em indutores implementados. Além destas ferramentas, serão descritas as estruturas de teste do indutor e suas estruturas de caracterização. As estruturas de caracterização servem para obter os elementos parasitas da estrutura de testes. Os elementos parasitas serão então utilizados para descontar a influência da estrutura de testes sobre as medidas elétricas.

No final do capítulo os indutores projetados serão descritos, incluindo seus parâmetros geométricos (como largura do segmento, comprimento, espaçamento e número de voltas) e estruturais.

Os programas foram configurados para os parâmetros best, típico e worst que se referem, respectivamente, ao melhor desempenho, ao desempenho típico e ao pior desempenho dos indutores, de acordo com as variações de parâmetros esperadas no processo (variações na espessura de óxido, na resistividade das camadas, etc.). É importante ressaltar que a simulação e as medias elétricas foram realizadas na faixa de freqüência de 1 a $5 \mathrm{GHz}$, que corresponde à faixa possível de aplicações da tecnologia.

\subsection{Ferramentas Utilizadas e Software para Implementação das Equações Analíticas}

Para o modelamento dos indutores foram utilizados as ferramentas ASITIC, SONNET e equações analíticas implementadas no MATLAB que foram apresentadas no capítulo anterior.

Para a comparação de resultados foi utilizada a tecnologia CMOS $0,35 \mu \mathrm{m}$ da AMS (AustriaMicroSystems) que apresenta quatro níveis de metal e dois de silício policristalino. Os dados desta tecnologia foram extraídos dos manuais AMS ([Au03a], [Au03b]) e são necessários para configuração do ASITIC, SONNET e do 
MATLAB. A Figura 13 ilustra a disposição e o nome das camadas, incluindo os níveis de metal, vias, entre outros [Au03a].

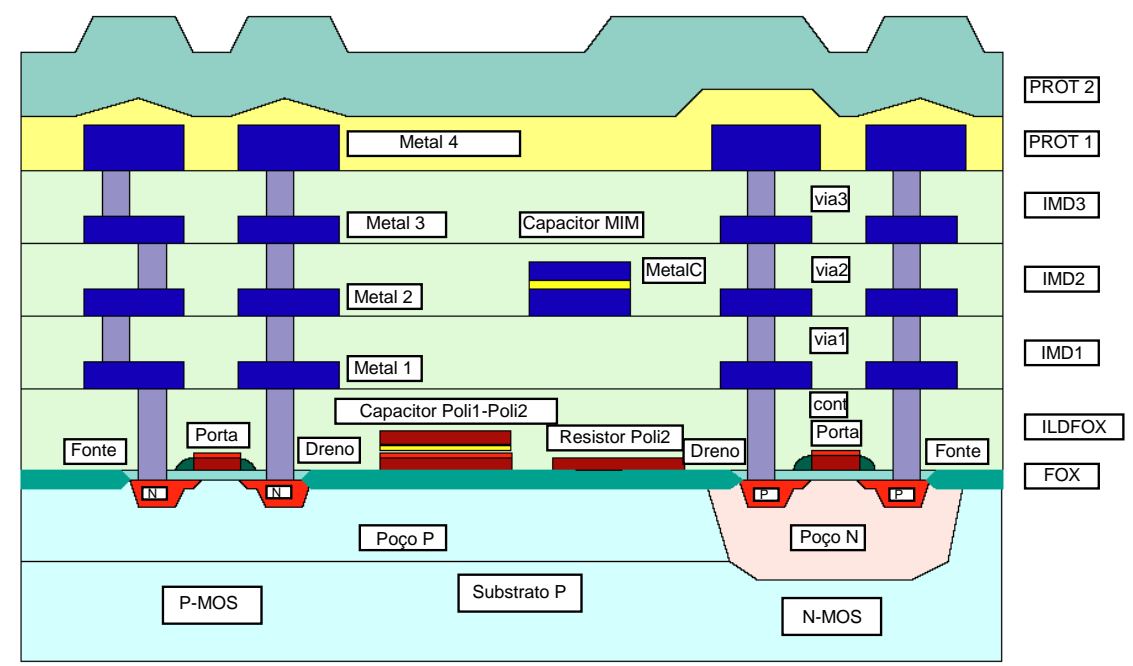

Figura 13 - Desenho das camadas do processo CMOS 0,35 $\mu \mathrm{m}$ da foundry AMS .

Analisando a ilustração da Figura 13 as camadas relevantes para um indutor são (na direção de baixo para cima): substrato, duas camadas de óxido (FOX e ILDFOX), quatro camadas de metal e óxido (Metal1-IMD1, Metal2-IMD2, Metal3IMD3 e Metal4-PROT1) e uma de passivação (PROT2).

A Tabela 2 apresenta os valores das espessuras das camadas de substrato, metal e óxido, da resistividade do substrato e da resistência dos metais e vias, nos parâmetros best, típico e worst. Esses dados foram extraídos do manual da AMS [Au03a]. 
Tabela 2 - Dados extraídos do manual AMS para a tecnologia CMOS 0,35 $\mu \mathrm{m}$.

\begin{tabular}{|c|c|c|c|c|c|c|c|}
\hline & \multicolumn{3}{|c|}{ Espessura (nm) } & \multicolumn{3}{|c|}{ Resistência de Folha (m $\Omega / s q)$} \\
\hline & & Best & Tip. & Worst & Best & Tip. & Worst \\
\hline \multirow{7}{*}{ 苞 } & Óxido de campo & 320 & 290 & 260 & - & - & - \\
\hline & Poli 1 & 300 & 282 & 264 & - & 8000 & 15000 \\
\hline & Metal 1 & 765 & 665 & 565 & - & 80 & 150 \\
\hline & Metal 2 & 740 & 640 & 540 & - & 80 & 150 \\
\hline & Metal 3 & 740 & 640 & 540 & - & 80 & 150 \\
\hline & Metal 4 & 1075 & 925 & 775 & - & 40 & 100 \\
\hline & Passivação & 1200 & 1000 & 800 & - & - & - \\
\hline \multirow{4}{*}{ ơ } & Met 1- Poli1 & 895 & 645 & 395 & - & - & - \\
\hline & Met 2-Met 1 & 1380 & 1000 & 620 & - & - & - \\
\hline & Met 3-Met 2 & 1380 & 1000 & 620 & - & - & - \\
\hline & Met 4-Met 3 & 1380 & 1000 & 620 & - & - & - \\
\hline \multirow[b]{2}{*}{ क } & & \multicolumn{3}{|c|}{ Espessura $(\mu \mathrm{m})$} & \multicolumn{3}{|c|}{ Resistividade ( $\Omega . c m)$} \\
\hline & Substrato $(\mathrm{Si})$ & 710 & 725 & 740 & 24 & 19 & 14 \\
\hline \multirow{5}{*}{$\stackrel{\mathscr{z}}{>}^{2}$} & & & & & \multicolumn{3}{|c|}{ Resistência $\Omega /$ via } \\
\hline & Via (Met1-Poli) & - & - & - & - & 2 & 10 \\
\hline & Via 1 (Met 2-1) & - & - & - & - & 1,2 & 3 \\
\hline & Via 2 (Met 3-2) & - & - & - & - & 1,2 & 3 \\
\hline & Via 3 (Met 4-3) & - & - & - & - & 1,2 & 3 \\
\hline
\end{tabular}

\subsubsection{ASITIC}

O ASITIC é um programa para projeto, análise, modelamento do comportamento eletromagnético e otimização de estruturas passivas de metal fabricadas sobre silício, que tem distribuição livre. Ele inclui indutores, transformadores, capacitores e linhas de transmissão em sua simulação. O programa trabalha com as equações de Maxwell [As03].

Para seu funcionamento devem ser fornecidas informações sobre o chamado domínio físico (arquivo de tecnologia), que descreve as características dos materiais usados, tais como condutividades, espessuras, permissividade e permeabilidade, e sobre o domínio geométrico, que descreve as características do indutor tais como dimensões, sua posição no circuito, camadas utilizadas, etc. A resposta será dada por informações no chamado domínio elétrico, que fornece as principais características elétricas do indutor, tal como o fator de qualidade, e no domínio de circuito, que descreve o indutor como modelos de n-portas [Ni00].

Foram escritos para o ASITIC arquivos de configuração da tecnologia best, típico e worst com os dados da Tabela 2 e que estão apresentados no ANEXO A. 
O primeiro passo para a utilização do ASITIC é carregar o arquivo de configuração desejado e descrever, através de linhas de comandos, quais as características do indutor a ser projetado (geometria e camadas de metal), como ilustrado na Figura 14. Em seguida, simula-se o indutor com as freqüências desejadas, obtendo os resultados.

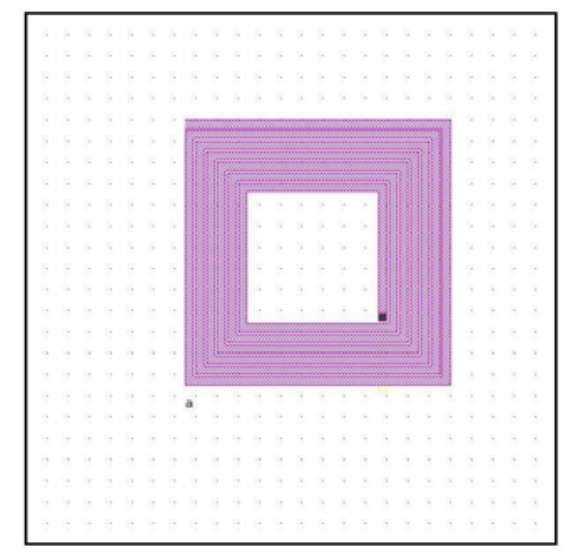

Figura 14 - Indutor projetado no ASITIC.

Para a comparação das ferramentas, os resultados foram gerados em parâmetros Y, real e imaginário. Posteriormente, foram utilizadas as equações abaixo para determinar a indutância e o fator de qualidade, dependentes de $y_{11}$ :

$$
\mathrm{L}=\frac{1}{\omega \operatorname{Im}\left(\mathrm{y}_{11}\right)} \quad \text { e } \quad Q=\frac{\operatorname{Im}\left(\frac{1}{y_{11}}\right)}{\operatorname{Re}\left(\frac{1}{y_{11}}\right)}
$$

onde $\omega$ é a freqüência em rad./seg. de simulação/medida.

A simulação no ASITIC para cada indutor leva cerca de cinco minutos em um computador com processador Pentium 4, 2,4 GHz de clock e 1 Gbyte de memória; foi utilizada neste caso uma área de simulação de $500 \mu \mathrm{m}$ x $500 \mu \mathrm{m}$. Na realidade este é o tempo da primeira simulação; se houver outras simulações utilizando o mesmo arquivo de configuração o tempo se reduz a segundos. O tempo reduzido de simulação é uma das grandes vantagens deste simulador; outra é o fato de que ele é gratuito. 
Para facilitar a utilização do ASITIC são apresentadas algumas observações para a descrição do layout e simulação de um indutor:

- Layout:

Um comando que facilita a utilização do ASITIC é o sqsh que desenha indutores em multicamadas paralelas de metal e gera automaticamente a saída. Neste comando é necessário apenas informar quais são as camadas de metal que devem ser usadas. Para a saída é escolhida a camada de metal mais elevada e que não foi utilizada no próprio indutor; por exemplo, um indutor projetado nas camadas de metal 3 e 4 terá o metal 2 como saída.

\section{- Simulação:}

Para conseguir uma simulação mais eficiente e rápida pode-se utilizar o comando 2portx, para indutores de duas portas. Com este comando é possível fazer a simulação em diversas freqüências, informando apenas as freqüências inicial e final e o passo entre freqüências. Podemos obter como resposta os parâmetros $\mathrm{S}, \mathrm{Y}$ e $\mathrm{Z}$ ou modelo PI e salvá-los em um arquivo de texto.

\subsubsection{SONNET}

O SONNET [So04] é um simulador de campos eletromagnéticos em 3-D planar, que faz análise de circuitos de alta freqüência, trabalhando com as equações de Maxwell associadas com condições de contorno [Mo99]. Faz análises eletromagnéticas, computa os parâmetros S, Y e Z, o modelo PI, os parâmetros de transmissão de linhas, o modelo SPICE e gera gráficos cartesianos e carta de Smith. Permite, também, para circuitos de alta freqüência, o modelamento de filtros distribuídos, transmissores, pacotes RF, guias de onda e antenas [Ky01]. Este software necessita de grande capacidade computacional (processador e memória) e despende um tempo considerável nas simulações. Para indutores com estruturas mais complexas ele deve ser aplicado criteriosamente.

Para configuração do SONNET é necessário fornecer informações sobre duas classes de camadas: de dielétricos e de metais.

A Figura 15 ilustra a janela de configuração de dielétricos com as oito camadas utilizadas. Para cada camada deve ser fornecida a espessura, a constante 
dielétrica relativa, a permeabilidade magnética relativa e a condutividade elétrica em $1 /(\Omega \mathrm{m})$. A interface entre cada duas camadas define um nível, que vai do nível 0 , entre as camadas Air e PROT2, até o nível 7, entre FOX e P-SUBSTRATE. Estes níveis indicam onde podem ser colocadas as camadas de metais que, diferente das camadas de dielétricos, não tem posição fixa na configuração.

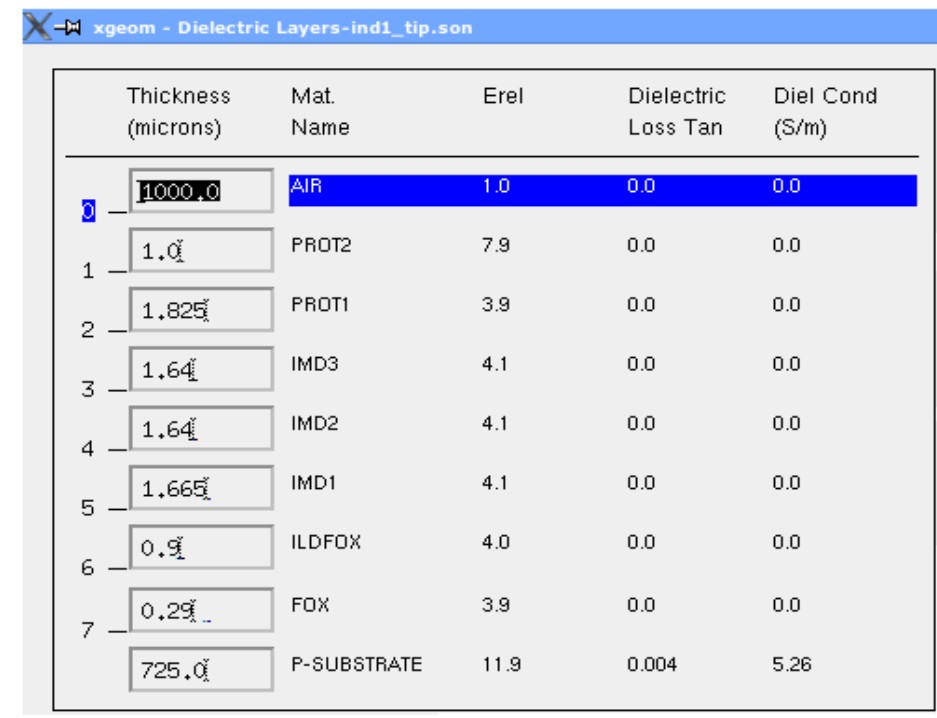

Figura 15 - Janela de configuração do SONNET para camadas dielétricas.

A Figura 16 mostra a janela de configuração para as camadas de metal propriamente dito, de silício policristalino e de vias. Estas formam dez camadas e são chamadas, genericamente, de metais. Para todas as camadas deve ser fornecido o valor de $R d c$, que representa a resistência de folha em $\Omega / s q$, e para as camadas de metal e silício policristalino, o valor de $R r f$, que representa o coeficiente de efeito pelicular em $\Omega \mathrm{Hz}^{-1 / 2} / \mathrm{sq}$. Observemos que o simulador SONNET trata as estruturas construídas nas camadas de metal e silício policristalino como planas, espessura zero, para simplificar as simulações (por esta razão é chamado de 3-D planar).

Um indutor pode ser construído com uma ou mais camadas de metal, que são colocadas em níveis específicos de acordo com a tecnologia: o metal 1 no nível 5, o metal 2 no nível 4, o metal 3 no nível 3 e o metal 4 no nível 2. 


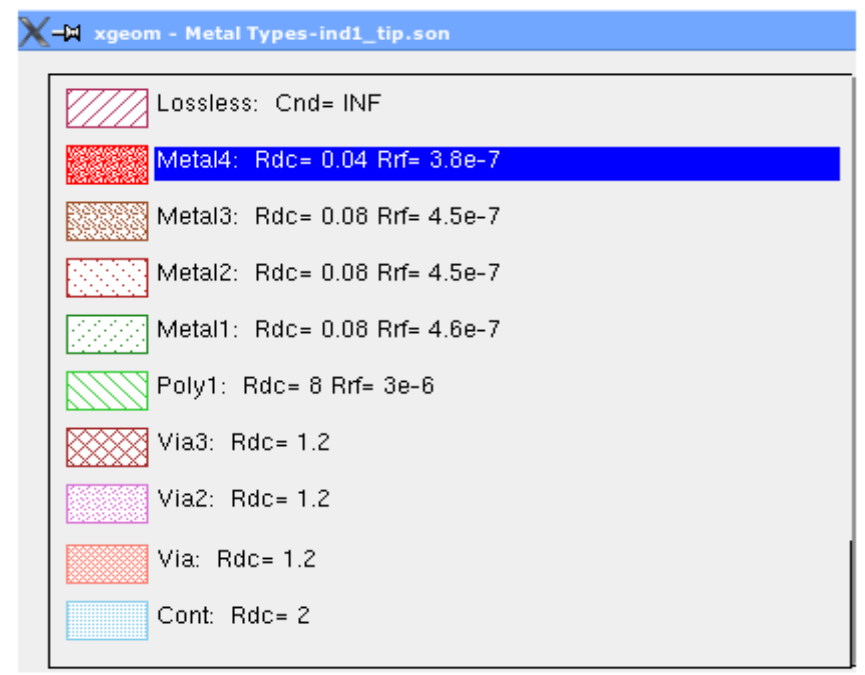

Figura 16 - Janela de configuração do SONNET para camadas metálicas.

Após a configuração do SONNET, descreve-se a geometria do indutor que é projetado nas camadas de metal desejadas, como ilustrado na Figura 17. O próximo passo é a simulação e depois a verificação dos resultados.
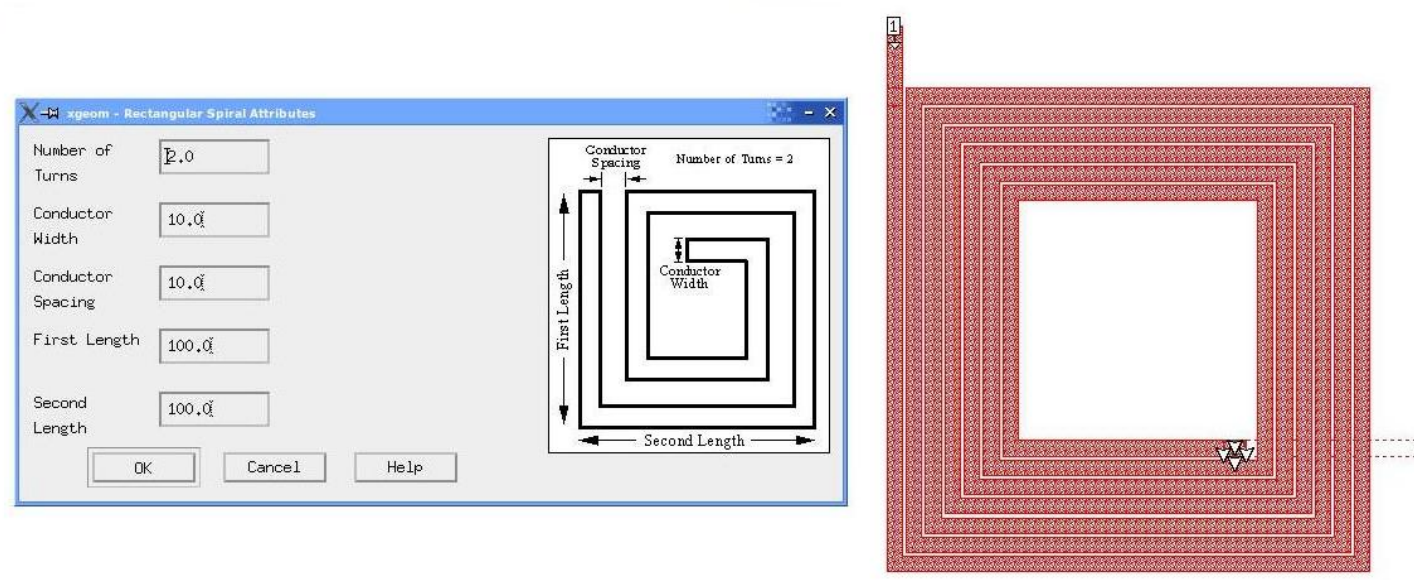

Figura 17 - Indutor projetado no SONNET.

No SONNET a simulação leva cerca de 1:10h para cada freqüência desejada em um computador com processador Pentium 4, 2,4 GHz de clock e 1 Gbyte de memória; foi utilizada neste caso uma área de simulação de $500 \mu \mathrm{m}$ x $500 \mu \mathrm{m}$. 
Para facilitar a utilização do SONNET são apresentadas algumas observações para a descrição do layout e simulação de um indutor:

- Layout:

É importante determinar corretamente a área a ser utilizada para o projeto. Quanto maior ela for, maiores serão a quantidade de memória utilizada e o tempo gasto na simulação, mas se obtém melhor precisão nos resultados.

$\mathrm{Na}$ simulação, as portas de um circuito introduzem uma descontinuidade nos resultados. Há uma opção no modo Avançado, o De-embedding, que, habilitada remove essa descontinuidade.

\section{- Simulação:}

Para aumentar a velocidade de simulação pode-se utilizar a opção Adaptative Sweep (ABS). Nela indicam-se apenas as freqüências inicial e final de simulação, sendo os pontos intermediários determinados automaticamente. No caso de desejarmos escolher o passo entre freqüências, utiliza-se a opção Linear Frequency Sweep onde, além das freqüências inicial e final, o passo também é fornecido. Normalmente teremos maior tempo de simulação neste caso, pois são analisados mais pontos.

Podemos melhorar a precisão da simulação aumentando o número de grids utilizados. Neste caso a opção Estimate, que estima a quantidade de memória necessária para a simulação, é bastante útil.

Para obter uma simulação mais rápida é conveniente utilizar para o número de grids um valor que seja potência de 2. Isto permitirá o software utilizar versões otimizadas de algoritmos que fazem a FFT-2D.

O SONNET é uma ferramenta útil para a análise de dados gerados tanto por ele mesmo como por outros meios (simulação ou medidas). Para permitir a importação de dados ele apresenta a capacidade de ler arquivos no formato touchstone. Nesse formato podemos fornecer parâmetros S, Z ou Y; por exemplo, no caso de parâmetros $\mathrm{S}$, cada linha do arquivo terá os valores de $\operatorname{Re}\left(\mathrm{S}_{11}\right), \operatorname{Im}\left(\mathrm{S}_{11}\right)$, $\operatorname{Re}\left(\mathrm{S}_{12}\right), \operatorname{Im}\left(\mathrm{S}_{12}\right) \operatorname{Re}\left(\mathrm{S}_{21}\right), \operatorname{Im}\left(\mathrm{S}_{21}\right), \operatorname{Re}\left(\mathrm{S}_{22}\right)$ e $\operatorname{Im}\left(\mathrm{S}_{22}\right)$, nessa ordem, para uma freqüência. Este formato é também compatível com a saída do analisador de redes utilizado na caracterização dos indutores implementados. 
Uma vez gerados os dados ou carregados via arquivos podemos no SONNET:

- Converter parâmetros $\mathrm{S}, \mathrm{Z}$ ou Y para qualquer formato (, $\mathrm{Z}$ ou Y);

- Determinar o valor de $L$ do quadripolo: o valor de $L$ é calculado a partir de $y_{m n}$ (onde $m$ e $n$ são 1 ou 2, não necessariamente diferentes) da matriz de admitâncias pela seguinte relação:

$L_{1}=\frac{1}{\omega \operatorname{Im}\left(y_{m n}\right)}$ onde $\omega$ é a freqüência em rad./seg. de simulação/medida.

- Determinar o valor de $Q$ do quadripolo: o valor de $Q$ é calculado a partir de $y_{n n}$ da matriz de admitâncias pela seguinte relação:

$$
Q=\frac{\operatorname{Im}\left(\frac{1}{y_{n n}}\right)}{\operatorname{Re}\left(\frac{1}{y_{n n}}\right)} ;
$$

Obs. utilizar apenas o parâmetro $y_{11}$ ou $y_{22}$ para calcular o $Q$, ou o $L$, eqüivale a aterrar um dos lados do indutor.

- Gerar gráficos em função da freqüência e Cartas de Smith;

- Salvar resultados em arquivos com extensão "csv", que podem ser abertos no software Excel.

\subsubsection{Software para Implementação das Equações Analíticas}

Para implementar as equações teóricas apresentadas no capítulo 2, utilizamos o MATLAB, que é um software que fornece recursos para cálculos matemáticos, computação de algoritmos, simulações, apresentações gráficas, entre outros. Utilizamos este software, pois é simples e possui uma linguagem própria para sua programação. Programas de cálculo executados nele devem demorar mais do que em programas desenvolvidos em linguagens como C, no entanto, dadas as equações implementadas e a baixa necessidade computacional que exigem, isto não é relevante para nós.

Para a comparação dos resultados das equações analíticas com as ferramentas e, posteriormente, com as medidas elétricas, é interessante se obter a indutância equivalente do modelo PI, $L_{e q}$ (indutância vista pela fonte $V_{\text {in }}$ na Figura 18 a e que 
leva em conta todos os elementos). Para isso podemos determinar a impedância equivalente do circuito e, então, calcular sua parte imaginária.

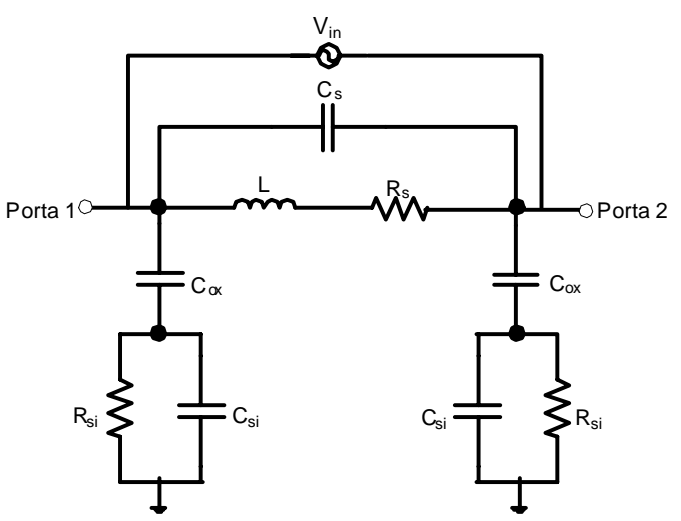

(a)

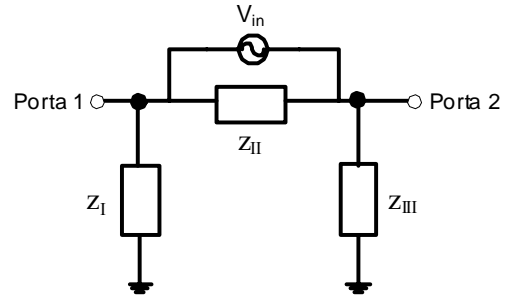

(b)

Figura 18 - Determinação do circuito equivalente: (a) modelo PI; (b) circuito equivalente.

Considere o circuito equivalente ao modelo PI da Figura 18b. Vamos utilizálo para achar a impedância vista pela fonte $V_{\text {in }}$, ou seja, a impedância entre os dois terminais (porta 1 e porta 2). Podemos escrever que a impedância equivalente é $z_{e q}=z_{I I} / /\left(z_{I}+z_{I I I}\right)$. Como $z_{I}=z_{I I I}$, tem-se $z_{e q}=z_{I I} / /\left(2 z_{I}\right)$. As expressões de $z_{I}$ e $z_{I I}$ são dadas abaixo,

$$
z_{I}=\left(\frac{R_{s i} \frac{1}{s C_{s i}}}{R_{s i}+\frac{1}{s C_{s i}}}\right)+\frac{1}{s C_{o x}}, \quad z_{I I}=\frac{\left(s L+R_{s}\right) \frac{1}{s C_{s}}}{\left(s L+R_{s}\right)+\frac{1}{s C_{s}}}
$$

onde $s=j \omega$ e $\omega$ é a freqüência em rad./seg. em que estamos interessados.

Por fim, a impedância equivalente será:

$$
\mathrm{z}_{e q}=\frac{\left[\frac{\left(s L+R_{s}\right) \frac{1}{s C_{s}}}{\left(s L+R_{s}\right)+\frac{1}{s C_{s}}}\right] 2\left[\left(\frac{R_{s i} \frac{1}{s C_{s i}}}{R_{s i}+\frac{1}{s C_{s i}}}\right)+\frac{1}{s C_{o x}}\right]}{\left[\frac{\left(s L+R_{s}\right) \frac{1}{s C_{s}}}{\left(s L+R_{s}\right)+\frac{1}{s C_{s}}}\right]+2\left[\left(\frac{R_{s i} \frac{1}{s C_{s i}}}{R_{s i}+\frac{1}{s C_{s i}}}\right)+\frac{1}{s C_{o x}}\right]}
$$


Uma vez conhecidos os valores dos parâmetros $L, R_{s}, R_{\mathrm{si}}, C_{o x}$ e $C_{s i}$ e da freqüência $\omega$, podemos determinar, então, o valor de $z_{e q}$. A Indutância equivalente entre os dois terminais do modelo PI é dado por:

$$
L_{e q}=\operatorname{Im}\left(z_{e q}\right) / \omega
$$

Observemos que só temos um indutor de fato enquanto $\operatorname{Im}\left(\mathrm{z}_{e f}\right)$ for maior do que zero.

Os valores das indutâncias equivalente obtidas no ASITIC, SONNET e nas medidas elétricas foram calculada utilizando o parâmetro $y_{11}$ (equações apresentadas previamente). Em razão disso, não devemos utilizar o valor de $L_{e q}$ dado pela equação (23) para comparações; devemos sim calcular uma novo valor de indutância considerando aterrado um dos lados do modelo PI, o que eqüivale a utilizar $z_{I}$ ou $z_{I I I}$ igual a zero. Assim, teremos $\mathrm{z}_{\text {eq }}=\mathrm{z}_{\mathrm{II}} / / \mathrm{z}_{\mathrm{I}}$ e o $\mathrm{L}_{\text {eq }}$ calculado analiticamente para comparação será:

$$
\mathrm{L}_{\mathrm{eqC}}=\operatorname{Im}\left(\mathrm{z}_{\mathrm{II}} / / \mathrm{z}_{\mathrm{I}}\right) / \omega
$$

O ANEXO B fornece o programa para o MATLAB utilizado para determinar os parâmetros do modelo PI além de $Q$ e $L_{e q}$.

A Tabela 3 ilustra como foram utilizadas as três ferramentas de modelamento de indutores, destacando como são a entrada e a saída de dados e como se obtiveram os resultados do $L$ e $Q$ versus a freqüência para cada uma delas.

Tabela 3 - Comparação dos métodos de utilização das ferramentas.

\begin{tabular}{|c|c|c|c|}
\cline { 2 - 4 } \multicolumn{1}{c|}{} & Entrada & Saída & $\begin{array}{c}\text { Como se obtiveram os resultados } L \\
\text { e } Q \text { (versus freqüência) }\end{array}$ \\
\hline ASITIC & $\begin{array}{c}\text { geometria } \\
\text { (desenho) }\end{array}$ & $\begin{array}{c}\text { parâmetros S, Y ou Z; } \\
\text { modelo PI }\end{array}$ & $\begin{array}{c}\text { através dos parâmetros Y obtendo } L \text { e } \\
Q \text { pela equação } 20\end{array}$ \\
\hline SONNET & $\begin{array}{c}\text { geometria } \\
\text { (desenho) }\end{array}$ & $\begin{array}{c}\text { parâmetros S, Y ou Z; } \\
\text { modelo SPICE; modelo } \\
\text { PI; Carta de Smith }\end{array}$ & $\begin{array}{c}\text { através dos parâmetros Y obtendo } L \text { e } \\
Q \text { pela equação } 20\end{array}$ \\
\hline MATLAB & geometria & $\begin{array}{c}\text { parâmetros PI e valores de } \\
\text { (parâmetros) }\end{array}$ & $\begin{array}{c}\text { obtendo } L \text { pela equação } 24 \text { e o } Q \text { pela } \\
\text { equação } 17\end{array}$ \\
\hline
\end{tabular}

\subsection{Medidas Elétricas}

Para realizar as medidas elétricas foi projetado um chip-teste com cinco indutores implementados em estruturas de teste e com estruturas de caracterização que servem para determinar os elementos parasitas das estruturas de teste. 


\subsubsection{Estruturas de Teste}

Foram implementadas duas estruturas de teste com dois terminais de acesso para os indutores: uma estrutura simples, Figura 19, e outra completa, Figura 20, com uma placa metálica de terra sob ela. Este placa tem a finalidade de definir melhor um ponto de referência para as medidas. Os terminais dessas estruturas são: $\mathrm{S}_{1}$ e $\mathrm{T}_{1}$ para os sinais de entrada e terra, respectivamente, da porta 1; e $\mathrm{S}_{2}$ e $\mathrm{T}_{2}$ para os sinais de entrada e terra da porta 2. Em ambas estruturas os sinais de entrada e saída são aplicados ou lidos por meio de micro-pontas de prova do tipo ground-signalground (GSG);

Cada uma das estruturas de teste apresenta vários elementos parasitas que são incluídos nas medidas elétricas do indutor [Ko00]. A Figura 21 ilustra um modelo equivalente para estas estruturas, com os diversos elementos parasitas incorporados, e o indutor sob teste. Os elementos parasitas são dados por: $z_{c}$, a impedância de contato entre as pontas de prova e a superfície dos pads; $z_{p}$, a impedância de acoplamento entre os pads de sinal de entrada/saída e o terra; $z_{1}$ e $z_{2}$, impedância série entre os pads de entrada/saída e os terminais do indutor; $z_{3}$ e $z_{4}$, o acoplamento entre a entrada/saída e o substrato; e $z_{f}$, o acoplamento direto entre os pads de entrada e de saída.

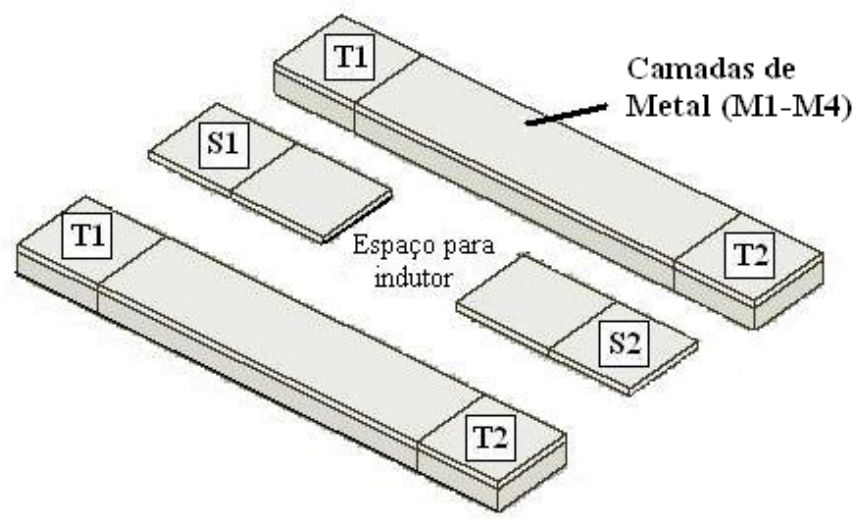

Figura 19 - Estrutura de teste simples. 


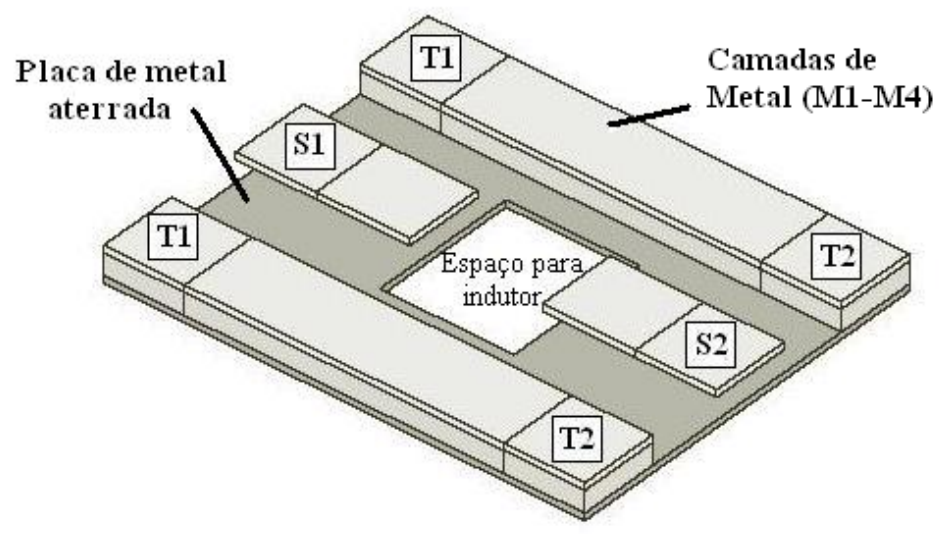

Figura 20 - Estrutura de teste completa.

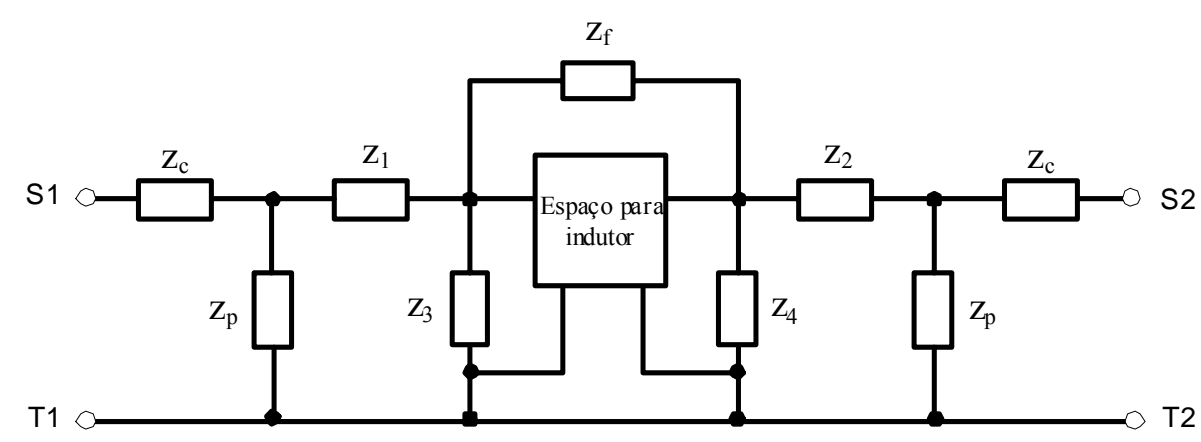

Figura 21 - Modelo equivalente das impedâncias das estruturas de teste.

A cada estrutura de teste estão associadas estruturas de caracterização que permitirão determinar o valor dos elementos $z_{c}, z_{p}, z_{1}, z_{2}, z_{3}, z_{4}$, e $z_{f}$, descritos acima, para que seja possível cancelar seus efeitos nas medidas dos indutores. As estruturas de caracterização são montadas a partir de modificação das próprias estruturas de teste, e são três como descritas abaixo:

- Estrutura de caracterização short/open: esta estrutura é montada a partir da estrutura de teste fazendo um curto entre um dos terminais de sinal $\left(\mathrm{S}_{1}\right.$ ou $\left.\mathrm{S}_{2}\right)$ e o terra e deixando aberto o outro terminal. Ela servirá para determinar as impedâncias $z_{c}$ e $z_{p}$.

- Estrutura de caracterização short: esta estrutura é montada a partir da estrutura de teste fazendo um curto entre as trilhas que vêm dos terminais $S_{1}$ e $\mathrm{S}_{2}$ e o metal sob a estrutura, próximo ao ponto onde deve ser ligado o indutor. 
Esta estrutura servirá para determinar as impedâncias $z_{1}$ e $z_{2}$ e será utilizada apenas na estrutura completa.

- Estrutura de caracterização open: esta estrutura é montada a partir da estrutura de teste deixando em aberto os terminais $\mathrm{S}_{1}$ e $\mathrm{S}_{2}$. Ela servirá para determinar as impedâncias $z_{3}, z_{4}$ e $z_{f}$;

Para exemplificar, as estruturas de caracterização utilizadas com a estrutura completa estão ilustradas na Figura 22, short/open, na Figura 23, short, e na Figura 20, a própria estrutura de teste, open.

Tanto para determinar os elementos parasitas de cada estrutura como para cancelar seus efeitos nas medidas utilizou-se o método de subtração de impedâncias descrito por [Ko00]. Vejamos como isso é feito, iniciando pela estrutura simples.

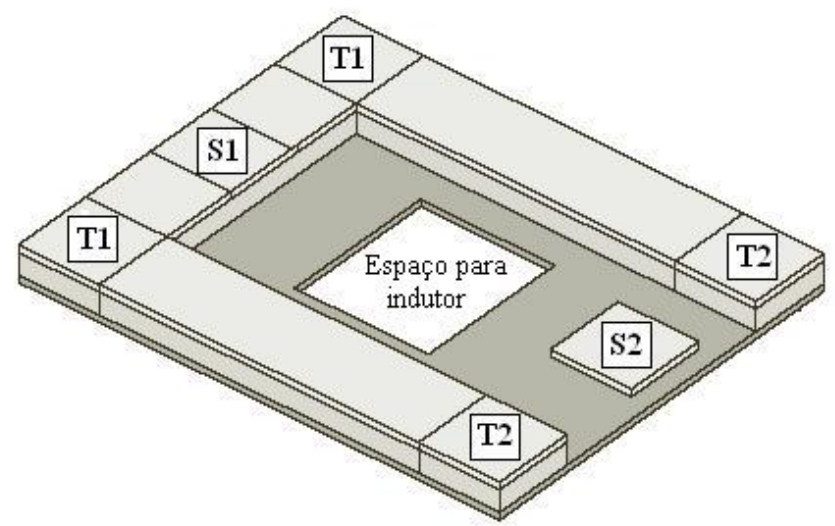

Figura 22 - Estrutura de caracterização short-open para a estrutura completa.

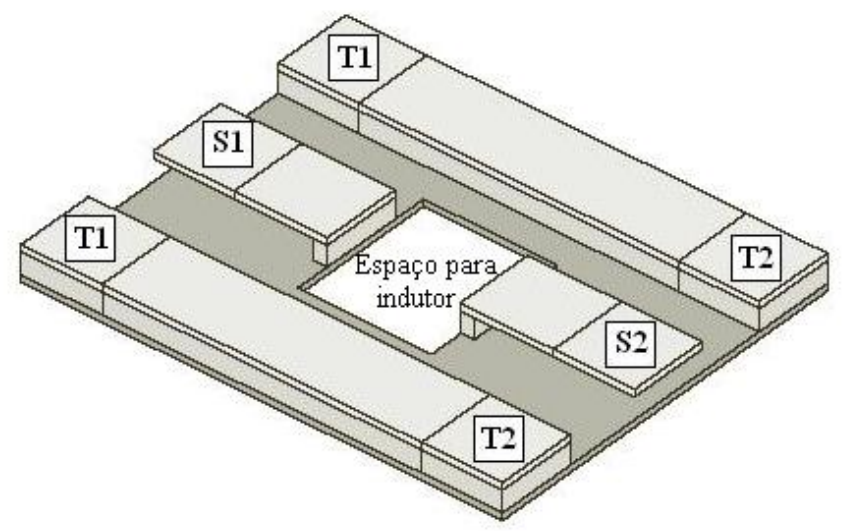

Figura 23 - Estrutura de caracterização short para a estrutura completa. 
Para o caso da estrutura simples vamos considerar que $z_{1}$ e $z_{2}$ têm valores pequenos e que $z_{3}$ e $z_{4}$, valores grandes, portanto, que nenhum dos quatro elementos afeta as medidas. Assim, quando estamos medindo um indutor com esta estrutura, na verdade estaremos trabalhando com o quadripolo da Figura 24. Ao utilizarmos esta simplificação reduzimos as estruturas de caracterização necessárias aqui a apenas duas (a estrutura short é eliminada).

Para a estrutura simples é necessário então medir as estruturas de caracterização short/open e open, cujos quadripolos equivalentes estão indicados nas Figuras 25 e 26, respectivamente, obtendo as matrizes de parâmetros $Z, Z_{(\mathrm{s} / \mathrm{o})}$ para a short/open, e $Z_{(o)}$ para a open.

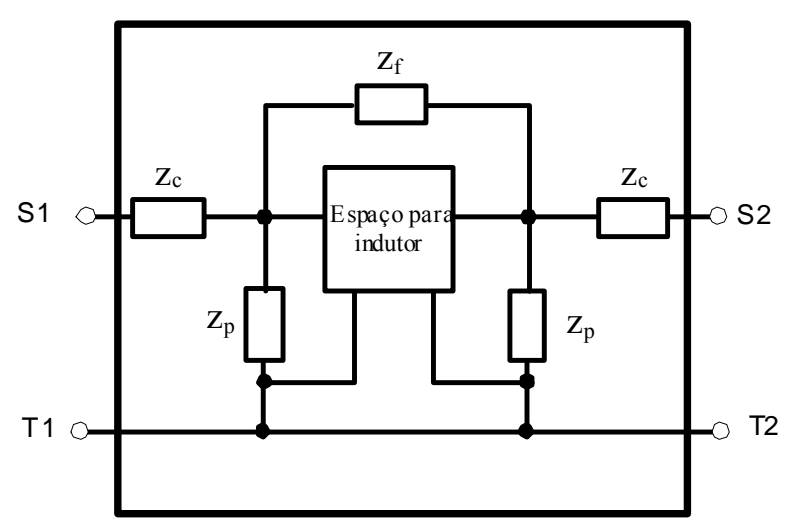

Figura 24 - Quadripolo equivalente da estrutura de teste simples mais o indutor.
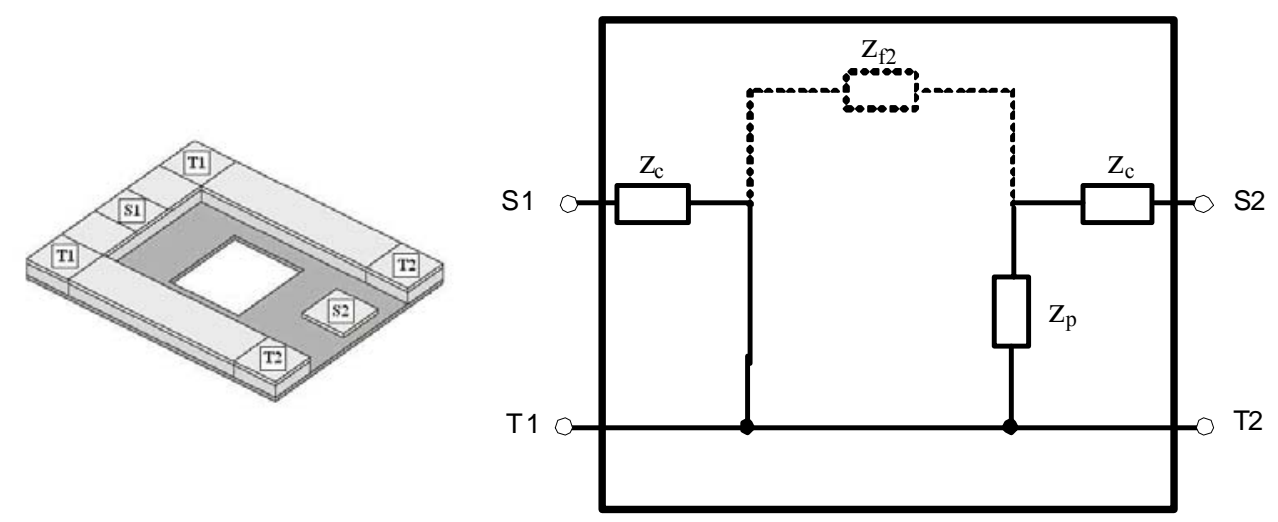

Figura 25 - Quadripolo equivalente da estrutura de caracterização short/open da estrutura de teste simples. 


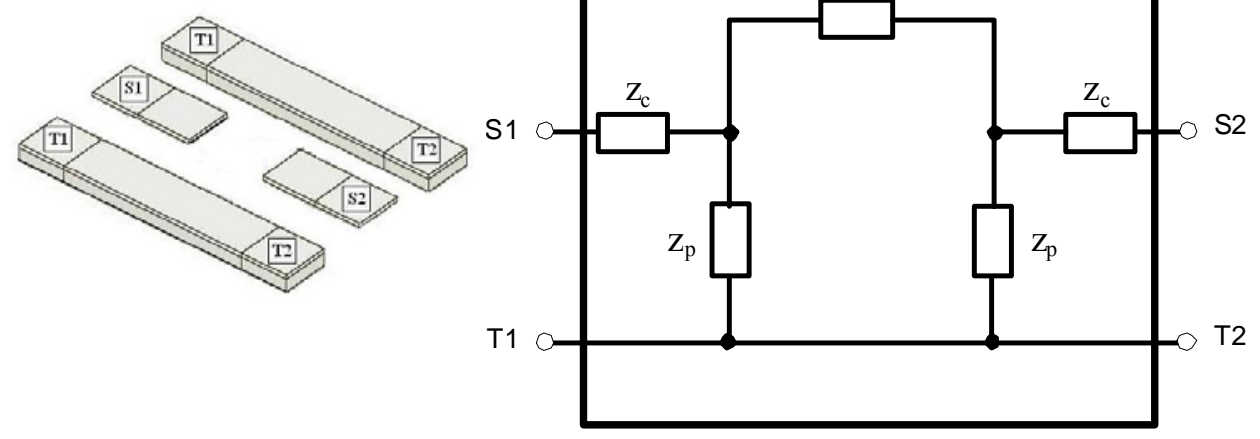

Figura 26 - Quadripolo equivalente da estrutura de caracterização open da estrutura de teste simples

A partir do quadripolo da estrutura short/open (matriz $\left.Z_{(s / o)}\right)$ podemos ver que:

$$
z_{c}=z_{11_{(s / o)}} \text { e } \quad z_{p}=z_{22_{(s / o)}}-z_{c}
$$

Neste caso, a impedância de acoplamento entre os terminais, $z_{f 2}$, muito menor do que $z_{f}$, foi desconsiderada [Ko00].

Para determinar o valor da impedância $z_{f}$ devemos observar que:

- o quadripolo da estrutura open é constituído da associação de três quadripolos: um quadripolo composto apenas por $Z_{f}$, com matriz de admitâncias $Y=\left[\begin{array}{cc}1 / z_{f} & -1 / z_{f} \\ -1 / z_{f} & 1 / z_{f}\end{array}\right]$; outro constituído de duas impedâncias $z_{p}$, com matriz $Y=\left[\begin{array}{cc}1 / z_{p} & 0 \\ 0 & 1 / z_{p}\end{array}\right]$, em paralelo com o primeiro; e um quadripolo constituído de duas impedâncias $Z_{c}$, com matriz de impedâncias $Z=\left[\begin{array}{cc}z_{c} & 0 \\ 0 & z_{c}\end{array}\right]$, em série com os anteriores.

- as matrizes de admitâncias $Y$ e de impedâncias $Z$ obedecem a relação $Y=Z^{-1}$;

- a matriz $Z$ de um quadripolo formado pela associação de dois quadripolos em série é a soma das matrizes $Z s$ destes quadripolos [Or04];

- a matriz $Y$ de um quadripolo formado pela associação de dois quadripolos em paralelo é a somas das matrizes $Y$ s destes quadripolos.

Em vista disso $Z_{\mathrm{f}}$ será determinado pela seguinte sequência de operações sobre a matriz $Z_{(o)}$ da estrutura open : 


$$
\begin{aligned}
& Z_{(o)}^{\prime}=\left[\begin{array}{ll}
z_{11_{(o)}} & z_{12_{(o)}} \\
z_{21_{(o)}} & z_{22_{(o)}}
\end{array}\right]-\left[\begin{array}{cc}
z_{c} & 0 \\
0 & z_{c}
\end{array}\right], \quad Y_{(o)}^{\prime}=Z_{(o)}^{\prime-1}, \\
& Y_{(o)}^{\prime \prime}=\left[\begin{array}{ll}
y_{11_{(o)}^{\prime}}^{\prime} & y_{12_{(o)}^{\prime}}^{\prime} \\
y_{21_{(o)}}^{\prime} & y_{22_{(o)}^{\prime}}^{\prime}
\end{array}\right]-\left[\begin{array}{cc}
1 / z_{p} & 0 \\
0 & 1 / z_{p}
\end{array}\right] \text { e } \quad z_{f}=-\frac{1}{y_{12_{(o)}^{\prime \prime}}^{\prime}}=-\frac{1}{y_{21_{(o)}}^{\prime \prime}}
\end{aligned}
$$

Assim são determinados os valores dos elementos parasitas da estrutura de testes simples. Vejamos agora como é feito o cancelamento dos seus efeitos nas medidas. Suponha que obtivemos a matriz de parâmetros $Z$, que chamaremos de $Z_{(i)}$, de um indutor utilizando a estrutura simples. O quadripolo medido neste caso é constituído da associação de quatro quadripolos: o quadripolo que descreve o apenas o indutor testado e que desejamos avaliar; outro composto apenas por $z_{f}$, com matriz de admitâncias $Y=\left[\begin{array}{cc}1 / z_{f} & -1 / z_{f} \\ -1 / z_{f} & 1 / z_{f}\end{array}\right]$, em paralelo com o primeiro; um quadripolo constituído de duas impedâncias $z_{p}$, com matriz $Y=\left[\begin{array}{cc}1 / z_{p} & 0 \\ 0 & 1 / z_{p}\end{array}\right]$, em paralelo com os anteriores; e um quadripolo constituído de duas impedâncias $z_{c}$, com matriz de impedâncias $Z=\left[\begin{array}{cc}Z_{c} & 0 \\ 0 & Z_{c}\end{array}\right]$, em série com os anteriores (ver ANEXO C):

Em vista do que foi dito acima, podemos cancelar o efeito dos elementos parasitas na matriz $Z_{(i)}$ através da sequência de operações abaixo:

$$
\begin{aligned}
Z_{(i)}^{\prime} & =\left[\begin{array}{ll}
z_{11_{(i)}} & z_{12_{(i)}} \\
z_{21_{(i)}} & z_{22_{(i)}}
\end{array}\right]-\left[\begin{array}{cc}
z_{c} & 0 \\
0 & z_{c}
\end{array}\right], \quad Y_{(i)}^{\prime}=Z_{(i)}^{\prime-1}, \\
Y_{(i)}^{\prime \prime} & =\left[\begin{array}{ll}
y_{11_{(i)}}^{\prime} & y_{12_{(i)}}^{\prime} \\
y_{21_{(i)}}^{\prime} & y_{22_{(i)}}^{\prime}
\end{array}\right]-\left[\begin{array}{cc}
1 / z_{p} & 0 \\
0 & 1 / z_{p}
\end{array}\right], \\
Y_{(i)}^{\prime \prime \prime} & =\left[\begin{array}{ll}
y_{11_{(i)}}^{\prime \prime} & y_{12_{(i)}^{\prime \prime}}^{\prime \prime} \\
y_{21_{(i)}}^{\prime \prime} & y_{22_{(i)}}^{\prime}
\end{array}\right]-\left[\begin{array}{cc}
1 / z_{f} & -1 / z_{f} \\
-1 / z_{f} & 1 / z_{f}
\end{array}\right] \mathrm{e} \\
Z_{(i)}^{\prime \prime \prime} & =Y_{(i)}^{\prime \prime \prime-1}
\end{aligned}
$$


onde $Z_{(i)}^{\text {"' }}$ é a matriz do indutor testado sem o efeito dos elementos parasitas.

Passemos agora para a estrutura completa. Neste caso consideramos todos os elementos parasitas da estrutura. Assim, quando estamos medindo um indutor com esta estrutura, na verdade estamos realizando a medida sobre o quadripolo da Figura 27.

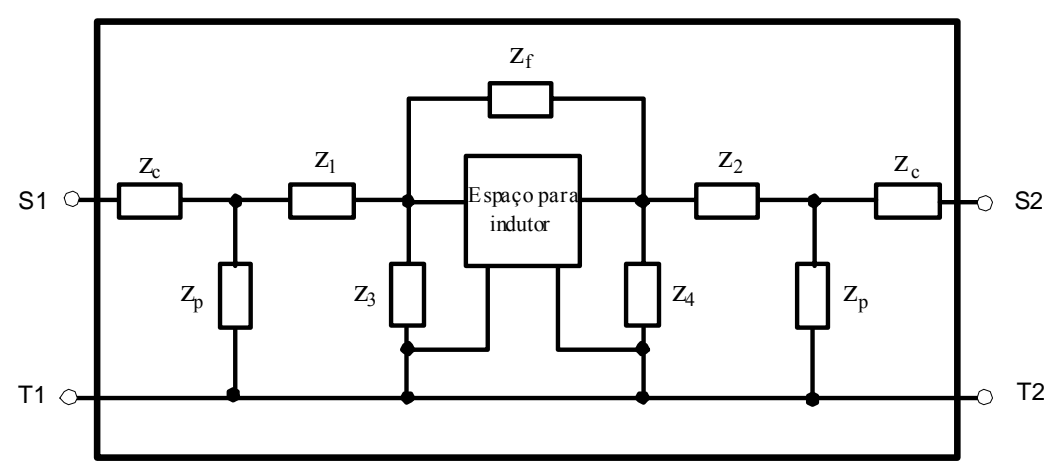

Figura 27 - Quadripolo equivalente da estrutura de teste completa mais o indutor.

Para a estrutura completa é necessário medir as estruturas de caracterização short/open, short e open, cujos quadripolos equivalentes estão indicados nas Figuras 28, 29 e 30, respectivamente, obtendo as matrizes de parâmetros $Z, Z_{(s / o)}$ para a short/open, $Z_{(s)}$ para a short, e $Z_{(o)}$ para a open.
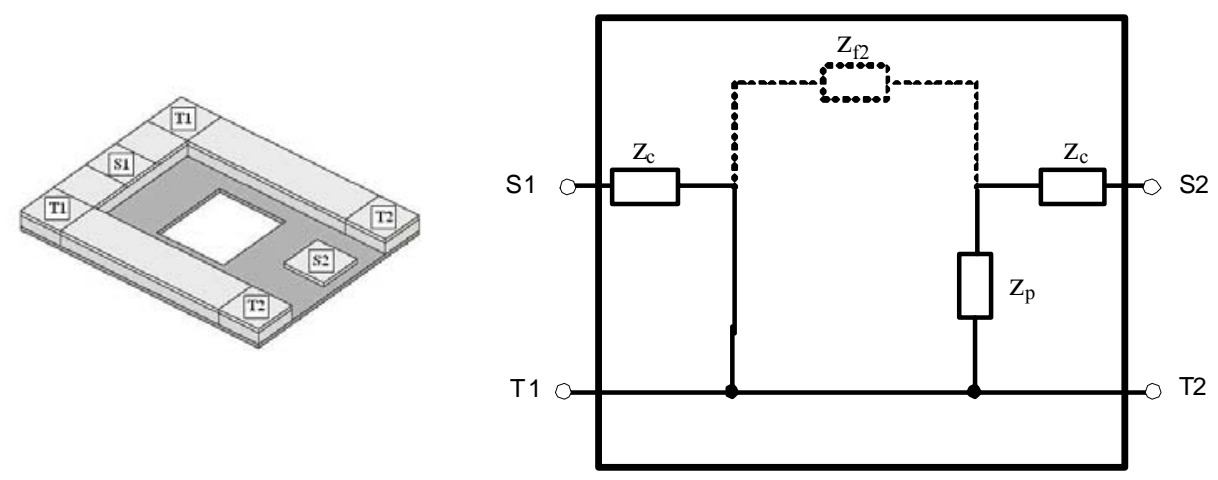

Figura 28 - Quadripolo equivalente da estrutura de caracterização short/open da estrutura de teste completa. 

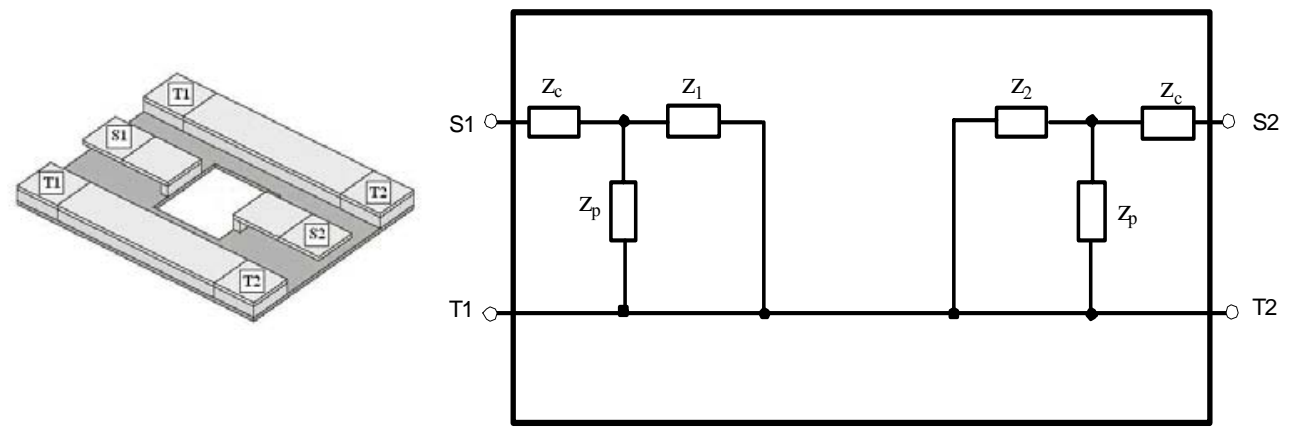

Figura 29 - Quadripolo equivalente da estrutura de caracterização short da estrutura de teste completa.

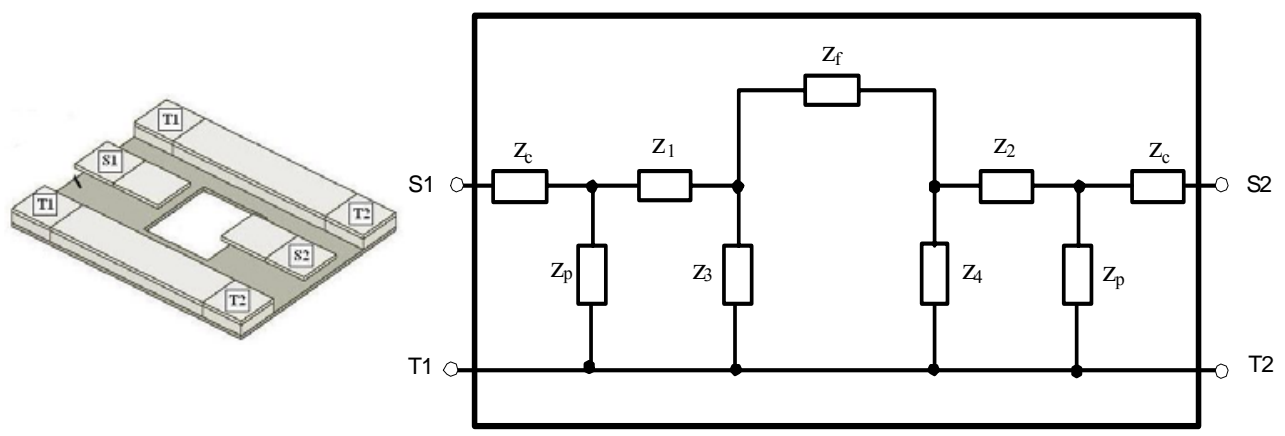

Figura 30 - Quadripolo equivalente da estrutura de caracterização open da estrutura de teste completa.

A partir do quadripolo da estrutura short/open (matriz $\left.Z_{(s / o)}\right)$ podemos ver que: $z_{c}=z_{11_{(s / o)}}$ e $z_{p}=z_{22_{(s / o)}}-z_{c}$

As impedâncias de acoplamento entre os terminais, $z_{f 2}$, foi desconsiderada aqui também.

Para determinar o valor das impedâncias $z_{1}$ e $z_{2}$ devemos observar que:

- o quadripolo da estrutura short é constituído da associação de três quadripolos: um quadripolo composto apenas pelas impedâncias $z_{1}$ e $z_{2}$, com matriz $Z=\left[\begin{array}{cc}z_{1} & 0 \\ 0 & z_{2}\end{array}\right] ; \quad$ outro constituído de duas impedâncias $z_{p}$, com matriz $Y=\left[\begin{array}{cc}1 / z_{p} & 0 \\ 0 & 1 / z_{p}\end{array}\right]$, em paralelo com o primeiro; e um quadripolo constituído de 
duas impedâncias $Z_{c}$, com matriz de impedâncias $Z=\left[\begin{array}{cc}z_{c} & 0 \\ 0 & Z_{c}\end{array}\right]$, em série com os anteriores.

Em vista disso $z_{1}$ e $z_{2}$ serão determinados pela seguinte sequência de operações sobre a matriz $Z_{(s)}$ da estrutura short :

$$
\begin{aligned}
& Z_{(s)}^{\prime}=\left[\begin{array}{ll}
z_{11_{(s)}} & z_{12_{(s)}} \\
z_{21_{(s)}} & z_{22_{(s)}}
\end{array}\right]-\left[\begin{array}{cc}
z_{c} & 0 \\
0 & z_{c}
\end{array}\right], \quad Y_{(s)}^{\prime}=Z_{(s)}^{\prime-1}, \\
& Y_{(s)}^{\prime \prime}=\left[\begin{array}{ll}
y_{11_{(s)}^{\prime}}^{\prime} & y_{12_{(s)}^{\prime}}^{\prime} \\
y_{21_{(s)}}^{\prime} & y_{22_{(s)}^{\prime}}^{\prime}
\end{array}\right]-\left[\begin{array}{cc}
1 / z_{p} & 0 \\
0 & 1 / z_{p}
\end{array}\right], \quad Z_{(s)}^{\prime \prime}=Y_{(s)}^{\prime \prime-1}, \\
& z_{1}=z_{11_{(s)}^{\prime \prime}}^{\prime \prime} \text { e } \quad z_{2}=z_{22_{(s)}^{\prime \prime}}
\end{aligned}
$$

Para determinar o valor das impedâncias $z_{3}, z_{4}$ e $z_{f}$, observe que:

- o quadripolo da estrutura open é constituído da associação de quatro quadripolos: um quadripolo composto apenas pelas impedâncias $z_{f}, z_{3}$ e $z_{4}$, ligados em uma configuração PI e com matriz $Y=\left[\begin{array}{cc}1 / z_{3}+1 / z_{f} & -1 / z_{f} \\ -1 / z_{f} & z_{4}+1 / z_{f}\end{array}\right]$; outro constituído das impedâncias $z_{1}$ e $z_{2}$, com matriz $Z=\left[\begin{array}{cc}z_{1} & 0 \\ 0 & z_{2}\end{array}\right]$, em série com o primeiro; um quadripolo constituído de duas impedâncias $z_{p}$, com matriz $Y=\left[\begin{array}{cc}1 / z_{p} & 0 \\ 0 & 1 / z_{p}\end{array}\right]$, em paralelo com os anteriores; e um quadripolo constituído de duas impedâncias $z_{c}$, com matriz de impedâncias $Z=\left[\begin{array}{cc}Z_{c} & 0 \\ 0 & z_{c}\end{array}\right]$, em série com os anteriores.

Em vista disso $z_{3}, z_{4}$ e $z_{f}$ serão determinados pela seguinte sequência de operações sobre a matriz $Z_{(o)}$ da estrutura open : 


$$
\begin{aligned}
& Z_{(o)}^{\prime}=\left[\begin{array}{ll}
z_{11_{(o)}} & z_{12_{(o)}} \\
z_{21_{(o)}} & z_{22_{(o)}}
\end{array}\right]-\left[\begin{array}{cc}
z_{c} & 0 \\
0 & z_{c}
\end{array}\right], \quad Y_{(o)}^{\prime}=Z_{(o)}^{\prime-1}, \\
& Y_{(o)}^{\prime \prime}=\left[\begin{array}{ll}
y_{11_{(o)}^{\prime}}^{\prime} & y_{12_{(o)}^{\prime}}^{\prime} \\
y_{21_{(o)}}^{\prime} & y_{22_{(o)}}^{\prime}
\end{array}\right]-\left[\begin{array}{cc}
1 / z_{p} & 0 \\
0 & 1 / z_{p}
\end{array}\right], \quad Z_{(o)}^{\prime \prime}=Y_{(o)}^{\prime \prime-1}, \\
& Z_{(o)}^{\prime \prime \prime}=\left[\begin{array}{ll}
z_{11_{(o)}^{\prime \prime}}^{\prime \prime} & z_{12_{(o)}^{\prime \prime}}^{\prime \prime} \\
z_{21_{(o)}}^{\prime \prime} & z_{22_{(o)}}^{\prime \prime}
\end{array}\right]-\left[\begin{array}{cc}
z_{1} & 0 \\
0 & z_{2}
\end{array}\right], \\
& z_{f}=\frac{-1}{y_{21_{(o)}^{\prime \prime}}^{\prime \prime}}, \quad z_{3}=\frac{Y_{(o)}^{\prime \prime \prime}=Z_{(o)}^{\prime \prime \prime-1}}{y_{11_{(o)}^{\prime \prime \prime}}+y_{21_{(o)}^{\prime \prime \prime}}^{\prime \prime}} \text { e } z_{4}=\frac{1}{y_{22_{(o)}^{\prime \prime \prime}}^{\prime \prime}+y_{21_{(o)}}^{\prime \prime \prime}}
\end{aligned}
$$

Assim são determinados os valores dos elementos parasitas da estrutura de teste completa. Vejamos agora como é feito o cancelamento do efeito destes elementos. Suponha que obtivemos a matriz de parâmetros Z, que chamaremos de $Z_{(i)}$, de um indutor utilizando a estrutura completa. O quadripolo medido neste caso é constituído da associação de cinco quadripolos: o quadripolo que descreve apenas o indutor testado e que desejamos avaliar; um quadripolo composto pelas impedâncias $z_{f}, z_{3}$ e $z_{4}$, com matriz $Y=\left[\begin{array}{cc}1 / z_{3}+1 / z_{f} & -1 / z_{f} \\ -1 / z_{f} & z_{4}+1 / z_{f}\end{array}\right]$, em paralelo com o primeiro; outro constituído das impedâncias $z_{1}$ e $z_{2}$, com matriz $Z=\left[\begin{array}{cc}z_{1} & 0 \\ 0 & z_{2}\end{array}\right]$, em série com os anteriores; um quadripolo constituído de duas impedâncias $z_{p}$, com matriz $Y=\left[\begin{array}{cc}1 / z_{p} & 0 \\ 0 & 1 / z_{p}\end{array}\right]$, em paralelo com os anteriores; e um quadripolo constituído de duas impedâncias $Z_{c}$, com matriz de impedâncias $Z=\left[\begin{array}{cc}Z_{c} & 0 \\ 0 & Z_{c}\end{array}\right]$, em série com os anteriores.

Em vista do que foi dito acima, podemos cancelar o efeito dos elementos parasitas na matriz $Z_{(i)}$ através da sequência de operações abaixo:

$$
Z_{(i)}^{\prime}=\left[\begin{array}{ll}
Z_{11_{(i)}} & Z_{12_{(i)}} \\
Z_{21_{(i)}} & Z_{22_{(i)}}
\end{array}\right]-\left[\begin{array}{cc}
Z_{c} & 0 \\
0 & Z_{c}
\end{array}\right], \quad \quad Y_{(i)}^{\prime}=Z_{(i)}^{\prime-1},
$$




$$
\begin{aligned}
& Y_{(i)}^{\prime \prime}=\left[\begin{array}{ll}
y_{11_{(i)}^{\prime}}^{\prime} & y_{12_{(i)}^{\prime}}^{\prime} \\
y_{21_{(i)}}^{\prime} & y_{22_{(i)}^{\prime}}^{\prime}
\end{array}\right]-\left[\begin{array}{cc}
1 / z_{p} & 0 \\
0 & 1 / z_{p}
\end{array}\right], \quad Z_{(i)}^{\prime \prime}=Y_{(i)}^{\prime \prime-1}, \\
& Z_{(i)}^{\prime \prime \prime}=\left[\begin{array}{ll}
z_{11_{(i)}^{\prime \prime}}^{\prime \prime} & z_{12_{(i)}^{\prime \prime}}^{\prime \prime} \\
z_{21_{(i)}}^{\prime \prime} & z_{22_{(i)}}^{\prime \prime}
\end{array}\right]-\left[\begin{array}{cc}
z_{1} & 0 \\
0 & z_{2}
\end{array}\right], \quad Y_{(i)}^{\prime \prime \prime}=Z_{(i)}^{\prime \prime \prime-1}, \\
& Y_{(i)}^{\prime \prime \prime \prime}=\left[\begin{array}{ll}
y_{11_{(i)}}^{\prime \prime \prime} & y_{12_{(i)}^{\prime \prime \prime}}^{\prime \prime \prime} \\
y_{21_{(i)}}^{\prime \prime} & y_{22_{(i)}}^{\prime \prime \prime}
\end{array}\right]-\left[\begin{array}{cc}
1 / z_{3}+1 / z_{f} & -1 / z_{f} \\
-1 / z_{f} & 1 / z_{4}+1 / z_{f}
\end{array}\right] \mathrm{e} \\
& Z_{(i)}^{\prime \prime \prime \prime}=Y_{(i)}^{\prime \prime \prime-1}
\end{aligned}
$$

onde $Z_{(i)}^{\prime \prime \prime}$ é a matriz do indutor testado sem o efeito dos elementos parasitas.

As relações acima foram implementadas no MATLAB e o arquivo contendo as equações utilizadas está apresentado no ANEXO D.

\subsubsection{Projeto}

Para podermos avaliar as ferramentas de modelamento foram projetados cinco indutores retangulares, que diferem entre si pelo número de camadas utilizadas (uma ou duas camadas de metal em paralelo), comprimento externo do indutor $\left(l_{e x t}\right)$, número de voltas $(n)$, largura do segmento $(w)$ e espaçamento entre os segmentos $(s)$. Há também um indutor contendo uma grade de silício policristalino. As características geométricas e as camadas de metal utilizadas nos indutores podem ver

\begin{tabular}{|c|c|c|c|c|c|c|c|c|}
\hline \multicolumn{4}{|c|}{ Indutores } & 1 & 2 & 3 & 4 & 5 \\
\hline \multirow{7}{*}{ 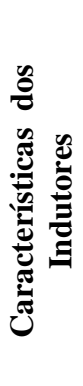 } & \multirow{4}{*}{ 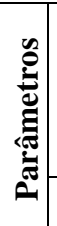 } & \multirow{3}{*}{ છ્ } & $L_{\text {ext }}$ & 250 & 250 & 200 & 200 & 210 \\
\hline & & & $W$ & 8 & 8 & 6 & 6 & 10 \\
\hline & & & $S$ & 2 & 2 & 2 & 2 & 2 \\
\hline & & & $N^{*}$ & 6,5 & 6,5 & 9,5 & 9,5 & 2 \\
\hline & \multirow{2}{*}{\multicolumn{2}{|c|}{ 胥 }} & 3 & $\operatorname{sim}$ & sim & $\operatorname{sim}$ & não & $\operatorname{sim}$ \\
\hline & & & 4 & $\operatorname{sim}$ & $\operatorname{sim}$ & $\operatorname{sim}$ & $\operatorname{sim}$ & $\operatorname{sim}$ \\
\hline & \multicolumn{2}{|c|}{ Grade } & Poli 1 & $\operatorname{sim}$ & não & não & não & não \\
\hline
\end{tabular}
vistas na Tabela 4. Apenas o indutor 1 foi implementado com grade de silício policristalino.

Tabela 4 - Características dos indutores implementados. 
Neste trabalho foram estudados apenas os indutores retangulares, pois as relações teóricas para eles são mais simples. A associação das camadas metálicas em paralelo foi escolhida com a intenção de se obter um melhor valor do $Q$.

Os cinco indutores apresentados na Tabela 4 foram implementados na estrutura de teste completa; dois indutores (3 e 4) foram também implementados na estrutura simples; outros três indutores (2, 4 e 5) foram implementados apenas com os pads de entrada/saída. Além dos indutores foram projetados cinco estruturas de caracterização para medir os elementos parasitas das estruturas de teste simples e completa.

A Figura 31 contém o layout do chip-teste. Este chip possui dimensões de $2675 \mu \mathrm{m}$ x $1720 \mu \mathrm{m}$ e nele podemos ver três grupos de dispositivos implementados:

a) grupo 1: dois indutores na estrutura simples, ind3-simples, ind4-simples, e as estruturas de caracterização open-simples e short/open-simples da estrutura simples;

b) grupo 2: cinco indutores na estrutura completa, ind1-completa, ind2-completa, ind3-completa, ind4-completae ind5-completa, e as estruturas de caracterização short-completa, short/open-completa e open-completa da estrutura completa.

c) grupo 3: três indutores com apenas os pads, ind2-pad, ind4-pad e ind5-pad.

Em todos os indutores testados, a saída externa é considerada a porta 1 e a saída interna, a porta 2.

Observemos que houve um erro na implementação dos indutores sem a estrutura de teste, grupo 3. Neles deveria haver uma camada de metal interligando os pads de terra. Como isso não foi feito, as medidas nestes indutores forneceram valores de indutância extremamente altos (dezenas de $\mathrm{nH}$ ), o que fez com que não fossem considerados no trabalho. 


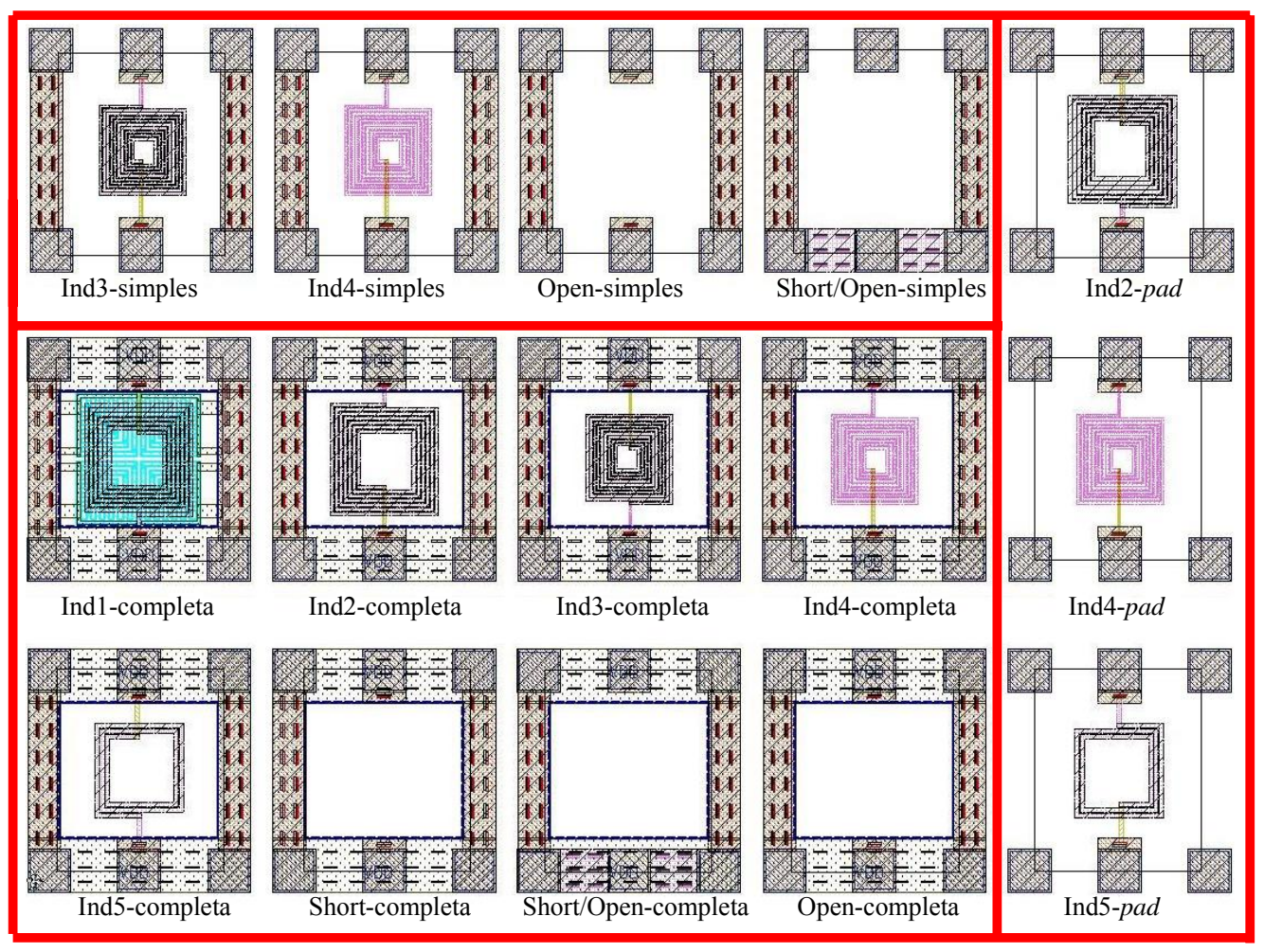

Figura 31 - Layout do chip-teste. 


\section{4 - Apresentação e Análise dos Resultados}

Neste capítulo serão apresentados os resultados, obtidos através das ferramentas de modelamento, das equações analíticas e das medidas elétricas, dos indutores descritos na Tabela 4 e a análise destes resultados. Para atingir os objetivos do trabalho foram comparados os resultados de indutância e de fator de qualidade, obtidos por todos os métodos e por medidas elétricas. Foram medidos ao todo quatros chips para se obter resultados mais confiáveis sobre os indutores.

Para realizar as medidas dos indutores foram utilizadas micropontas de prova [Gg06], conectadas a um analisador de redes. As micropontas são do tipo GSG, ground-signal-ground, constituídas por três pequenas pontas com distância fixa entre elas. Esta distância pode ser de $200 \mu \mathrm{m}$, como nos modelos de pontas disponíveis no LSI/LME da USP, ou de outras dimensões. O analisador de redes utilizado para as medidas foi um HP 8722D que fornece parâmetros S para duas portas.

Lembremos que foi projetado e fabricado um primeiro chip-test onde a distância entre os pads utilizada era menor que $200 \mu \mathrm{m}$, o que impossibilitou a realização de medidas elétricas. Esse fato nos obrigou a projetar e fabricar um segundo chip, aqui testado, e causou um considerável atraso no trabalho.

A foto do chip-teste fabricado e testado está ilustrada na Figura 32

O procedimento para obtenção dos resultados experimentais nos indutores foi o seguinte:

- fez-se a calibração do analisador de redes, com as micropontas de prova, para as duas portas (S11, S12, S21 e S22), através dos seguintes passos:

o calibração em curto;

o calibração em aberto;

o calibração da carga (casamento de impedância $(50 \Omega)$ );

o calibração direta (entre as duas portas);

- mediram-se os parâmetros S nos indutores e nas estruturas de caracterização (ANEXO E);

- calcularam-se os valores dos parâmetros parasitas (ANEXO F); 
- subtraíram-se os efeitos dos elementos parasitas das medidas, utilizando as medidas das estruturas de caracterização e as relações apresentadas no capítulo 3 (programa no MATLAB);

- Ao final das subtrações, através da equação 20 foram obtidos os resultados de indutância e do fator de qualidade versus a freqüência.

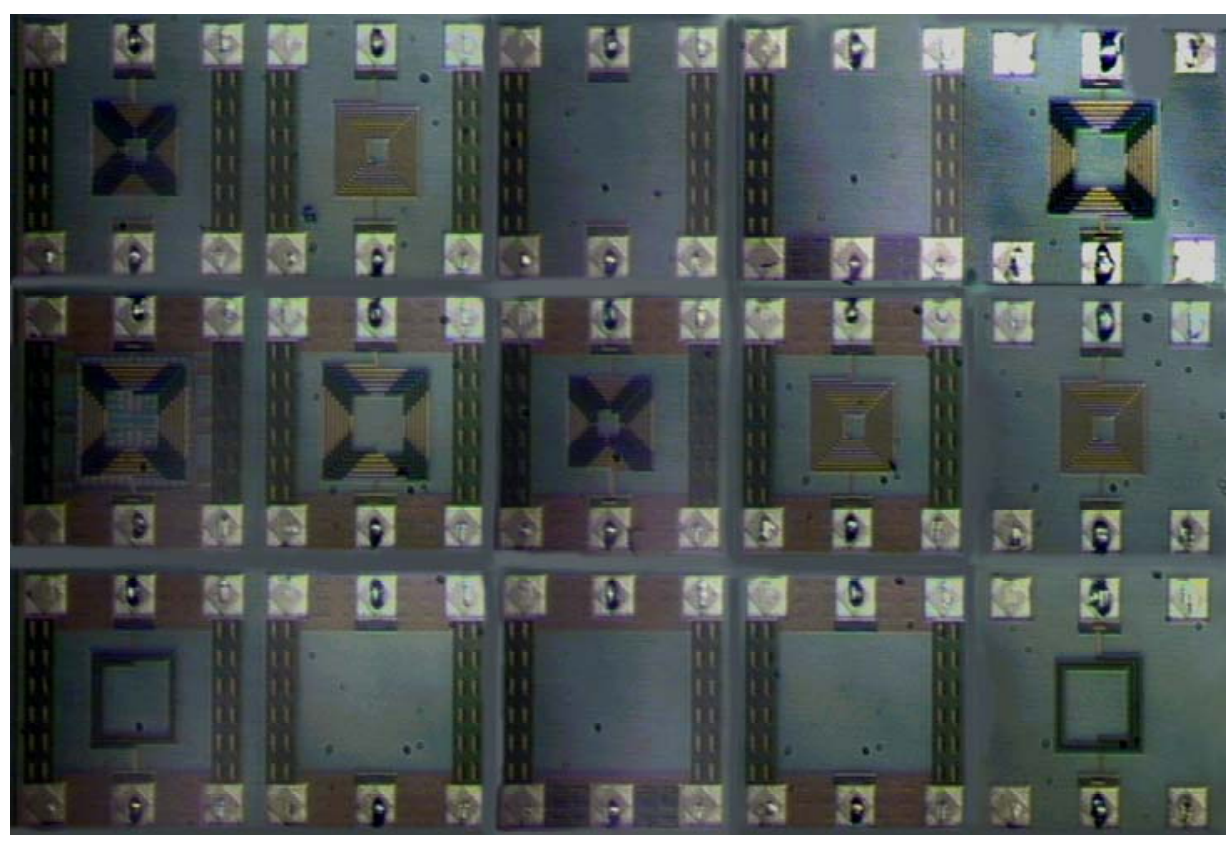

Figura 32 - Foto do chip-teste fabricado.

\subsection{Resultados Obtidos}

As Figuras deste item ilustram os resultados obtidos. Elas são referentes à indutância $(L)$ e ao fator de qualidade $(Q)$ em função da freqüência para cada um dos indutores. Estão apresentados os resultados das medidas elétricas (estruturas simples e completa), juntamente com os de simulações com os parâmetros best, típico e worst.

As Figuras 33 a 46 mostram a indutância e o fator de qualidade medidos nos quatro chips, já subtraídos os efeitos dos parâmetros parasitas, para as estruturas implementadas. Nestas Figuras estão ilustradas, além das medidas, as curvas típicas das ferramentas de simulação. 
Os nomes utilizados na legenda de curvas destas Figuras têm os seguintes significados:

- chip1, chip2, chip3 e chip4: as medidas elétricas dos quatros chips;

- $\quad \boldsymbol{S}$ tip, $\boldsymbol{A}$ tip e $\boldsymbol{M}$ tip: simulações no SONNET, ASITIC e MATLAB (equações analíticas) para parâmetros típico, respectivamente;

Observemos ainda que:

- o indutor 1 tem grade de silício policristalino e sua simulação é possível apenas com o SONNET;

- os indutores 1, 2 e 5 foram implementados apenas na estrutura completa;

- os indutores 3 e 4 foram implementadas em ambas estruturas. 


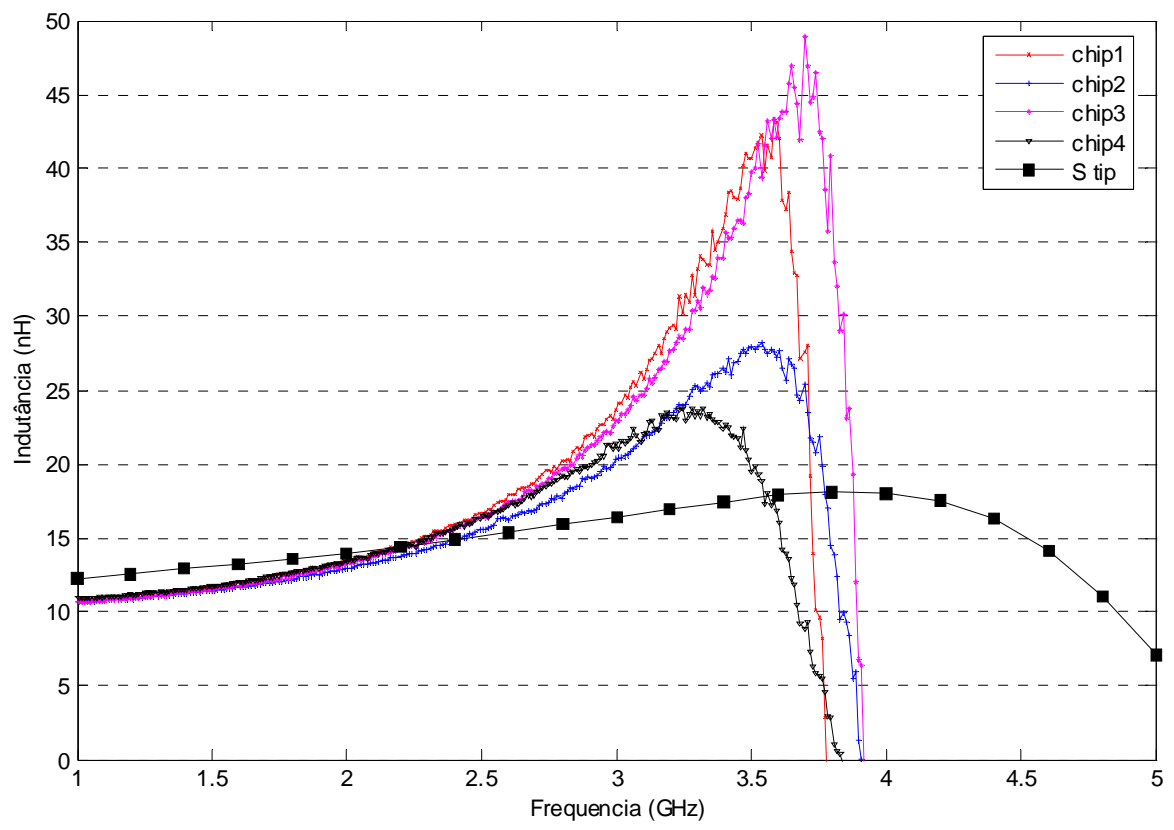

Figura 33 - Medidas dos quatro chips para a estrutura Ind1-completa e a curva típica das ferramentas: indutância em função da freqüência.

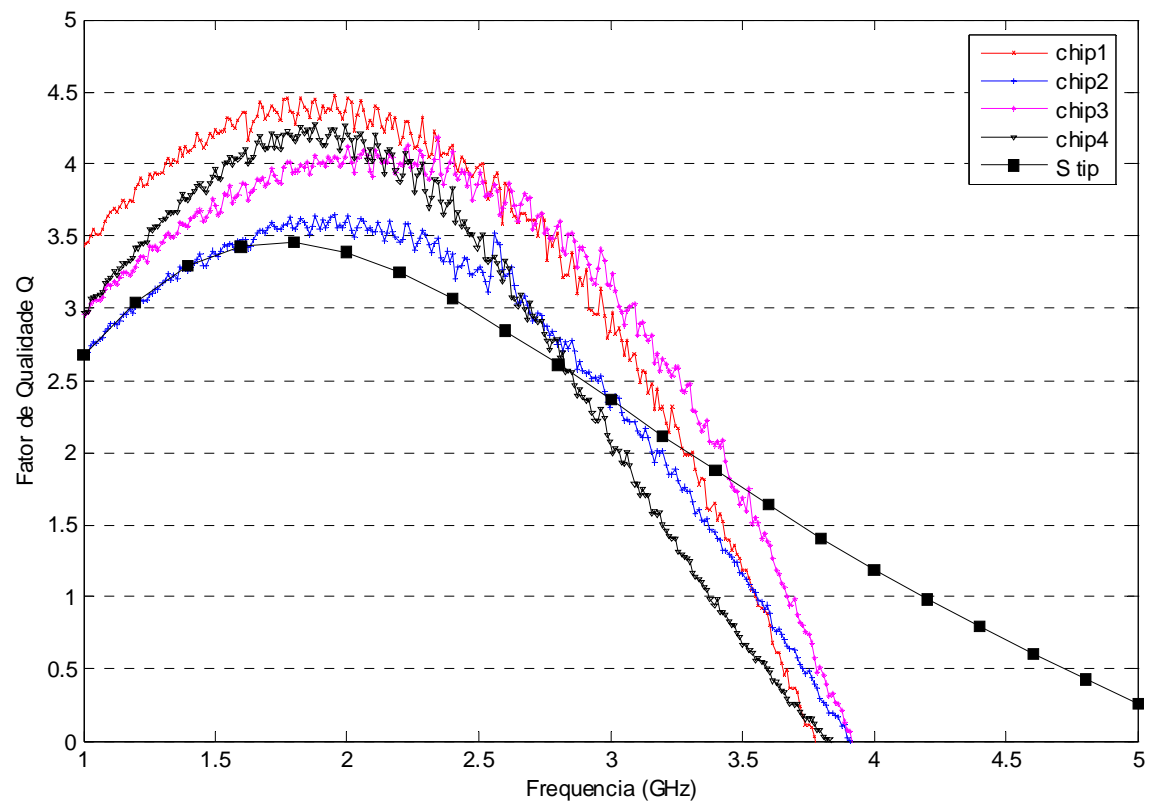

Figura 34 - Medidas dos quatro chips para a estrutura Ind1-completa e a curva típica das ferramentas: fator de qualidade em função da freqüência. 


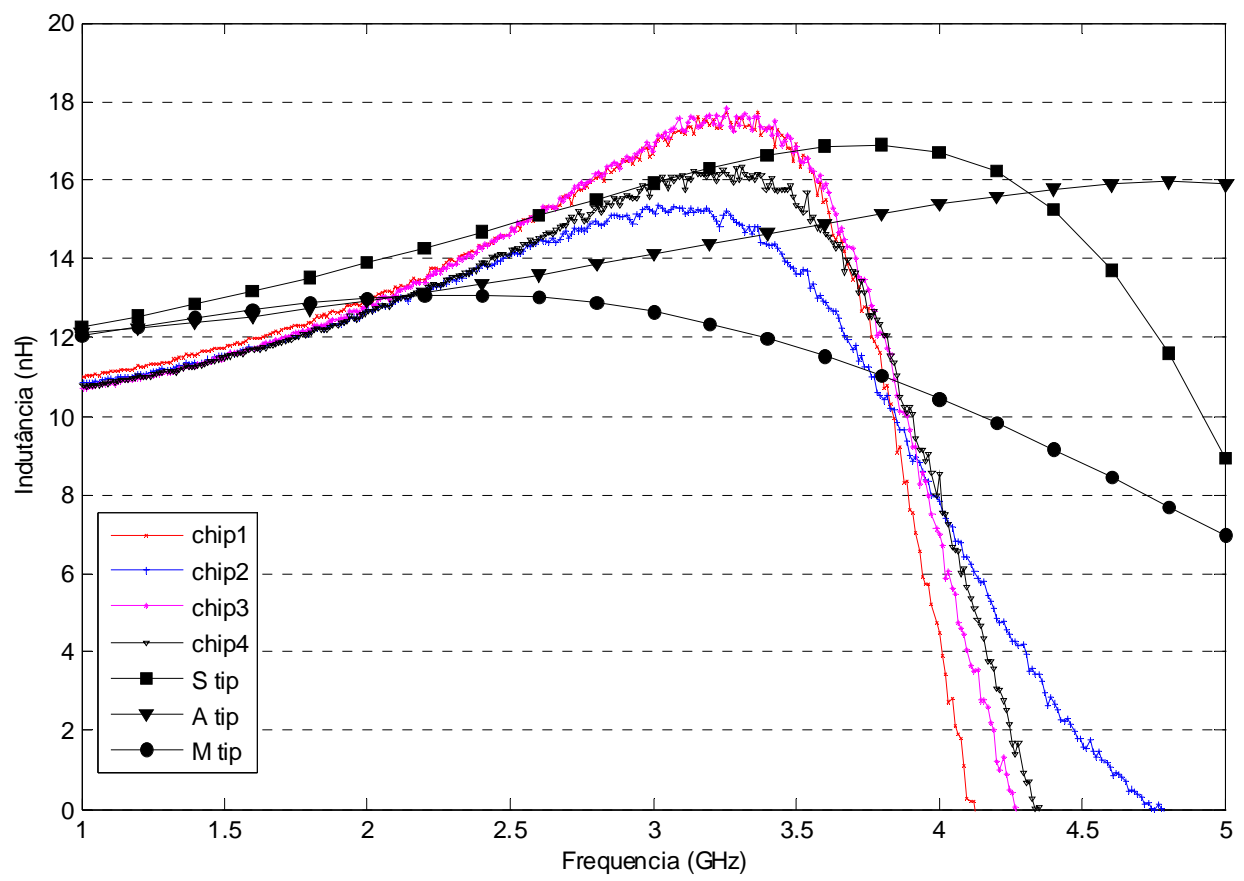

Figura 35 - Medidas dos quatro chips para a estrutura Ind2-completa e as curvas típicas das ferramentas: indutância em função da freqüência.

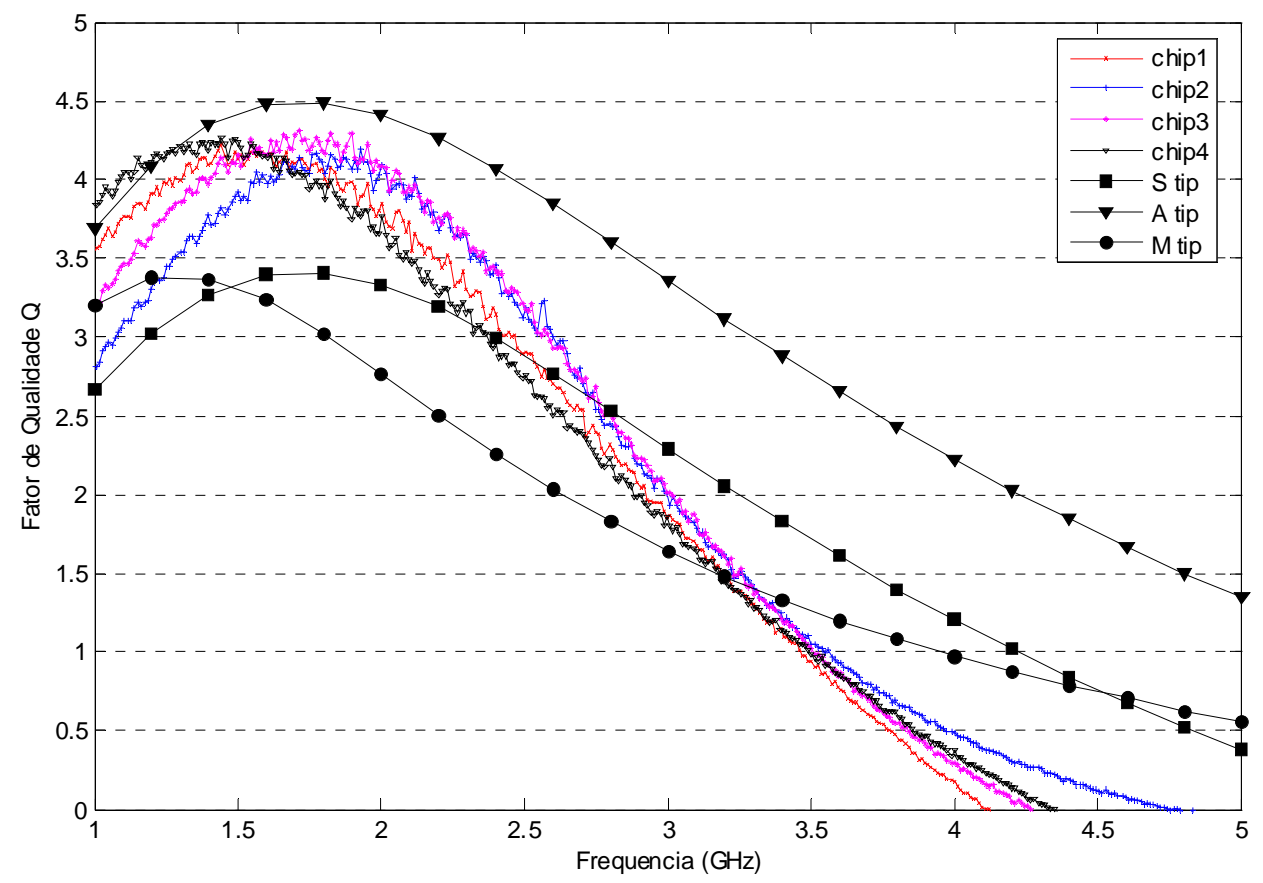

Figura 36 - Medidas dos quatro chips para a estrutura Ind2-completa e as curvas típicas das ferramentas: fator de qualidade em função da freqüência. 


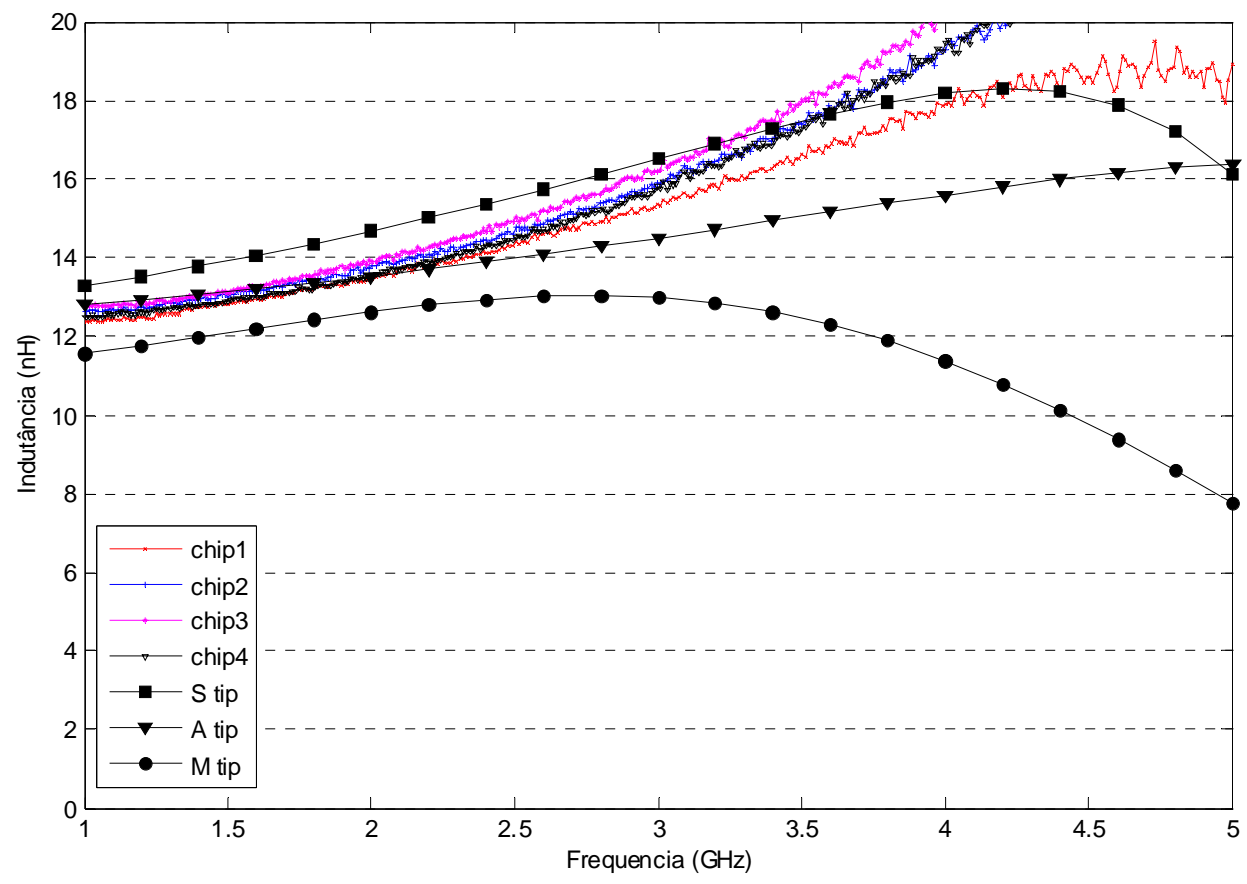

Figura 37 - Medidas dos quatro chips para a estrutura Ind3-simples e as curvas típicas das ferramentas: indutância em função da freqüência.

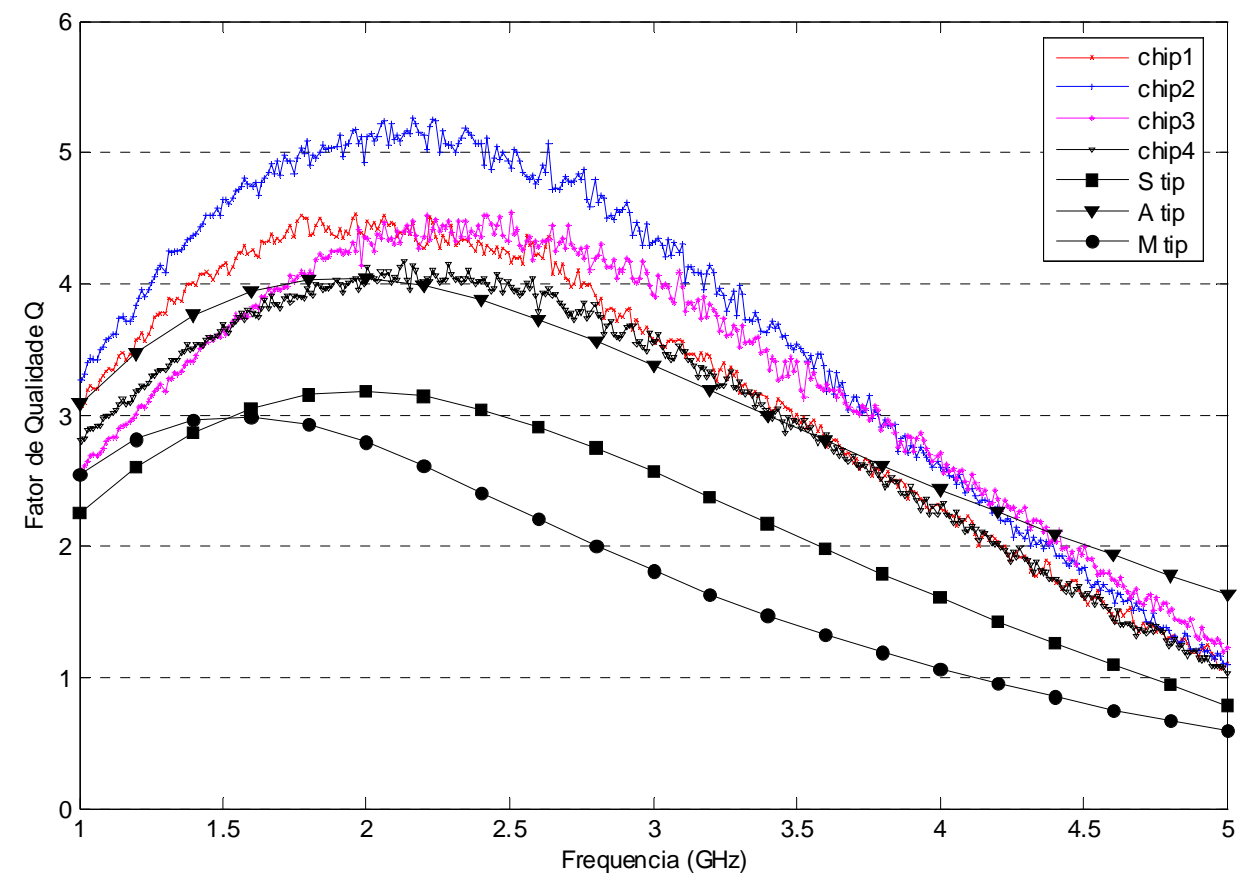

Figura 38 - Medidas dos quatro chips para a estrutura Ind3-simples e as curvas típicas das ferramentas: fator de qualidade em função da freqüência. 


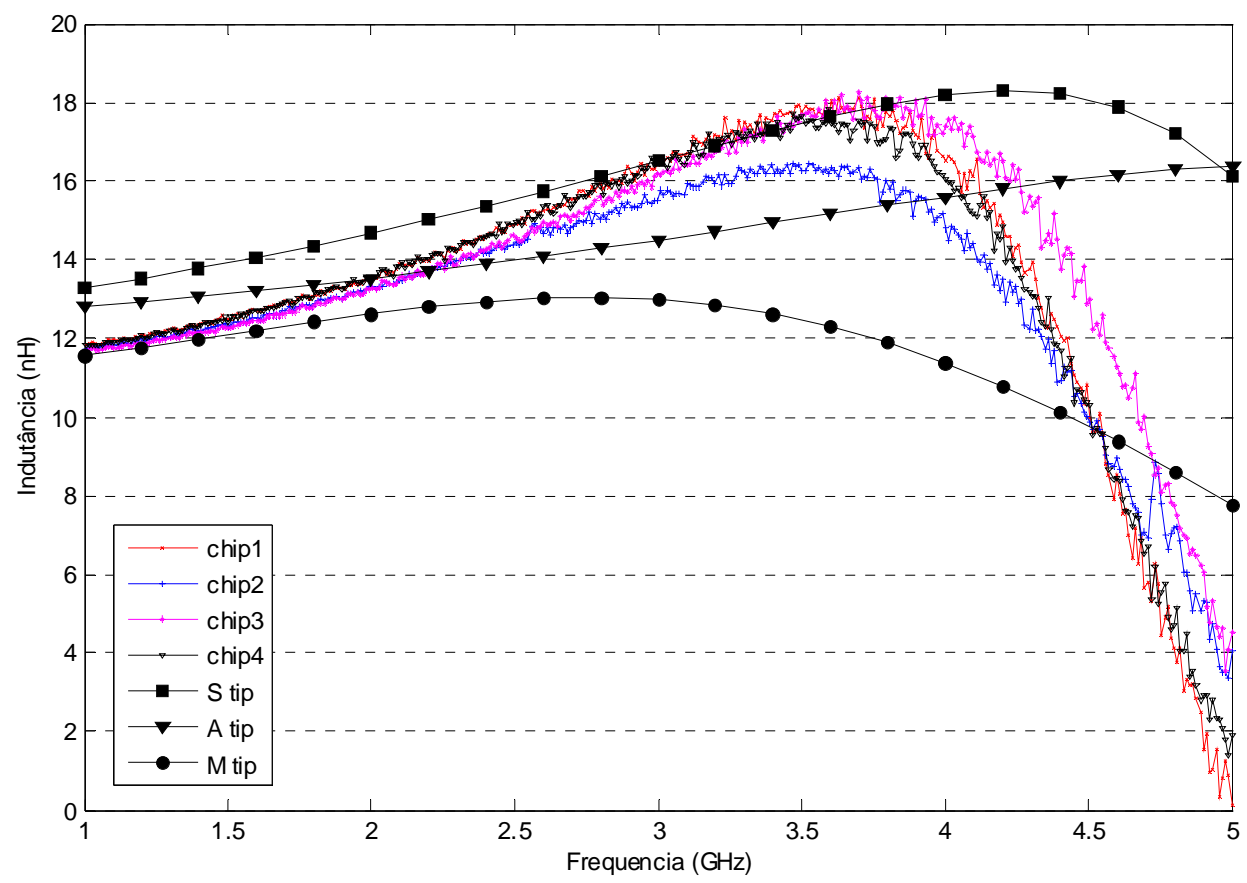

Figura 39 - Medidas dos quatro chips para a estrutura Ind3-completa e as curvas típicas das ferramentas: indutância em função da freqüência.

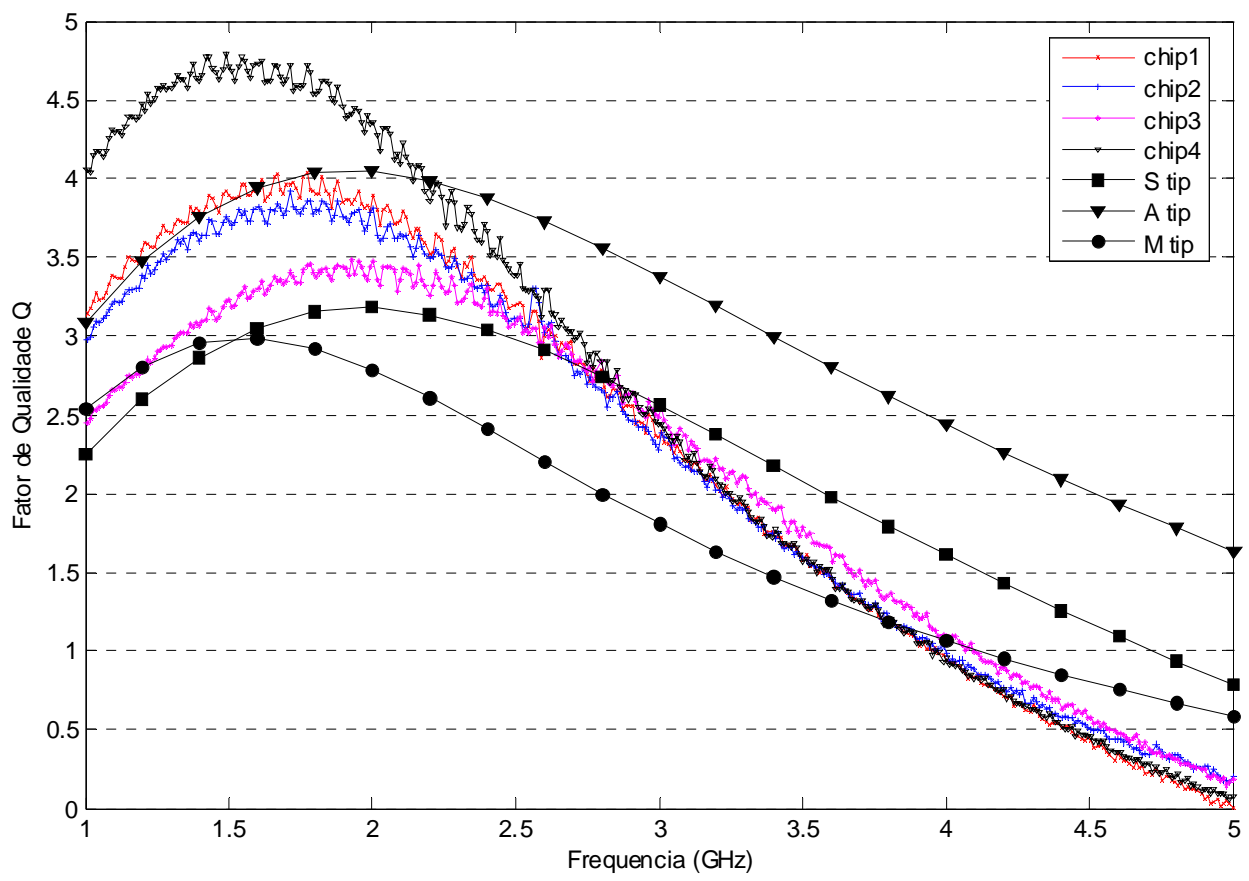

Figura 40 - Medidas dos quatro chips para a estrutura Ind3-completa e as curvas típicas das ferramentas: fator de qualidade em função da freqüência. 


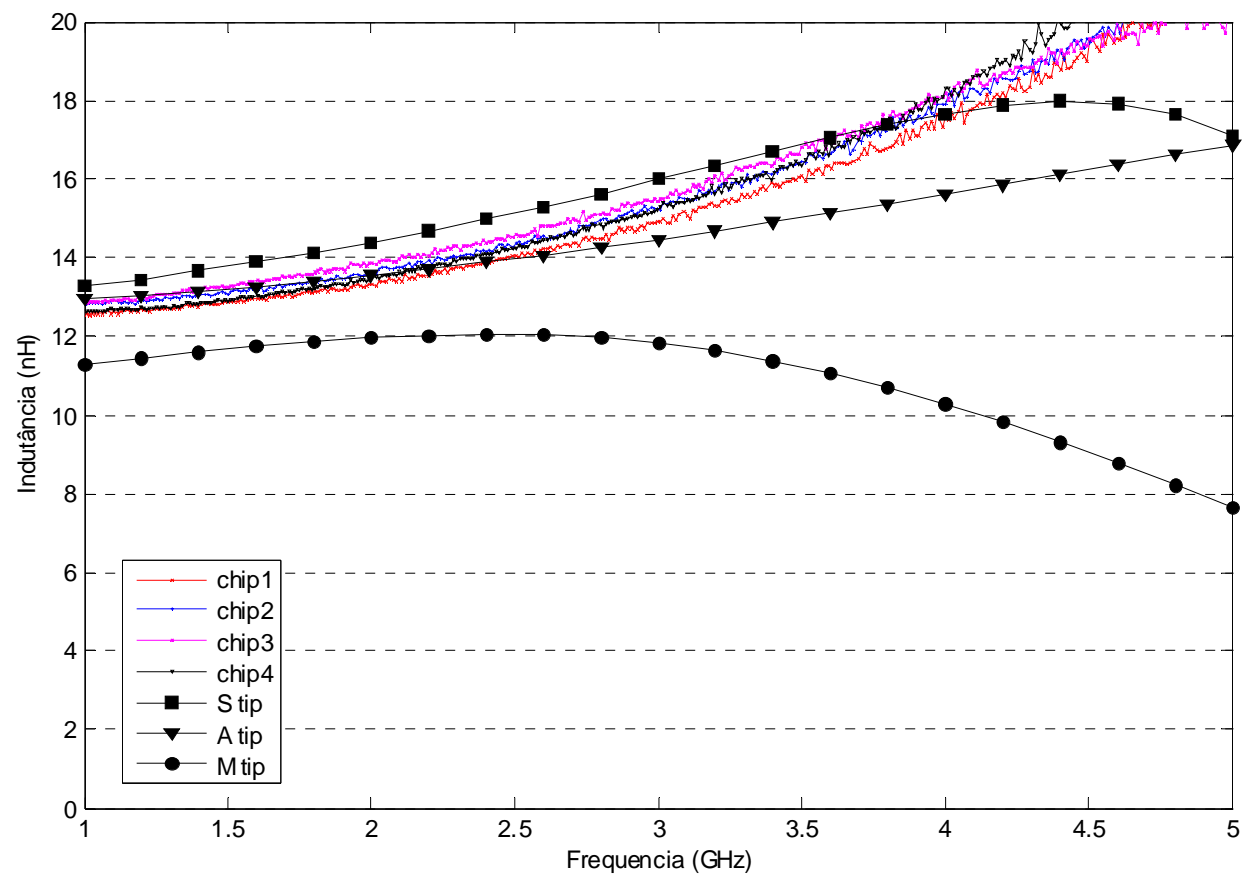

Figura 41 - Medidas dos quatro chips para a estrutura Ind4-simples e as curvas típicas das ferramentas: indutância em função da freqüência.

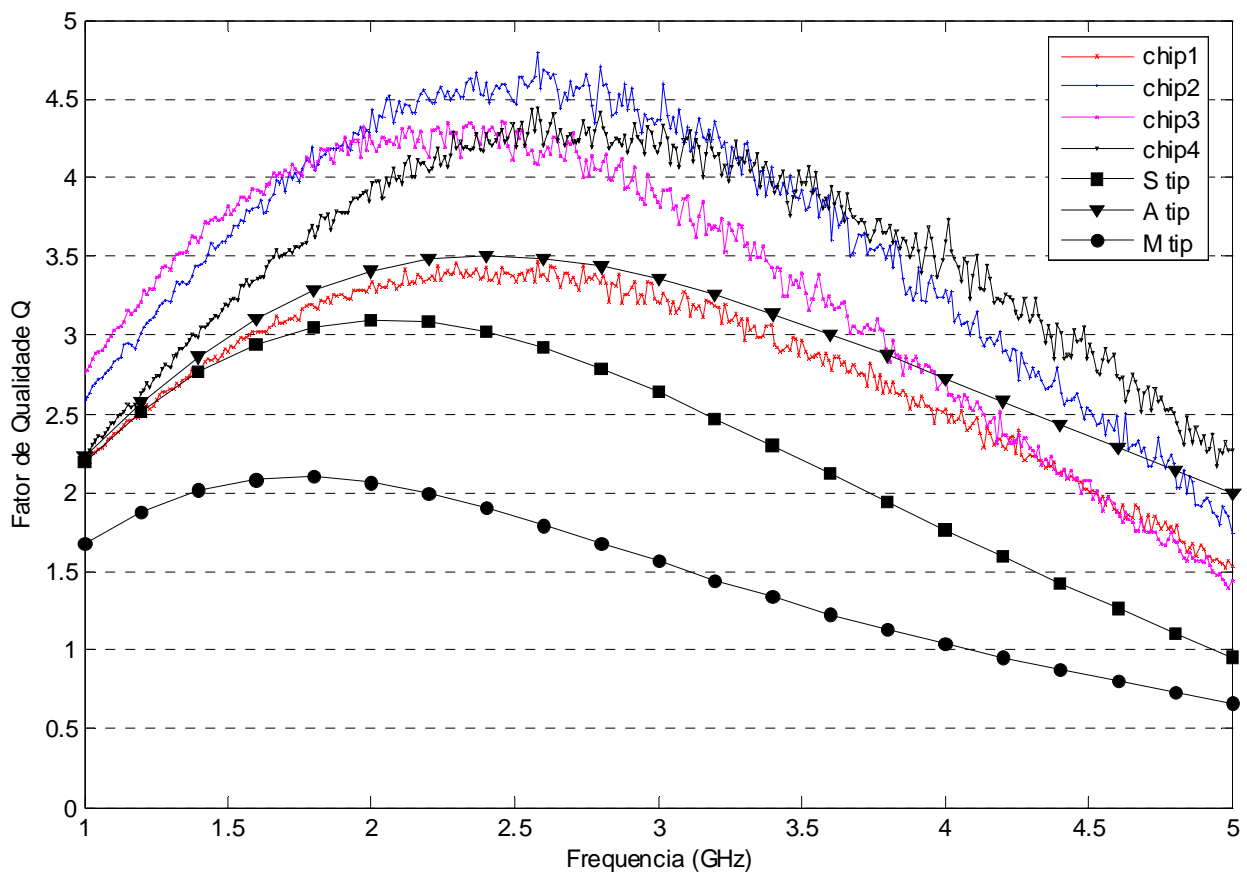

Figura 42 - Medidas dos quatro chips para a estrutura Ind4-simples e as curvas típicas das ferramentas: fator de qualidade em função da freqüência. 


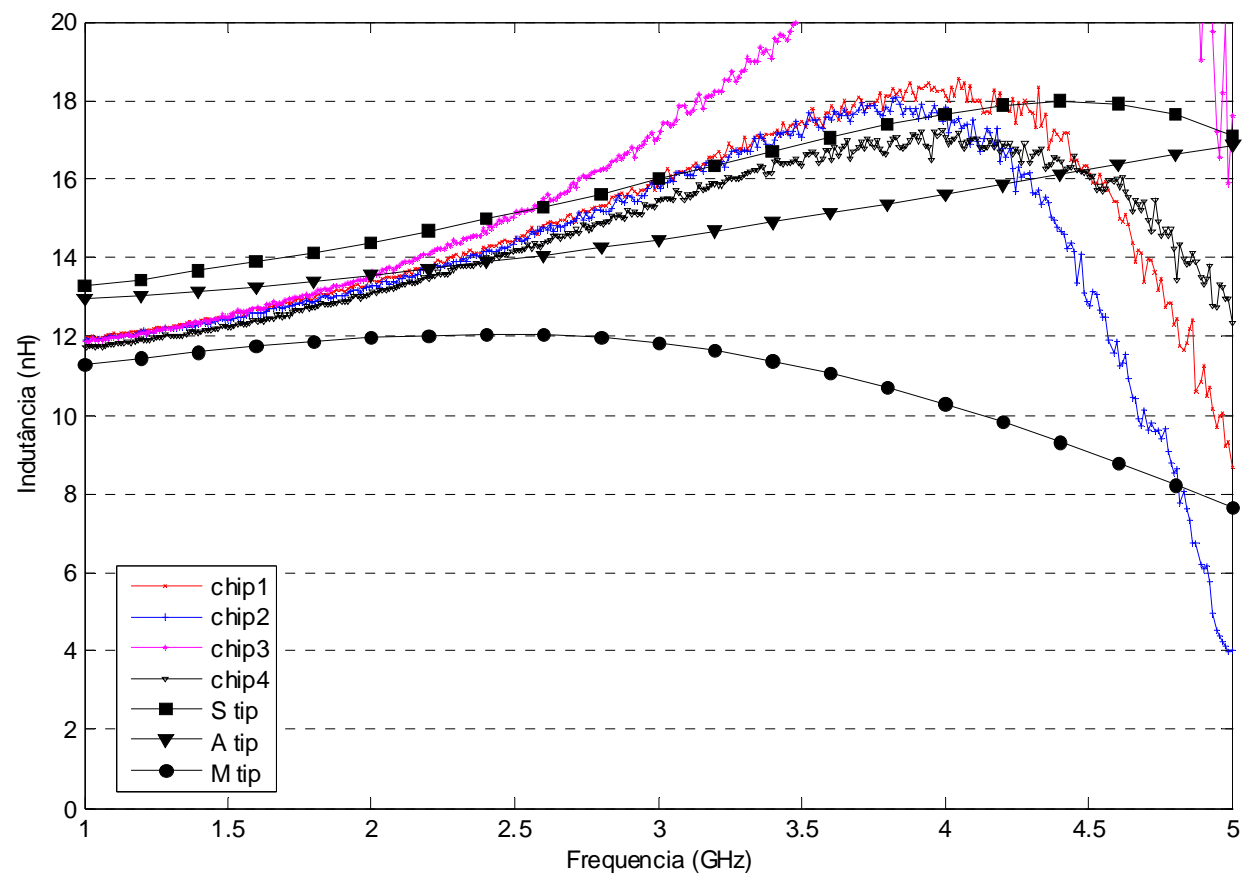

Figura 43 - Medidas dos quatro chips para a estrutura Ind4-completa e as curvas típicas das ferramentas: indutância em função da freqüência.

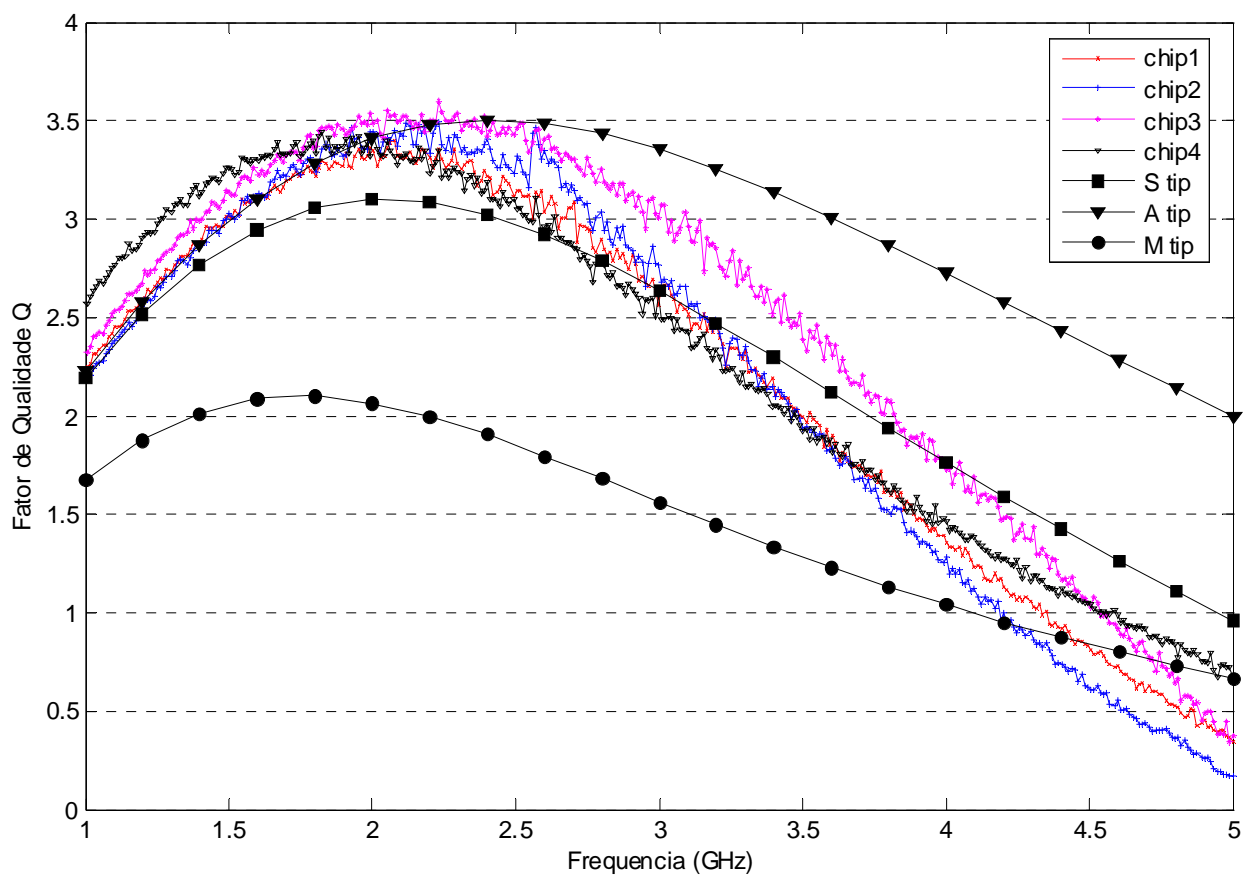

Figura 44 - Medidas dos quatro chips para a estrutura Ind4-completa e as curvas típicas das ferramentas: fator de qualidade em função da freqüência. 


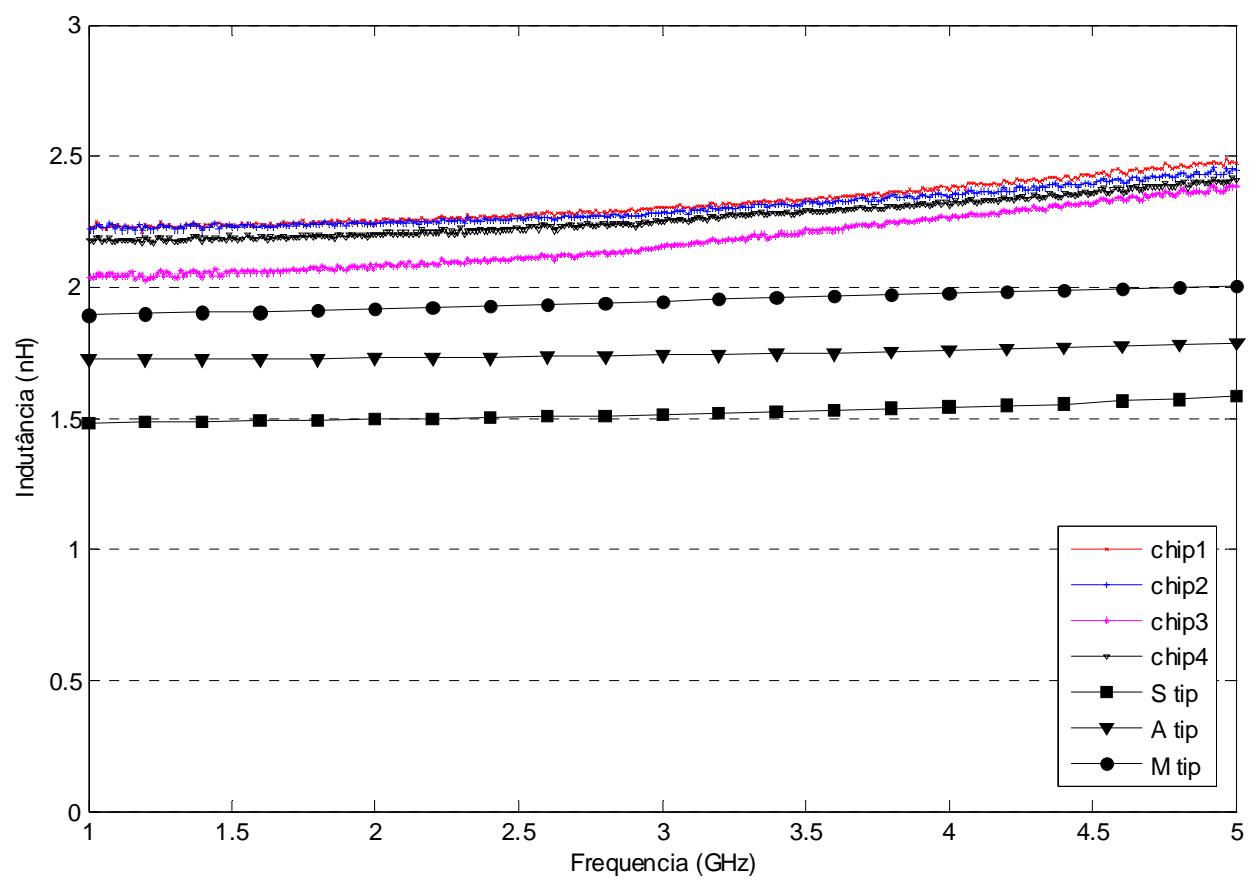

Figura 45 - Medidas dos quatro chips para a estrutura Ind5-completa e as curvas típicas das ferramentas: indutância em função da freqüência.

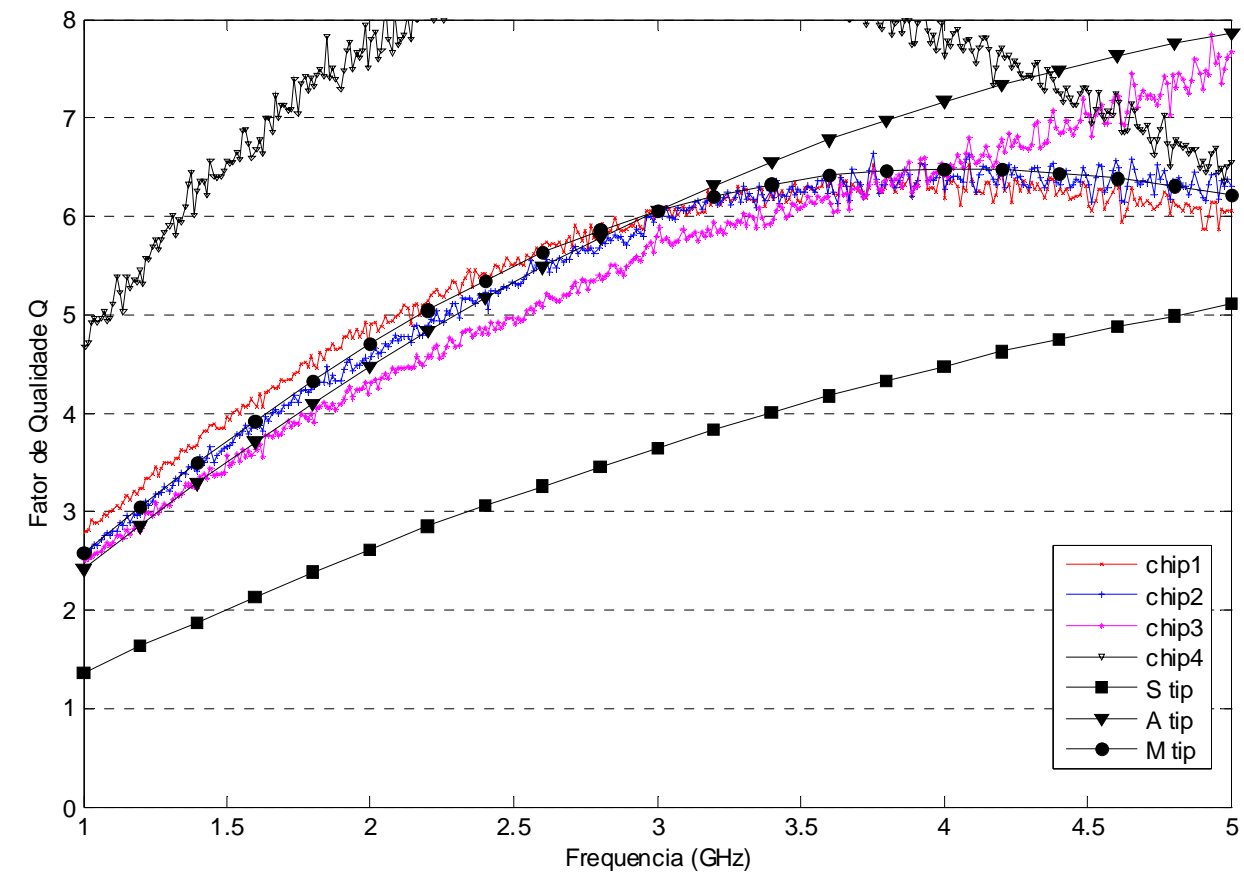

Figura 46 - Medidas dos quatro chips para a estrutura Ind5-completa e as curvas típicas das ferramentas: fator de qualidade em função da freqüência. 
As Figuras 47 a 56 ilustram os resultados das simulações das ferramentas de modelamento e das equações analíticas implementadas, juntamente com o resultado da média das medidas elétricas dos quatro chips. São apresentados os gráficos de indutância e de fator de qualidade em função da freqüência para cada indutor.

Os nomes utilizados na legenda de curvas destas Figuras têm os seguintes significados:

- Completa: curvas com valor médio das medidas nos quatro chips, do indutor implementado na estrutura de testes completa;

- Simples: curvas com valor médio das medidas nos quatro chips, do indutor implementado na estrutura de testes simples;

- A best, A tip e $\boldsymbol{A}$ worst: curvas das simulações no ASITIC, para parâmetros best, típico e worst, respectivamente;

- $\boldsymbol{M}$ best, $\boldsymbol{M}$ tip e $\boldsymbol{M}$ worst: curvas das equações analíticas implementadas no MATLAB, para parâmetros best, típico e worst, respectivamente;

- $\quad \boldsymbol{S}$ best, $\boldsymbol{S}$ tip e $\boldsymbol{S}$ worst: curvas das simulações no SONNET, para parâmetros best, típico e worst, respectivamente.

Observemos ainda que:

- no indutor Ind4-completa foram desconsiderados os resultados do chip 3 para a obtenção da média da indutância. Isto se deve ao fato de que o chip 3 teve um resultado muito distinto dos demais, o que sugere algum erro na medida;

- no indutor Ind5-completa foram desconsiderados os resultados do chip 4 para a obtenção da média do fator de qualidade, pelo mesmo motivo. 


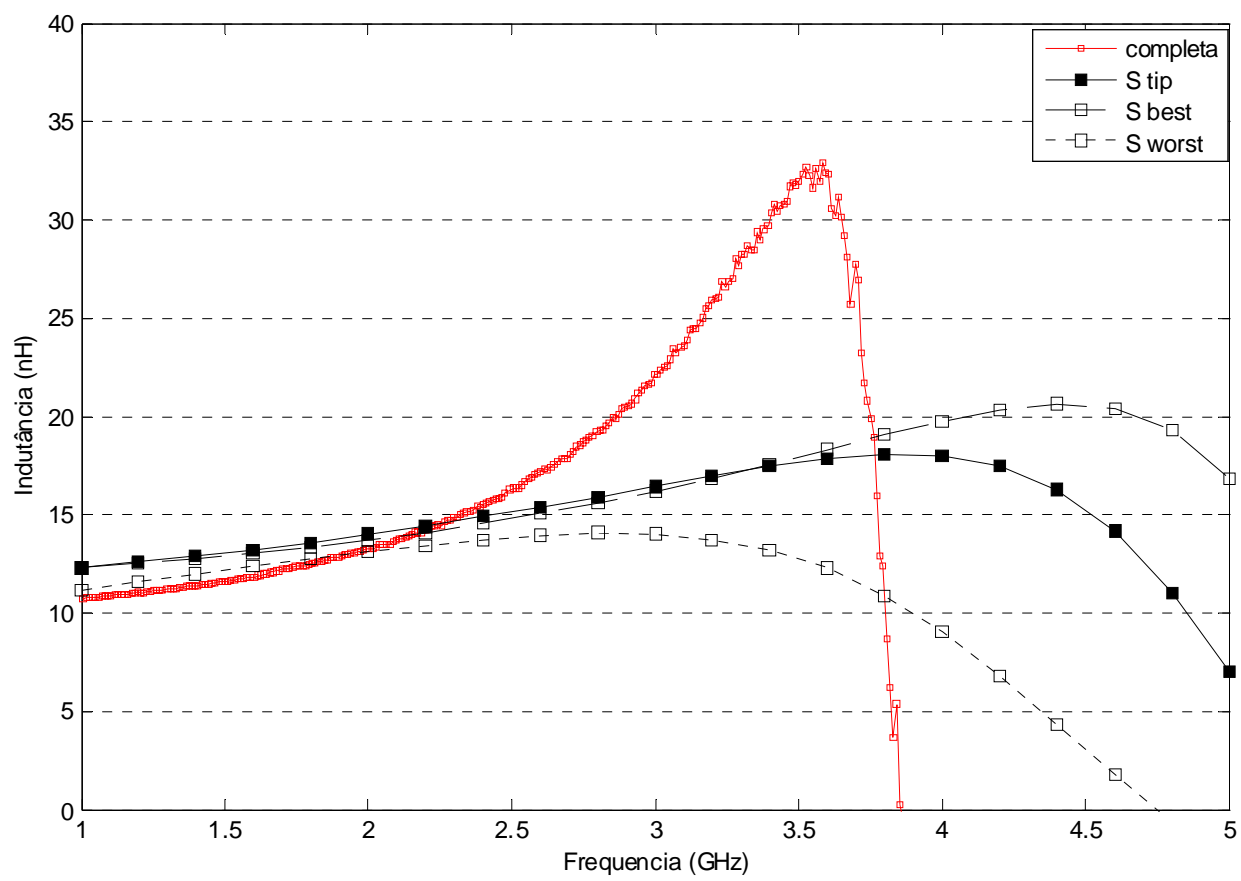

Figura 47 - Resultados de simulações e da média das medidas elétricas para o indutor 1: indutância em função da freqüência.

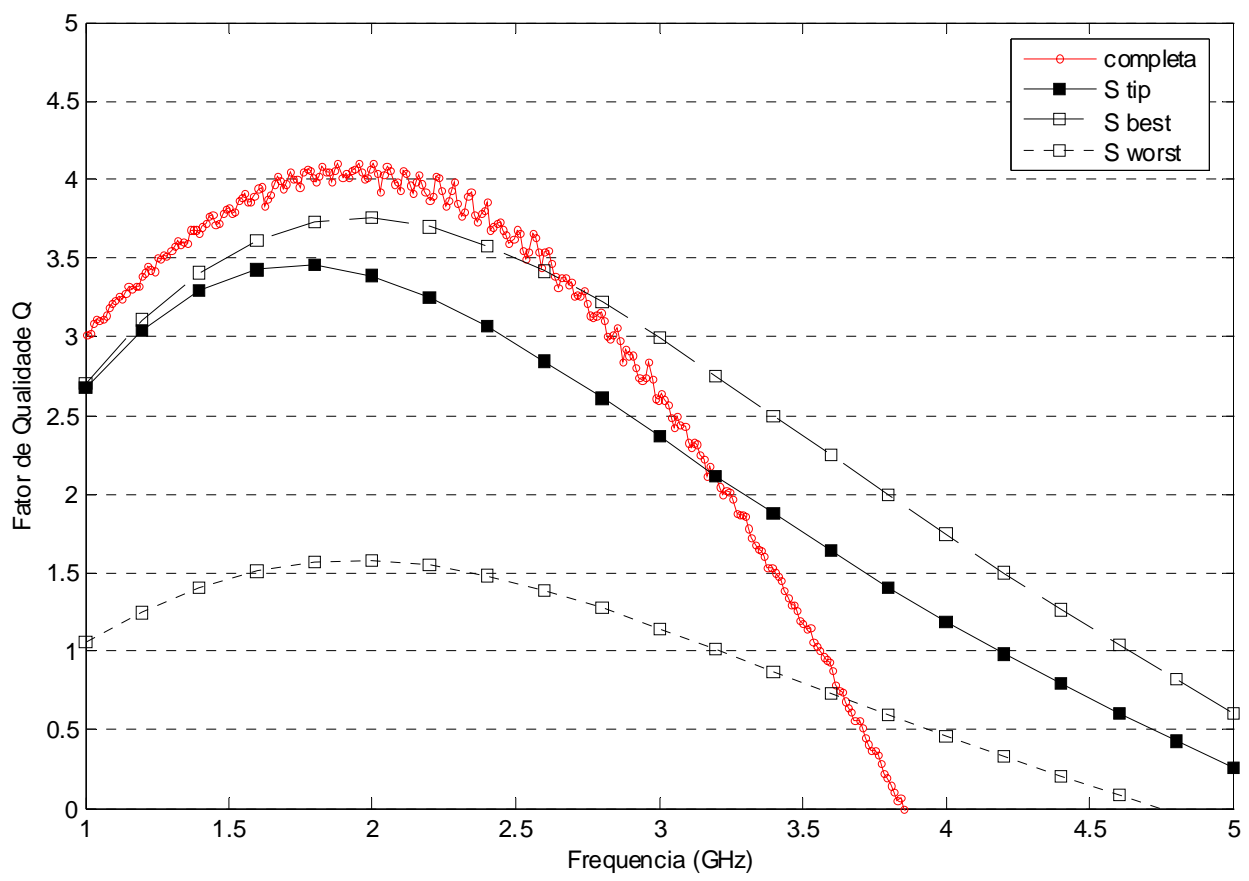

Figura 48 - Resultados de simulações e da média das medidas elétricas para o indutor 1: fator de qualidade em função da freqüência. 


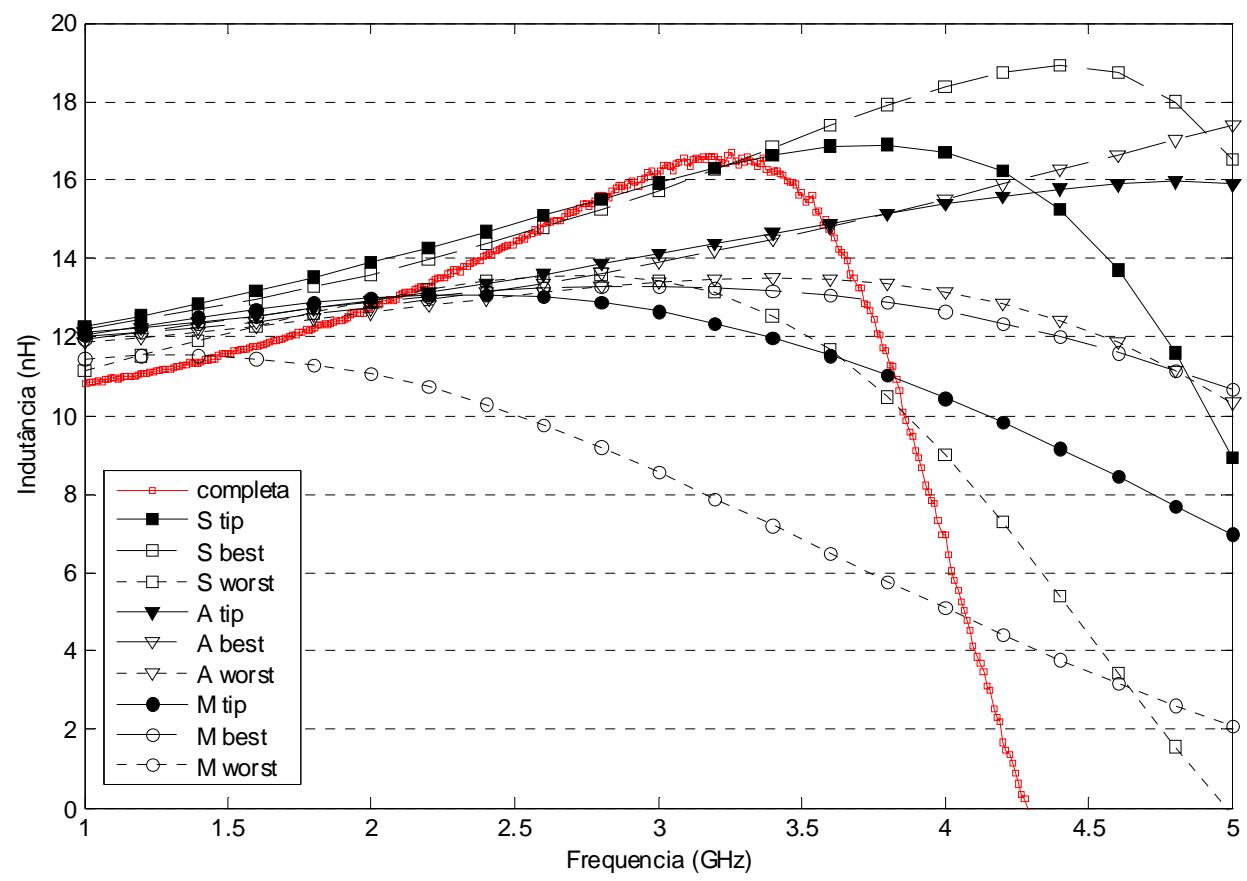

Figura 49 - Resultados de simulações e da média das medidas elétricas para o indutor 2: indutância em função da freqüência.

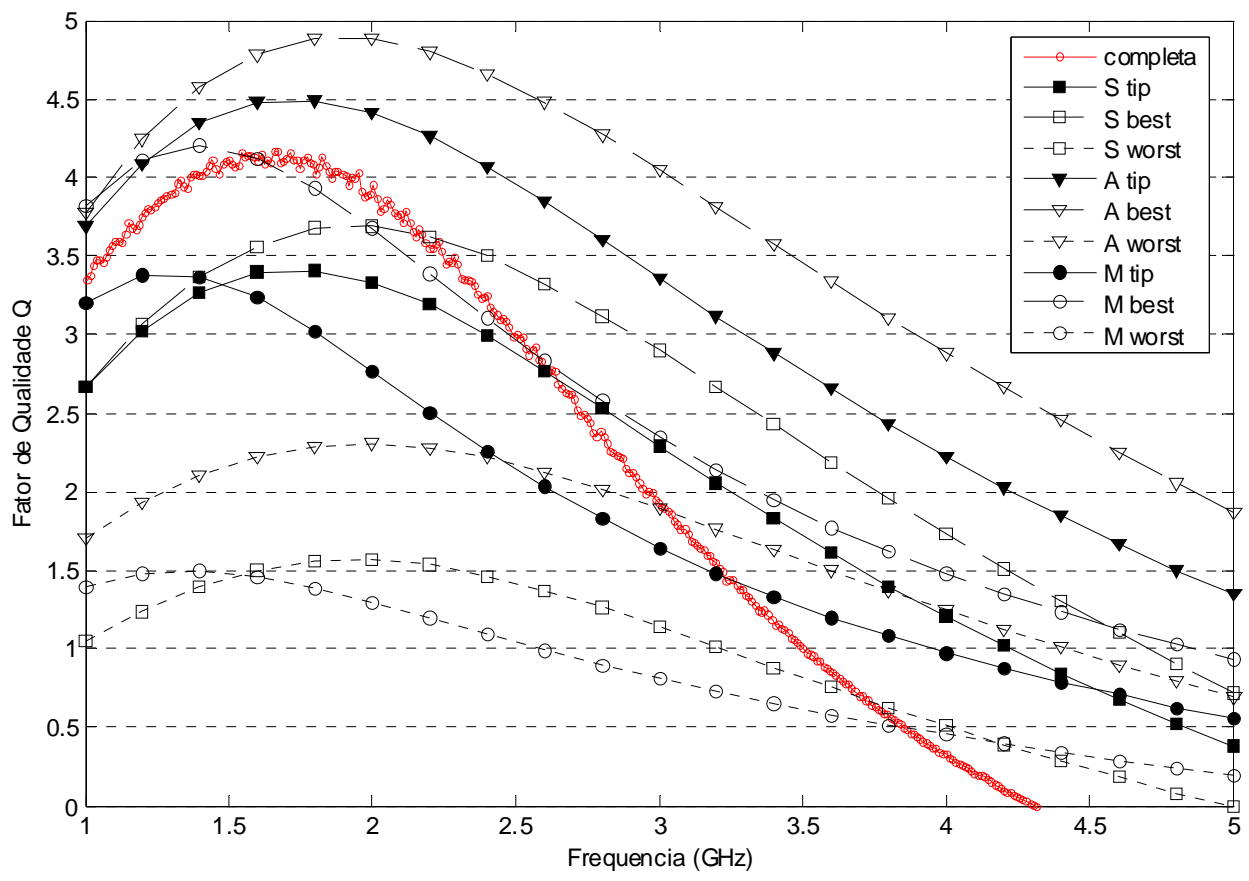

Figura 50 - Resultados de simulações e da média das medidas elétricas para o indutor 2: fator de qualidade em função da freqüência. 


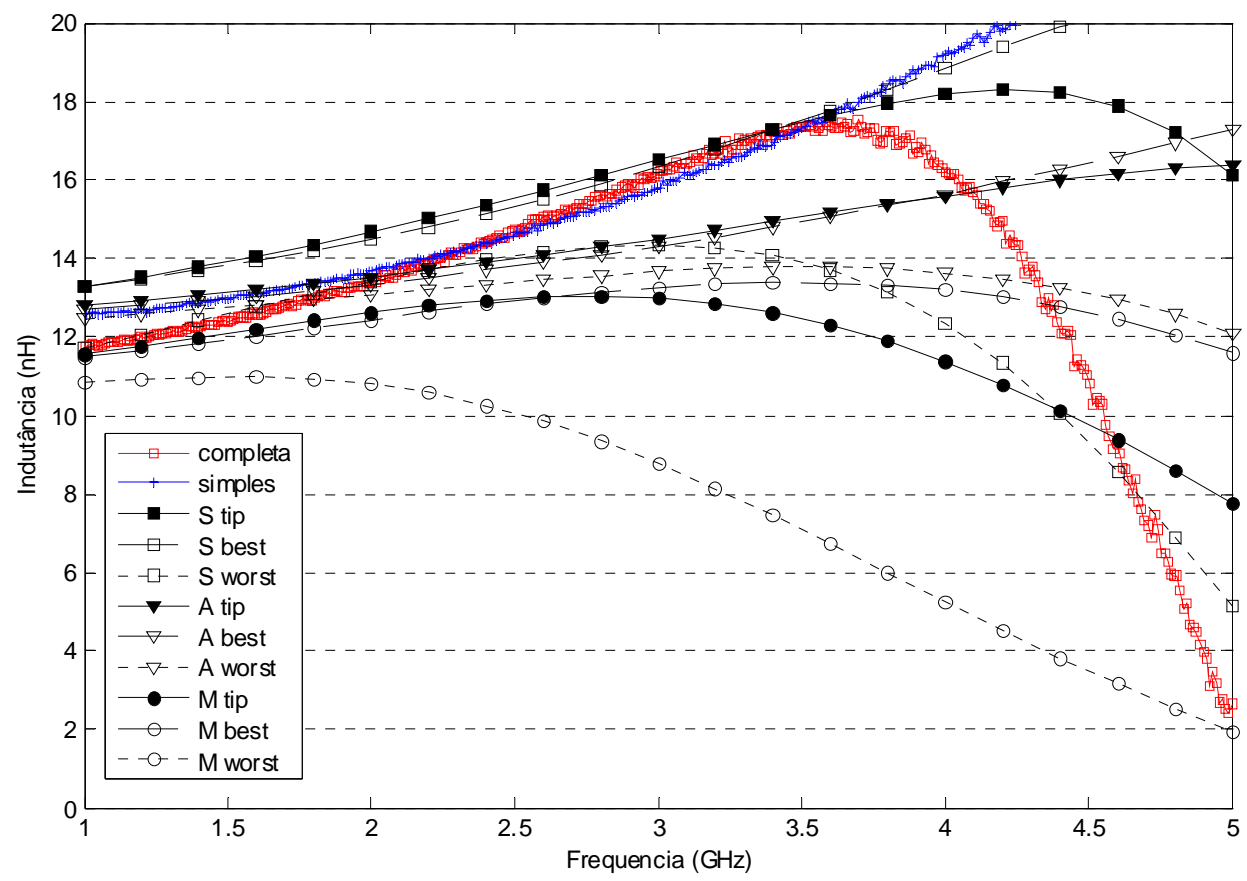

Figura 51 - Resultados de simulações e da média das medidas elétricas para o indutor 3: indutância em função da freqüência.

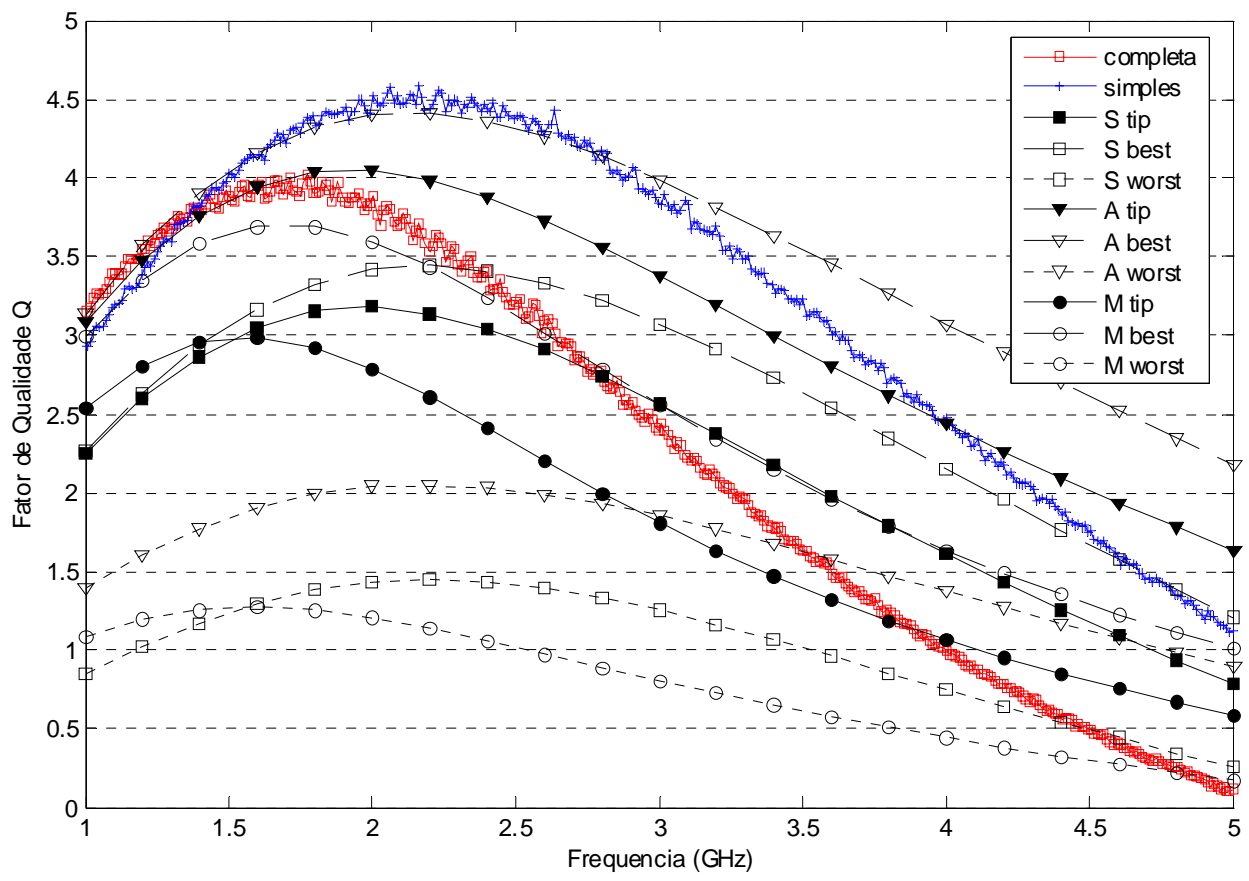

Figura 52 - Resultados de simulações e da média das medidas elétricas para o indutor 3: fator de qualidade em função da freqüência. 


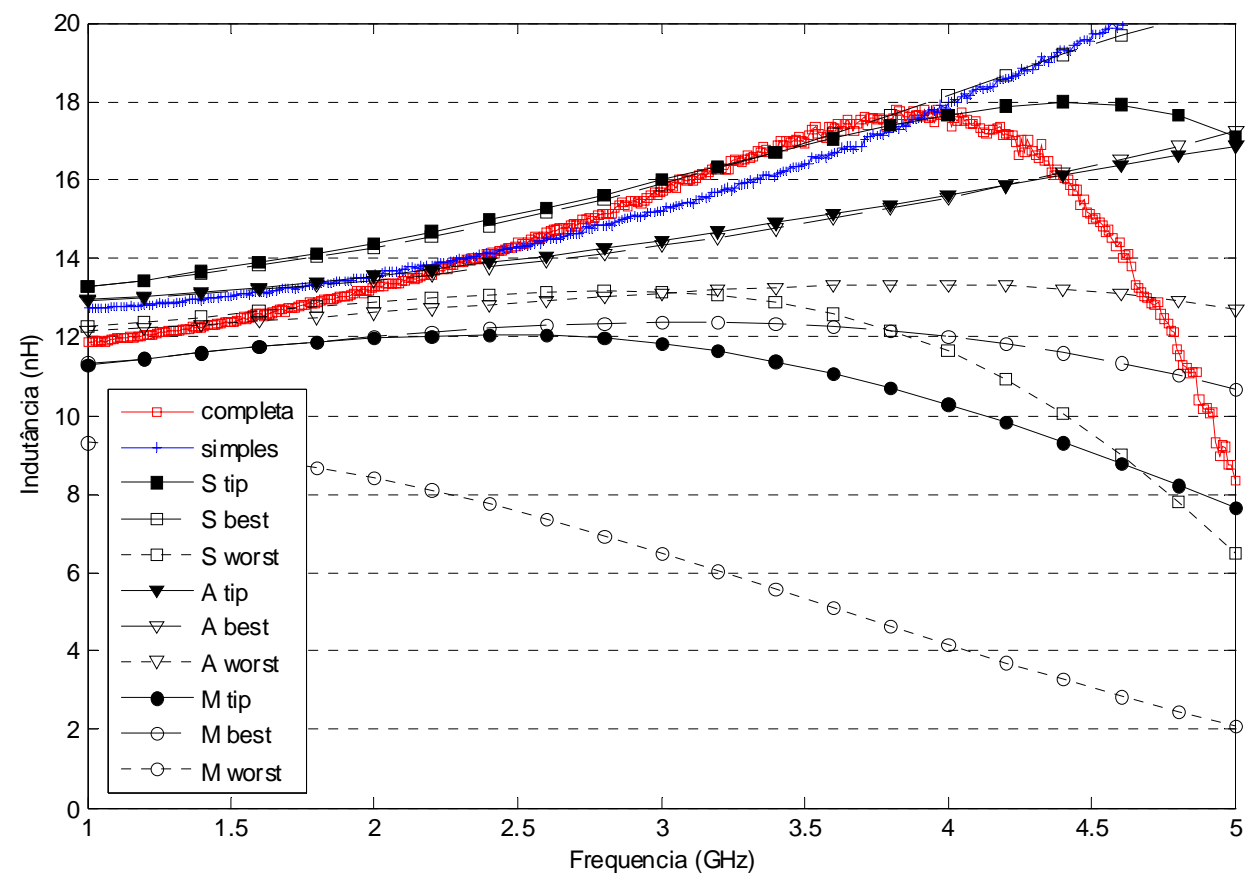

Figura 53 - Resultados de simulações e da média das medidas elétricas para o indutor 4: indutância em função da freqüência. A curva completa não inclui os resultados do chip3.

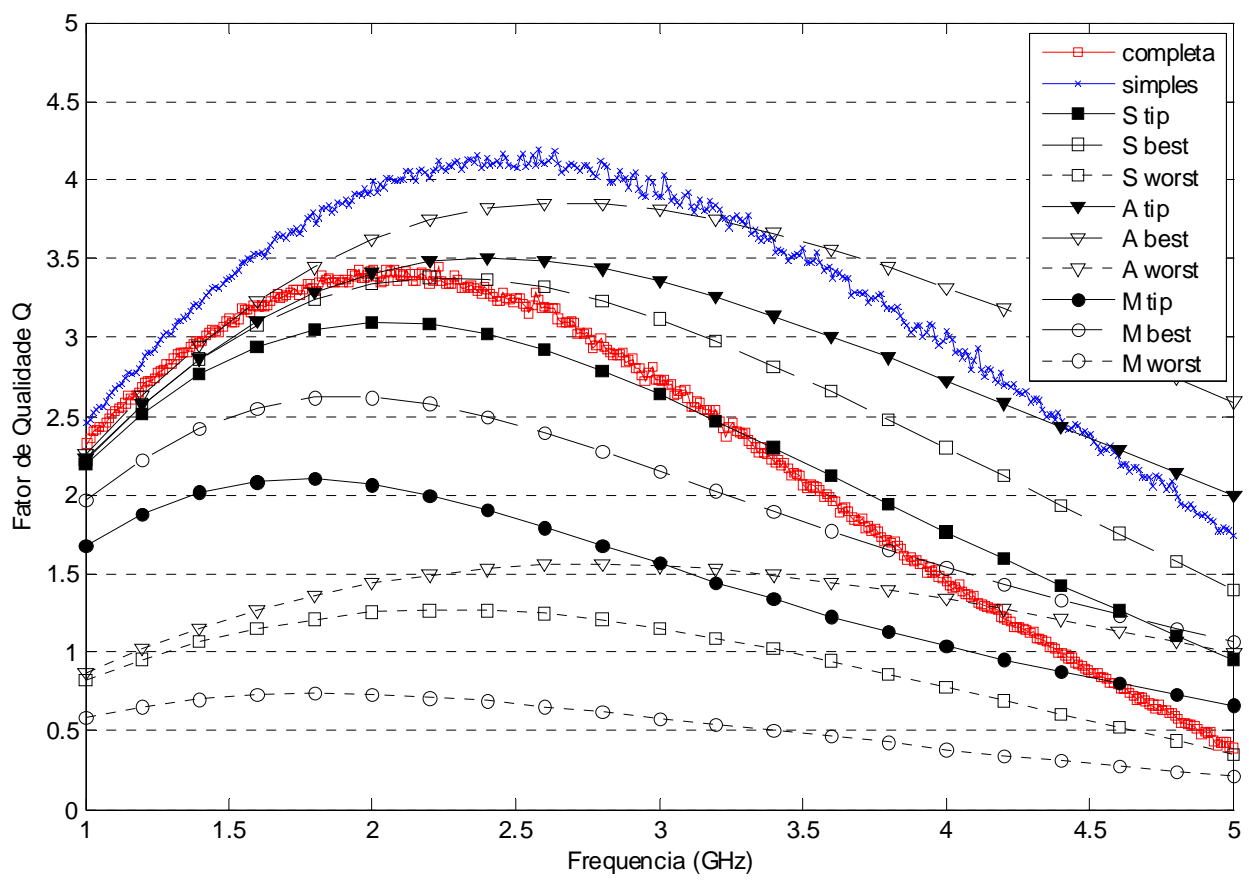

Figura 54 - Resultados de simulações e da média das medidas elétricas para o indutor 4: fator de qualidade em função da freqüência. 


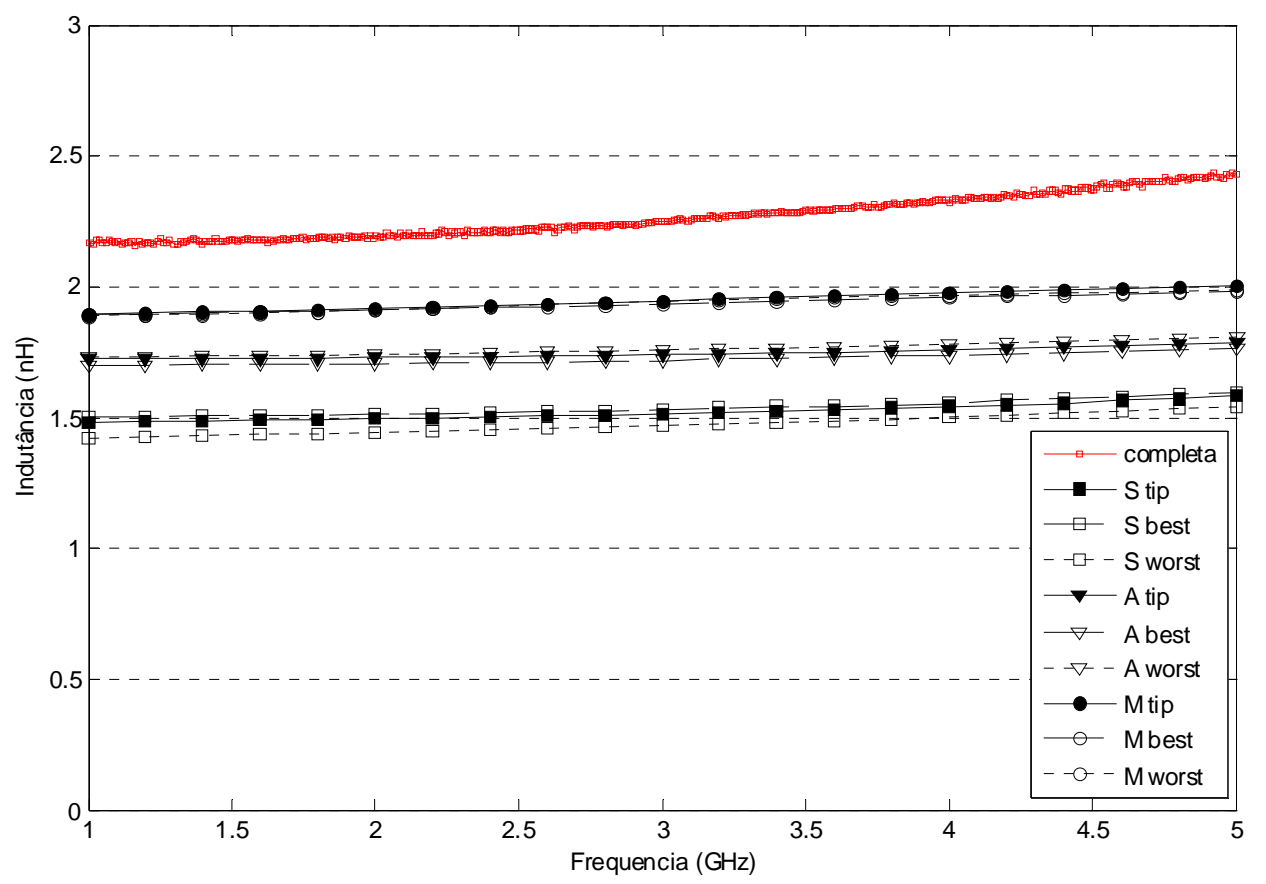

Figura 55 - Resultados de simulações e da média das medidas elétricas para o indutor 5: indutância em função da freqüência.

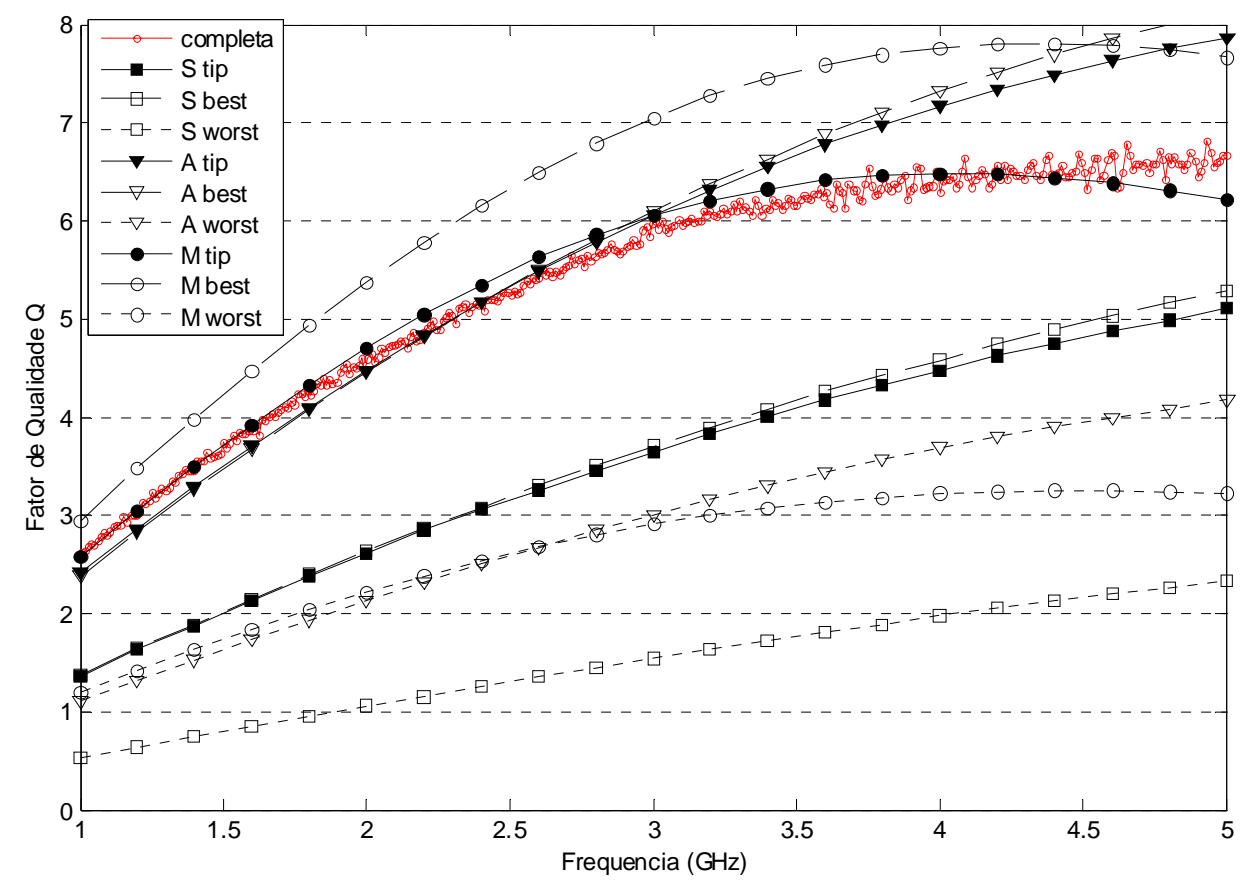

Figura 56 - Resultados de simulações e da média das medidas elétricas para o indutor 5: fator de qualidade em função da freqüência. A curva completa não inclui os resultados do chip4. 


\subsection{Análise dos Resultados}

A seguir serão realizadas algumas comparações de resultados relacionadas com os seguintes tópicos: os quatros chips; as estruturas de testes; as características estruturais dos indutores; e as ferramentas de modelamento juntamente com as equações analíticas.

- Comparação dos resultados obtidos nos quatros chips:

A faixa de variação dos resultados obtidos (tanto do $L$ quanto do $Q$ ) nos quatro chips foi pequena, desconsiderando uma curva do indutor 4 e outra do indutor 5. Assim sendo, é possível dizer que o processo de fabricação está bem desenvolvido, havendo pequena dispersão dos parâmetros entre os indutores feitos na mesma lâmina. As variações maiores foram encontrada nos valores do $Q$.

- Comparação dos resultados obtidos com as estruturas de testes:

Os resultados obtidos nas estruturas simples mostram que o valor do $L$ cresce continuamente, enquanto que os resultados obtidos nas estruturas completas mostram que o valor do $L$ começa a diminuir por volta de $4 \mathrm{GHz}$ (indutores 3 e 4). Os valores medidos em ambas estruturas estão próximos até ocorrer tal diminuição.

No caso do $Q$, os resultados obtidos nas estruturas simples mostram que seu valor tem uma queda menos acentuada do que a obtida com os resultados da estrutura completa. Ainda, os valores medidos com as estruturas simples são sempre superiores (valores de pico superiores em cerca de 0,6).

Tanto os resultados relativos à indutância como os relativos ao fator de qualidade indicam que há maior efeito capacitivo nas medidas com a estrutura completa, efeitos que podem ou não ser causados por elementos parasitas da própria estrutura de testes. Não foi possível identificar, por fim, qual é a melhor estrutura. $\mathrm{Na}$ literatura tem-se apontado para a estrutura completa como a melhor, por ter um procedimento de extração dos parasitas mais elaborado e por ser mais bem concebida. 
- Comparação dos resultados em função das características estruturais dos indutores:

Indutor 1 e 2 - eficiência da grade de silício policristalino: podemos analisar a eficiência da grade de polisilício nesta tecnologia através da comparação destes dois indutores (a grade é a única diferença entre eles). A grade fez com que o indutor 1 deixasse de se comportar como indutor em freqüências menores do que aquelas encontradas com o indutor 2. Isso era esperado pois a grade aumenta as capacitâncias parasitas. Por outro lado, ela não causou o esperado aumento no valor do fator de qualidade, apenas deslocando a curva do $Q$ para a direita.

Indutor 3 e 4 - camadas de metais diferentes: o indutor 3 foi implementado com camadas de metal 3 e 4 em paralelo, o que levou a apresentar um valor de $Q$ máximo maior do que o valor no indutor 4 (diferença máxima de 0,5 no caso da estrutura completa). Isto acontece, como esperado, devido à redução das resistências de segmento.

O indutor 4, construído apenas com o metal 4, obteve uma melhora na resposta com freqüência: o valor da indutância começa a diminuir em $4 \mathrm{GHz}$ para este indutor e em 3,6 GHz para o indutor 3. Isto é devido à redução entre a capacitância indutorsubstrato (o metal 4 está mais afastado do substrato).

O valor de $L$ sofre ainda um pequeno aumento no caso do indutor 4 (máximo de 0,1 $\mathrm{nH}$ comparado ao indutor 3, para as duas estruturas), devido ao fato do indutor estar mais afastado do substrato e, portanto, sofrer uma influência menor do campo magnético reverso.

Observemos que essas diferenças entre valores em $Q$ e $L$ são reduzidas.

Indutor 3 e 5 (estrutura completa) - geometrias diferentes: ambos indutores têm duas camadas de metal (metal 3 e 4), porém as geometrias deles são diferentes (variação nos valores de $\boldsymbol{L}_{\text {ext }}, \boldsymbol{W}$ e $\boldsymbol{N}$, ver Tabela 4 ). O indutor 5 tem uma indutância muito menor (entre 2,2 e 2,5 nH), comparada com a do indutor 3 (entre 2 e $17 \mathrm{nH}$ ). Isto se deve ao fato do valor da indutância ser diretamente proporcional ao número de voltas; o indutor 5 tem 2 voltas, enquanto o outro tem 9,5. 
$O Q$ do indutor 5 é maior (diferença máxima de 2,5 em relação ao indutor 3) por causa das menores resistências do segmento.

- Comparação dos resultados obtidos com as ferramentas de modelamento e as equações analíticas:

Para melhor comparar os resultados das ferramentas de modelamento, das equações analíticas e das medidas elétricas, foram geradas duas Tabelas (Tabelas 5 e 6) contendo informações sobre a faixa de freqüências onde o modelamento de cada ferramenta é aceitável. Para determinar essa faixa trabalhamos com a curva média das medidas experimentais e com as curvas típicas das ferramentas. Diremos que o modelamento é aceitável para indutância em certa freqüência quando a medida experimental nessa freqüência está entre as curvas “típica mais 15\%” e "típica menos 15\%"; diremos que o modelamento é aceitável para o fator de qualidade quando a medida está entre as curvas "típica mais 20\%" e "típica menos 20\%”. Erros de até $15 \%$ são mais do que razoáveis para valores absolutos de quaisquer parâmetros em circuitos integrados (quando se deseja precisão maior trabalha-se com valores relativos); no caso do fator de qualidade, que sabemos ser mais difícil de modelar, aumentamos os erros para $20 \%$.

A figura 57 ilustra como a faixa de freqüências de modelamento aceitável para a indutância é determinada (indutor 2 e ferramenta SONNET).

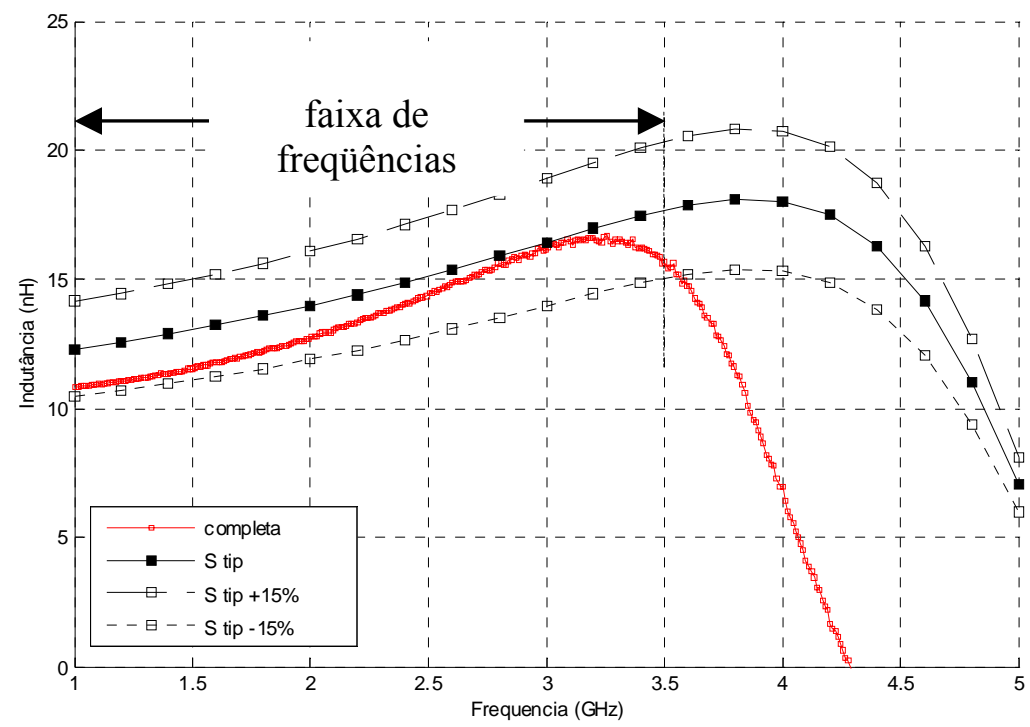

Figura 57 - Curva média para medidas de indutância, curva típica determinada pelo SONNET e curvas "típica $+15 \%$ " e "típica-15\%" (indutor 2). 
Nas Tabelas:

- as colunas fornecem os resultados relativos a cada um dos indutores analisados (Ind1 a Ind5);

- a coluna de cada indutor pode estar dividida em duas sub-colunas nomeadas de compl, para resultados relativos à estrutura completa, e de simpl, para resultados relativos à estrutura simples;

- as linhas, com exceção da última, fornecem os resultados relativos a cada uma das ferramentas (Son para o SONNET, Asi para o ASITIC e Mat para o MATLAB, onde foram implementadas as equações analíticas);

- a última linha indica qual ferramenta fornece a maior faixa de freqüências (Res).

Tabela 5 - Faixa de freqüências onde o modelamento para o valor de $L$ é aceitável. A determinação da faixa de freqüências é realizada a partir das curvas típica $\pm 15 \%$.

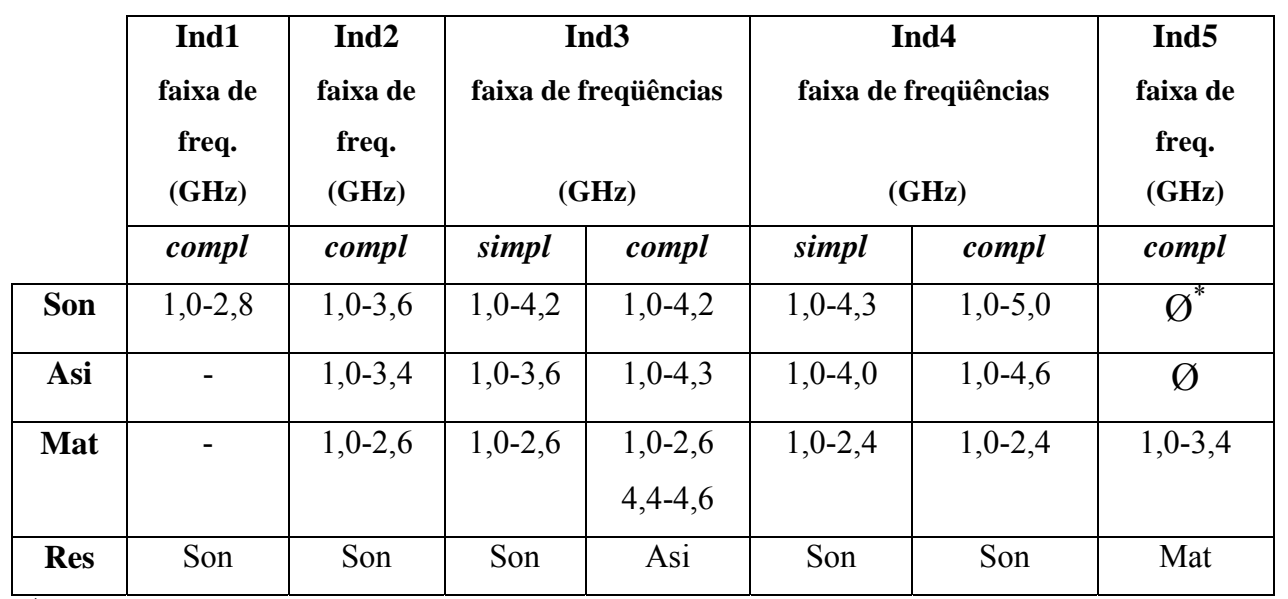

${ }^{*} \mathrm{O}$ símbolo $\emptyset$ indica que para todas as freqüências a medida experimental cai fora da faixa $\pm 15 \%$.

Tabela 6 - Faixa de freqüências onde o modelamento para o valor de $Q$ é aceitável. A determinação da faixa de freqüências é realizada a partir das curvas típica $\pm 20 \%$.

\begin{tabular}{|c|c|c|c|c|c|c|c|}
\cline { 2 - 8 } \multicolumn{1}{c|}{} & $\begin{array}{c}\text { Ind1 } \\
\text { faixa de } \\
\text { freq. } \\
\text { (GHz) }\end{array}$ & $\begin{array}{c}\text { Ind2 } \\
\text { faixa de } \\
\text { freq. } \\
\text { (GHz) }\end{array}$ & \multicolumn{2}{c|}{\begin{tabular}{c}
\multicolumn{2}{c|}{ Ind3 } \\
faixa de freqüências
\end{tabular}} & \multicolumn{2}{|c|}{$\begin{array}{c}\text { Ind4 } \\
\text { faixa de freqüências }\end{array}$} & $\begin{array}{c}\text { Ind5 } \\
\text { faixa de } \\
\text { freq. } \\
\text { (GH) }\end{array}$ \\
\cline { 2 - 9 } & compl & compl & simpl & compl & simpl & compl & compl \\
\hline Son & $1,0-2,8$ & $1,0-3,0$ & $1,0-1,6$ & $1,0-5,0$ & $1,0-2,1$ & $1,0-4,4$ & $\varnothing$ \\
\hline Asi & - & $1,0-2,4$ & $1,0-4,6$ & $1,0-2,8$ & $1,0-5,0$ & $1,0-3,0$ & $1,0-5,0$ \\
\hline Mat & - & $1,0-1,4$ & $1,0-1,2$ & $3,4-4,2$ & $\varnothing$ & $4,4-4,8$ & $1,0-5,0$ \\
& & $3,0-3,4$ & & & & & \\
\hline Res & - & Son & Asi & Son & Asi & Son & Asi/Mat \\
\hline
\end{tabular}


Da Tabela 5, que fornece a faixa de freqüências da indutância, podemos fazer as seguintes observações:

- O ASITIC é a segunda melhor ferramenta. A diferença entre a largura das faixas de freqüência, para o ASITIC e o SONNET, é pequena na maior parte dos casos;

- O SONNET é a melhor ferramenta, ou seja, é a aquela que apresenta maiores faixas de modelamento aceitável para as indutâncias;

- O MATLAB, ou seja, as equações analíticas não determinam muito bem o valor da indutância, visto que a faixa onde o modelamento é aceitável é pequena (largura máxima de 1,6 GHz). A exceção é com o indutor 5, bem estimado apenas por essa ferramenta;

- Por fim, SONNET e ASITIC são ferramentas que fornecem bons valores de $L$ para freqüências de até cerca de 3,6 GHz. Para freqüências maiores ou indutores muito pequenos, como no caso do indutor 5, seus resultados devem ser considerados com desconfiança.

Da Tabela 6, que fornece a faixa de freqüências para o fator de qualidade, podemos fazer as seguintes observações:

- O ASITIC acompanha melhor o comportamento dos indutores 3 , 4 e 5 (principalmente aqueles medidos na estrutura simples);

- O SONNET determina melhor que as demais ferramentas o valor do fator de qualidade no caso dos indutores 2, 3 e 4 (apenas aqueles medidos na estrutura completa);

- O MATLAB, ou seja, as equações analíticas não determinam muito bem o fator de qualidade, visto que, da mesma forma que com a indutância, a faixa onde o modelamento é aceitável é pequena (largura máxima de $0,8 \mathrm{GHz}$ ). A exceção, novamente, é o indutor 5, excepcionalmente bem estimado por ele neste caso;

- Por fim, o fator de qualidade é, em geral, muito mal estimado em todos as ferramentas consideradas. O ASITIC foi a ferramenta que melhores resultados apresentou, fornecendo estimativas com erros inferiores a $20 \%$ para freqüências até $2,4 \mathrm{GHz}$. 
No que se refere às curvas dos parâmetros best, típico e worst um aspecto a observar é a distância entre elas. Consideremos o fator de qualidade inicialmente. Caso tomemos a faixa entre as curvas best e worst do fator de qualidade como a região de valores esperados, veremos que os valores possíveis para o $Q$ variam em mais de $100 \%$ para freqüências baixas $(1 \mathrm{GHz})$. Isso significa que, ou as variações dos parâmetros são tão grandes que nenhuma previsão razoável do fator de qualidade é possível ou os arquivos montados para best e worst são muito pessimistas. Qualquer decisão a este respeito só pode ser feita com novas fabricação e medidas.

Consideremos a indutância agora. Neste caso a faixa entre as curvas best e worst é mais estreita, principalmente para freqüências mais baixas. A figura 58, valor da (curva best - curva worst)/(curva típica) em porcentagem versus a freqüência, ilustra como a faixa best-worst se comporta no caso de cada ferramenta. Vemos que para o SONNET esta faixa só ultrapassa os $30 \%$ (equivalente $\pm 15 \%$ ) em freqüências superiores a 3,5 GHz e para o ASITIC, em freqüências superiores a 4,5 GHz. Para o as equações analíticas (MATLAB) a faixa pode já se tornar larga em freqüências de $2 \mathrm{GHz}$.

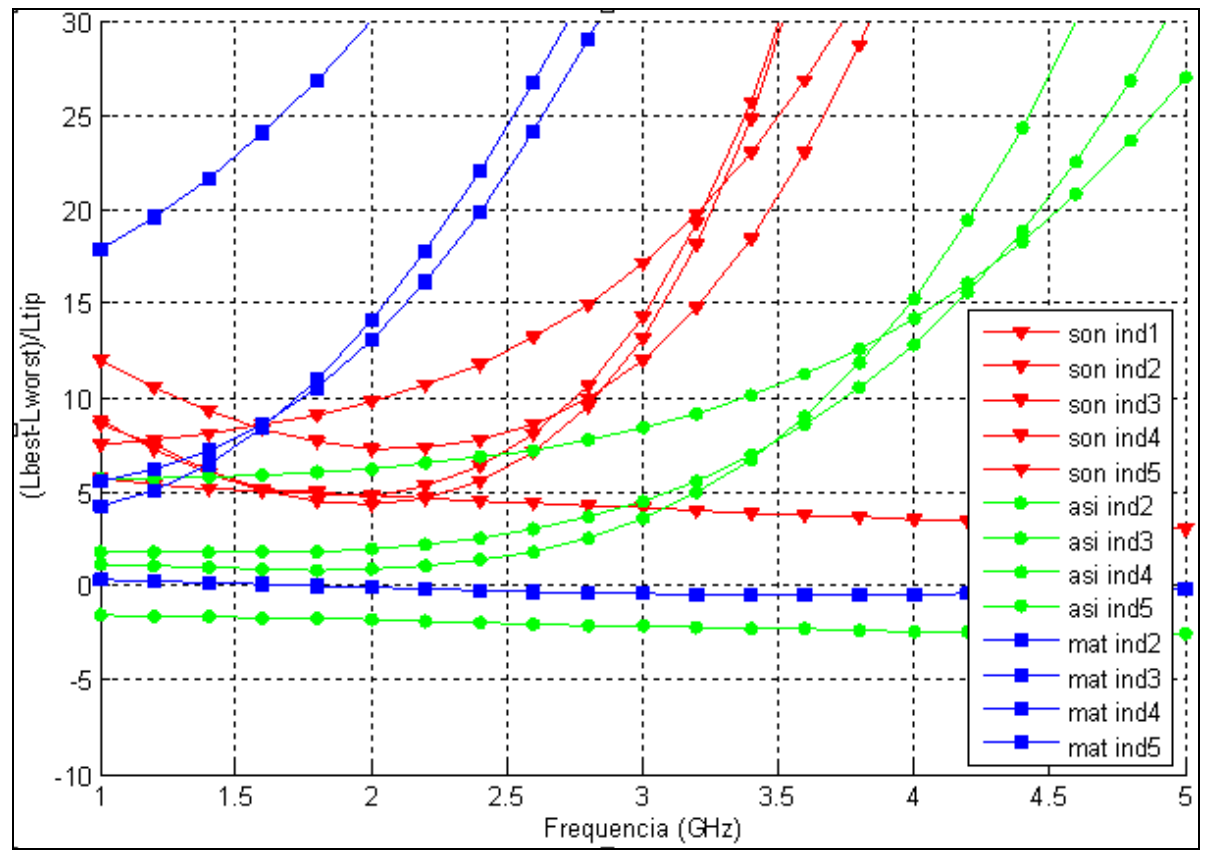

Figura 58 - O valor de (curva best - curva worst)/(curva típica) em porcentagem versus a freqüência. $\mathrm{Na}$ legenda son é para o SONNET, asi para o ASITIC e mat para o MATLAB; ind1 é para o indutor 1 , ind2 para o indutor 2 e assim por diante. 
Outros aspectos importantes relativos às ferramentas e ao MATLAB são (ressaltando que o MATLAB foi uma plataforma qualquer para implementar as equações analíticas):

Custo de aquisição: quanto ao custo de aquisição, o ASITIC é a melhor opção pois é gratuito; a segunda melhor opção é o MATLAB pois, apesar de ser custoso, normalmente está disponível como ferramenta para cálculos e simulações; a pior opção é o SONNET, uma ferramenta cara e que tem aplicações restritas.

Custo computacional: quanto ao custo computacional, o MATLAB, que leva apenas alguns segundos para realizar os cálculos, é a melhor opção; a segunda melhor opção é o ASITIC que leva, aproximadamente, cinco minutos para simulação de um indutor; a pior opção é novamente o SONNET que leva mais de uma hora para simulação em cada freqüência;

Modelamento de indutores mais complexos: o SONNET é a ferramenta que fornece maior flexibilidade para modelar indutores, seja lá qual for seu formato e estrutura; a segunda melhor opção é o ASITIC que permite a simulação de estruturas poligonais, circulares além de transformadores; a pior opção fica com o MATLAB, pois esta exige que para cada diferente estrutura sejam determinadas as equações a serem aplicadas;

Facilidade para configurar a ferramenta: o SONNET é a ferramenta mais simples de configurar e isso é realizado através de janelas de configuração de fácil interação; a segunda melhor opção é o ASITIC, que exige a elaboração de arquivos de configuração, um pouco complexos, para cada tecnologia; a pior opção é o MATLAB, pelo elevado tempo consumido na elaboração de seus arquivos de programas.

Facilidade para trabalhar com a ferramenta: o ASITIC é a ferramenta mais simples porque, normalmente, são necessários apenas alguns comando para desenhar e 
simular um indutor; a segunda opção é o MATLAB, desde que a ferramenta e sua linguagem sejam conhecidas; a pior opção é o SONNET pois nela é necessário desenhar o indutor com camadas corretas, vias, ports, etc. 


\section{5 - Conclusões e Trabalhos Futuros}

Neste trabalho estudamos e analisamos duas ferramentas de modelamento de indutores planares, retangulares e integrados, o ASITIC e o SONNET e as equações analíticas implementadas no MATLAB. O objetivo deste estudo é estabelecer aquela que fornece melhores resultados. Para realizar tal tarefa foram projetados, implementados e caracterizados diversos indutores na tecnologia CMOS 0,35 $\mu \mathrm{m}$ da AMS. Adicionalmente também foram estudadas e projetadas estruturas de teste e estruturas de caracterização.

Das ferramentas estudadas, foi o ASITIC que concluímos ser a melhor ferramenta para o modelamento de indutores. Isto se deve ao fato de que:

- ele modela o comportamento do valor do $L$ em freqüências até 3,5 GHz (curva típica $\pm 15 \%)$;

- $\quad$ ele modela o comportamento do valor do $Q$ em freqüências até 2,4 GHz (curva típica $\pm 20 \%$ );

- ele seja gratuito;

- ele tenha baixo custo computacional;

- $\quad$ ele seja de fácil operação.

O SONNET, por sua vez, modela bem o valor do $L$ em freqüências até 3,5 $\mathrm{GHz}$, e o valor do $Q$ em freqüências até 2,0 GHz. Por outro lado, seus custos de aquisição e computacional são elevados. As equações analíticas (MATLAB), estima bem o valor do $L$ em freqüências até $2,4 \mathrm{GHz}$, e precariamente o valor do $Q$.

Em geral, o valor da indutância foi melhor estimado pelas ferramentas consideradas, do que o valor do fator de qualidade, tanto em termos de precisão quanto em relação à freqüência máxima.

Com relação às estruturas de teste e de caracterização, não foi possível determinar qual é a melhor delas, completa ou simples, ou seja, aquela que mais reduz os efeitos dos elementos parasitas dos pads.

Como sugestões para trabalhos futuros propomos:

- realizar novas medidas elétricas nos indutores 4 e 5, visto que eles apresentaram resultados muito distintos em um dos quatro chips medidos; 
- fabricar novamente o chip projetado, para analisar os possíveis efeitos das variações da tecnologia sobre os resultados dos indutores;

- fazer um novo projeto com mais indutores utilizando as estruturas simples e completa para comparação das mesmas;

- analisar por meio de simulações quais parâmetros tecnológicos (resistividades, espessura de isolantes, etc.) influenciam mais no comportamento do fator de qualidade. Com isso poderemos configurar melhor as ferramentas de modelamento. 


\section{REFERÊNCIAS}

[Ar98] ARCIONI, Paolo; CASTELlO, Rinaldo; ASTIS, Giuseppe De; SACCHI, Enrico; SVELTO, Francesco. Measurement and Modeling of Si Integrated Inductors, IEEE Transactions on Instrumentation and measurement, vol. 47, n. 5, p. 1372-1378, Oct. 1998.

[As03] Manual do ASITIC (Analysis and Simulation of Inductors and Transformers in Integrated Circuits), disponível em: $<$ http://formosa.eecs.berkeley.edu $>$. Acesso em 05/fev./2003.

[Au03a] AUSTRIAMICROSYSTEMS. 0.35 pm CMOS C35 Process Parameters. Document number: Eng-182, Rev.: 2, AustriaMicroSystems, 2003.

[Au03b] AUSTRIAMICROSYSTEMS. 0.35 um CMOS Process Technology. Seven digit document: Eng-183, Rev.: 3, Release date: 2003/08/06.

[Br98] BREWER, Joe E. A new and improved roadmap. IEEE Circuits \& Devices, v. 14, n. 2, p. 13-18, 1998.

[Ca03] Cao, Yu; GROVES, Robert A.; HUANG, Xuejue; ZAMDMER, Noah D.; et al. Frequency-Independent Equivalent-Circuit Model for On-Chip Spiral Inductors, IEEE J. Solid-State Circuits, vol. 38, n. 3, p. 419-426, Mar. 2003.

[Cr96] CROLS, Jan; KINGET, Peter; CRANINCKX, Jan; STEYAERT, Michiel. An Analytical Model of Planar Inductors on Lowly Doped Silicon Substrates for High frequency Analog Design up to $3 \mathbf{G H z}$, Symp. on VLSI Circuits Digest of Technical Papers, p. 28-29, 1996.

[Ed98] Edelstein, Daniel C.; BURGHARTZ, Joachim N. Spiral and solenoidal inductor structures on silicon using Cu-damascene interconnects, Interconnect Technology Conference - Proceedings of IEEE International, p. 18-20, Jun. 1998.

[Fe62] FEYNMAN, R.P. et al. Lectures on Physics. Reading, Addison-Wesley Publishing Company, vol. 2, 1962.

[Fu03] FUENTES, Elkim Felipe Roa. Metodologia de Projeto para Amplificadores de Baixo Ruído em CMOS (tese de doutorado), 
Departamento de Engenharia de Sistemas Eletrônicos, Escola Politécnica da Universidade de São Paulo, São Paulo - Brasil, 2003.

[Gg06] GGB - Industries, INC, disponível em: $<\underline{\mathrm{http}}$ ://www.ggb.com/40a.html $>$. Acesso em 08/ago./2006.

[Go96] GOZZI, G.G.M. Circuitos Magnéticos, Coleção Estude e Use, São Paulo, Ed. Érica, 1996.

[Gr74] GREENHOUSE, H. M. Design of Planar Rectangular Microelectronic Inductors, IEEE Trans. on Parts, Hybrid, and Packaging, vol. 10, no. 2, pp. 101-109, Jun. 1974.

[Ha94] HAYT, W.H. Eletromagnetismo, $4^{\mathrm{a}}$ ed., Rio de Janeiro, Ed. Livros Técnicos e Científicos, 1994.

[Ha96] HALLIDAY, D. et al. Fundamentos de Física 3 - Eletromagnetismo, $4^{\mathrm{a}}$ ed., Rio de Janeiro, Ed. Livros Técnicos e Científicos, 1996.

[In03] CMOS RF Modeling, disponível em: < $\underline{\text { http://inca.kaist.ac.kr/research/ }}$ research_RFmodel2.htm $>$. Acesso em 01/maio/2003.

[It05] ITRS, International technology roadmap for semiconductors, 2005 edition. disponível em: <http://www.itrs.net/reports.html $>$. Acesso em 15/maio/2007.

[Ky01] KYTHAKYAPUZHA, Shobak Ramakrishnan. Modeling of Spiral Inductors and Transformers (Master thesis), Dept. Electrical of Engineering and Computer Engineering, Kansas State University, Manhattan, 2001.

[Ko00] KOLDING, Troel Emil; JENSEN, Ole Kiel; LARSEN, Torben. GroundShielded Measuring Technique for Accurate On-Wafer Characterization of RF CMOS Devices, IEEE International Conference on Microelectronic Test Structure, p. 246-251, Mar. 2000.

[Me04] MEI, Shizhong; ISMAIL, Yehea I. Modeling Skin and Proximity Effects with Reduced Realizable RL Circuits, IEEE Transactions on Very Large Scale Integration (VLSI) Systems, vol. 12, no. 4, p. 437-447, Apr. 2004

[Me95] MERRILL, R.B.; LEE, T. W.; You, Hong; et al. Optimization of High Q Integrated Inductors for Multi-level Metal CMOS, IEEE International Electron Devices Meeting, vol. 10, no. 13, p. 983-986, Dec. 1995. 
[Me98] MELLIAR-SMITH, C. Mark; BORRUS, Michael G.; HAGGAN, Tyler Lowrey; et al. The transistor: an invention becomes a big business. Proceedings of the IEEE, v.86, n.1, p. 86-110, 1998.

[Mo99] MOHAN, Sunderarajan S. The Design, Modeling and Optimization of On-Chip Inductor and Transformer Circuits (PhD thesis), Dept. Electrical Engineering, Stanford University, 1999.

[Mo01] MOREIRA, Luiz Carlos. Estruturas de Indutores Monolíticos para Circuitos RF na Tecnologia CMOS (tese de doutorado), Departamento de Engenharia de Sistemas Eletrônicos, Escola Politécnica da Universidade de São Paulo, São Paulo - Brasil, 2001.

[Ni00] NIKNEJAD, Ali M. Analysis, Simulation, and Applications of Passive Devices on Conductive Substrates (PhD thesis), Dept. EngineeringElectrical Engineering and Computer Science, University of California, Berkeley, 2000.

[Ni96] NIKNEJAD, Ali M. Analysis, Design, and Optimization of Spiral Inductors and Transformers for Si RF ICs (Master thesis), Dept. Engineering-Electrical Engineering and Computer Science, University of California, Berkeley, 1996.

[Oh03] OHARA, Gilson Mikio. Projeto de um Oscilador LC-tanque Controlável por Tensão em Tecnologia CMOS para Rádio Freqüência (dissertação de mestrado), Departamento de Engenharia Elétrica, Escola Politécnica da Universidade de São Paulo, São Paulo - Brasil, 2003.

[Or04] ORSINI, L.Q.; CONSONNI, Denise. Curso de Circuitos Elétricos, vol. 2, $2^{\mathrm{a}}$ ed., São Paulo, Editora Edgard Blücher LTDA, 2004.

[Ro98] ROSS, Ian M. The invention of the transistor, Proceedings of the IEEE, vol.86, p. 7-28, Jan. 1998.

[Sa88] SAH, Chi-Tang. Evolution of the MOS transistor-from conception to VLSI, Proceedings of the IEEE, vol.76, p. 1280-1326, Oct. 1988.

[So04] SONNET, disponível em: <http://www.sonnetusa.com>. Acesso em 23/jan./2004. 
[Ts97] TSAI, Huan-Shang; LIN, Jenshan; FRYE, Robert C. Investigation of Current Crowding Effect on Spiral Inductors, IEEE MTT-S Symposium on Technologies for Wireless Application Digest, p. 139-142, Feb. 1997.

[Th00] The VLSI Handbook, Ed. Wai-Kai Chen, Boca Raton: CRC Press LLC, 2000.

[Va05] Vandi, Luca; ANDREANI, Pietro; TEMPORITI, Enrico; et al. Toroidal Inductors in CMOS Processes, Norchip Conference, p. 293-296, Nov. 2005.

[Vi00] VILLEGAS, J. M. Loppez; SAMITIER, J.; CANE, C. Improvement of the Quality Factor of RF Integrated Inductors by Layout Optimization, IEEE Trans. Microwave Theory and Techniques, vol. 48, no. 1, p. 76-83, Jan. 2000.

[We93] WESTE, Nei H .E.; ESHRAGHIAN, Kamran. Principles of CMOS VLSI Design, 2a ed. Reading, Addison-Wesley Publishing Company, 1993.

[Yu96] YUE, C. Patrick; RYU, Changsup; LAU, Jack; et al. A Physical Model for Planar Spiral Inductors on Silicon, IEEE Electron Devices Meeting, p. 155-158, Dec. 1996.

[Yu98] YUE, C. Patrick WONG, Simon. On-Chip Spiral Inductors with Patterned Ground Shields for Si-Based RF IC's, IEEE J. Solid-State Circuits, vol. 33, no. 5, p. 743-752, May. 1998.

[Yu99] YUE, C. Patrick; WONG, Simon. Design strategy of on-chip inductors for highly integrated RF systems, Design Automation Conference, p. 982987, Jun. 1999.

[Yu00] YUE, C. Patrick; WONG, Simon. Physical Modeling of Spiral Inductors on Silicon, IEEE Trans. on Electron Devices, vol. 47, no. 3, p. 560-568, Mar. 2000. 


\section{ANEXO A - Configuração do ASITIC}

Estão descritos a seguir os arquivos de configuração, technology files, necessários para o ASITIC. Estes arquivos contém parâmetros específicos do processo como espessura e resistências por quadrado das várias camadas. A vista em corte da lâmina com algumas camadas esta ilustrada na figura 64 e serve para facilitar a compreensão dos arquivos.

Os arquivos de configuração estão divididos em sub-seções. A primeira subseção é iniciada com a declaração <chip>. As primeiras duas linhas desta seção definem as dimensões $\mathbf{x}$ e $\mathbf{y}$ do chip, que deve ter, para bons resultados, cerca de quatro vezes a área do dispositivo simulado. Os próximos dois parâmetros são as dimensões para a realização da FFT-2D. A relação entre as dimensões do chip e as dimensões para a FFT-2D definem a menor unidade de análise: um retângulo com dimensão de chipx/fftx por chipy/ffty.

As próximas sub-seções do arquivo, iniciadas com a declaração < layer >, $<$ metal $>$ ou $<$ via $>$, definem camadas, metais e elementos de conexão entre metais.

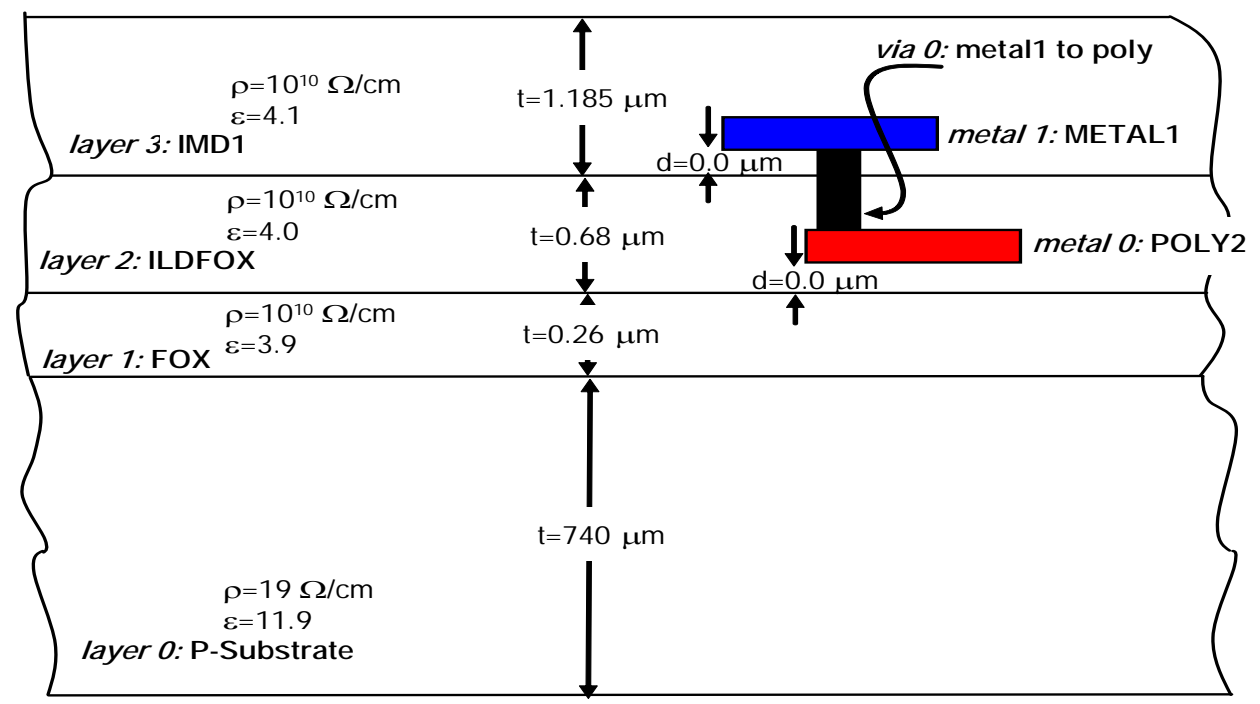

Figura 59 - Vista em corte com algumas camadas: layer 0, layer 1, layer2, layer 3, metal 0, metal1 e via 0. Os parâmetros são relativos ao arquivo de configuração típico. 


\section{Parâmetros Típicos:}

;C35B4C3 0.35um CMOS technology file

;Based on documentation of AMS - Austria Micro Systeme International AG ;Document ENG-182 Rev 2

;DMPSV - LSI - USP

;Last changed on 05/05/2005

;Typical Pamemeters

;Navarro/Angelica/Andres/Eduard

$<$ chip $>$

chipx $=1000$

chipy $=1000$

; dimensions of the chip in $\mathrm{x}$ direction

$\mathrm{fftx}=512$

ffty $=512$

TechFile $=$ c35tip.tek ; dimensions of the chip in y direction ; $\mathrm{x}$-fft size (must be a power of 2)

;y-fft size

TechPath $=$

freq $=2.4$

edd $=1$

;?? frequency of operation

;eddy-current calculation flag

$<$ layer $>0$

rho $=19$

$\mathrm{t}=725$

eps $=11.9$

;P-SUBSTRATE

;ohm-cm

;microns, media entre minimo e maximo

$<$ layer $>1$

rho $=1 \mathrm{e} 10$

$\mathrm{t}=0.290$

eps $=3.9$

;FOX

;ohm-cm

$<$ layer $>2$

rho $=1 \mathrm{e} 10$

$\mathrm{t}=0.845$

eps $=4$

\section{;ILDFOX}

;ohm-cm

$<$ metal $>0$

layer $=2$

;POLY2

$\mathrm{rsh}=50000$

;sheet resistance Mili-Ohms/Square

$\mathrm{t}=0.2$

$\mathrm{d}=0$

name $=$ POLY2

;thickness (microns)

;dist from bottom of layer (at surface)

color $=$ red

$<$ via $>0$

top $=1$

bottom $=0$

$\mathrm{r}=20$

;metal 1 to poly

; via connects up to this metal layer ; via connectsdown to this metal layer ;resistance per via 


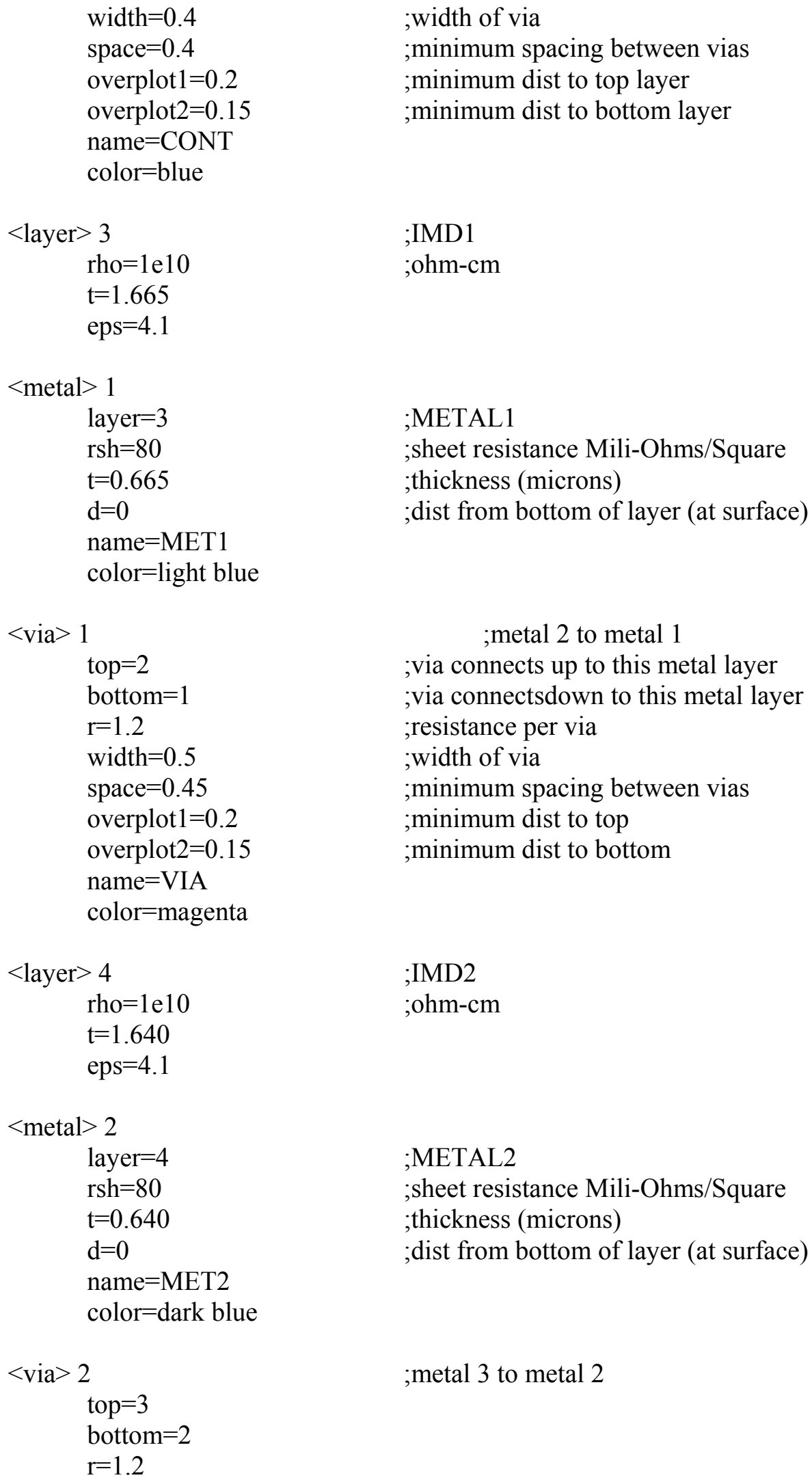




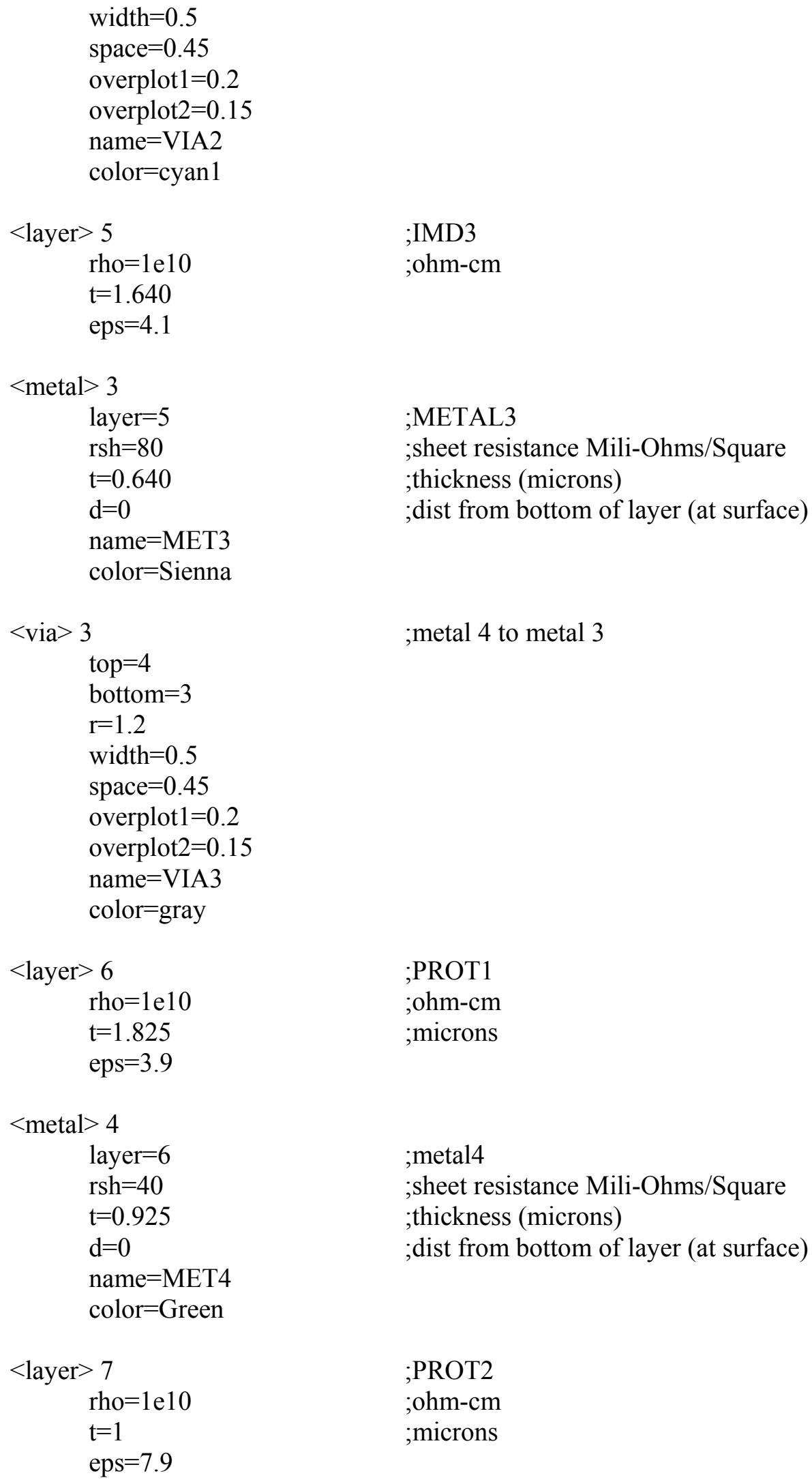

;PROT2

;ohm-cm

;microns 


\section{Parâmetros Best:}

;C35B4C3 0.35um CMOS technology file

;Based on documentation of AMS - Austria Micro Systeme International AG ;Document ENG-182 Rev 3

;DMPSV - LSI - USP

;Last changed on 07/10/2005

;Best Pamemeters

;Navarro/Angelica/Andres/Eduard

$<$ chip $>$

chipx $=1000$

chipy $=1000$

; dimensions of the chip in $\mathrm{x}$ direction

fftx $=512$

$\mathrm{ffty}=512$

TechFile $=$ c35tip.tek ; dimensions of the chip in y direction ; $\mathrm{x}$-fft size (must be a power of 2)

TechPath $=$ freq $=2.4$ ;y-fft size eddy $=1$

;?? Frequency of operation ; eddy-current calculation flag

$<$ layer $>0$

rho $=24$

$\mathrm{t}=710$

eps $=11.9$

\section{;P-SUBSTRATE}

;ohm-cm

;microns, media entre minimo e maximo

$<$ layer $>1$

rho $=1 \mathrm{e} 10$

$\mathrm{t}=0.320$

eps $=3.9$

;FOX

;ohm-cm

$<$ layer $>2$

;ILDFOX

rho $=1 \mathrm{e} 10$

;ohm-cm

$\mathrm{t}=1.280$

eps $=4$

$<$ metal $>0$

layer $=2$

;POLY2

$\mathrm{rsh}=40000$

;sheet resistance Mili-Ohms/Square

$\mathrm{t}=0.215$

;thickness (microns)

$\mathrm{d}=0$

name $=$ POLY2

;dist from bottom of layer (at surface)

color $=$ red

$<$ via $>0$

top $=1$

bottom $=0$

;metal 1 to poly2

; via connects up to this metal layer

; via connectsdown to this metal layer 


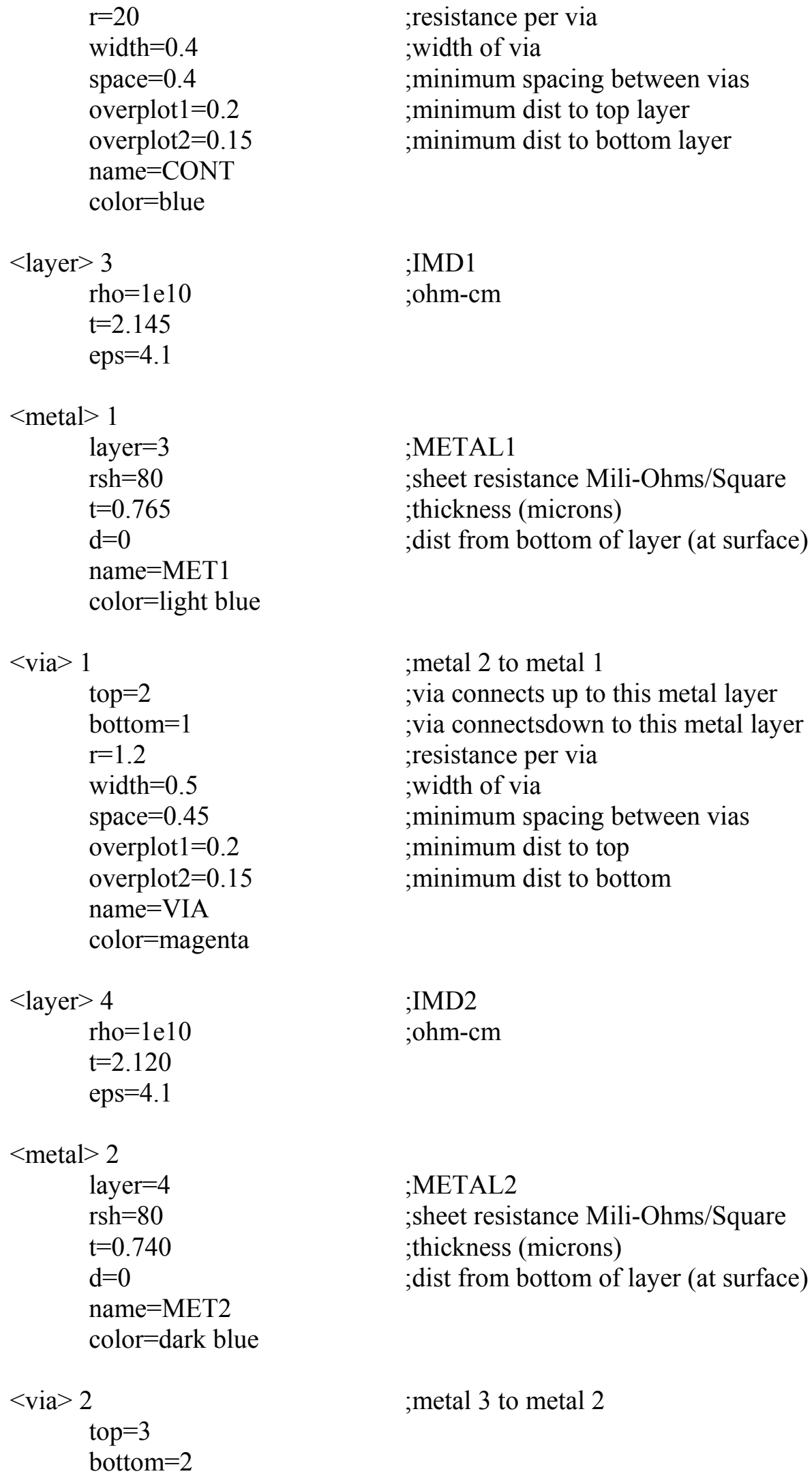




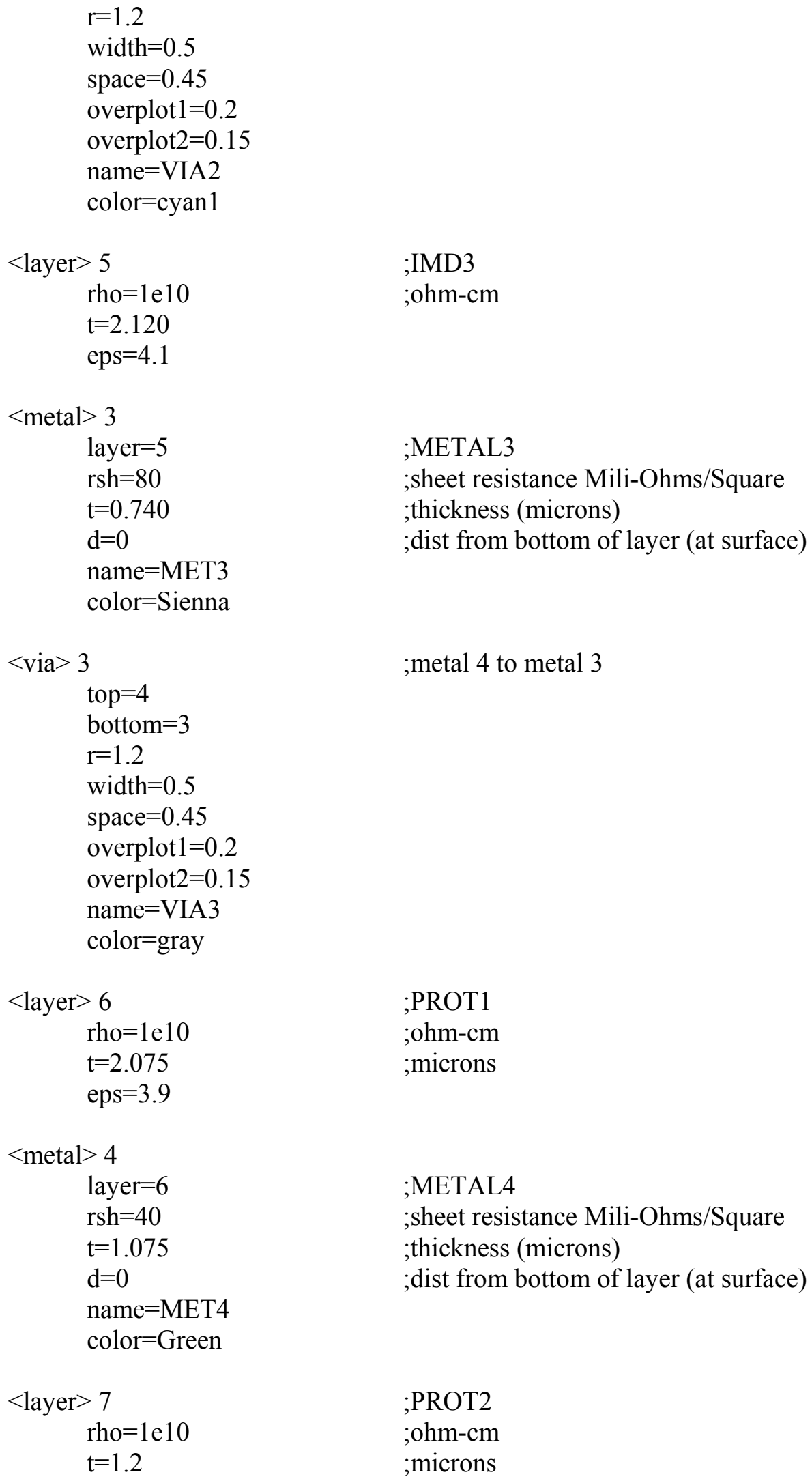


eps $=7.9$

\section{Parâmetros Worst:}

;C35B4C3 0.35um CMOS technology file

;Based on documentation of AMS - Austria Micro Systeme International AG ;Document ENG-182 Rev 2

;DMPSV - LSI - USP

;Last changed on 05/05/2005

;Worst Pamemeters

;Navarro/Angelica/Andres/Eduard

$<$ chip $>$

chipx $=1000$

chipy $=1000$

$\mathrm{fftx}=512$

ffty $=512$

TechFile $=$ c35tip.tek

TechPath $=$

freq $=2.4$

edd $=1$

$; ? ?$ frequency of operation
;eddy-current calculat ;eddy-current calculation flag

$<$ layer $>0$

rho $=19$

$\mathrm{t}=740$

eps $=11.9$

; dimensions of the chip in $\mathrm{x}$ direction ; dimensions of the chip in y direction ; $\mathrm{x}$-fft size (must be a power of 2)

;y-fft size

;P-SUBSTRATE ;ohm-cm

;microns, media entre minimo e maximo

$<$ layer $>1$

rho $=1 \mathrm{e} 10$

$\mathrm{t}=0.260$

eps $=3.9$

;FOX

;ohm-cm

$<$ layer $>2$

rho $=1 \mathrm{e} 10$

$\mathrm{t}=0.680$

eps $=4$

\section{;ILDFOX}

;ohm-cm

$<$ metal $>0$

layer $=2$

$\mathrm{rsh}=60000$

$\mathrm{t}=0.185$

$\mathrm{d}=0$

name $=$ POLY2

color $=$ red

$<$ via $>0$

top $=1$

;metal 1 to poly

; via connects up to this metal layer

;POLY2

; sheet resistance Mili-Ohms/Square ;thickness (microns)

; dist from bottom of layer (at surface) 


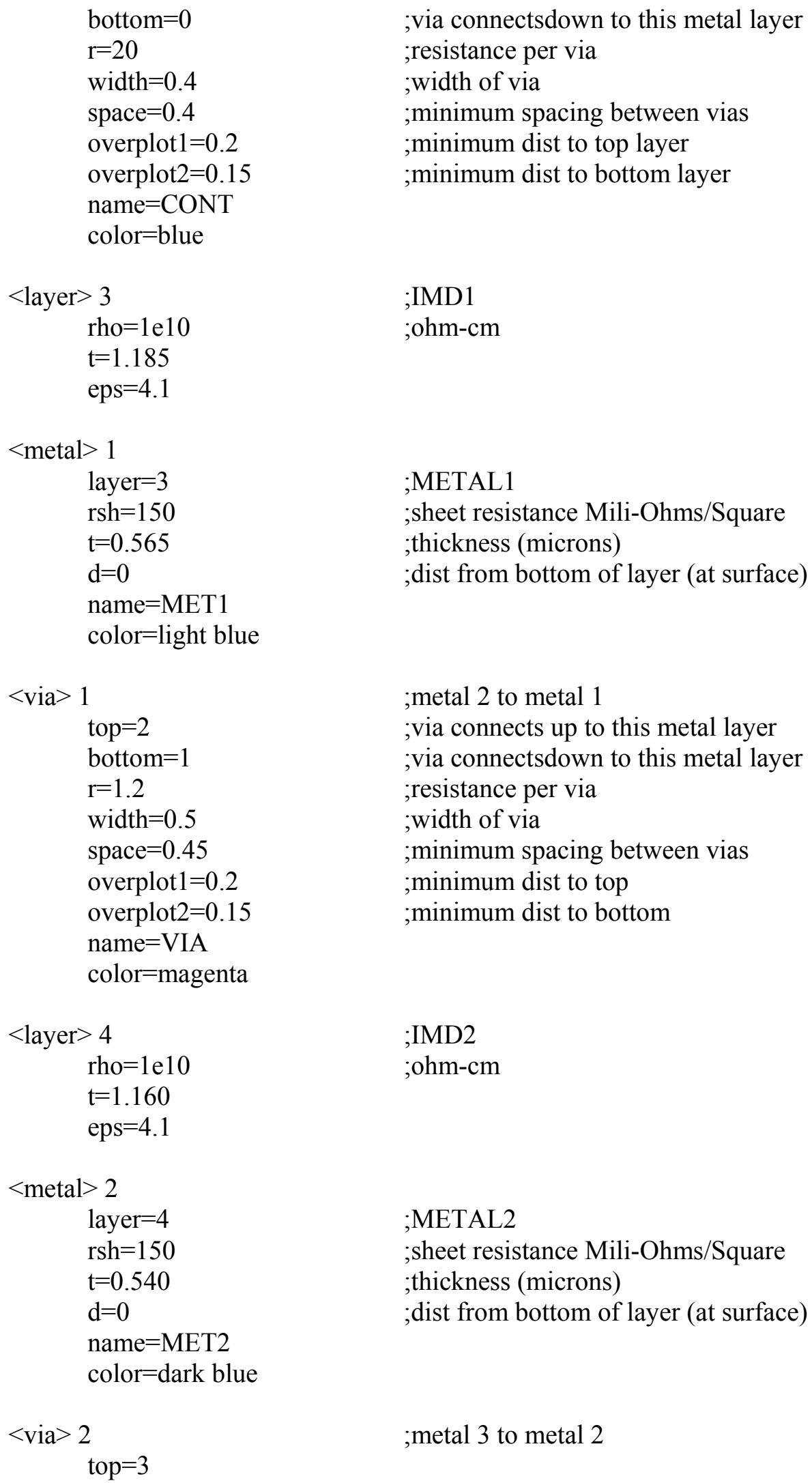




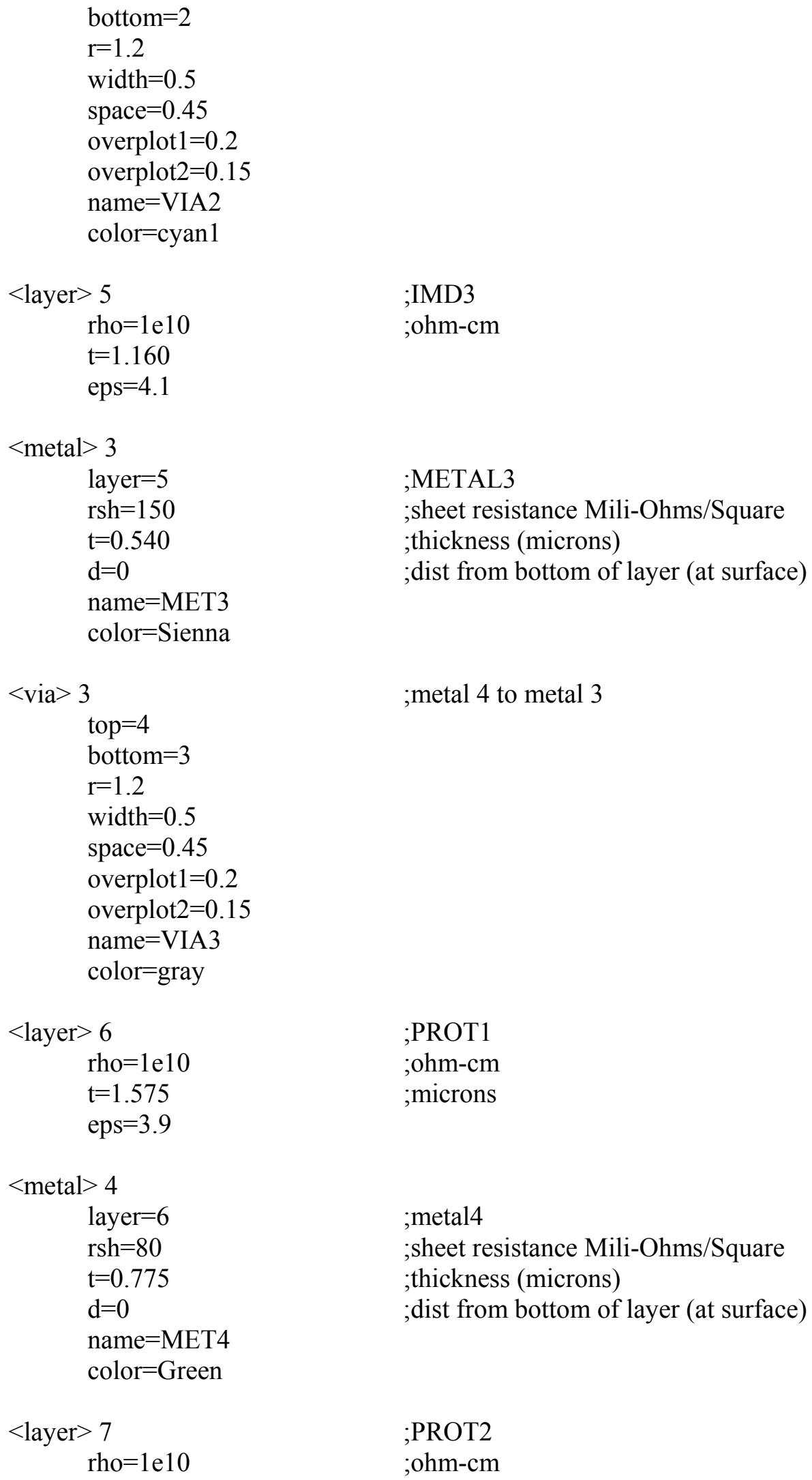


$\mathrm{t}=0.800$

;microns

eps $=7.9$ 


\section{ANEXO B - Configuração do Matlab}

Neste anexo está apresentado o arquivo utilizado no MATLAB para cálculo dos parâmetros do modelo PI do indutor, o fator de qualidade e a indutância equivalente.

\section{Equações Teóricas:}

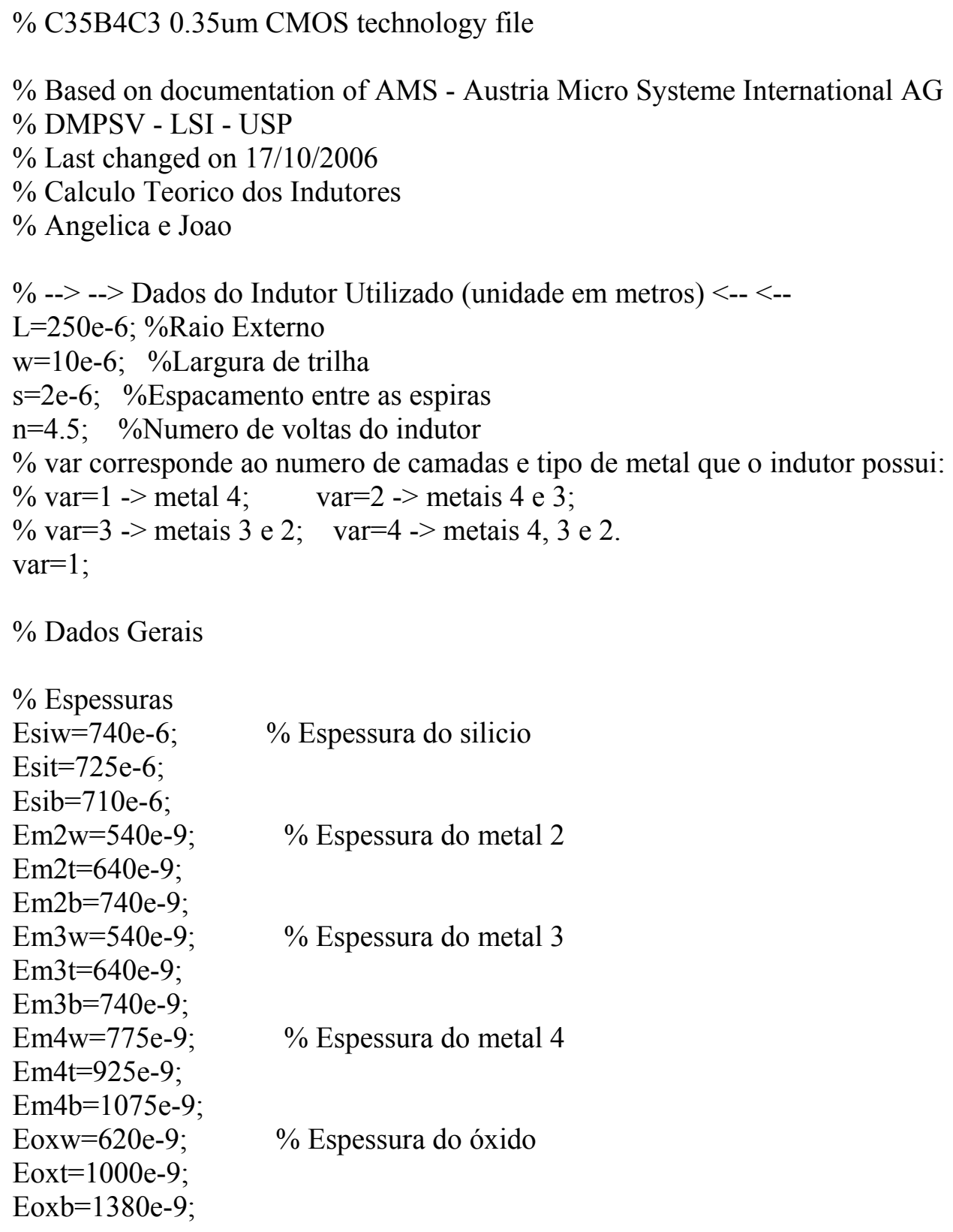




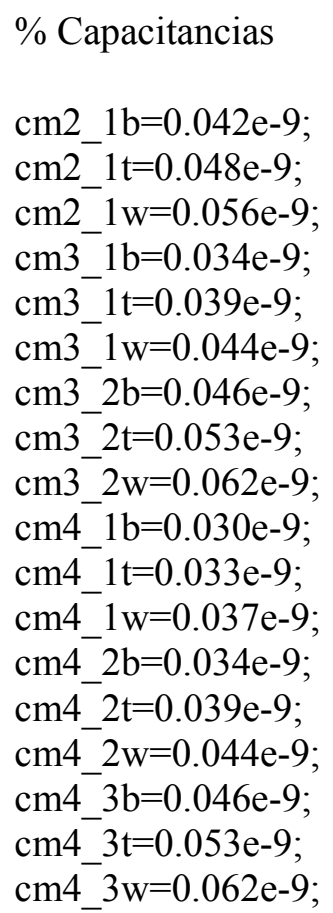

$\%$ Resistividade do silicio

$\mathrm{Rsib}=24 \mathrm{e}-2$;

Rsit=19e-2;

Rsiw $=14 \mathrm{e}-2$;

$\%$ Resistencias de Folha

$\mathrm{Rm} 2 \mathrm{t}=80 \mathrm{e}-3$; $\quad \%$ Metal 2

$\mathrm{Rm} 2 \mathrm{w}=150 \mathrm{e}-3$;

$\mathrm{Rm} 3 \mathrm{t}=80 \mathrm{e}-3 ; \quad \%$ Metal 3

$\mathrm{Rm} 3 \mathrm{w}=150 \mathrm{e}-3$;

$\mathrm{Rm} 4 \mathrm{t}=40 \mathrm{e}-3 ; \quad \%$ Metal 4

$\mathrm{Rm} 4 \mathrm{w}=100 \mathrm{e}-3$;

$\%$ Dados úteis

Eox $=3.45 \mathrm{e}-11$;

$\mathrm{Esi}=1.04 \mathrm{e}-10$

$\mathrm{mi}=4 * \mathrm{pi}^{*} 1 \mathrm{e}-7$;

$\%$ Resistividade do metal

Rom $2 \mathrm{t}=\mathrm{Rm} 2 \mathrm{t} * \mathrm{Em} 2 \mathrm{t} ; \quad \%$ Metal 2

Rom $2 b=R m 2 t * E m 2 t ;$

$\mathrm{Rom} 2 \mathrm{w}=\mathrm{Rm} 2 \mathrm{w} * \mathrm{Em} 2 \mathrm{w}$;

Rom $3 \mathrm{t}=\mathrm{Rm} 3 \mathrm{t} * \mathrm{Em} 3 \mathrm{t} ; \quad$ \% Metal 3

Rom $3 b=R m 3 t * E m 3 t ;$

$\mathrm{Rom} 3 \mathrm{w}=\mathrm{Rm} 3 \mathrm{w} * \mathrm{Em} 3 \mathrm{w}$;

Rom $4 \mathrm{t}=\mathrm{Rm} 4 \mathrm{t} * \mathrm{Em} 4 \mathrm{t} ; \quad \%$ Metal 4

Rom $4 b=R m 4 t * E m 4 t$; 


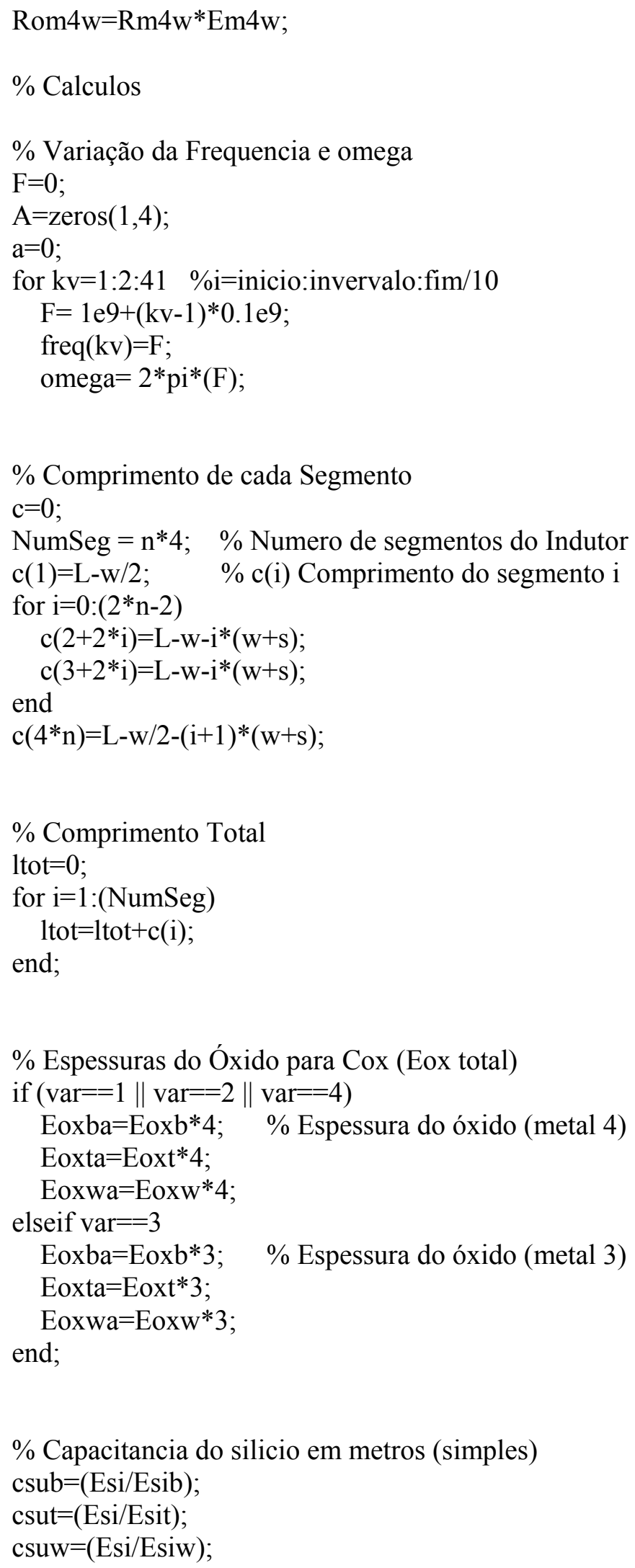




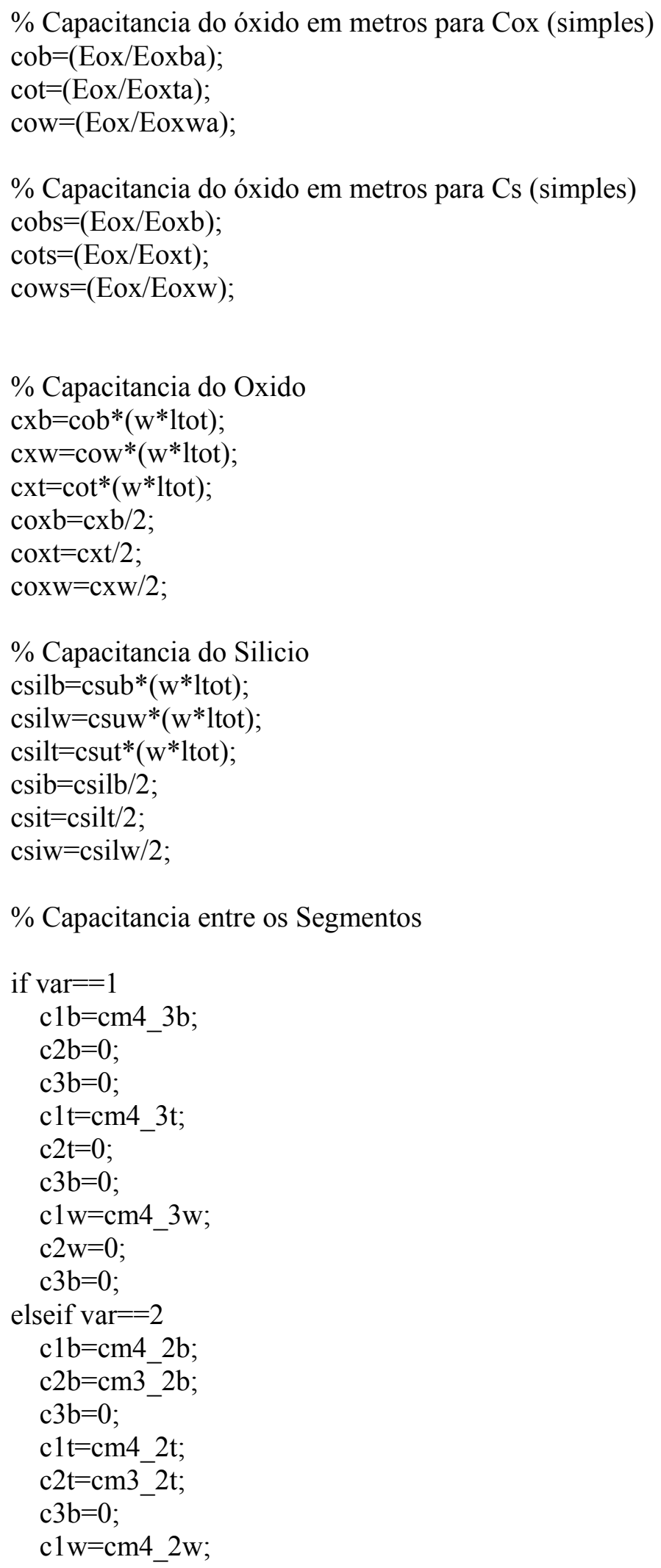




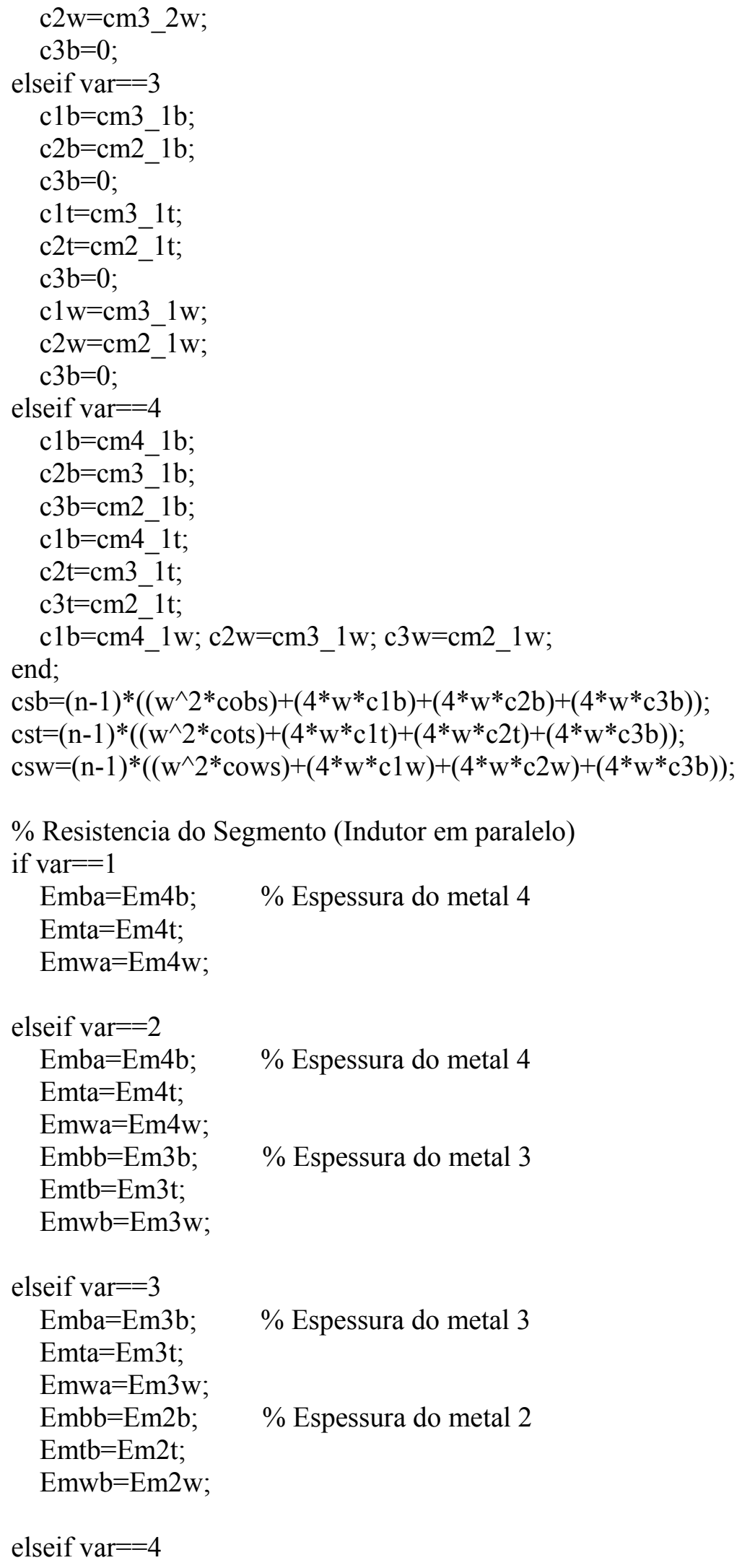




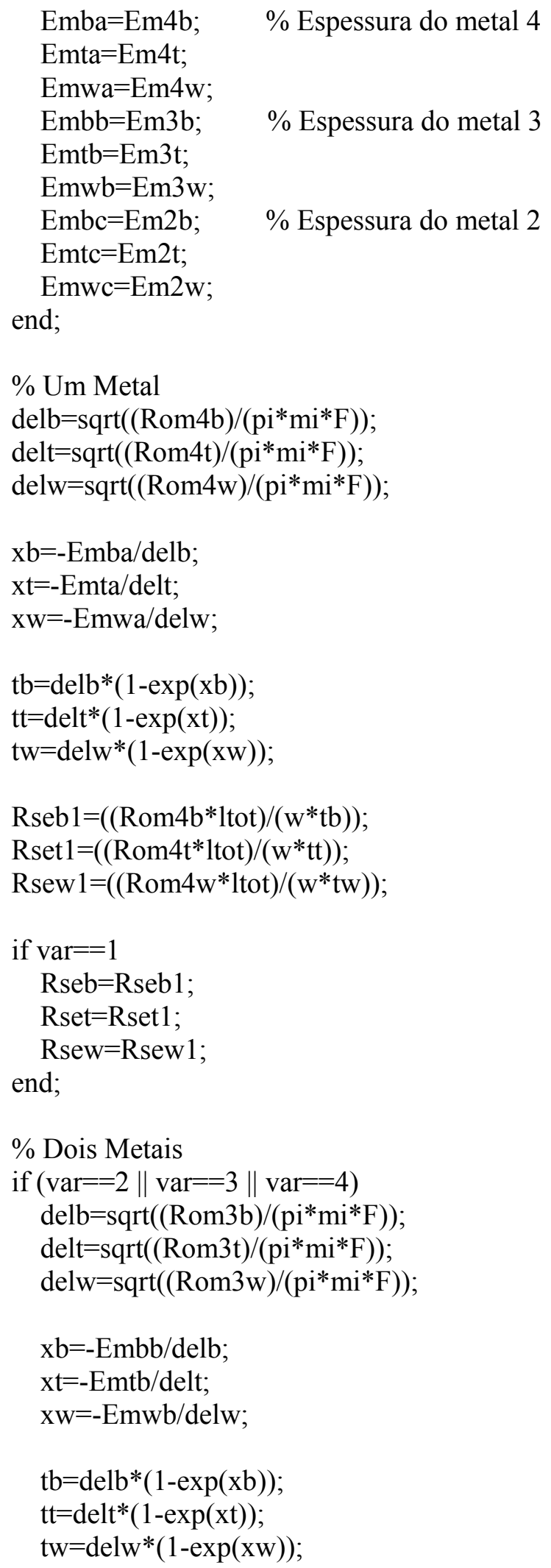




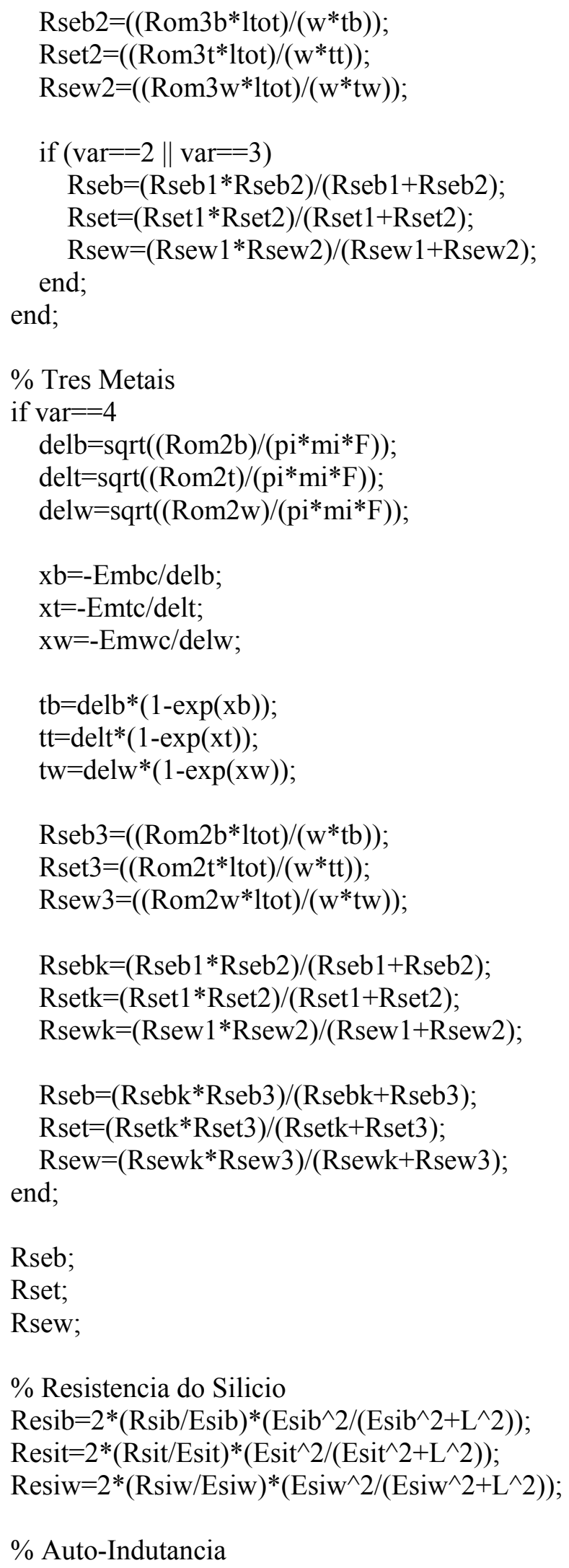




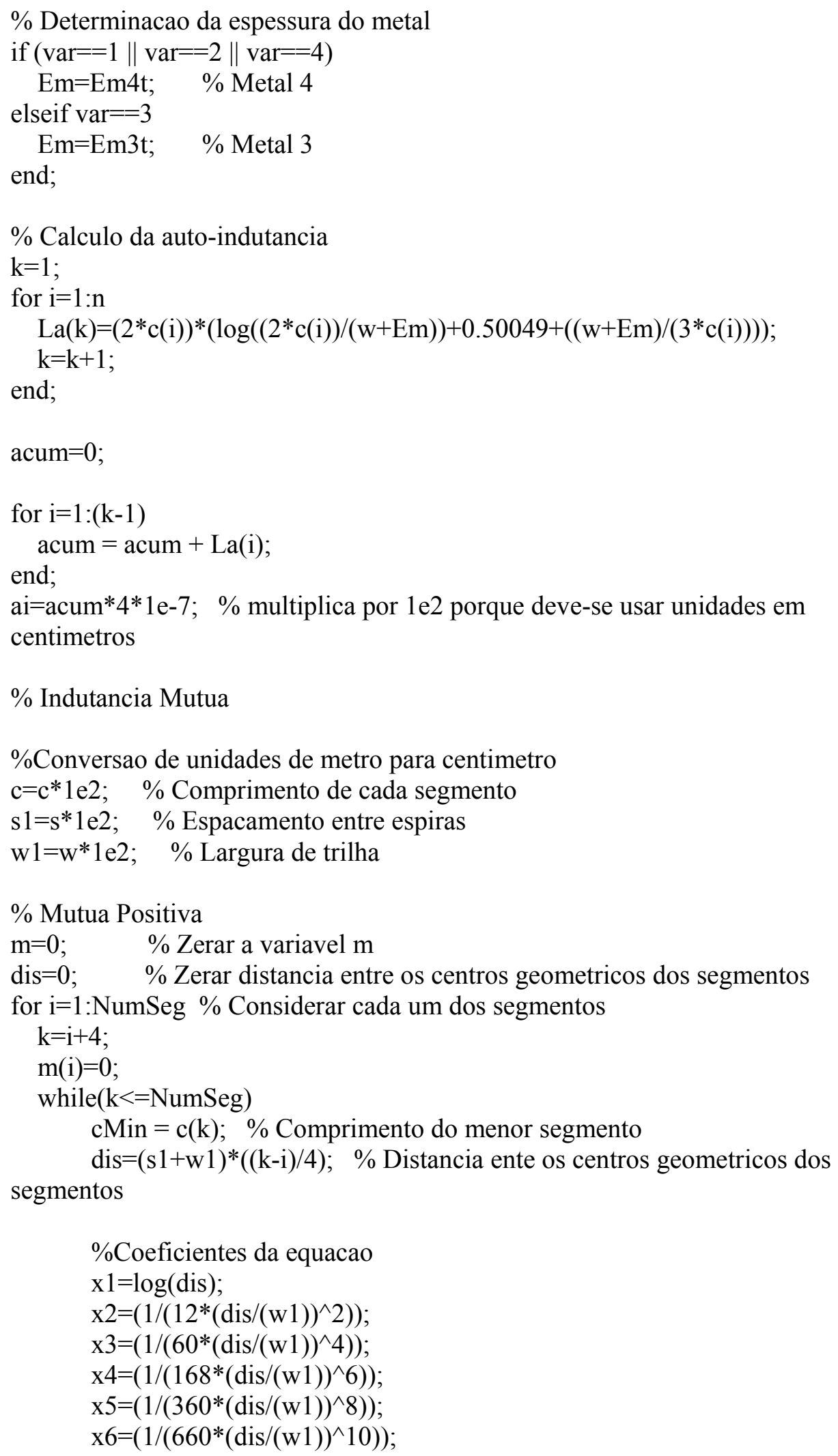


$\mathrm{x}=\mathrm{x} 1-(\mathrm{x} 2+\mathrm{x} 3+\mathrm{x} 4+\mathrm{x} 5+\mathrm{x} 6) ;$

$\mathrm{GMD}=\exp (\mathrm{x}) ; \quad \%$ Geometric Mean Distance

phi $=\log \left((\mathrm{cMin} / \mathrm{GMD})+\operatorname{sqrt}\left(\left(1+(\mathrm{cMin})^{\wedge} 2 /(\mathrm{GMD})^{\wedge} 2\right)\right)\right)-(1+\operatorname{sqrt}((\mathrm{GMD}) \wedge 2 /$

$\left.\left.(\mathrm{cMin})^{\wedge} 2\right)\right)+(\mathrm{GMD} / \mathrm{cMin})$;

MutTemp $=2 *$ cMin*phi;

$\mathrm{m}(\mathrm{i})=\mathrm{m}(\mathrm{i})+$ MutTemp;

end

$\mathrm{k}=\mathrm{k}+4$;

end

m;

mutpos $=0$;

for $\mathrm{i}=1$ :NumSeg

mutpos $=$ mutpos $+\mathrm{m}(\mathrm{i})$;

end;

mutpos=mutpos*1e-9;

$\%$ Mutua Negativa

$\mathrm{m}=0 ; \quad \%$ Zerar a variavel $\mathrm{m}$

dis $=0 ; \quad \%$ Zerar distancia entre os centros geometricos dos segmentos

MutTemp $=0 ; \quad \%$ Zerar a variavel temporaria

for $\mathrm{i}=1$ :NumSeg $\%$ Considerar cada um dos segmentos

$\mathrm{k}=\bmod (\mathrm{i}, 4)+2$;

$\mathrm{m}(\mathrm{i})=0$;

while $(\mathrm{k}<=$ NumSeg)

$\mathrm{cMin}=\min (\mathrm{c}(\mathrm{k}), \mathrm{c}(\mathrm{i})) ; \quad \%$ Comprimento do menor segmento

dis $=(\mathrm{L}-\mathrm{w}-(\mathrm{fix}((\mathrm{i}-1) / 4)+\mathrm{fix}((\mathrm{k}-1) / 4)) *(\mathrm{w}+\mathrm{s})) * 1 \mathrm{e} 2 ; \%$ Distancia ente os centros

geometricos dos segmentos

$\%$ Coeficientes da equacao

$\mathrm{x} 1=\log ($ dis $)$;

$\mathrm{x} 2=\left(1 /\left(12^{*}(\operatorname{dis} /(\mathrm{w} 1))^{\wedge} 2\right)\right)$;

$\mathrm{x} 3=\left(1 /\left(60^{*}(\operatorname{dis} /(\mathrm{w} 1))^{\wedge} 4\right)\right)$;

$\mathrm{x} 4=\left(1 /\left(168 *(\operatorname{dis} /(\mathrm{w} 1))^{\wedge} 6\right)\right)$;

$\mathrm{x} 5=\left(1 /\left(360 *(\operatorname{dis} /(\mathrm{w} 1))^{\wedge} 8\right)\right)$;

$x 6=\left(1 /\left(660 *(\operatorname{dis} /(w 1))^{\wedge} 10\right)\right)$;

$\mathrm{x}=\mathrm{x} 1-(\mathrm{x} 2+\mathrm{x} 3+\mathrm{x} 4+\mathrm{x} 5+\mathrm{x} 6)$

$\mathrm{GMD}=\exp (\mathrm{x}) ; \quad \%$ Geometric Mean Distance

phi $=\log \left((\mathrm{cMin} / \mathrm{GMD})+\operatorname{sqrt}\left(\left(1+(\mathrm{cMin})^{\wedge} 2 /(\mathrm{GMD})^{\wedge} 2\right)\right)\right)-$

$\left(1+\operatorname{sqrt}\left((\mathrm{GMD})^{\wedge} 2 /(\mathrm{cMin})^{\wedge} 2\right)\right)+(\mathrm{GMD} / \mathrm{cMin}) ;$

MutTemp $=2 *$ cMin $*$ phi;

$\mathrm{m}(\mathrm{i})=\mathrm{m}(\mathrm{i})+$ MutTemp;

end

$\mathrm{k}=\mathrm{k}+4$;

end

$\mathrm{m}$; 


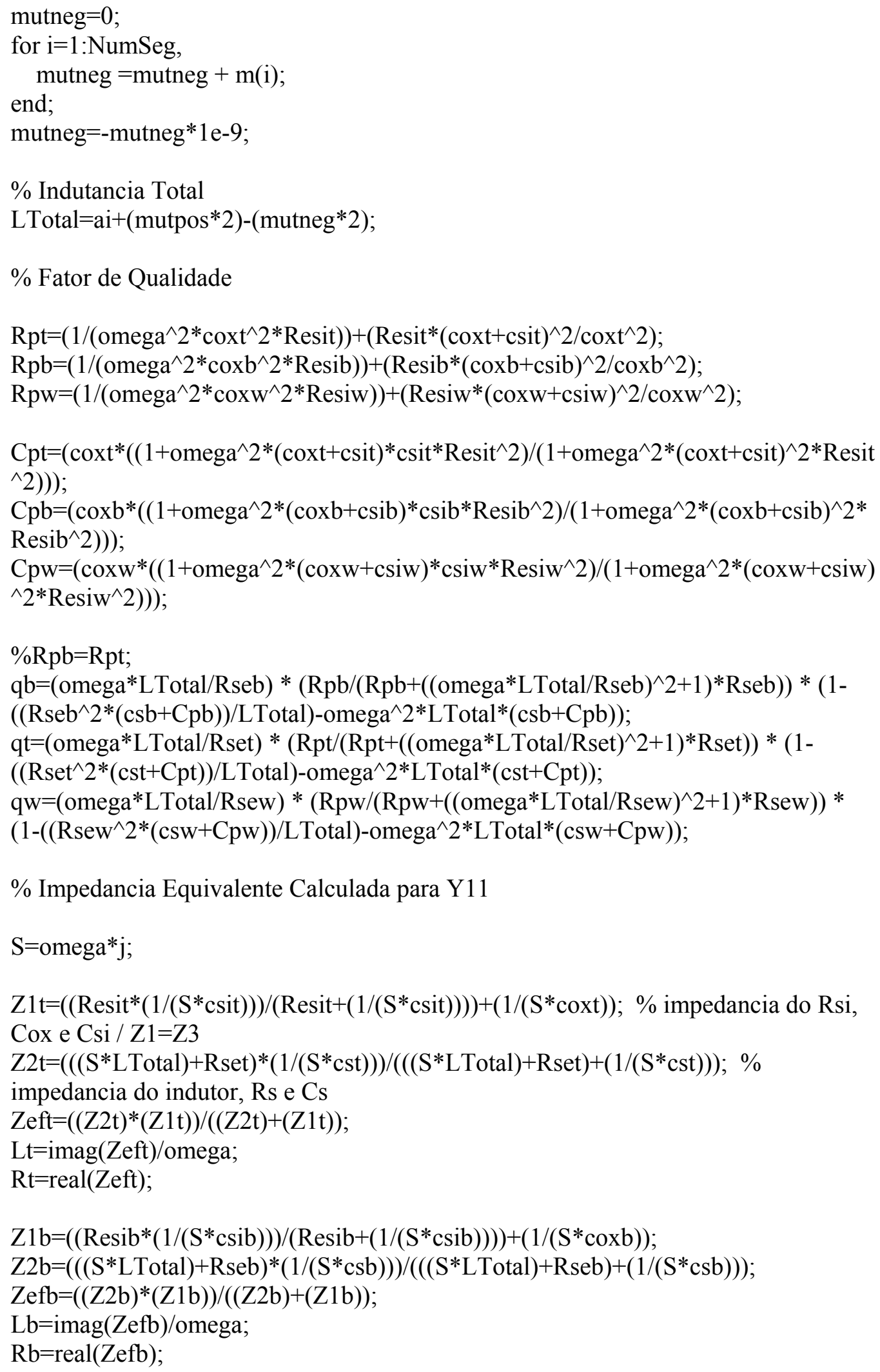


$\mathrm{Z} 1 \mathrm{w}=((\operatorname{Resiw} *(1 /(\mathrm{S} * \operatorname{csiw}))) /(\operatorname{Resiw}+(1 /(\mathrm{S} * \operatorname{csiw}))))+(1 /(\mathrm{S} * \operatorname{coxw})) ;$

$\mathrm{Z} 2 \mathrm{w}=(((\mathrm{S} * \mathrm{LTotal})+\mathrm{Rsew}) *(1 /(\mathrm{S} * \mathrm{csw}))) /(((\mathrm{S} * \mathrm{LTotal})+\mathrm{Rsew})+(1 /(\mathrm{S} * \operatorname{csw})))$;

$\mathrm{Zefw}=\left((\mathrm{Z} 2 \mathrm{w})^{*}(\mathrm{Z} 1 \mathrm{w})\right) /((\mathrm{Z} 2 \mathrm{w})+(\mathrm{Z} 1 \mathrm{w}))$;

$\mathrm{Lw}=\mathrm{imag}(\mathrm{Zefw}) /$ omega;

$\mathrm{Rw}=\operatorname{real}(\mathrm{Zefw})$; 


\section{ANEXO C - Estrutura de Teste Simples - Associação Série e Paralelo de Quadripolos}

Para determinar a matriz do indutor sem a interferência das impedâncias parasitas da estrutura de teste, devemos desmembrar o modelo equivalente da estrutura de teste mais o indutor nos quadripolos que o compões (cinco quadripolos). A Figura 60 ilustra o modelo equivalente para a estrutura simples, o chamado quadripolo $\mathbf{Z}$.

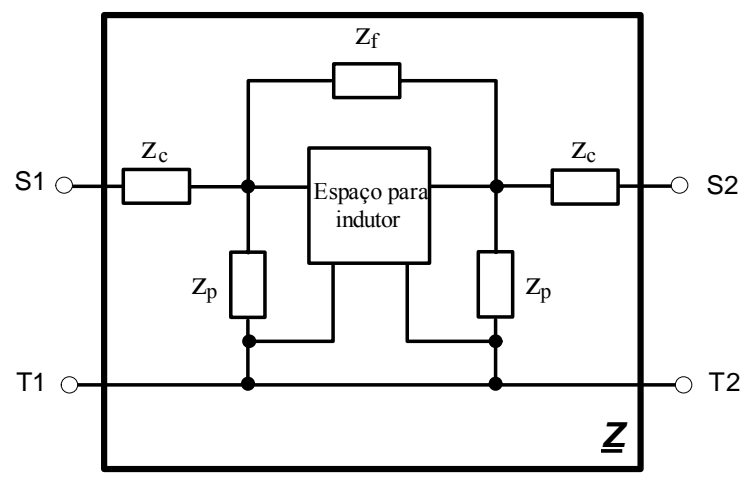

Figura 60 - Quadripolo Z: modelo equivalente das impedâncias da estrutura simples.

$\mathrm{O}$ quadripolo $\mathbf{Z}$ pode ser visto como formado pela associação série de dois outros quadripolos, como ilustra a Figura 61. São estes o quadripolo $\mathbf{Z}_{\mathbf{c}}$ ', com matriz de impedâncias $\left[\begin{array}{cc}z_{c} & 0 \\ 0 & z_{c}\end{array}\right]$, e o quadripolo $\mathbf{Z}$ '.

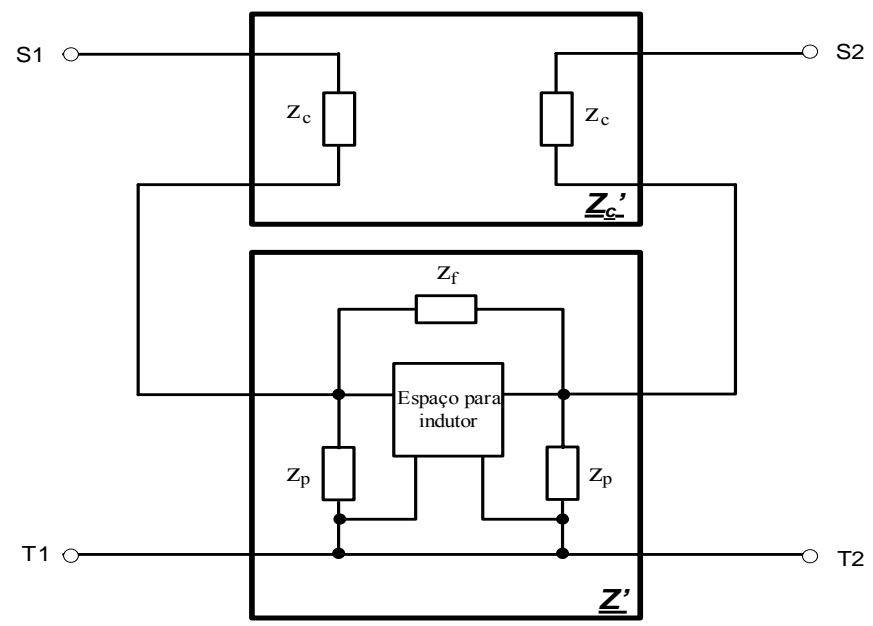

Figura 61 - Quadripolo Z: associação série entre $Z_{c}^{\prime}$ e Z'. 
Dado que $\mathbf{Z}$ é a associação série de $\mathbf{Z}_{\mathbf{c}}$ ' com $\mathbf{Z}$ ', podemos escrever a seguinte relação entre matrizes de impedâncias:

$Z=Z_{c}^{\prime}+Z^{\prime}$ onde $Z, Z_{c}^{\prime}$ e $Z$ ' são as matrizes de impedâncias dos quadripolos $\mathbf{Z}$ e $\mathbf{Z}_{\mathbf{c}}$ ' e Z', respectivamente.

Ainda teremos

$$
Z^{\prime}=Z-Z_{c}^{\prime} \quad \text { e } \quad Z^{\prime}=\left[\begin{array}{ll}
Z_{11} & Z_{12} \\
Z_{21} & Z_{22}
\end{array}\right]-\left[\begin{array}{cc}
Z_{c} & 0 \\
0 & Z_{c}
\end{array}\right]
$$

O quadripolo Z’ pode ser visto, por sua vez, como formado pela associação paralela de dois outros quadripolos, como ilustra a Figura 62. São estes o quadripolos $\mathbf{Z}_{\mathbf{p}}$, com matriz de admitâncias $\left[\begin{array}{cc}1 / z_{p} & 0 \\ 0 & 1 / z_{p}\end{array}\right]$, e o quadripolo $\mathbf{Y}^{\prime}$. Observe que, no caso de associações em paralelo, é melhor se trabalhar com matrizes de admitâncias e que a relação entre as matrizes de impedâncias $\mathrm{Z}$ e admitâncias $\mathrm{Y}$ de um quadripolo é $\mathrm{Z}=\mathrm{Y}^{-1}$.

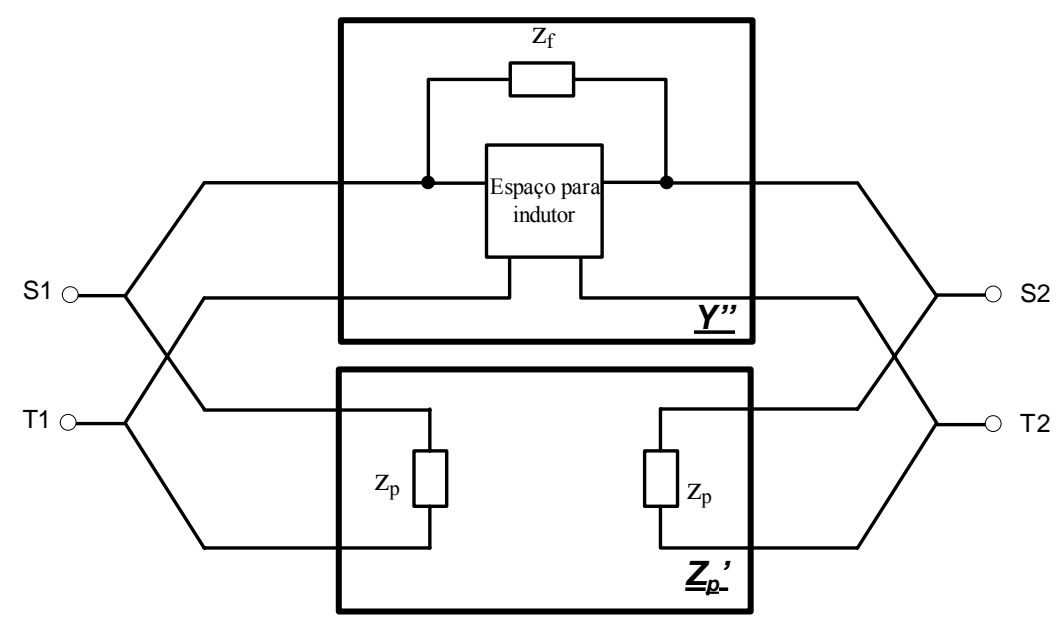

Figura 62 - Quadripolo $Y^{\prime}$ : associação paralela entre $Z_{p}$ ' e $Y^{\prime \prime}$.

Dado que Z' é a associação paralela de $\mathbf{Z}_{\mathbf{p}}$ ' com $\mathbf{Y}$ ', podemos escrever a seguinte relação entre matrizes de admitâncias:

$Y^{\prime}=Y^{\prime \prime}+Y_{p}^{\prime}$, onde $Y^{\prime}=Z^{,-1}, Y^{\prime \prime}$ e $Y_{p}^{\prime}$ são as matrizes de admitâncias dos quadripolos $\mathbf{Y}^{\prime}, \mathbf{Y}^{\prime}$ ' e $\mathbf{Z}_{\mathbf{P}}$ '.

Ainda teremos 


$$
Y^{\prime \prime}=Y^{\prime}-Y_{p}^{\prime} \quad \text { e } \quad Y^{\prime \prime}=\left[\begin{array}{ll}
y_{11}^{\prime} & y_{12}^{\prime} \\
y_{21}^{\prime} & y_{22}^{\prime}
\end{array}\right]-\left[\begin{array}{cc}
1 / z_{p} & 0 \\
0 & 1 / z_{p}
\end{array}\right]
$$

$\mathrm{O}$ quadripolo $\mathbf{Z}_{\mathbf{p}}$ ' pode ser visto como formado pela associação paralela de dois outros quadripolos, como ilustra a Figura 63. São estes o quadripolos $\mathbf{Z}_{\mathbf{f}}$, com matriz de admitâncias $\left[\begin{array}{cc}1 / z_{f} & -1 / z_{f} \\ -1 / z_{f} & 1 / z_{f}\end{array}\right]$, e o quadripolo $\mathbf{Y}$ ', ' que é o próprio indutor.

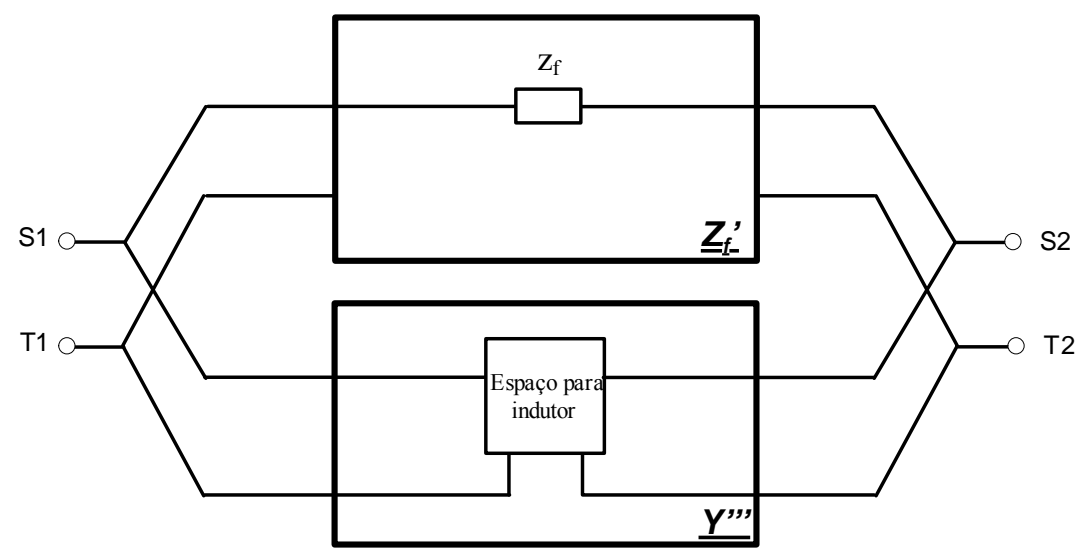

Figura 63 - Quadripolo Y',: associação paralela entre $Z_{f}^{\prime}$ e $Y^{\prime \prime \prime}$ '.

Dado que $\mathbf{Z}_{\mathbf{p}}$ ' é a associação paralela de $\mathbf{Z}_{\mathbf{f}}$ ' com $\mathbf{Y}$ '’', podemos escrever a seguinte relação entre matrizes de admitâncias:

$$
Y^{\prime \prime}=Y^{\prime \prime \prime}-\left(z_{f}^{\prime}\right) \text { e } Y^{\prime \prime \prime}=\left[\begin{array}{ll}
y_{11}^{\prime \prime} & y_{12}^{\prime \prime} \\
y_{21}^{\prime \prime} & y_{22}^{\prime \prime}
\end{array}\right]-\left[\begin{array}{cc}
1 / z_{f} & -1 / z_{f} \\
-1 / z_{f} & 1 / z_{f}
\end{array}\right]
$$

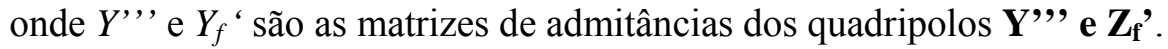

Como conclusão, para obter a matriz $Y^{\text {,', }}$ do indutor a partir de $Z$ basta realizar as operações das equações 32, 33 e 34 .

Para determinar a matriz do indutor implementado na estrutura completa, utiliza-se um procedimento semelhante ao mostrado aqui. 


\section{ANEXO D - Estruturas de Teste (MATLAB)}

Neste anexo está apresentado o arquivo utilizado no MATLAB para cálculo dos elementos parasitas das estruturas de testes e sua eliminação das medidas.

\section{Estrutura Simples:}

\% Subtração de Parametros dos pads dos indutores

$\%$ Arquivo para a Estrutura Simples

$\% 19 / 12 / 2006$

$\%$ Angelica dos Anjos

\% Dados dos Indutores em $\mathrm{Z}$ em real e imag (no excel abrir os dados delimitado por espaço; trocar . por ,);

\% Salvar como arquivo do matlab com qqer nome; trocar, por .; save

"MatrizIndutor".

clc;

clear all;

$\%$ Carrega matrizes

load MatrizShortOpen

load MatrizOpen

load MatrizIndutor

MatrizShortOpen=[MatrizShortOpen(:,1)+j*MatrizShortOpen(:,2)

MatrizShortOpen(:,3)+j*MatrizShortOpen $(:, 4)$

MatrizShortOpen $(:, 5)+\mathrm{j} *$ MatrizShortOpen $(:, 6)$

MatrizShortOpen $(:, 7)+\mathrm{j} *$ MatrizShortOpen $(:, 8)]$;

MatrizOpen $=[$ MatrizOpen $(:, 1)+\mathrm{j} *$ MatrizOpen $(:, 2)$

MatrizOpen(:,3)+j*MatrizOpen(:,4) MatrizOpen(:,5)+j*MatrizOpen(:,6)

MatrizOpen(:,7)+j*MatrizOpen(:,8)];

MatrizIndutor $=[$ MatrizIndutor $(:, 1)+j *$ MatrizIndutor $(:, 2)$

MatrizIndutor(:,3)+j*MatrizIndutor(:,4) MatrizIndutor(:,5)+j*MatrizIndutor(:,6)

MatrizIndutor(:,7)+j*MatrizIndutor(:,8)];

tamanho=size(MatrizShortOpen);

Admitancia_Medida=[]; \%Corresponde ao valor da MatrizIndutorutancia

$\%$ inicio do processo

for $\mathrm{i}=1: \operatorname{tamanho}(1)$, 
\%Ler as matrizes e transformá-las em matriz quadrada MatrizShortOpen_temp=[MatrizShortOpen $(i, 1)$ MatrizShortOpen(i,3);

MatrizShortOpen(i,2) MatrizShortOpen(i,4) ];

MatrizOpen_temp=[MatrizOpen(i,1) MatrizOpen(i,3); MatrizOpen(i,2)

MatrizOpen $(\bar{i}, 4)]$;

MatrizIndutor_temp=[MatrizIndutor(i,1) MatrizIndutor(i,3); MatrizIndutor(i,2)

MatrizIndutor(i,4) ];

$\% * * * * * * * * * * * * * * *$ Short Open

\%Importantíssimo saber a ordem das pontas de prova (S11 e S22)

$\% \% \% \% \% \% \% \% \% \% \%$ Este caso foi S22 para curto

\%Determinar Zc e Zp:

$\mathrm{Zc}=$ MatrizShortOpen_temp $(2,2)$;

$\mathrm{Zp}=$ MatrizShortOpen_temp $(1,1)-\mathrm{Zc}$;

$\% * * * * * * * * * * * * * * * *$ Open

\%Subtrair Zc para achar Z':

Zlo=MatrizOpen_temp -[Zc 0; 0 Zc];

\%Transformar Z' em Y'

Ylo=inv(Zlo);

\%Subtrair Zp para achar Y":

Yllo=Ylo-[1/Zp 0; 0 1/Zp];

\%Determinar Zf:

$\mathrm{Zf}=-2 /(\mathrm{Yllo}(1,2)+\mathrm{Yllo}(2,1))$;

$\% * * * * * * * * * * * * * * *$ MatrizIndutorutor

\%Subtrair Zc para achar Z'

ZlI=MatrizIndutor_temp-[Zc 0; 0 Zc];

\%Transformar Z' em Y'

YlI $=\operatorname{inv}(Z 1 \mathrm{I})$;

\%Subtrair Zp para achar Y":

YllI=Y1I-[1/Zp 0; 0 1/Zp];

\%Subtrair Zf para achar Ydut:

Ydut=Y11I-[1/Zf -1/Zf; -1/Zf 1/Zf];

\%Escrever o valor da admitância medida

Admitancia_Medida=[Admitancia_Medida; Ydut $(1,1) \operatorname{Ydut}(2,1) \operatorname{Ydut}(1,2)$

Ydut $(2,2)]$;

end

\% Admitancia_Medida - Valores organizados em [Y11 Y21 Y12 Y22] 
\% Transformação em dados para o Sonnet em Y

\% Não estará com a freq, tem que colocar igual a q vem do analisador

real (Admitancia_Medida);

imag (Admitancia_Medida);

re=real (Admitancia_Medida);

im=imag (Admitancia_Medida);

format short;

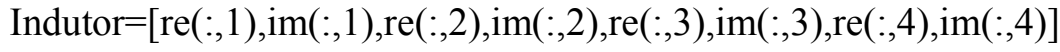

\section{Estrutura com metal 1:}

\% Subtração de Parametros dos pads dos indutores

$\% 19 / 12 / 2006$

$\%$ Angelica dos Anjos

\% Dados dos Indutores em $\mathrm{Z}$ em real e imag (no excel abrir os dados delimitado por espaço; trocar . por ,);

\% Salvar como arquivo do matlab com qqer nome; trocar, por .; save

"MatrizIndutor".

clc;

clear all;

$\%$ Carrega matrizes

load MatrizShortOpen

load MatrizShort

load MatrizOpen

load MatrizIndutor

MatrizShortOpen=[MatrizShortOpen(:,1)+j*MatrizShortOpen(:,2)

MatrizShortOpen $(:, 3)+\mathrm{j} *$ MatrizShortOpen(:,4)

MatrizShortOpen $(:, 5)+\mathrm{j} *$ MatrizShortOpen $(:, 6)$

MatrizShortOpen(:,7)+j*MatrizShortOpen(:,8)];

MatrizShort=[MatrizShort(:,1)+j*MatrizShort(:,2)

MatrizShort(:,3)+j*MatrizShort(:,4) MatrizShort(:,5)+j*MatrizShort(:,6)

MatrizShort(:,7)+j*MatrizShort(:,8)];

MatrizOpen=[MatrizOpen(:,1)+j*MatrizOpen(:,2)

MatrizOpen(:,3)+j*MatrizOpen(:,4) MatrizOpen(:,5)+j*MatrizOpen(:,6)

MatrizOpen(:,7)+j*MatrizOpen(:,8)];

MatrizIndutor $=[$ MatrizIndutor $(:, 1)+\mathrm{j} *$ MatrizIndutor $(:, 2)$

MatrizIndutor(:,3)+j*MatrizIndutor(:,4) MatrizIndutor(:,5)+j*MatrizIndutor(:,6)

MatrizIndutor(:,7)+j*MatrizIndutor(:,8)];

tamanho=size(MatrizShortOpen);

Admitancia_Medida $=[] ; \%$ Corresponde ao valor da indutancia 
\%inicio do processo

for $\mathrm{i}=1$ :tamanho(1),

$\%$ Ler as Matrizes

MatrizShortOpen_temp=[MatrizShortOpen(i,1) MatrizShortOpen(i,3);

MatrizShortOpen(i,2) MatrizShortOpen(i,4) ];

MatrizShort_temp=[MatrizShort(i,1) MatrizShort(i,3); MatrizShort(i,2)

MatrizShort $(\mathrm{i}, 4)]$;

MatrizOpen_temp=[MatrizOpen(i,1) MatrizOpen(i,3); MatrizOpen(i,2)

MatrizOpen $(\mathrm{i}, 4)]$;

MatrizIndutor_temp=[MatrizIndutor(i,1) MatrizIndutor(i,3); MatrizIndutor(i,2)

MatrizIndutor $(\mathrm{i}, 4)]$;

$\% * * * * * * * * * * * * * * *$ Short Open

$\%$ Determinar Zc e Zp:

$\mathrm{Zc}=$ MatrizShortOpen_temp $(2,2)$;

$\mathrm{Zp}=$ MatrizShortOpen_temp $(1,1)-Z \mathrm{c}$;

$\% * * * * * * * * * * * * * * *$ Short

\%Subtrair Zc para achar Z'

$\mathrm{Zl}=$ MatrizShort_temp-[Zc 0; $0 \mathrm{Zc}]$;

\%Transformar Z' em Y'

$\mathrm{Yl}=\operatorname{inv}(\mathrm{Zl})$;

\%Subtrair Zp para achar Y":

Yll=Yl-[1/Zp $0 ; 0$ 1/Zp];

\%Transformar Y" em Z"

$\mathrm{Zll}=\mathrm{inv}(\mathrm{Y} 11)$;

\%Determinar Z1 e Z2:

$\mathrm{Z} 1=\mathrm{Zll}(1,1)$;

$\mathrm{Z} 2=\mathrm{Zll}(2,2)$;

$\% * * * * * * * * * * * * * * * *$ Open

\%Subtrair Zc para achar Z':

Zlo=MatrizOpen_temp -[Zc 0; 0 Zc];

\%Transformar Z' em $Y^{\prime}$

Ylo=inv(Zlo);

\%Subtrair Zp para achar Y":

Yllo=Ylo-[1/Zp 0; 0 1/Zp];

\%Transformar Y" em Z"

Zllo=inv(Yllo); 
\%Subtrair Z1 e Z2 para achar Z"'

Zlllo=Zllo-[Z1 0; 0 Z2];

\%Transformar Z"' em Y'"

Ylllo=inv(Z1llo);

\%Determinar Zf, Z3 e Z4:

$\mathrm{Zf}=-2 /(\mathrm{Ylllo}(1,2)+\mathrm{Y} \operatorname{lllo}(2,1))$;

$\mathrm{Z3}=1 /(\mathrm{Y} 11 \mathrm{lo}(1,1)+(\mathrm{Y} 11 \mathrm{lo}(1,2) * 0.5)+(\mathrm{Y} 11 \mathrm{lo}(2,1) * 0.5))$

$Z 4=1 /($ Ylllo $(2,2)+($ Ylllo $(1,2) * 0.5)+($ Ylllo $(2,1) * 0.5)) ;$

$\% * * * * * * * * * * * * * * * * *$ Indutor

$\%$ Subtrair Zc para achar Z'

$\mathrm{ZlI}=$ MatrizIndutor_temp-[Zc 0; $0 \mathrm{Zc}]$;

\%Transformar Z' em $Y^{\prime}$

$\mathrm{Y} 1 \mathrm{I}=\operatorname{inv}(\mathrm{ZlI})$;

\%Subtrair Zp para achar Y":

$\mathrm{Y} 11 \mathrm{I}=\mathrm{Y} 1 \mathrm{II}-[1 / \mathrm{Zp}$ 0; 0 1/Zp];

\%Transformar Y" em Z":

$\mathrm{ZllI}=\operatorname{inv}(\mathrm{Y} 11 \mathrm{I})$;

\%Subtrair Z1 e Z2 para achar Z"':

Zl11I=Z11I-[Z1 0; 0 Z2];

\%Transformar Z"' em Y"':

$\mathrm{Y} 111 \mathrm{I}=\operatorname{inv}(\mathrm{Z} 111 \mathrm{I})$;

\%Subtrair Zf, Z3 e Z4 para achar Ydut:

$Z 11=1 / Z 3+1 / Z f$

$Z 12=-1 / Z f$

$\mathrm{Z} 21=-1 / \mathrm{Zf}$

$Z 22=1 / Z 4+1 / Z f$

Ydut=Y111I-[Z11 Z12; Z21 Z22];

\%Escrever o valor da admitância medida

Admitancia_Medida=[Admitancia_Medida; $Y \operatorname{dut}(1,1) \operatorname{Ydut}(2,1) \operatorname{Ydut}(1,2)$

Ydut(2,2)];

end

\% Admitancia_Medida - Valores organizados em [Y11 Y21 Y12 Y22]

\% Transformação em dados para o Sonnet em Y

\% Não estará com a freq, tem que colocar igual a q vem do analisador real (Admitancia_Medida);

imag (Admitancia_Medida);

re $=$ real (Admitancia_Medida); 
Anexo D 110

im=imag (Admitancia_Medida);

format short;

indutor=[re(:,1),im(:,1), re(:,2), $\operatorname{im}(:, 2), \operatorname{re}(:, 3), \operatorname{im}(:, 3), \operatorname{re}(:, 4), \operatorname{im}(:, 4)]$ 


\section{ANEXO E - Carta de Smith das Medidas do Indutor 3}

As Cartas de Smith do indutor 3, na estrutura de teste simples e completa, extraídas diretamente do analisador de redes HP 8722D estão apresentadas abaixo. As Figuras 64 e 65 são referentes à estrutura simples e as Figuras 66 e 67 são referentes à estrutura completa.

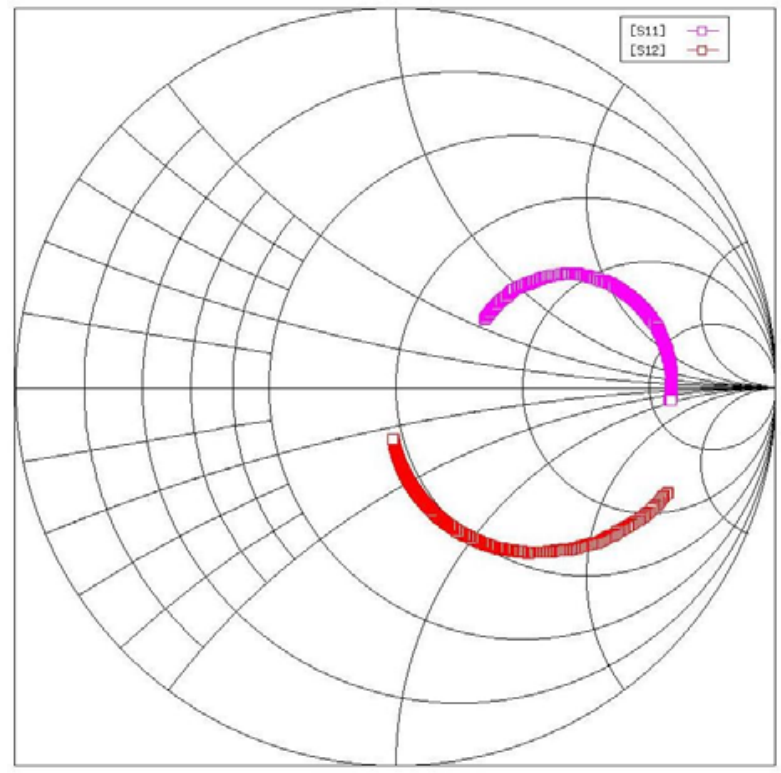

Figura 64 - Carta de Smith do ind3-simples - S11 e S12.

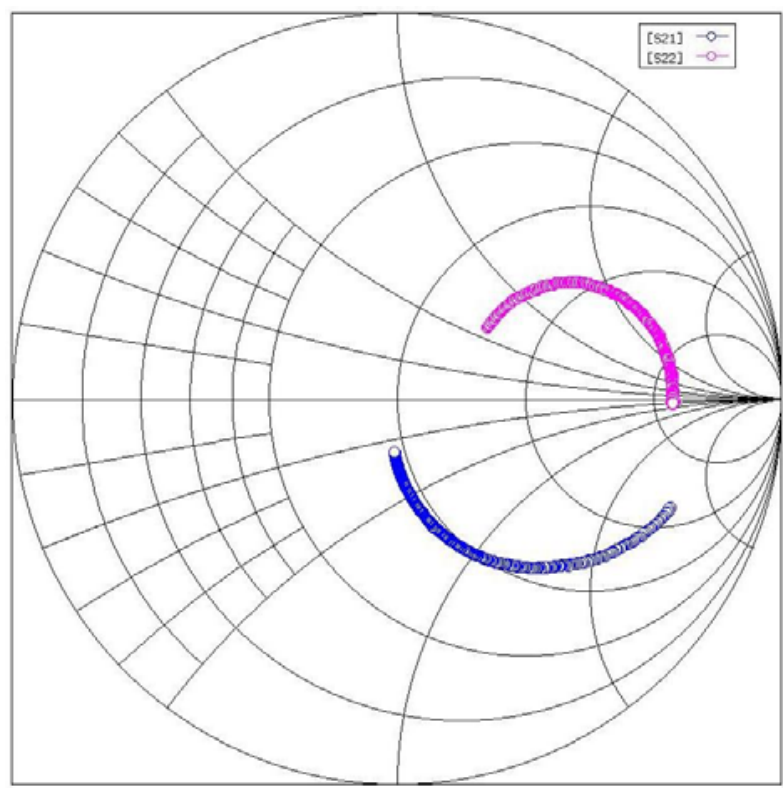

Figura 65 - Carta de Smith do ind3-simples - S21 e S22. 


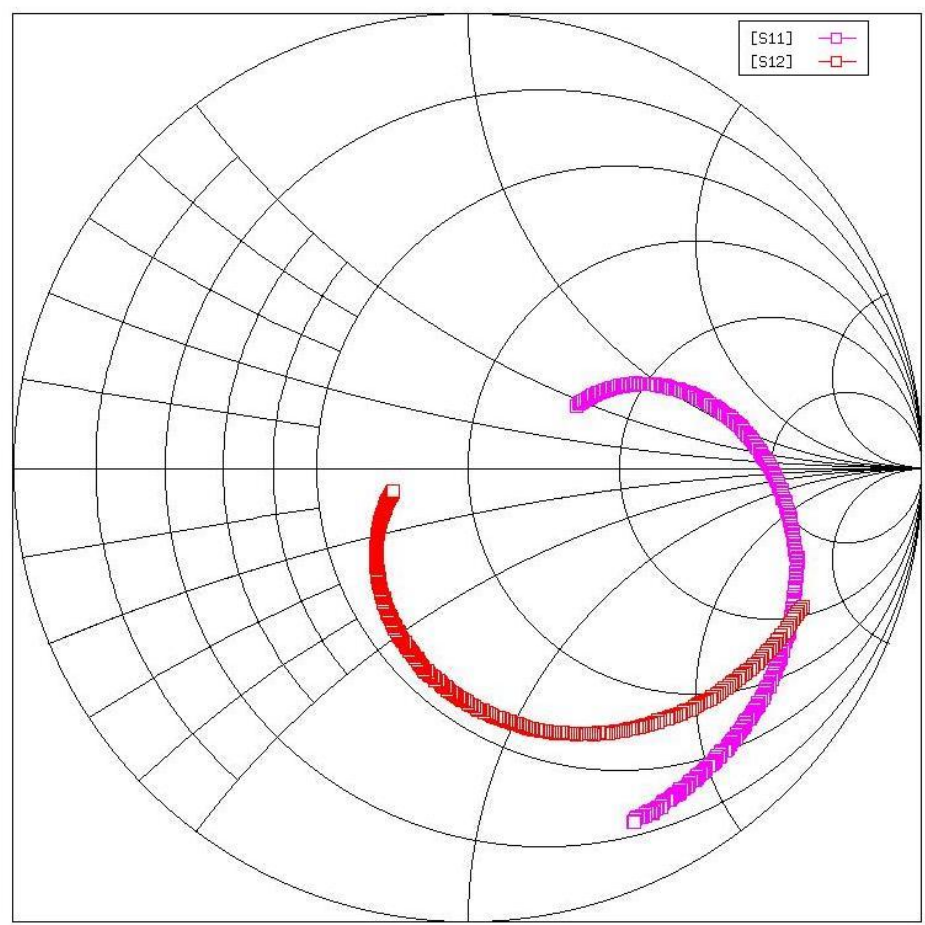

Figura 66 - Carta de Smith do ind3-completa - S11 e S12.

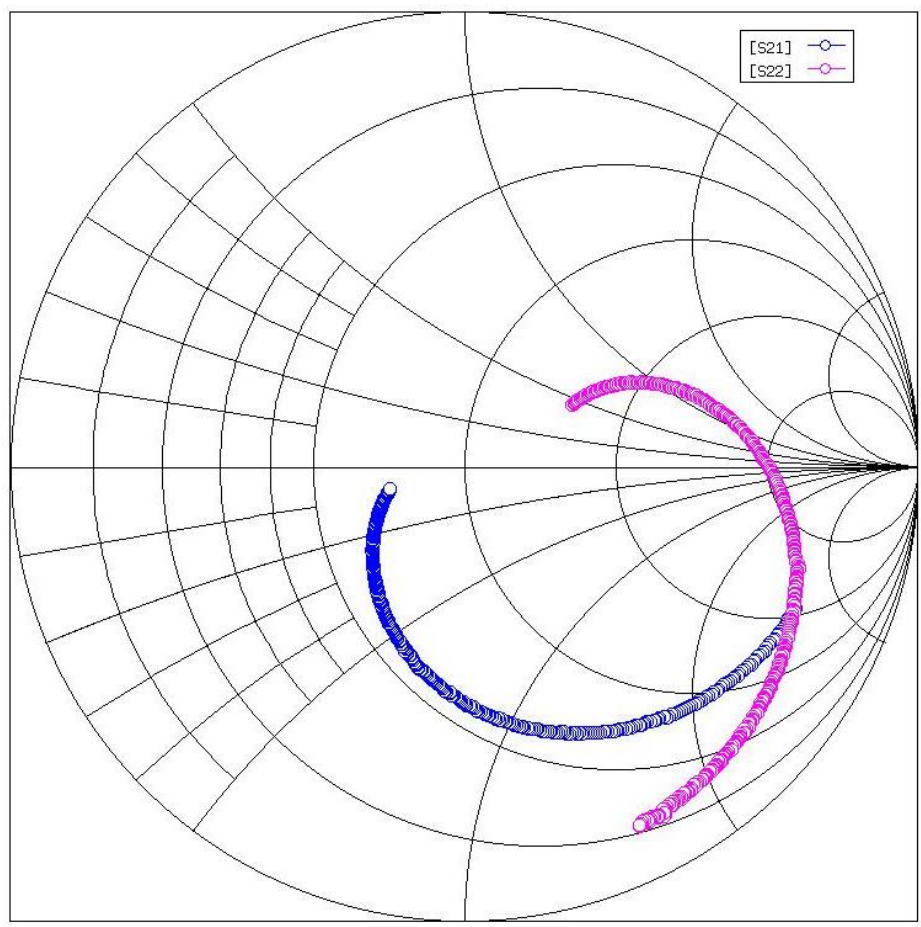

Figura 67 - Carta de Smith do ind3-completa - S21 e S22. 


\section{ANEXO F - Valores Medidos dos Elementos Parasitas}

Os valores dos elementos $z_{c}, z_{p}, z_{1}, z_{2}, z_{3}, z_{4}$, e $z_{f}$ (parte real e imaginária) em função da freqüência, para um dos chips testados (chip1), estão mostradas nas Figuras 68 a 74. Estas impedâncias variam de um chip para o outro, principalmente $z_{c}, z_{1}, z_{2}$ e $z_{f}$

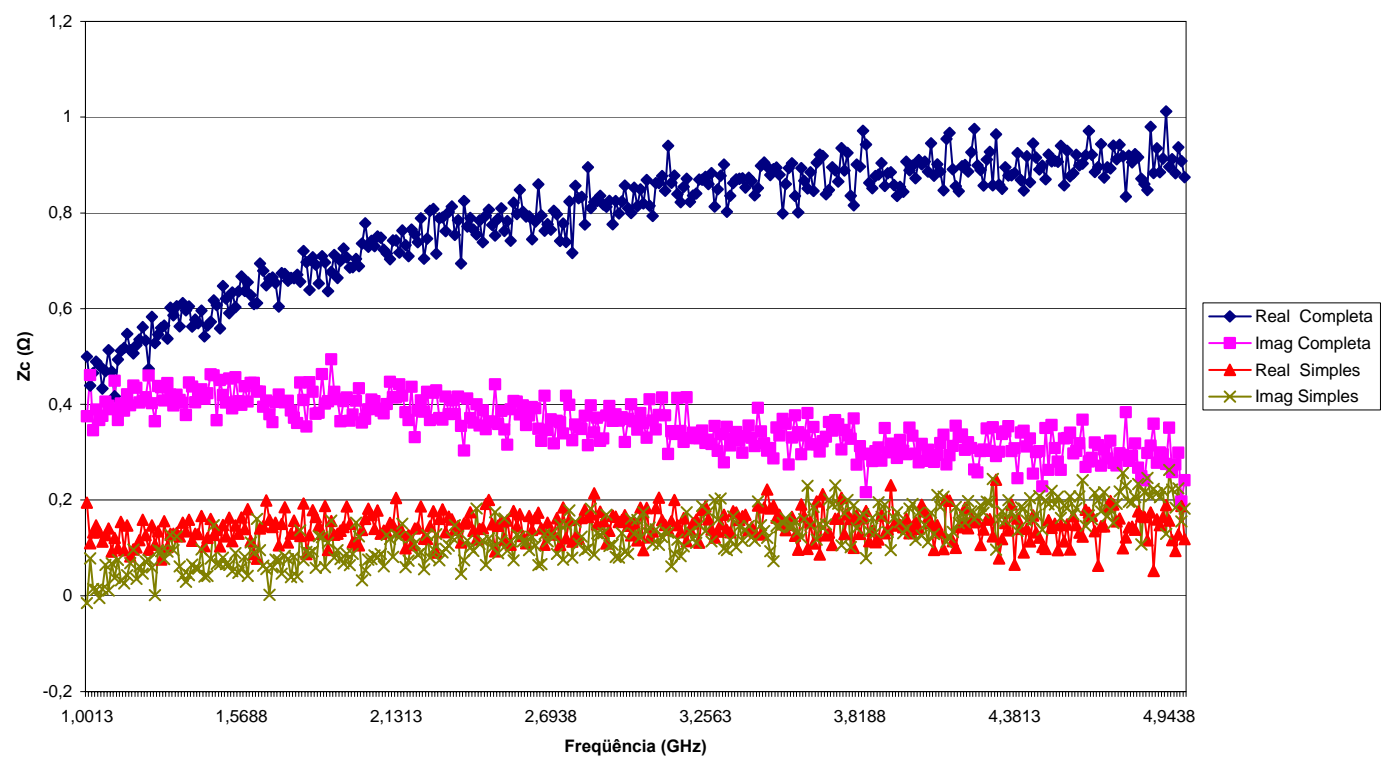

Figura 68 - Impedância $z_{c}$ em função da freqüência para as estruturas completa e simples.

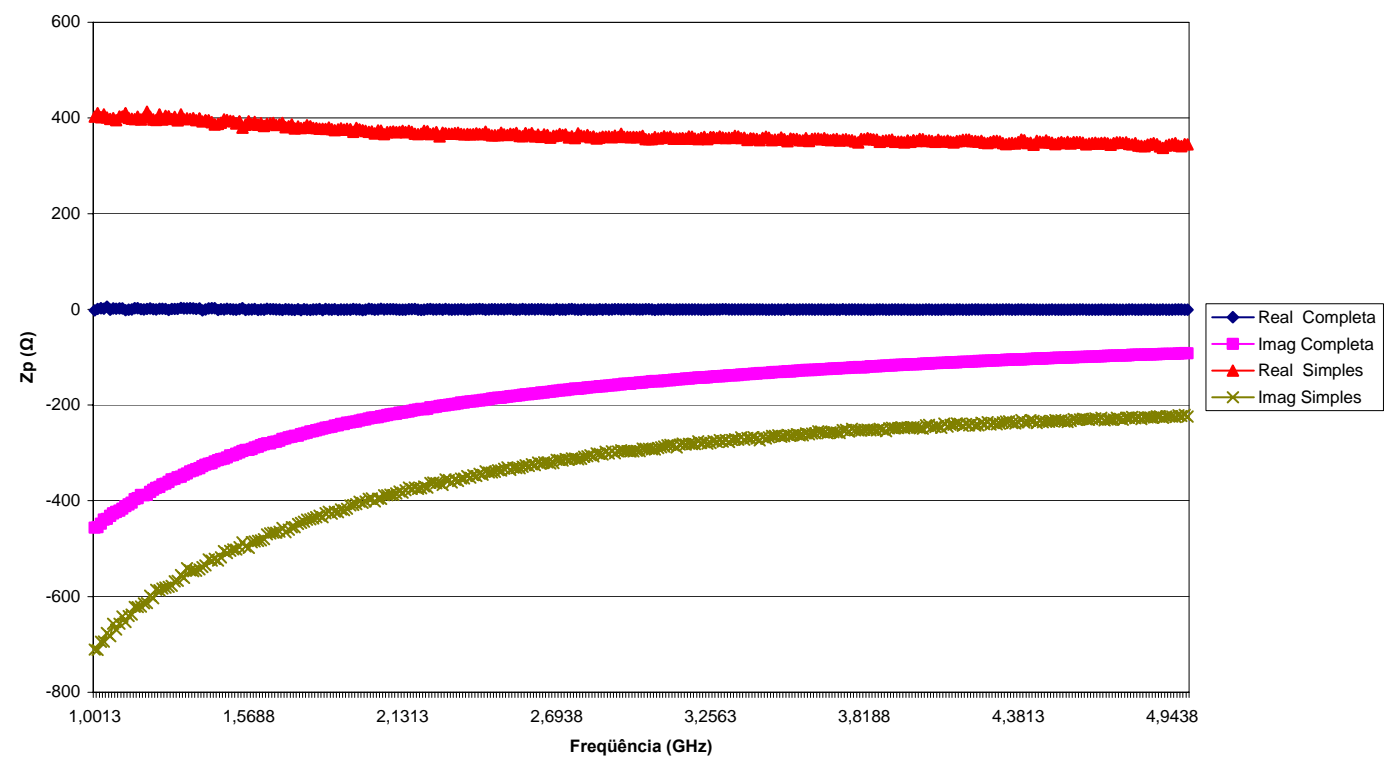

Figura 69 - Impedância $z_{p}$ em função da freqüência para as estruturas completa e simples. 


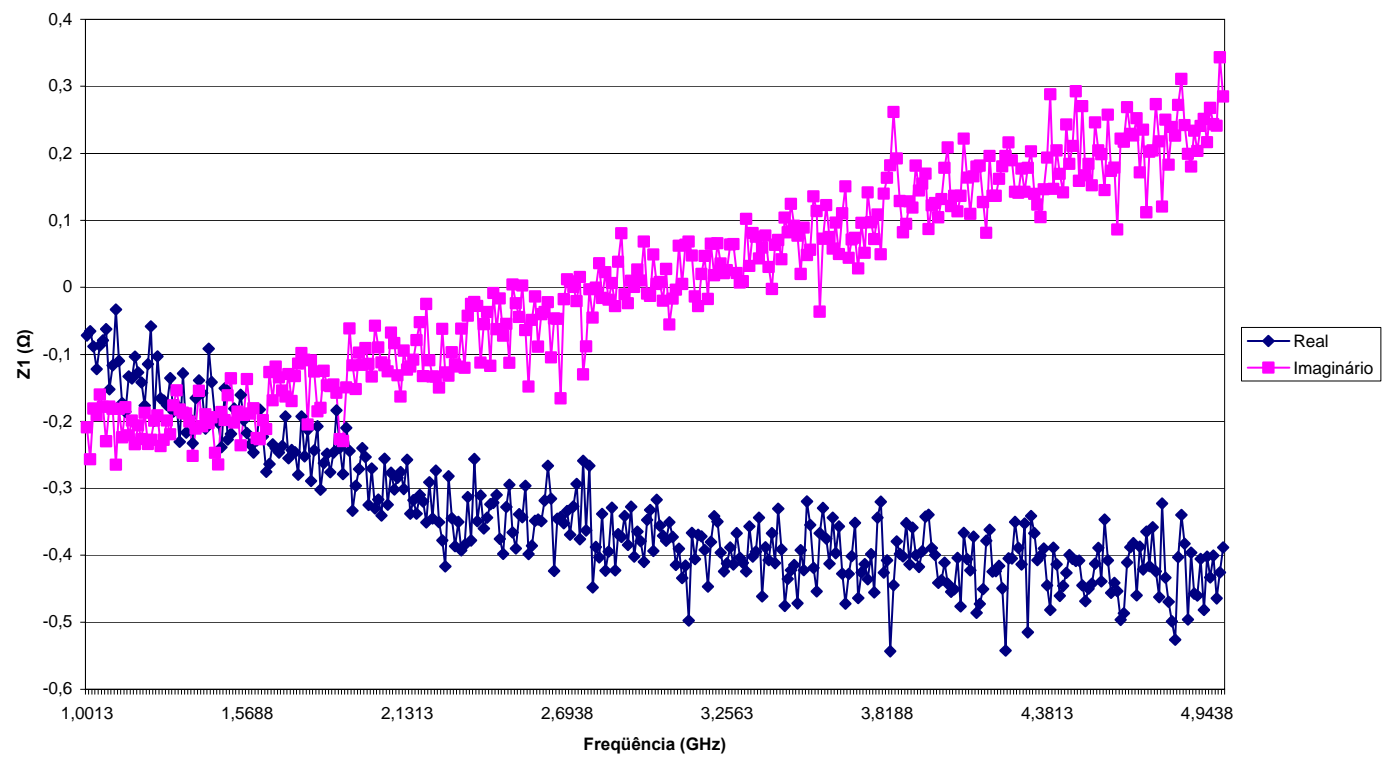

Figura 70 - Impedância $z_{1}$ em função da freqüência para a estrutura completa.

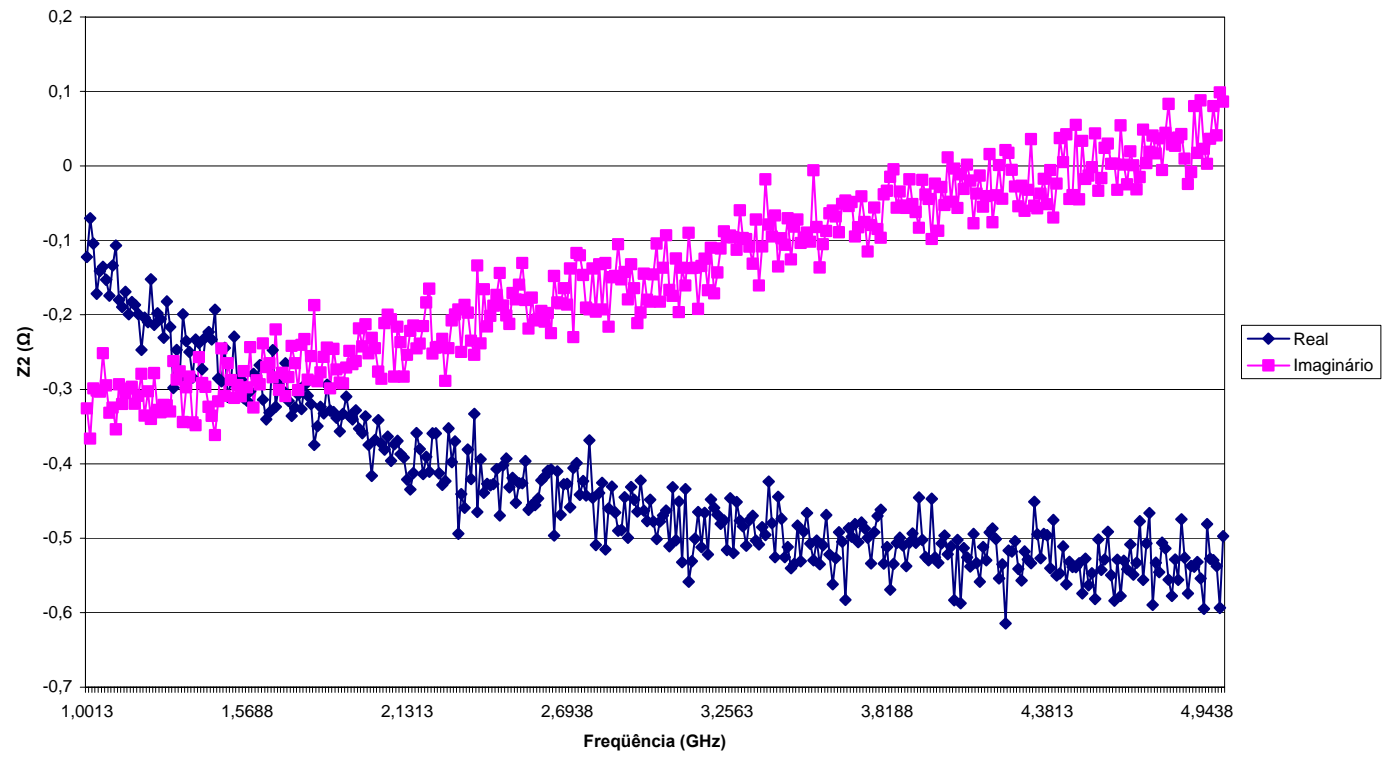

Figura 71 - Impedância $z_{2}$ em função da freqüência para a estrutura completa.

Como podemos observar nas Figuras 66 e 67, as impedâncias $z_{1}$ e $z_{2}$ têm suas partes reais negativas. Como elas indicam as impedâncias de uma trilha de metal que conecta o terminal do indutor com o pad, isto não deveria ocorrer. Supomos que os valores muito pequenos de $z_{1}$ e $z_{2}$, a série de operações realizadas para obtê-los e a precisão nas medições facilmente levam a tal resultado. 


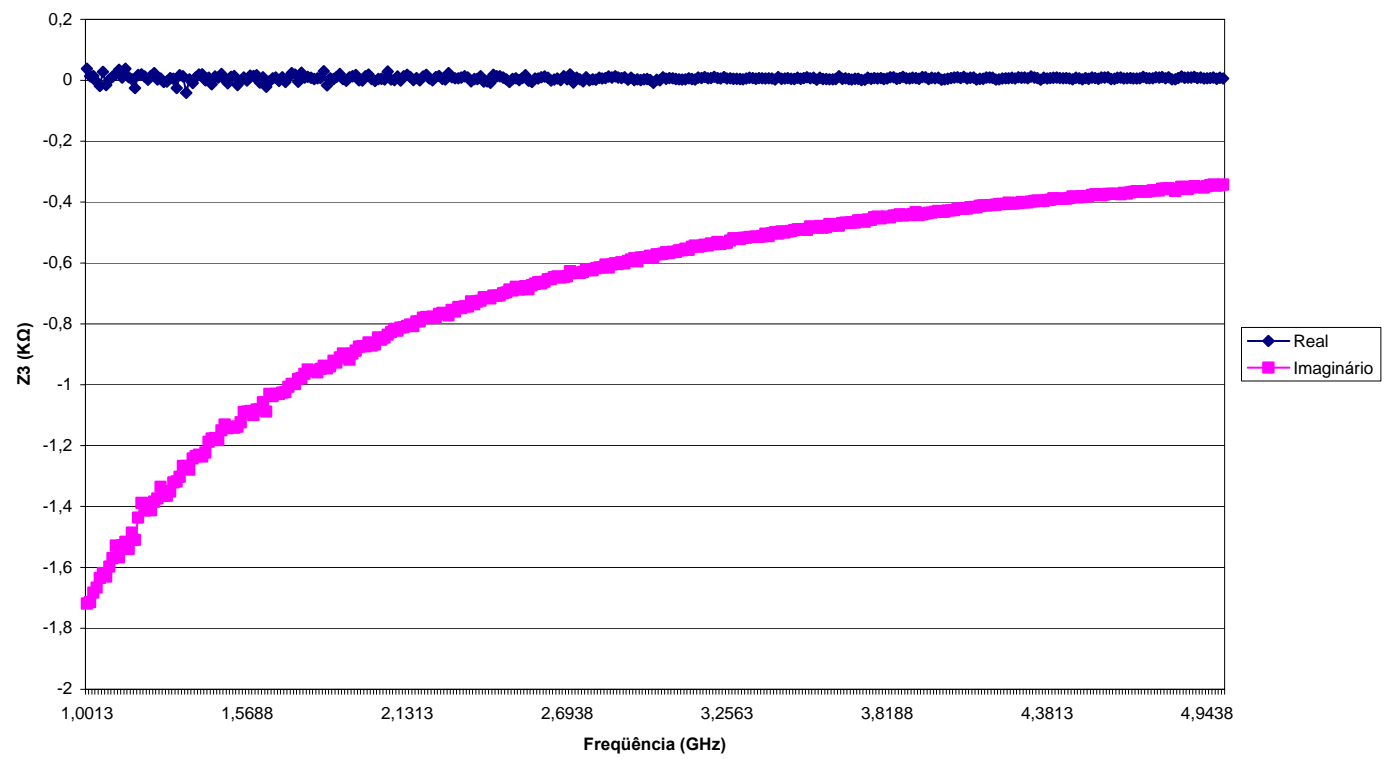

Figura 72 - Impedância $z_{3}$ em função da freqüência para a estrutura completa.

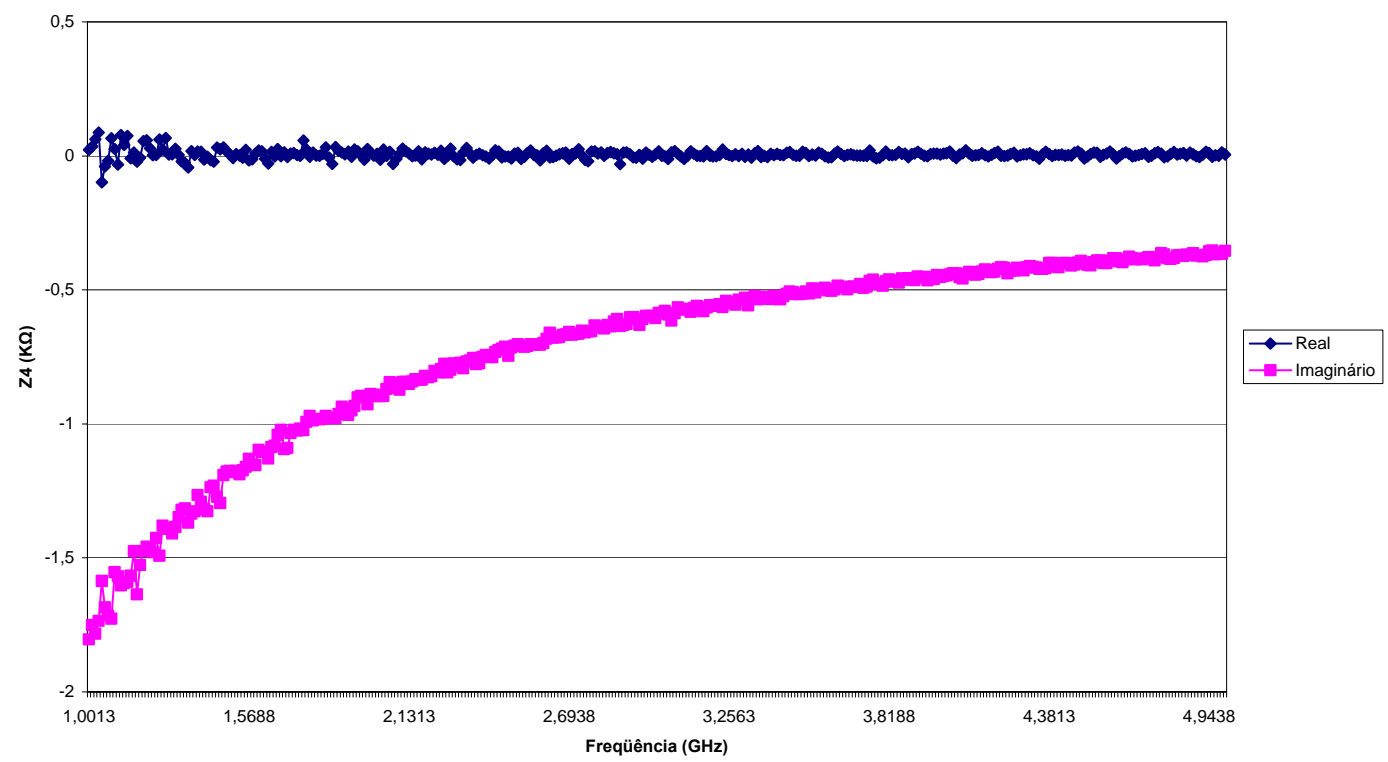

Figura 73 - Impedância $\mathrm{z}_{4}$ em função da freqüência para a estrutura completa. 


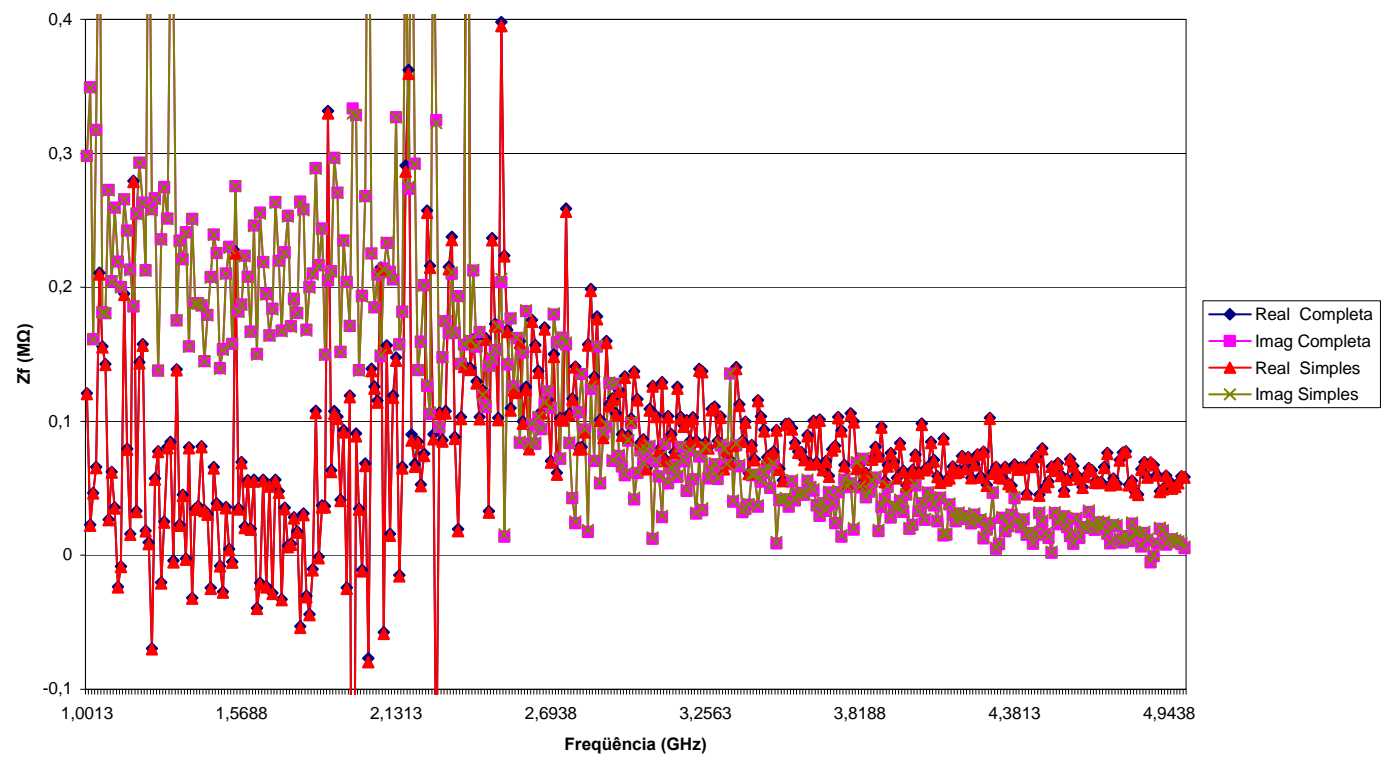

Figura 74 - Impedância $z_{\mathrm{f}}$ em função da freqüência para as estruturas completa e simples. 